\title{
ENHANCING STAKEHOLDER ACCEPTANCE OF BIOREMEDIATION TECHNOLOGIES
}

Dr. Will Focht, Director, Institute for Sustainable Environments Matt Albright, Doctoral Student, Environmental Science Graduate Program Oklahoma State University

Report Submitted to the U.S. Department of Energy

Bioremediation and its Societal Implications and Concerns (BASIC) Initiative Natural and Accelerated Bioremediation Research (NABIR) Program Grant Award No. DE-FG02-04ER63798

Principal Investigator

Dr. Robert P. Anex, Department of Agricultural and Biosystems Engineering lowa State University 


\section{TABLE OF CONTENTS}

Section

Page

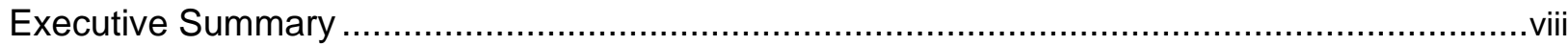

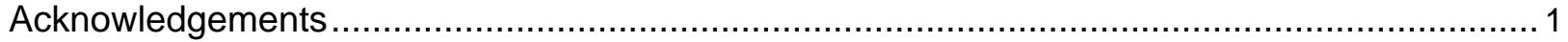

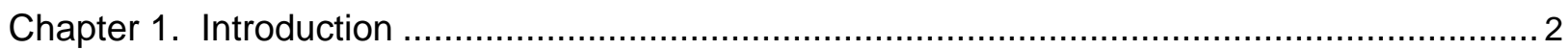

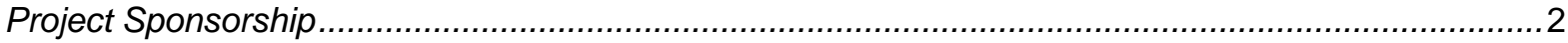

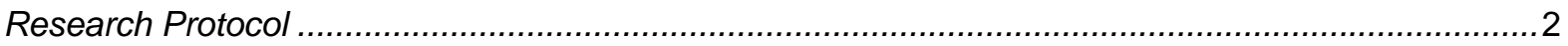

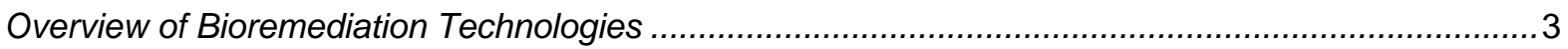

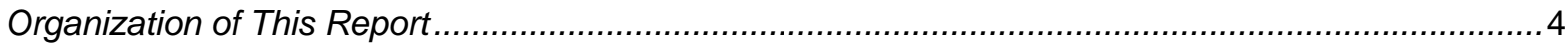

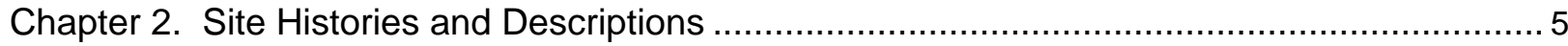

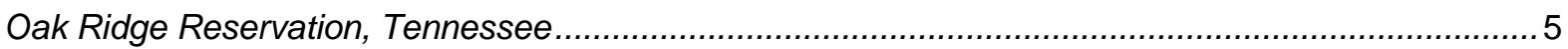

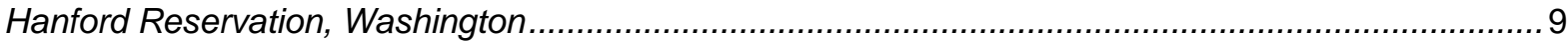

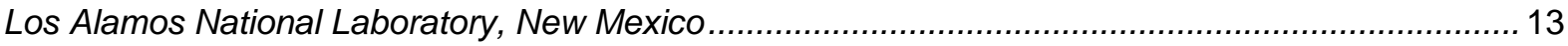

Chapter 3. Stakeholder Interviews: Bioremediation and Participation Themes ......................17

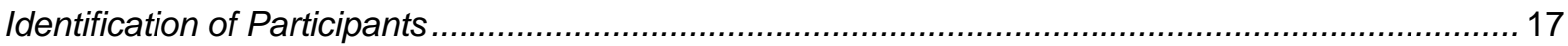

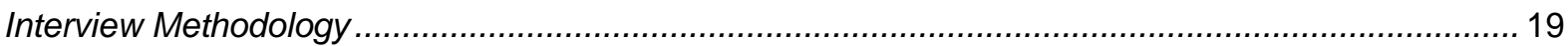

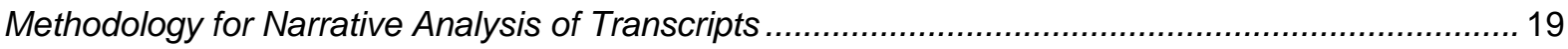

Narrative Analysis Results I: Themes Related to Bioremediation ................................................. 20

Narrative Analysis Results II: Themes Related to Stakeholder Participation ................................... 22

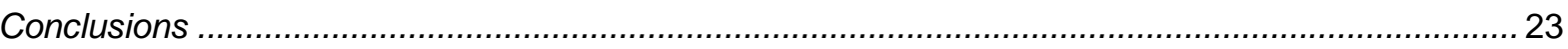

Chapter 4. Stakeholder Perspectives on Bioremediation and Participation..........................24

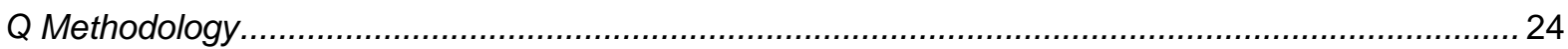

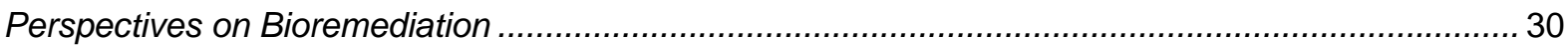

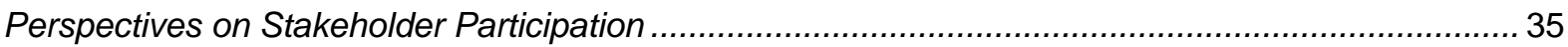

Chapter 5. Telephone Survey: Sample Description and Demographic Analysis .....................42

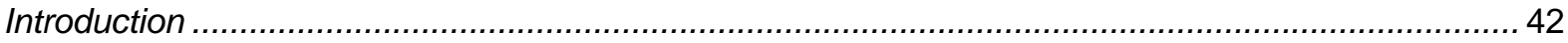

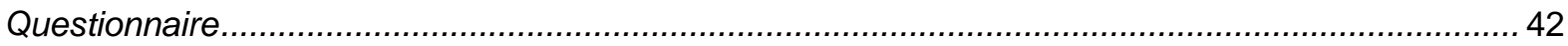

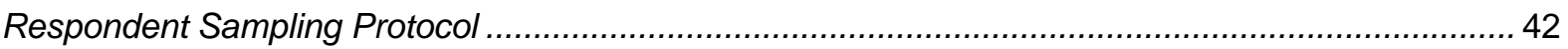

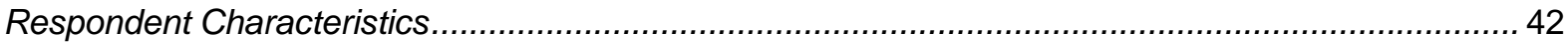

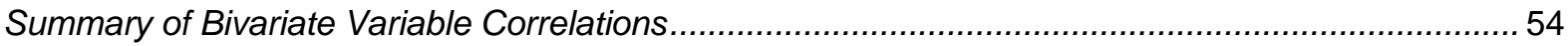

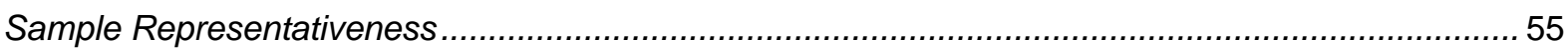

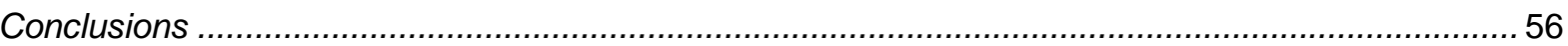

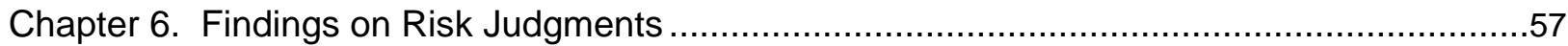

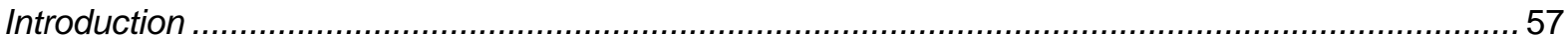

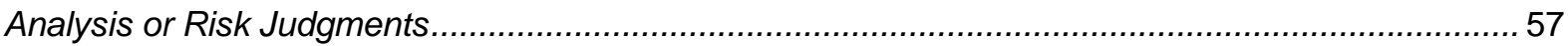

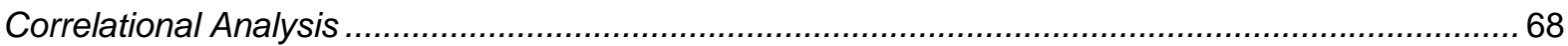

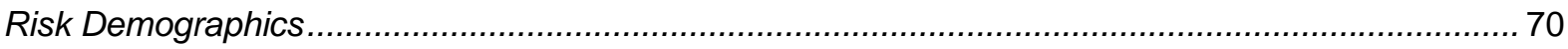

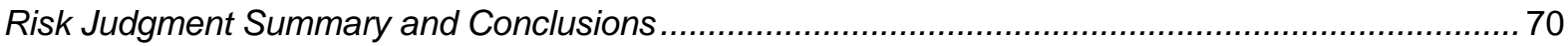

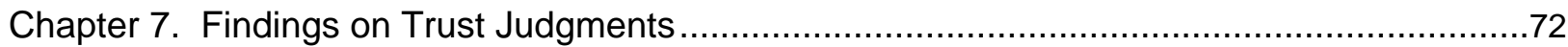

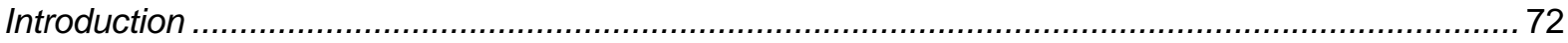

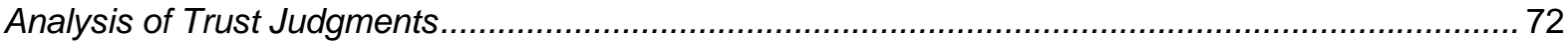

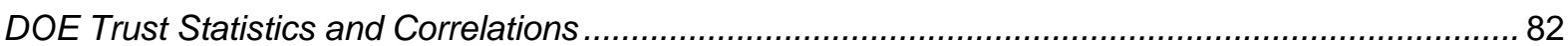




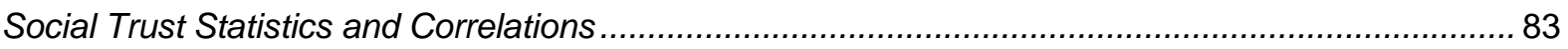

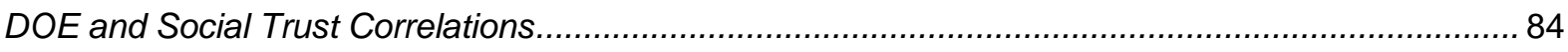

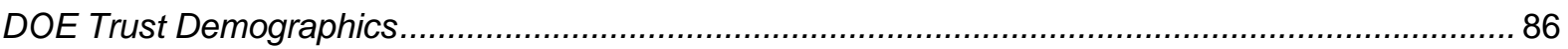

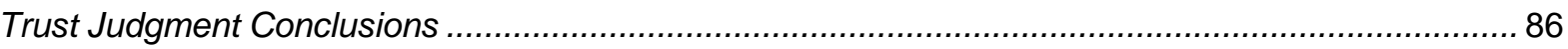

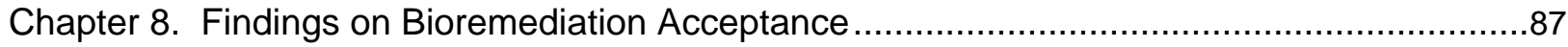

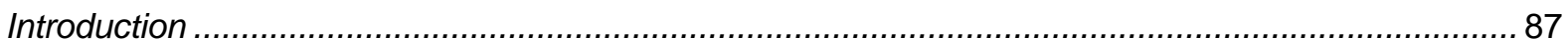

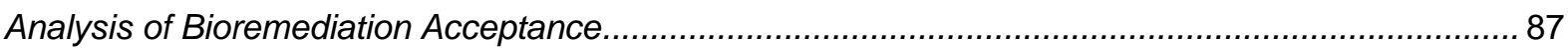

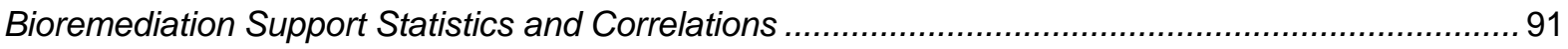

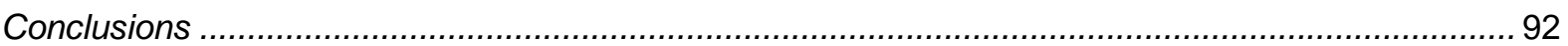

Chapter 9. Findings on Stakeholders' Participation Preferences ....................................93

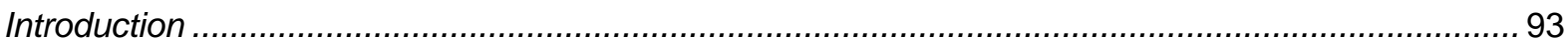

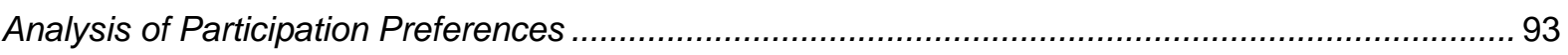

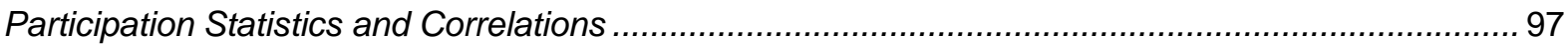

Relationship between Trust Judgments and Participation Preferences ........................................ 97

Participation Preference Conclusions ......................................................................................... 98

Chapter 10. Predictions of Stakeholders' Participation Preferences ....................................99

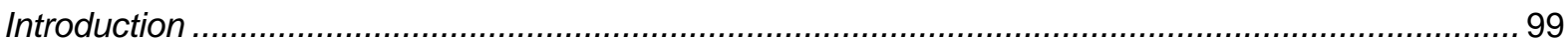

Model of the Relationship between DOE Trust and Participation Preference................................. 99

Relationship between Trust Asymmetry and Threshold of Participation Acceptability.......................101

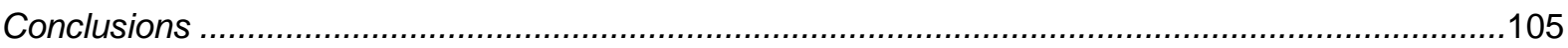

Chapter 11. Stakeholder Dialogue on Bioremediation Acceptance................................. 106

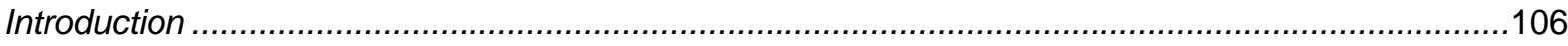

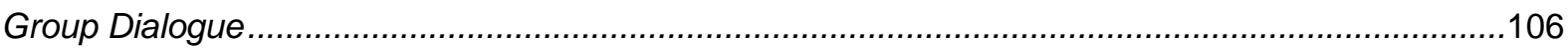

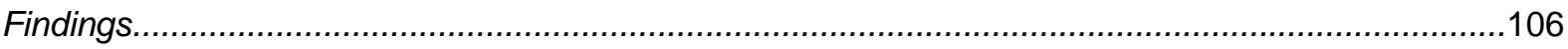

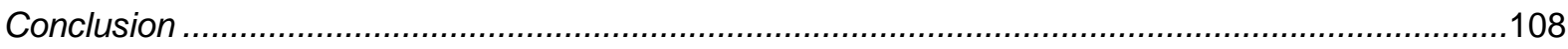

Chapter 12. Enhancement of Public Support for Bioremediation ...................................... 109

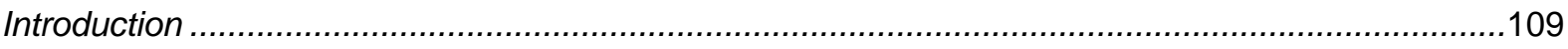

Relationships among Risk, Trust, Deference, Participation, and Bioremediation Acceptance ...........114

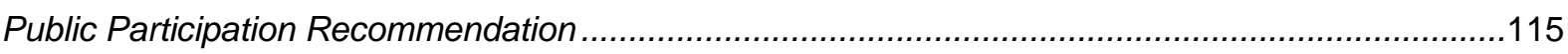

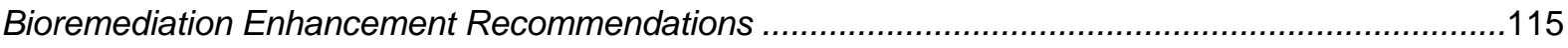

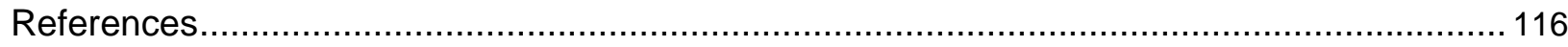

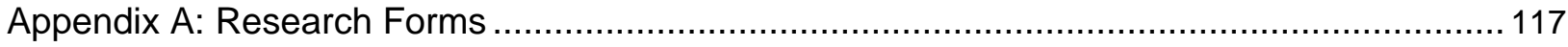

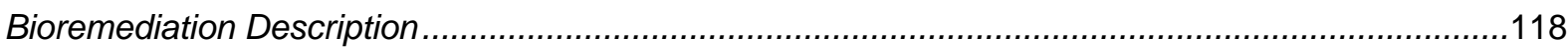

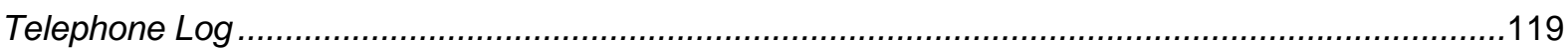

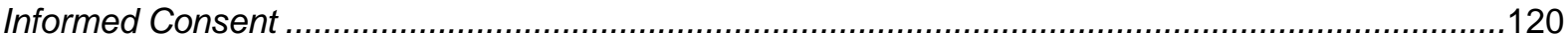

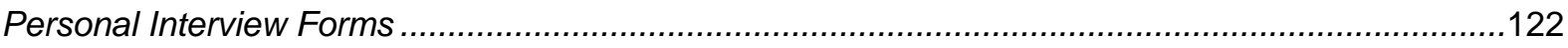

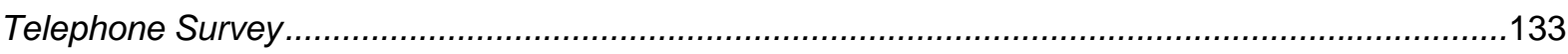

Appendix B: Narrative Analysis Themes and Nodes ................................................. 141

Appendix C: Presentation Delivered at Stakeholder Dialogue on Bioremediation................... 159

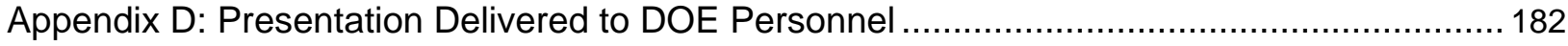




\section{LIST OF TABLES}

Table $\quad$ Page

Table 1. Stakeholder interviewee demographic characteristics ................................................. 17

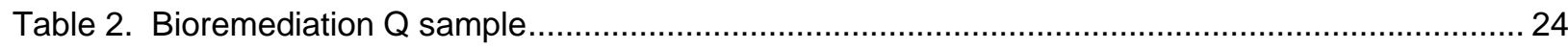

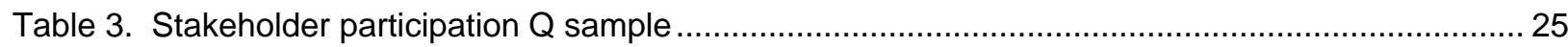

Table 4. Distribution of bioremediation Q sample items across interview themes ................................. 26

Table 5. Distribution of stakeholder participation items across interview themes ............................... 26

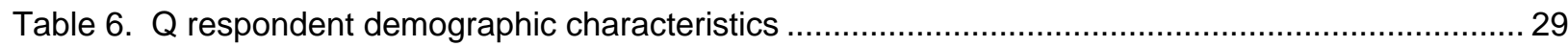

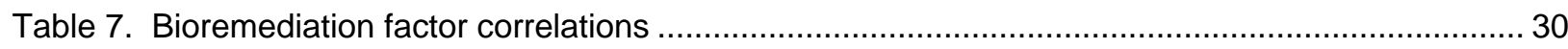

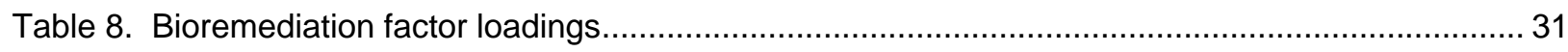

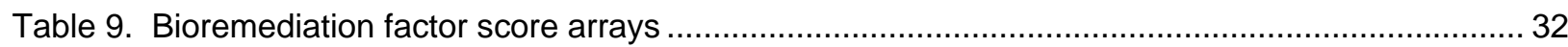

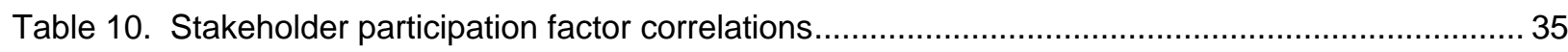

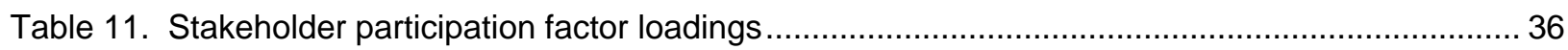

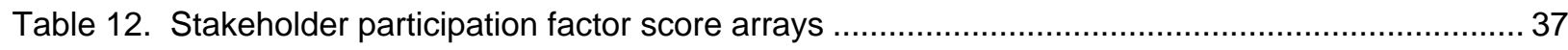

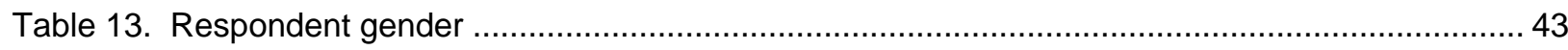

Table 14. "As the crow flies, in miles, about how far away from the site do you live?" ......................... 43

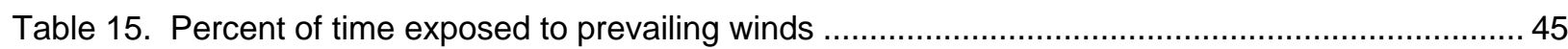

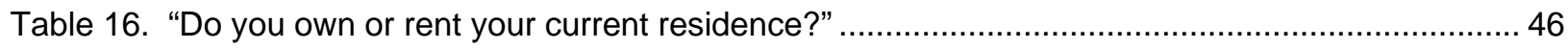

Table 17. "How long have you lived at your present residence?" ........................................................4 47

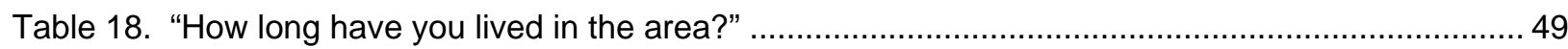

Table 19. "Have you ever worked or are you now working at the site?" ........................................... 51

Table 20. "Other than you, has any one in your immediate family worked at the site?"........................ 52

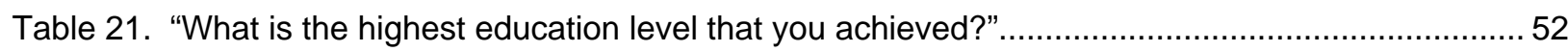

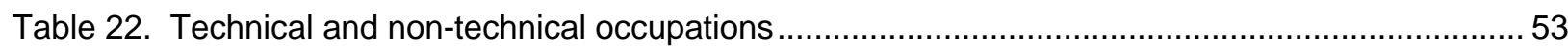

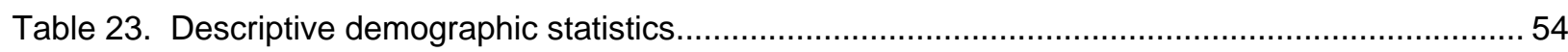

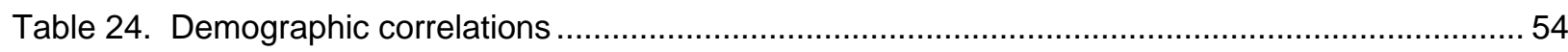

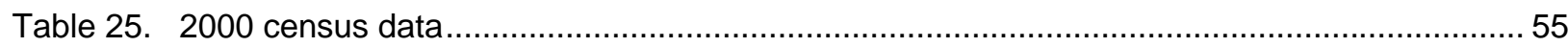

Table 26. Questions about whether respondents believe they have suffered, or could suffer,

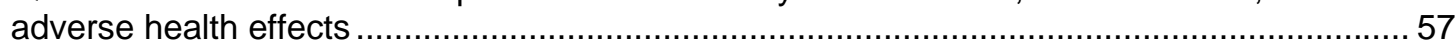

Table 27. "How significant do you believe these health risks are?" ..................................................... 58

Table 28. "How long have you known about the subsurface radioactive contamination at the site and the health risks that this contamination may pose?" ...................................................... 59

Table 29. "How would you rate your knowledge of how you are exposed to subsurface radioactive contamination?"....

Table 30. "How would you rate your knowledge of the health effects of exposure to subsurface radioactive contamination?"

Table 31. "In your opinion, how much choice do you have whether you are exposed to subsurface

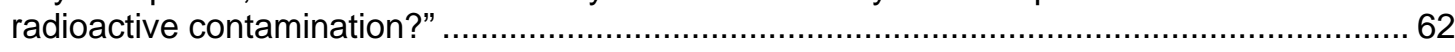

Table 32. "In your opinion, how ghastly or awful are the health risks from subsurface radioactive

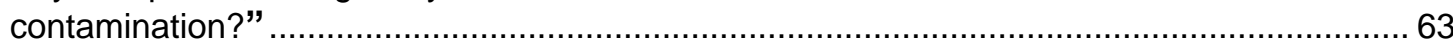

Table 33. "Just because there is contamination doesn't mean we are at risk" ..................................... 64

Table 34. "Since many people perceive that there is a higher risk than is actually present, they should become better educated so that their risk perceptions would be better calibrated"..... 
Table 35. "No agency has the right to talk anyone into accepting risk" 66

Table 36. "The costs of site cleanup must be balanced against the benefits"..................................... 67

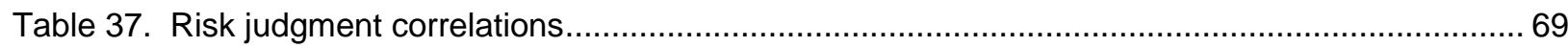

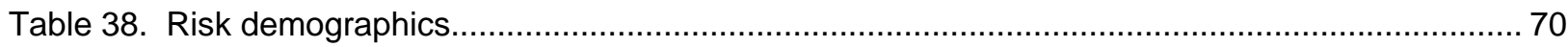

Table 39. "How much do you trust DOE to make decisions about the cleanup of contamination at the site?"

Table 40. "How much do you trust DOE officials to make decisions on your behalf to manage the site properly?"

Table 41. "How would you rate your willingness to defer to DOE officials to make decisions on your behalf to manage these risks properly?". 74

Table 42. "How would you judge the technical competence of DOE managers to manage these risks properly?".

Table 43. "How would you rate the degree to which DOE managers share your values when it comes to managing these risks properly?"

Table 44. "How would you rate the degree of influence that you have over how DOE manages these risks?" 77

Table 45. "How much do you trust other stakeholders to make decisions on your behalf to manage the risks of subsurface radioactive contamination properly?".

Table 46. "How would you rate your willingness to defer to other stakeholders to make decision on your behalf to manage the risks of subsurface radioactive contamination properly?"........ 79

Table 47. "How would you judge the technical competence of other stakeholders to make decision on your behalf to manage the risks of subsurface radioactive contamination properly?"........ 80

Table 48. "How would you rate the degree to which other stakeholders share your values when it comes to managing the risks of subsurface radioactive contamination properly?" .............. 81

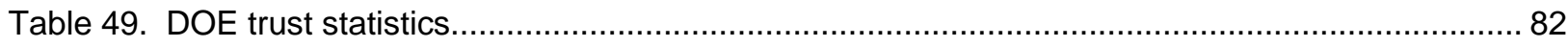

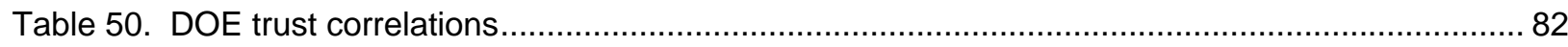

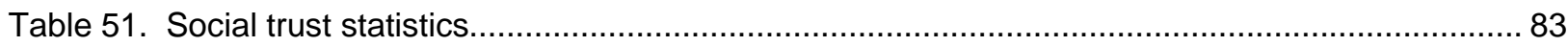

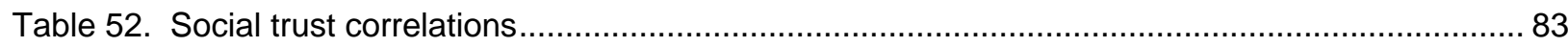

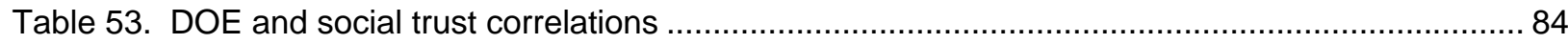

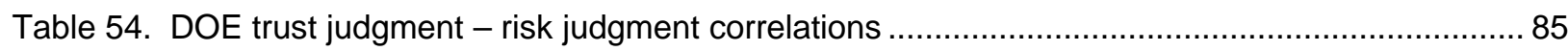

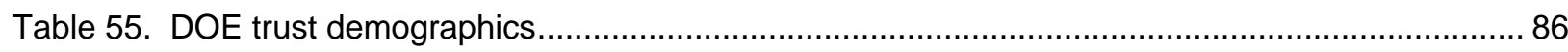

Table 56. "How much do you support or oppose the use of bioremediation to reduce these risks??...... 87

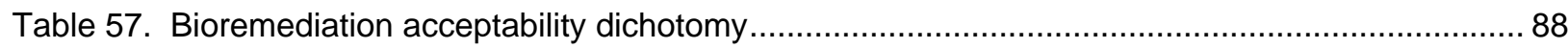

Table 58. "I believe that bioremediation is a short-term fix at best; therefore other technologies

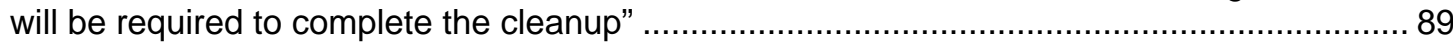

Table 59. "We have the time to investigate technologies and pick the ones that will best protect us and the environment. We need not rush into bioremediation." ...................................... 90

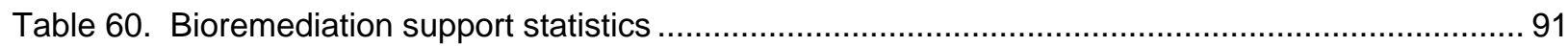

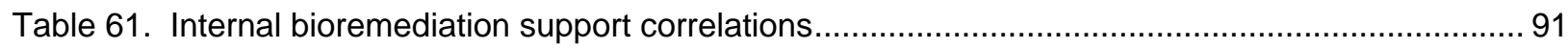

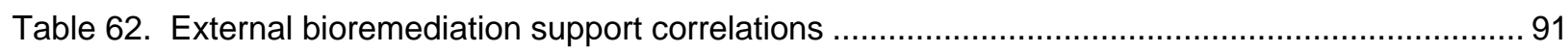

Table 63. Stakeholder participation strategies......................................................................... 93

Table 64. "DOE officials make a tentative decision and then submit it to stakeholders for their feedback before making a final decision (Feedback Strategy)" ........................................... 93

Table 65. "DOE officials consult with stakeholders first before making a decision that considers stakeholders' preferences (Consultation Strategy)".............................................................. 94

Table 66. "DOE officials sponsor and moderate a discussion with stakeholders to make a decision (DOE Facilitation Strategy)". 
Table 67. "In a negotiation moderated by an independent mediatory and assisted by independent analysts, DOE officials participate as equal partners with stakeholders to make a decision (Independent Facilitation Strategy)"....................................................................... 96

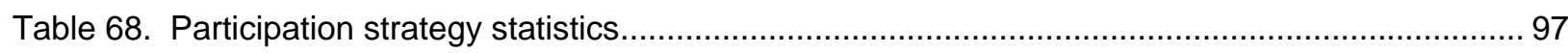

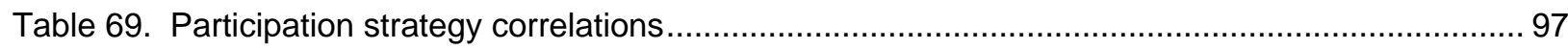

Table 70. Stakeholder participation preference and DOE trust correlations ...................................... 97

Table 71. Hypothesized stakeholder participation roles related to level of trust...................................... 99

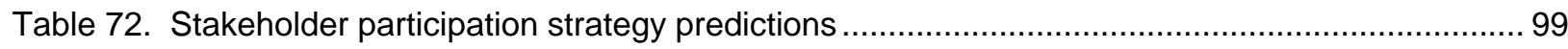

Table 73. Context-specific stakeholder participation strategy predictions.......................................100

Table 74. Trust asymmetries versus "not strongly opposed" strategy acceptability ..............................102

Table 75. Trust asymmetries versus "tolerated" strategy acceptability .............................................103

Table 76. Trust asymmetries versus "supported" strategy acceptability ..........................................104

Table 77. Popularity test of the participation preference model.............................................................104

Table 78. Acceptability test of the participation preference model ...................................................105

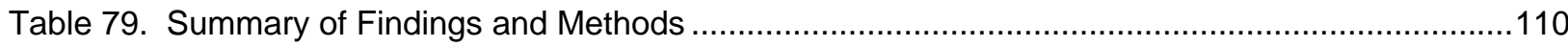




\section{LIST OF FIGURES}

Figure Page

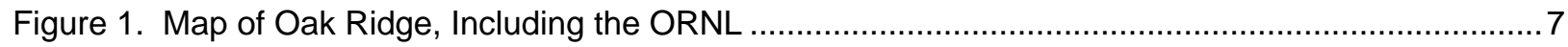

Figure 2. Map of the Area Surrounding Oak Ridge, Tennessee...................................................... 8

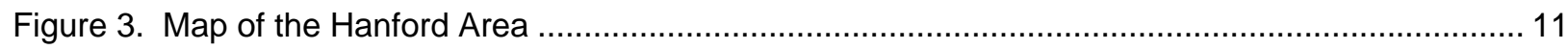

Figure 4. Map of the Columbia River Basin, Which Includes the Hanford Site ................................. 12

Figure 5. Map of the Los Alamos National Laboratory ..................................................................... 15

Figure 6. Map of the Area Surrounding Los Alamos, New Mexico ................................................... 16

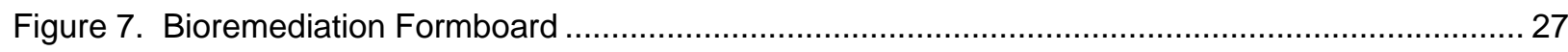

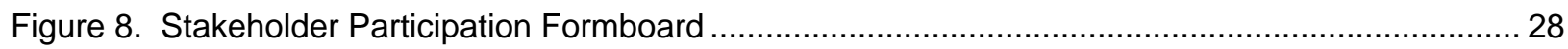

Figure 9. Relationships among Bioremediation Perspectives ........................................................ 30

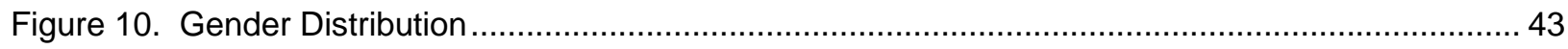

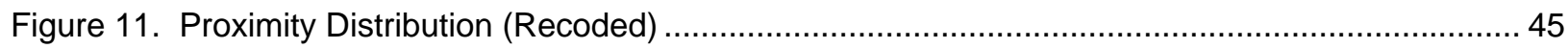

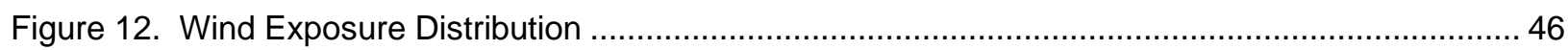

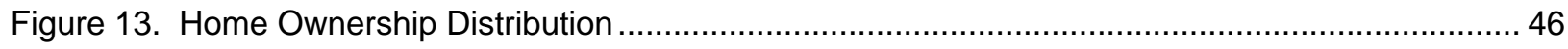

Figure 14. Household Residence Time Distribution (Recoded) ..................................................... 48

Figure 15. Community Residence Time Distribution (Recoded) ..................................................... 51

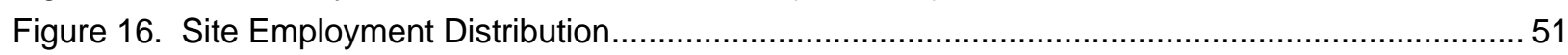

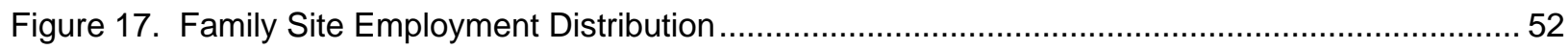

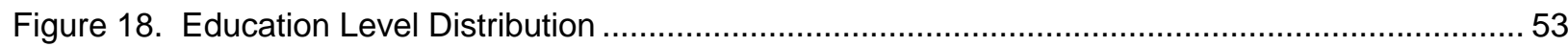

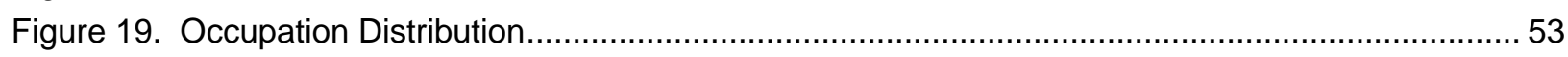

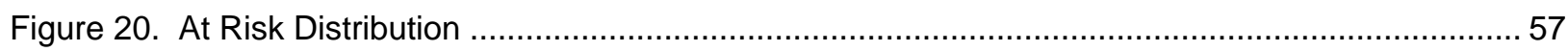

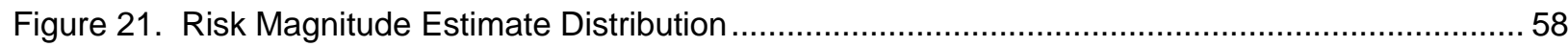

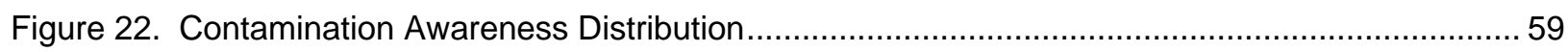

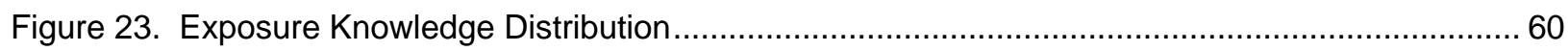

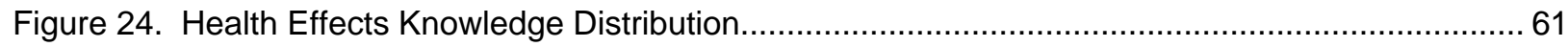

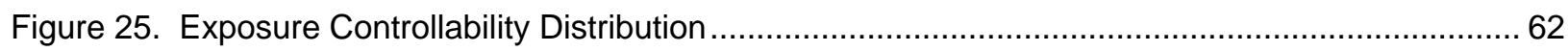

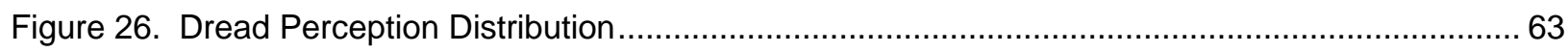

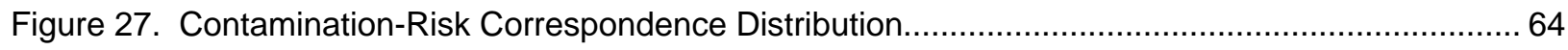

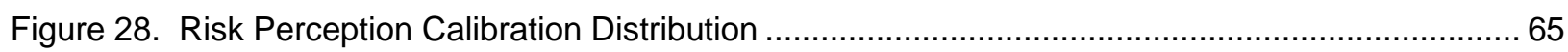

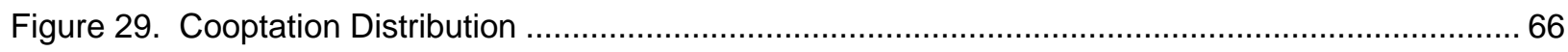

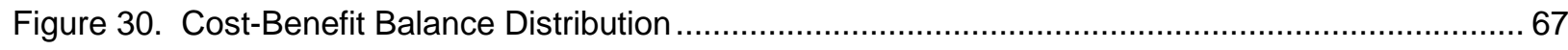

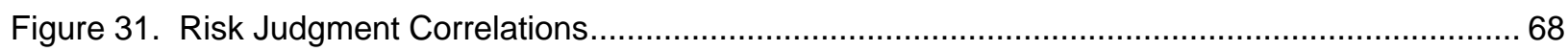

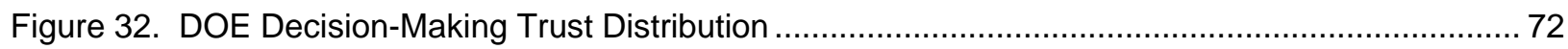

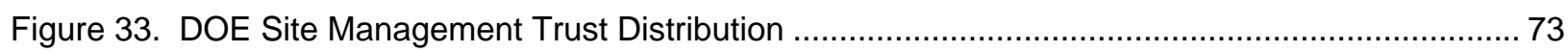

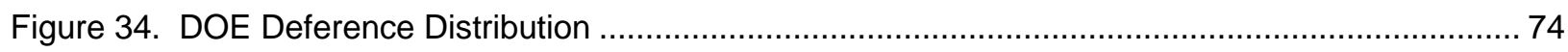

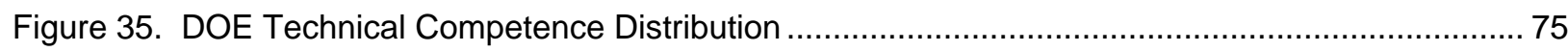

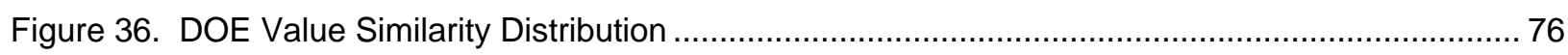

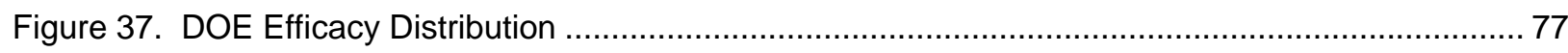

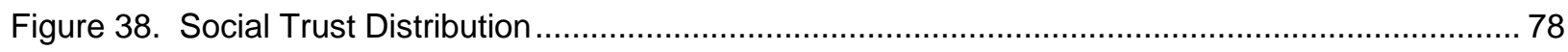

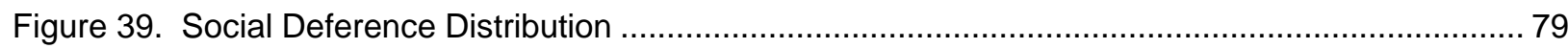

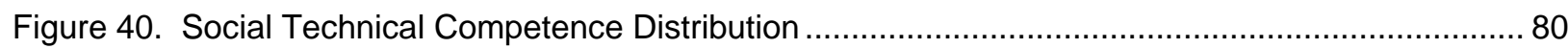

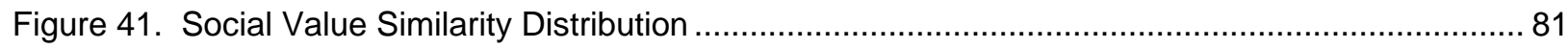

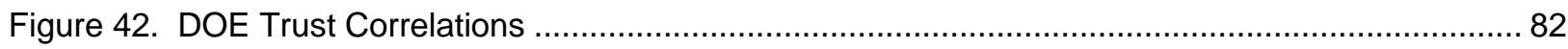




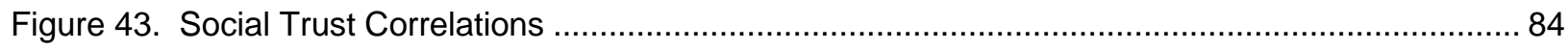

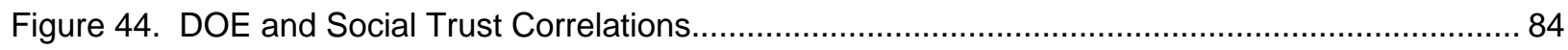

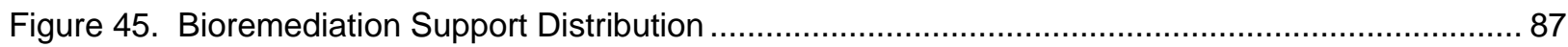

Figure 46. Dichotomized Bioremediation Support Distribution ...................................................... 88

Figure 47. Bioremediation as a Short-Term Fix Distribution.......................................................... 89

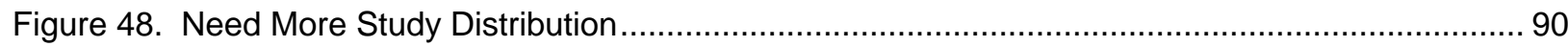

Figure 49. Feedback Strategy Preference Distribution .................................................................... 94

Figure 50. Consultation Strategy Preference Distribution.............................................................. 94

Figure 51. DOE Facilitation Strategy Preference Distribution....................................................... 95

Figure 52. Independent Facilitation Strategy Preference Distribution ............................................. 96

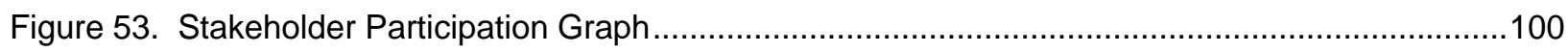

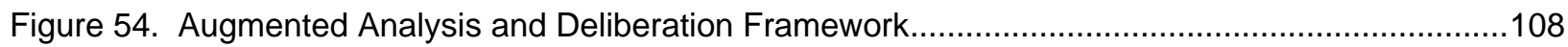

Figure 55. Schematic of Variables Influencing Bioremediation Success.........................................114 


\section{EXECUTIVE SUMMARY}

This project inquired into the judgments and beliefs of people living near DOE reservations and facilities at Oak Ridge, Tennessee; Hanford, Washington; and Los Alamos, Tennessee about bioremediation of subsurface contamination. The purpose of the investigation was to identify strategies based on these judgments and beliefs for enhancing public support of bioremediation. Several methods were used to collect and analyze data including content analysis of transcripts of face-to-face personal interviews, factor analysis of subjective perspectives using Q methodology, and statistical analysis of results from a large-sample randomized telephone survey.

Content analysis of interview transcripts identified themes about public perceptions and constructions of contamination risk, risk management, and risk managers. This analysis revealed that those who have no employment relationship at the sites and are not engaged in technical professions are most concerned about contamination risks. We also found that most interviewees are unfamiliar with subsurface contamination risks and how they can be reduced, believe they have little control over exposure, are frustrated with the lack of progress in remediation, are concerned about a lack of commitment of DOE to full remediation, and distrust site managers to act in the public interest. Concern is also expressed over frequent site management turnover, excessive secrecy, ineffective and biased communication, perceived attempts to talk the public into accepting risk, and apparent lack of concern about community welfare.

The interview transcripts were also used to develop representative sets of statements concerning bioremediation and public participation in bioremediation decision-making. These statements were $\mathrm{Q}$ sorted and factor analyzed to reveal perspectives shared by members of the public. We found that two major families of perspectives on bioremediation exist: a rationalist perspective that is optimistic, favors benefit-cost balance, believes that support of bioremediation can be enhanced through education, endorses a balance between remediation costs and benefits, and advises site managers to be more caring about public concerns with less arrogance. The pessimistic perspective wants more public accountability, doubts site management commitment to public safety, and favors more public involvement. We found four perspectives on public participation: a willingness to let site managers decide, allowing site managers to decide but with citizen oversight, letting elected officials decide after consultation with site management and outside experts, inclusive and robust participation,.

In the telephone survey, we asked respondents who were aware of site contamination about their perceptions of risk from exposure to subsurface contamination, trust of DOE in managing this risk, trust of each other in remediation decision-making, willingness to defer to and perceived influence on DOE in its remediation decision-making, acceptability of bioremediation, and preferences for public participation. Response analysis revealed that most people believe that they are at significant risk from subsurface contamination but they acknowledge that more education is needed to calibrate risk perceptions against scientific risk assessments. Most rate their personal control over exposure as low. Slightly more than half believe that risk reduction should be balanced against cost.

We also found that distrust of DOE and its contractors exists, primarily due to the perception that site managers do not share public values; hence, the public is generally unwilling to defer to DOE in its decision-making. The concomitant belief of inefficacy confounds distrust by generating frustration that DOE does not care. Moreover, the public is split with respect to trust of each other, primarily because of the belief that citizens lack technical competence.

With respect to bioremediation support, we found that more than $40 \%$ of the public has no opinion. However, of those who do, 3 of 4 are favorably disposed - particularly among those who believe that risk is lower and who are more trusting of site management. Nevertheless, we believe that this support is fragile at best. Support could be eroded in several ways, including information that suggests that bioremediation is only a partial solution to risk management, an excuse to save money rather than provide safety to the public, not reliable, takes too long to complete, or less effective than alternatives.

We presented survey respondents with four alternative participation strategies based on the results of the $\mathrm{Q}$ analysis and asked their judgments of each. The public prefers strategies that shifts power to them. The least empowered strategy (feedback) was supported by 46\%; support grew as public power 
increased, reaching 66\% support for independently facilitated deliberation. More DOE distrust generates more support for high power strategies.

We offer the following recommendations to enhance public acceptance.

First, and perhaps most importantly, site managers should pursue robust trust-building efforts to gain public confidence in DOE risk management that meets public expectations. Public trust decreases risk perception, which increases public willingness to defer to site managers' discretion in decision-making, which in turn increases public acceptance of the decisions that result. Trust-building efforts should endeavor to build confidence in site managers' technical expertise (through review by independent experts and credentialing), in value similarity (through relationship building), in education (about risk and bioremediation), and in communication (through open, forthright, and unbiased messages and channels).

Second, site managers should address public concerns about bioremediation such as its effectiveness in reducing risk, performance compared to other remediation alternatives, costs compared against benefits, time required to start and complete remediation, level of risk that is currently posed by contamination, and scope of application (problems for which it is best suited and locations where it will be used).

Third, more should be done to involve the public in bioremediation decision-making. We recommend a two-stage process: independent facilitated deliberation to build trust and address concerns about the motives and competence of site managers, followed by consultation to maintain that trust. Both stages should be inclusive, transparent, and respectful. Participation objectives and roles of participants should be well specified by the participants. A record of discussion should be published that codifies the concerns raised and how they were addressed, which will facilitate progress by averting the need to reconsider the same issues repeatedly. It is most important that the processes convince the public that its participation influences decision outcomes and that participants genuinely (informed and voluntarily) consent to risk exposure.

A word of caution is offered regarding choice of public participation strategy. We believe that no choice can be made that will please everyone. Our test of a predictive model in Chapter 10 suggests that the best that site managers can do is to choose a strategy that is least opposed. Our recommendation in the preceding paragraph is consistent with this advice. However, we also strongly recommend that the public be consulted on this choice. It is likely that they will prefer a high power strategy at first, but through this initial contact and the deliberations that will follow, they will prefer less intensity and settle on simple consultation - if site managers earn the public's trust through demonstration of shared values and technical competence. 


\section{ACKNOWLEDGEMENTS}

We first wish to thank the U.S. Department of Energy for its support of this research.

We also want to thank the Nancy Comstock, a graduate research assistant who conducted interviews of stakeholders at Hanford and James Hull, a graduate research assistant who conducted interviews of stakeholders at Los Alamos. We also thank J ane Carter, an undergraduate research assistant who helped conduct content analysis of interview transcripts using NVivo software. Finally, we thank Weldon Schieffer who professionally facilitated the stakeholder dialogue on bioremediation acceptance at the Oak Ridge National Laboratory and Amy Wolfe who assisted in recruiting ORNL staff for interviews. 


\section{CHAPTER 1 \\ INTRODUCTION}

\section{Project Sponsorship}

This project was funded by the U.S. Department of Energy, through its Bioremediation and its Societal Implications and Concerns (BASIC) initiative within the Natural and Accelerated Bioremediation Research (NABIR) program (grant award number DE-FG02-04ER63798).

\section{Research Protocol}

This project was conducted in seven phases. Each is briefly summarized below.

Phase I: Open-Ended Interviews of Stakeholders to Assess Bioremediation Knowledge, Trust, and Participation Preferences

Researchers conducted face-to-face interviews with citizens living near three DOE sites that have experienced radionuclide and heavy metal contamination (Oak Ridge, Tennessee; Hanford, Washington; and Los Alamos, New Mexico). The interviews involved a cross-section of residents and workers at these sites and surrounding areas. Three topics were discussed during the interviews: knowledge of subsurface bioremediation of heavy metals and radionuclides, trust of stakeholders, and preferences for their participation in bioremediation decision-making.

Phase II: Transcription and Content Analysis of Interview Tapes

The taped interviews were professionally transcribed. Qualitative analysis of the transcripts was performed using the computer program NVivo to identify and characterize themes. Researchers identified relationships between demographic characteristics and these themes. The themes were also used in Phase III to select statements for inclusion in a Q sample.

Phase III: Q-Methodology Investigation of Stakeholder Perspectives on Bioremediation and Participation

Based on factor analysis of Q sorts of statements taken from the interview transcripts, stakeholders' perspectives were revealed and analyzed concerning two issues: site remediation (including bioremediation) to reduce risks and stakeholder participation preferences in remediation decision-making.

Phase IV: Telephone Survey Questionnaire to Generalize Results from Interviews

A random sample telephone survey was conducted at all three sites to extend the results of the earlier phases to the general population. Three topics were explored: knowledge of subsurface bioremediation, trust of stakeholders, and participation preferences. The results were also used to test the relationship between stakeholder trust and participation options.

Phase V: Stakeholder Focus Group to Obtain Reactions to Study Findings

A focus group meeting was held to report findings and receive feedback from people who were involved in the open-ended interviews. Results from the Q-sort and telephone survey were discussed for validity and inclusiveness. Consensus was reached on stakeholder participation strategies for bioremediation of subsurface contamination.

Phase VI: DOE Presentation of Results to DOE Personnel

Preliminary results from the project were presented to DOE managers from the NABIR program in Germantown, MD.

Phase VII: Preparation of Final Report

This report constitutes the last phase of the research. In it, we summarize the results of the research and provide recommendations for bioremediation of subsurface heavy metals and radionuclides and for stakeholder participation in bioremediation decisions. 


\section{Overview of Bioremediation Technologies}

Bioremediation is a technology that can be used to reduce, eliminate, or contain hazardous waste. Over the past two decades, it has become widely accepted that microorganisms, and to a lesser extent plants, can transform or degrade many types of contaminants. The transformation and degradation processes vary, depending on the physical-chemical environment, microbial communities, and nature of the contaminant. Over the past few years, interest in bioremediation has increased. It has become clear that many organic contaminants such as hydrocarbon fuels can be degraded to relatively harmless products such as $\mathrm{CO}_{2}$ (the result of the of the degradation process). Wastewater managers and scientists have also found that microorganisms can interact with metals to convert them form one chemical form to another. Laboratory tests and ex situ bioremediation applications show that microorganisms can change the oxidation state of some heavy metals (e.g., chromium and mercury) and radionuclides (e.g., uranium) by using them as electron acceptors. In some cases, the solubility of the altered species decreases and the contaminant is immobilized in situ, e.g., precipitated into an insoluble salt in the sediment. In other cases, the opposite occurs - the solubility of the altered species increases, increasing the mobility of the contaminant and allowing it to be more easily flushed from the environment. Both kinds of transformations present opportunities for bioremediation of metals and radionuclides -to either lock them in place or accelerate their removal (NABIR primer).

\section{Intrinsic Bioremediation}

This occurs in situ and relies on naturally occurring biological processes carried out by indigenous microorganisms. Intrinsic natural bioremediation is a component of natural attenuation, which includes physical and chemical processes. Cleanup activities that rely on natural attenuation to reduce contaminant levels and monitoring to determine the remedial effectiveness are referred to as "monitored natural attenuation" (NABIR primer)

\section{Biostimulation and Bioaugmentation}

Biostimulation is the addition of nutrients (usually sources of carbon, nitrogen, and/or phosphorus) and oxygen or other electron donors or acceptors. These amendments serve to increase the number or activity of naturally occurring microorganisms available for bioremediation. Bioaugmentation is the introduction of microorganisms that can biotransform or biodegrade a particular environment. Recent studies have shown this to be a viable alternative (NABIR primer).

\section{Permeable Reactive Barriers and Biobarriers}

Permeable reactive barriers (PRB) are in situ treatment zones that are engineered downgradient from a contaminated plume. As ground water passes the treatment zone, contaminants are absorbed, reduced and precipitated, biodegraded, biotransformed, or chemically degraded. Typically, PRBs are designed as trenches or funnel and gate-type systems; however, a series of closely spaced injection points can also be used (NABIR primer).

\section{Phytoremediation}

Phytoremediation is the use of plants to remediate contaminated soils within the rhizosphere - the soil that surrounds and is influenced by plant roots and their associated microbial communities. Two forms of phytorememdiation are applicable to the removal of toxic metals and radionuclides from the environment: phytoextraction and rhizofiltration. Phytoextraction is defined as the use of metal accumulation plants to remove contaminants from soil. Rhizofiltration is the use of plant roots to remove toxic metals and radionuclides from contaminated water (NABIR primer).

\section{Mycoremediation or Fungal Remediation}

Mycoremediation, or remediation using fungi, is another approach that can be useful in the cleanup of contaminated soils and sediments. Fungi account for most of the biomass in soils, and they are known to have powerful biodegradative abilities. Fungi can also accumulate metals, particularly radionuclides. Most fungi require oxygen for growth, so mycoremediation would probably be most useful for treatment of near-surface soils (NABIR primer). 


\section{Landfarming, Soil Piles, and Composting}

Landfarming is the mixing of waste with surface soil over a tract of land. A modified form of landfarming has been adopted to comply with revised environmental regulations. This modified form consists of soil biopiles, or prepared beds, constructed above ground within contained treatment cells. Composting is a process applied to soil biopiles that controls and utilizes heat generated by aerobic microbial metabolism Landfarming, prepared beds, biopiles, and composting hold a number of possibilities for bioremediation of radionuclides and metals by degrading organic chelating agents, altering $\mathrm{pH}$, changing redox potentials, and producing biosufactants (NABIR primer).

\section{Slurries and Soil or Sediment Washing}

Slurry bioreactors and soil- or sediment-washing equipment are commonly used to treat excavated soils or sediments to which water is added. Slurry bioreactors are stirred tanks within which biodegradation or biotransformation takes place in an aerated environment. Washing, which can be used in conjunction with the slurry process, is primarily a means of reducing the volume of contaminated soil or sediment by solubilizing readily desorbed contaminants and physically segregating the finer-grained portions of the sample to which contaminants tend to stick. The solubilized contaminants in the initial washing or, alternatively, now-contaminated wash-water can be passed to a second reactor where biological treatment takes place (NABIR primer).

\section{Organization of This Report}

The remainder of this report presents the findings of our research. We begin with brief descriptions and histories of the three study sites: Oak Ridge, Hanford, and Los Alamos. This is followed by the results of our narrative analysis of stakeholder interviews. Here, we identify the themes that were raised by interviewees concerning their view of subsurface bioremediation and their preferences for participation in bioremediation decision-making.

Based on the results of the factor analysis of $\mathrm{Q}$ sorts, we describe the perspectives that stakeholders have of bioremediation and participation preferences in Chapter 4. As expected, we did not find bipolar perspectives on these two issues. In other words, stakeholders hold differing, but not opposing, perspectives. This suggests that consensus is possible.

In Chapters 5-11, we present the results and findings obtained from our telephone survey of 1950 residents who live near the three study sites. These findings concern demographic characteristics, judgments of risk, judgments of trust, preferences for participation in bioremediation decision-making, analysis of bioremediation acceptance, predictions for enhancing acceptance, acceptability of four alternative participation strategies, and predictions for enhancement of participation strategy acceptance.

Chapter 12 summarizes a stakeholder dialogue that we held with stakeholders at Oak Ridge, which resulted in the development of a scheme to combine analysis and deliberation with special attention to building trust and efficacy.

Our conclusions and recommendations based on this research are presented in Chapter 13. 


\section{CHAPTER 2 SITE HISTORIES AND DESCRIPTIONS}

\section{Oak Ridge Reservation, Tennessee}

History

In early 1942, the Army Corps of Engineers designated a 60,000-acre portion of land northwest of Knoxville, Tennessee between Black Oak Ridge to the north and the Clinch River to the south as a federal reserve to serve as one of three sites nationwide for the development of the atomic bomb. About 3000 residents received court orders to vacate within weeks the homes that their families had occupied for generations. As many as 80,000 construction workers began a race against time to build three mystery plants known as K-25, Y-12, and X-10 on what became known as the Oak Ridge Reservation. Houses were built at a rate of two per minute. Originally planned for a population of 13,000 , Oak Ridge grew to more than 75,000 in less than three years - ultimately producing the two atomic bombs that helped end World War II.

On the reservation's western edge rose $\mathrm{K}-25$ or the gaseous diffusion plant - a warehouse building covering more area than any structure previously built. Completed at a cost of $\$ 500$ million and operated by 12,000 workers, the K-25 Plant separated uranium-235 from uranium-238. On its northern edge grew the workers' city named Oak Ridge; south of the city rose the Y-12 Plant, where an electromagnetic method was used to separate uranium-235. Built for $\$ 427$ million, the Y-12 Plant employed 22,000 workers.

Near the reservation's southwest corner, about 10 miles from $Y-12$, is the third plant, $X-10$. Built between February and November 1943 for \$12 million and employing only 1513 people during the war, X-10 was much smaller than $\mathrm{K}-25$ and $\mathrm{Y}-12$. As a pilot plant for the larger plutonium plant built at Hanford, $\mathrm{X}-10$ used neutrons emitted in the fission of uranium-235 to convert uranium-238 into a new element, plutonium-239. During the war, X-10 was called Clinton Laboratories, named after the nearby county seat of rural Anderson County; in 1948, Clinton Laboratories became Oak Ridge National Laboratory (ORNL website).

The Manhattan District was transferred to the Atomic Energy Commission (AEC) on June 1, 1947. In 1949, Oak Ridge was opened to the public. Six years later, the AEC sold the government-owned houses and land to city residents. Since that time, additional homes and churches have been built. Oak Ridge was incorporated under a City Council-City Manager charter in May 1959. It now has a population of 28,000 with federal offices, industrial facilities, a major medical center and approximately 800 private firms located there (Oak Ridge Convention \& Visitors Bureau).

The ORNL employs 3800 people with a budget of $\$ 1.07$ billion, $80 \%$ of which comes from the US Department of Energy and $20 \%$ from other sources. ORNL's economic impact includes wages- $\$ 274$ million; procurement- $\$ 270$ million; United Way contributions- $\$ 815,095$; medical services- $\$ 35$ million; Tennessee taxes-\$9 million: and pensions-\$60 million (ORNL website).

\section{Description}

The Oak Ridge Reservation (ORR) lies in Anderson and Roane Counties and borders Knox and Loudon Counties across the Clinch River. The ORR lies almost entirely within the city of Oak Ridge, Tennessee (1990 population: 27,310$)$. It covers an area of 35,252 acres (600-800 acres outside of city limits) and is approximately 20 miles from Knoxville (1990 population: 335,749). The Reservation currently provides employment for about 14,000 workers, including federal employees and contractors. Its total Fiscal Year 1998 budget was $\$ 1.8$ billion (Bradbury and Branch 1999).

The area impacted by the Reservation includes the city of Oak Ridge and a seven-county area. The 1990 population in the seven counties was 532,158 people; of these, almost two-thirds are from Knox County. The overall area population is $92 \%$ white and $6.5 \%$ African American. There is considerable variation among jurisdictions in terms of income, education, and occupation: Knox and Anderson 
Counties, as well as city of Oak Ridge residents, have higher incomes and education and are more likely to be in managerial and professional occupations (Bradbury and Branch 1999).

Environmental management is now the largest DOE Oak Ridge program. In addition to managing wastes produced by ongoing activities, DOE has large quantities of various types of waste to clean up and facilities to decontaminate. Portions of the reservation are contaminated with a variety of radioactive elements, mercury, PCBs, and industrial wastes that have contaminated areas downstream and downwind from the city and site.

ORR activities have high national, regional, and local salience. ORR environmental and safety concern issues are known and of central importance to the community. In the past, the potential impacts of massive releases of mercury and radionuclides from the Y-12 weapons plant were a high priority issue for citizens. More recently, increased attention has been given to the potential health impacts on residents in the Scarboro community. Scarboro, which is predominantly African American, is located within the city of Oak Ridge, approximately one-half mile from the Y-12 weapons plant. It houses many of those who worked as service workers at the plant. In addition, reindustrialization of K-25 and its conversion into a technology park is emerging as an issue of concern. There also has been concern over operation of a TSCA-approved hazardous chemical incinerator.

The city of Oak Ridge and surrounding communities have had a long history of active civic engagement in environmental issues. The most important citizen group organized by the ORR is known as the Oak Ridge Reservation Environmental Management Site-Specific Advisory Board (ORREM SSAB). Other local environmental groups include the Local Oversight Committee (LOC), which is funded by DOE under the DOE/State of Tennessee Oversight Agreement, the Oak Ridge Environmental Quality Advisory Board, and the Roane County Environmental Review Board.

\section{Bioremediation}

Several of in situ bioremediation studies have been proposed for the NABIR Field Research Center located in Bear Creek Valley near the Y-12 Plant (for examples, see http://www.lbl.gov/NABIR/ frcawards.html). Planned and proposed studies include those of the NABIR collaborators on this research project, Dr. Joseph Suflita and Dr. Lee Krumholz of the University of Oklahoma. For example, their project "In Situ Determination of Intrinsic and Enhanced Uranium-Technetium Precipitation/Reduction Kinetics at the Proposed Bear Creek Valley Field Research Site," that also involves Dr. J. D. Istook of Oregon State University, will deploy the single-well, "push-pull" test in determining the kinetics of microbially-mediated uranium reduction in unconsolidated sediments at the Bear Creek Valley Field Research Center (FRC).

The Oak Ridge site is attractive because of the active involvement of project collaborators in in situ bioremediation of radionuclides. The community has a long history of involvement in environmental issues and the large number of rural and suburban residents is likely to result in high study participation rates. (Historically, rural residents have been more willing to respond to surveys and participate in interviews than urban residents.)

\section{Oak Ridge Maps}

Figures 1 and 2 present maps of Oak Ridge and the surrounding area 


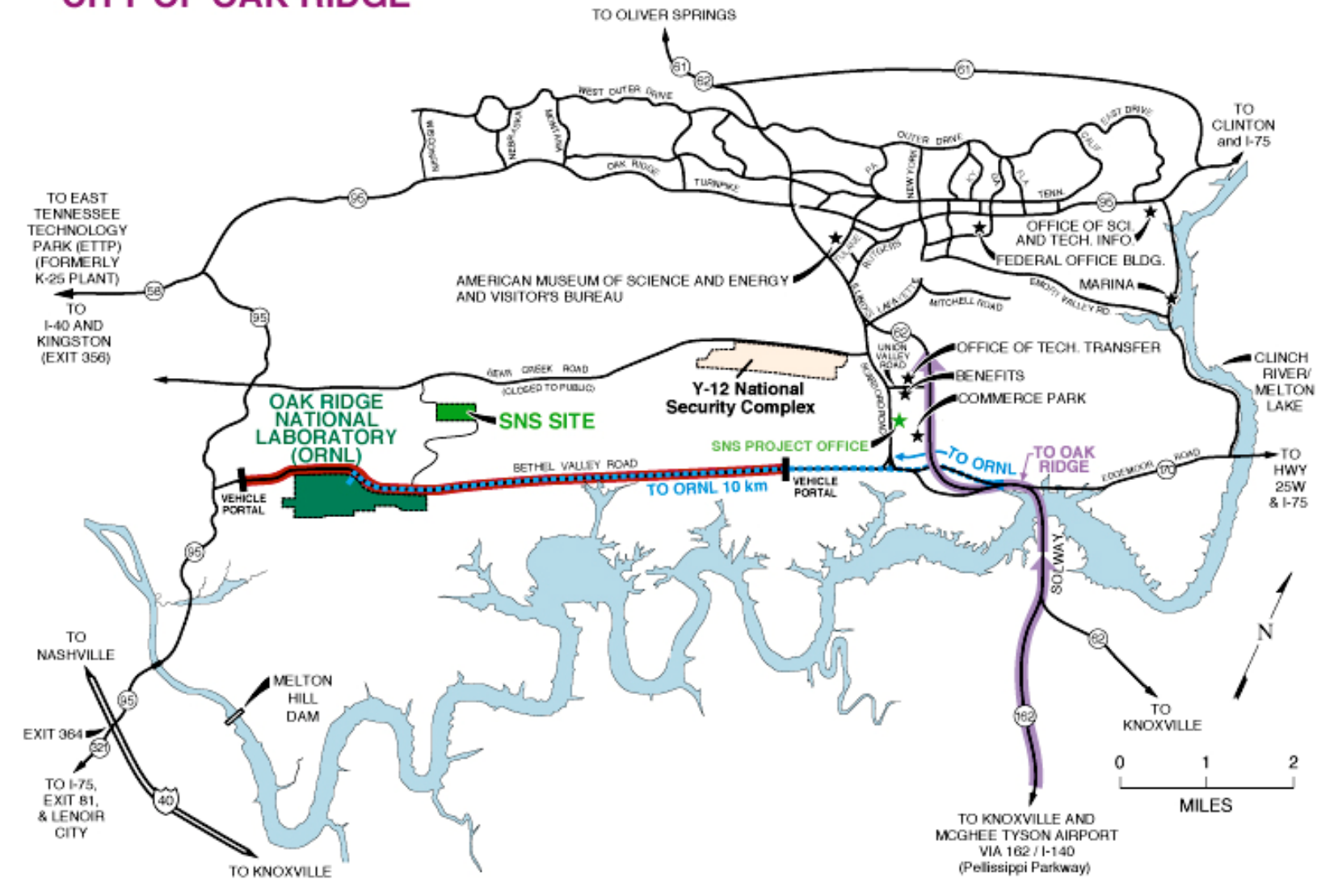

Figure 1. Map of Oak Ridge, Including the ORNL

(Extracted from ORNL website http://www.ornl.gov) 


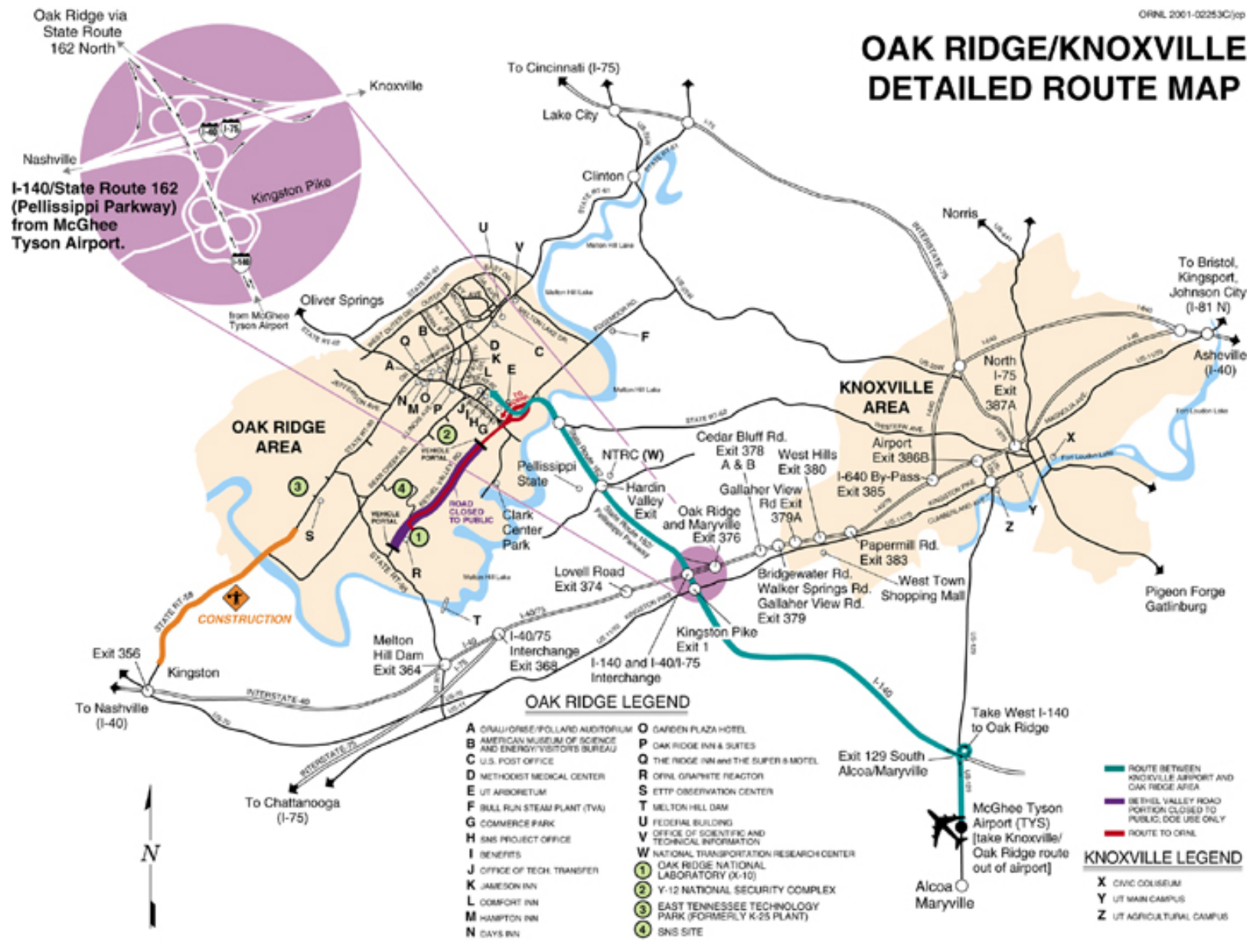

Figure 2. Map of the Area Surrounding Oak Ridge, Tennessee 


\section{Hanford Reservation, Washington}

History

In 1943, the Manhattan Project selected Hanford as a location to produce plutonium for the first atomic bombs. This area was selected due to its remoteness, dry climate, and abundance of water. Although only a small percentage of the land was actively used, the U.S. Department of Energy (DOE) Hanford Site covers 586 square miles. The area borders the Columbia River and is within close proximity of the Tri-Cities (Kennewick, Richland, and Pasco) in southeastern Washington. The Hanford Site became the largest DOE plutonium production facility in the United States.

Prior to the early 1940s, land use at the site included seasonal habitation by Native American tribes and nominal farming. The Nez Perce, Yakima Indian Nation, Wanapum, and the Confederated Tribes of the Umatilla Indian Reservation (Cayuse, Umatilla, and Walla Walla Tribes) have historical, cultural and religious interest in the site and have treaty rights to the area. These rights, as addressed in The Treaty of 1855, reserved rights for Native American Tribes to use reservation lands for economic and subsistence activities (Oregon Department of Energy website). The Treaty provided rights for hunting, fishing, and gathering of foods and medicines throughout the ceded lands. In addition to The Treaty of 1855, numerous other laws protect Native American lands, such as American Indian Religious Freedom Act, the Archaeological Resources Protection Act, the National Historic Preservation Act, and the Native American Graves Protection and Repatriation Act and Executive Order 13007 (Indian Sacred Sites) (DOE Indian Nations Program website).

The Columbia River is a significant mainstay to the residents of the Pacific Northwest, providing both economic and ecological benefits to the region in the form of electricity, irrigation, barge transportation, drinking water, as well as fish and wildlife habitat. The last free-flowing stretch of the river, an accidental by-product of the security requirements of the Department of Energy's Hanford Site, was designated by Presidential proclamation in 2000 as a National Monument. The Hanford Reach National Monument is one of the last remaining Chinook salmon fall spawning habitats (Oregon Hanford Waste Board 2002:1). Downstream of the Hanford Site, the Columbia River flows through the major metropolitan centers of Portland, Oregon, and Vancouver, Washington and drains a watershed of 259,000 square miles. The proximity to major population areas of two states along with Native American rights has resulted in regional concern over the future of the Columbia River. One of the major issues is the possible contamination of the river and its population of native salmon from the Hanford Site.

Since its beginning in the early 1940s, the Hanford Site has been the major economic force in southeastern Washington. The DOE annual budget for the Site accounts for $32 \%$ of all local employment and up to 44\% of local wages (DOE 2000:1). The Hanford Site remains the largest employer of the TriCity area and contributes $\$ 768$ million annually to the local economy. From the state's only nuclear power plant, Hanford supplies eight percent of Washington's electricity.

\section{Description}

The Hanford reservation is located in Benton, Franklin, and Grant counties in southeastern Washington near the communities of Richland, Kennewick, and Pasco. In 1990, the three county area had a population of 204,791 people, 150,033 of whom lived in the Richland-Kennewick-Pasco ("Tri-Cities") metropolitan area. The population in the three-county area is predominately white, with approximately 14 percent of Hispanic origin. The reservations of the Yakima, the Confederated Tribes of the Umatilla, and Nez Perce are located in the surrounding area and the Columbia River flows through the site. Interest in the Hanford site extends throughout the State of Washington and into Oregon, and thus includes the cities of Spokane, Seattle, Olympia, and Portland as well as an extensive rural, agricultural area (Bradbury and Branch 1999).

The reservation's nuclear weapons material production activities have left behind massive amounts of radioactive materials, unique radiation hazards, vast volumes of contaminated water and soil, and many contaminated structures ranging from reactors to chemical plants to evaporation ponds. Many aspects of the Hanford cleanup effort pose extraordinary technical and management challenges. The hazards posed by the waste stored on the site, the history of contamination and airborne releases, and the 
proximity of the Columbia River have created considerable public and regulatory concern (Bradbury and Branch 1999).

Hanford site activities have high local, regional, and national salience. The site has a long history of public involvement, including collaborative problem-solving efforts that have engaged a variety of local, regional, and national stakeholder organizations including, among others, the Washington League of Women Voters, Greenpeace, Hanford Education Action League, Hanford Watch, Heart of America Northwest, Physicians for Social Responsibility, Sierra Club, local unions, and the Tri-Cities Development Corporation. The DOE local Site-Specific Advisory Board (SSAB), known as the Hanford Advisory Board (HAB), was formed in 1993-1994 and was the first SSAB. Other bodies that bring together parties with an interest in the Hanford site include the Tri-City Technical Council, the Hanford Health Information Network, and the Vadose Zone Expert Panel) (Bradbury and Branch 1999).

Hanford is also salient because of its economic importance to the local area and region. Employing about 11,000 workers in 1997, DOE-RL and its contractors are the single most important component of the local economy, accounting, directly and indirectly, for an estimated $36 \%$ of all local non-farm employment and up to $67 \%$ of local wage income (including farm income) in Benton and Franklin counties (Bradbury and Branch 1999).

\section{Bioremediation}

A field demonstration of in situ bioremediation of chlorinated solvents was performed at the Hanford 200 West Area between January 1995 and March 1996. The demonstration included nutrient injection (acetate and nitrate) to accelerate bioremediation. Approximately two $\mathrm{kg}$ of carbon tetrachloride were biodegraded and more than $30 \mathrm{~kg}$ (dry weight) of bacteria were produced from the upper and lower zone tests.

The Hanford site differs from the Oak Ridge and Los Alamos sites in the severity of its contamination problems and the deep regional and national concern those problems have generated. The large amount of radioactive material and volume of contaminated water and soil, and the continuing threat of contamination of the Columbia River, make many aspects of the Hanford cleanup effort extraordinarily challenging. The salience of the environmental risks at Hanford and the large range and number of active stakeholders may complicate the problem of prescribing procedures for stakeholder participation. However, the severity of the contamination problems and their salience to the local communities may increase stakeholders' willingness to make risk tradeoffs. 


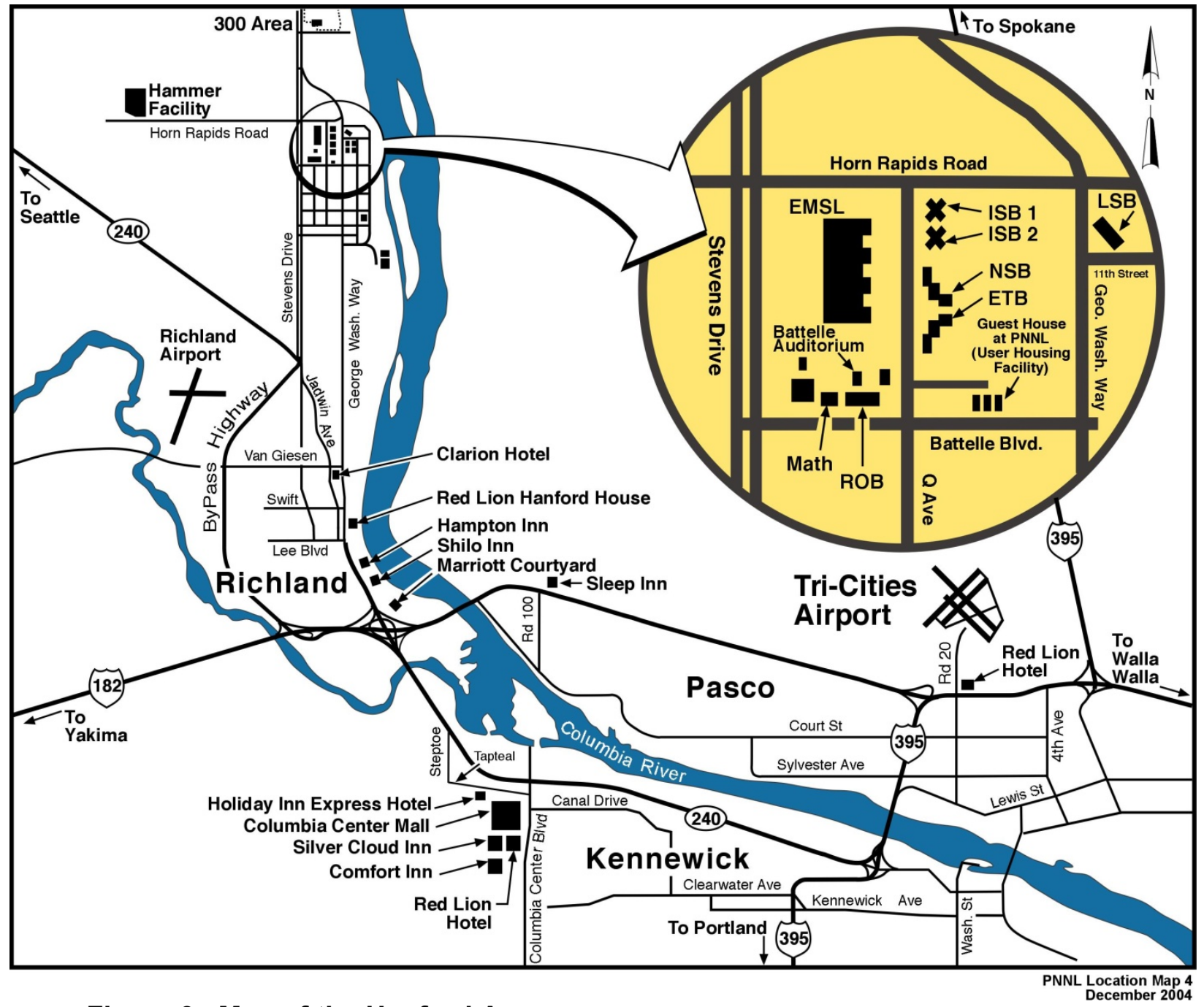

Figure 3. Map of the Hanford Area (Extracted from PNNL website http://www.pnl.gov/) 


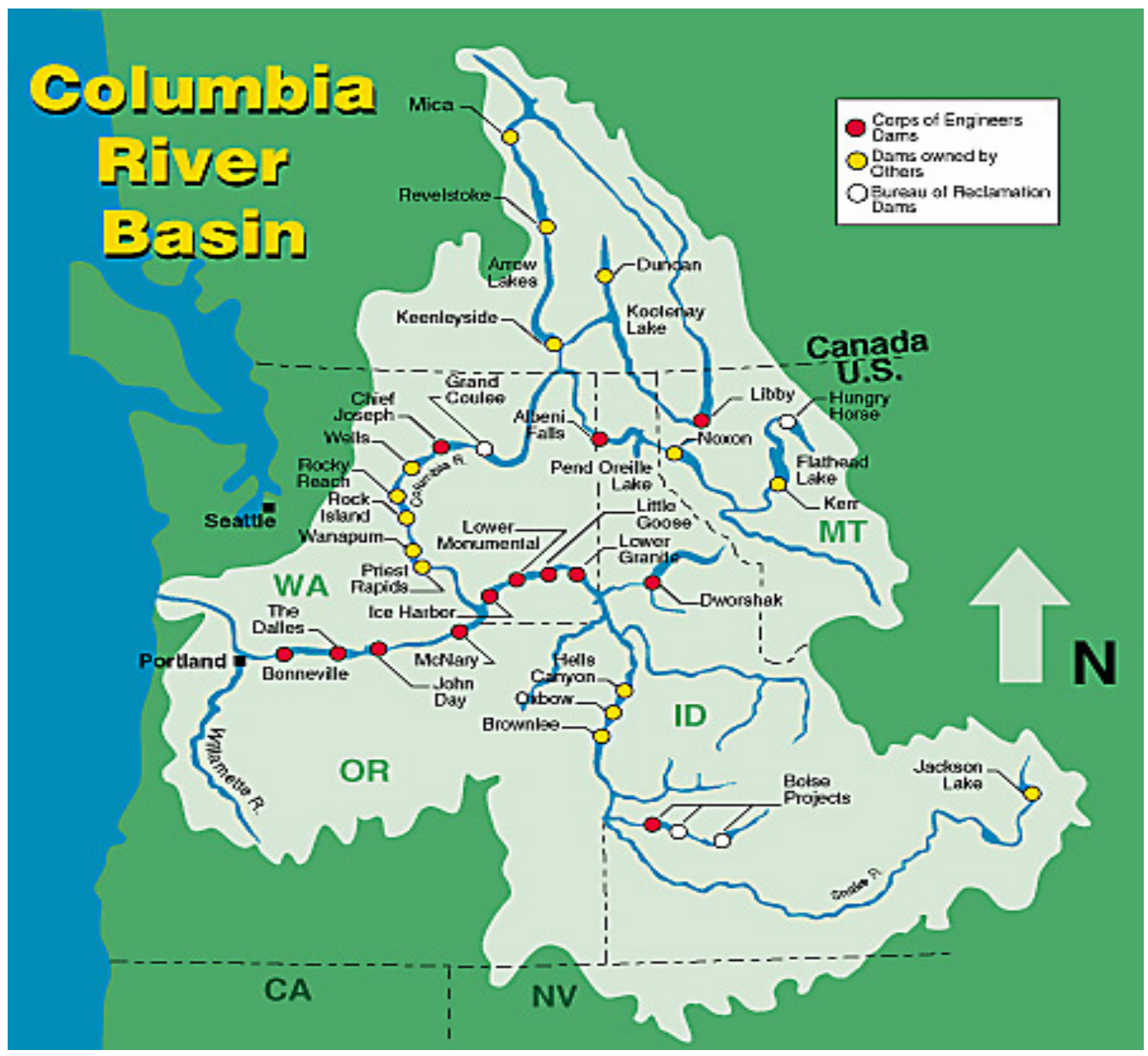

Figure 4. Map of the Columbia River Basin, Which Includes the Hanford Site (Extracted from U.S. Army Corps of Engineers, Northwestern Division website http://www.nwd.usace.army.mil/ps/colrvbsn.htm) 


\section{Los Alamos National Laboratory, New Mexico}

History

Los Alamos is located on the Pajarito Plateau at the foot of the Jemez Mountains in Northern New Mexico, a rural region made up of farms, ranches, and small villages. Pueblo tribes lived in the rugged Los Alamos area for well over 1000 years, and an exclusive boys' school (Los Alamos Ranch School) operated atop the 7300-foot plateau from 1918 to 1943. Then, the Los Alamos National Laboratory was established here in secrecy, code-named Site $Y$ of the Manhattan Project, the wartime program that developed the world's first atomic bombs.

Selecting a site for an atomic bomb design laboratory was not constrained by the need for hydroelectric power. Rather, the design and development of an atomic bomb required enhanced security. Such a site needed to be safe from bombing by enemy aircraft and equally safe from curious citizens. Army General Leslie Groves ordered a search for such a site conducted throughout the western United States. Jemez Springs, New Mexico, met the basic requirements, but upon closer inspection in November 1942, General Groves and Manhattan Project Director J. Robert Oppenheimer rejected the site because it was too confined by the high canyon walls and it lacked a good road. Oppenheimer suggested another site, not far away, called Los Alamos. Groves approved. The site was isolated, access to and from the site could be controlled, and the surrounding canyons could be used for tests involving high explosives. The War Department acted quickly to acquire the Los Alamos Ranch School (possession had to wait until the end of end of the academic term in February 1943) and a considerable amount of surrounding public and private land (Los Alamos National Laboratory Web site).

General Groves had just finished overseeing the building of the Pentagon in Washington, D.C., when he was assigned to supervise construction of buildings at Los Alamos. Groves and Oppenheimer arrived in the fall of 1942 to inspect the 54 buildings that comprised the Los Alamos Ranch School. Twenty-seven of these buildings, along with four houses acquired from nearby Anchor Ranch, were deemed adequate to serve the 30 scientists and their families who would be arriving to work for the Manhattan Project (Los Alamos National Laboratory Web site).

On July 16, 1945, the world's first atomic bomb was detonated two hundred miles south of Los Alamos at the Alamogordo bombing range. With Germany defeated, President Harry S Truman chose to employ the bomb against Japan. Atomic bombs fell on the cities of Hiroshima and Nagasaki, respectively, on August 6 and 9. On August 14, Japan surrendered and World War II officially ended (Los Alamos National Laboratory website).

After World War II, the laboratory was involved in developing and testing nuclear weapons. Many of the underground nuclear tests in the 1980s and early 1990s conducted by the United States were safety tests of stockpile weapons. With the current ban on nuclear weapon testing, other methods, primarily computer simulation, are now used in ensure the safety of the United States stockpile. Today, the Los Alamos continues work in many fields of science and national security. (Los Alamos National Laboratory website)

\section{Description}

The Los Alamos National Laboratory (LANL) is managed by the University of California under a management and operations contract for the DOE Los Alamos Area Office, Albuquerque Operations Office. LANL is located in Northern New Mexico, 90 miles north-northeast of Albuquerque, 35 miles northwest of the city of Santa Fe, and 20 miles southwest of Espanola in Rio Arriba County. It covers an area of almost 28,000 acres or approximately 43 square miles, of which $86 \%$ lies within Los Alamos County and 14 percent within Santa Fe County. The closest population centers are the communities of Los Alamos (1990 population of approximately 12,000) and White Rock (1990 population of approximately 8,000$)$. Santa Fe is the closest large population center. LANL continues to play a major role in national security and in the regional and State economy; approximately 9200 full-time contract staff and 68 Federal employees work at the site (Bradbury and Branch 1999).

Nearby jurisdictions affected by laboratory operations include six counties (Los Alamos, Mora, Rio Arriba, San Miguel, Sandoval, and Santa Fe) and ten Pueblos (Cochiti, Jemez, Nambe, Picuris, Pojoaque, San 
Ildefonso, Santa Clara, San Juan, Taos, and Tesuque). The population in the six-county area is diverse: approximately $60 \%$ white, $40 \%$ of Hispanic origin, and $7 \%$ American Indian. African-Americans comprise less than $1 \%$ of the population. Income and education levels vary widely. LANL and its activities were initially surrounded in secrecy, and the newly created scientific community developed in isolation from the rich Pueblo and Spanish heritage of the surrounding area (Bradbury and Branch 1999).

Issues related to environmental management are of growing salience to the local communities in Northern New Mexico. Of particular concern are issues related to the management of legacy wastes, contamination of groundwater, and contamination of the aquifer. Other issues include the site's mission and associated national, regional, and local opposition to specific policies such as weapons production and waste-generating activities; longstanding distrust and ambivalence about the economic dominance and technical expertise of LANL; equity concerns as they relate to hiring and firing; safety and management concerns; and negotiation over land transfers from DOE to Los Alamos County and San Ildefonso Pueblo under legislation passed in 1997 (Bradbury and Branch 1999).

The SSAB that addresses issues at Los Alamos is the Northern New Mexico Citizens' Advisory Board. The composition and selection of board members, board accountability and autonomy, and board responsiveness to public recommendations have been subjects of controversy.

\section{Bioremediation}

The Environmental Science and Waste Technology Division of Los Alamos National Laboratory has received permission to test a multi-barrier bioremediation system in Mortandad Canyon upstream of San Ildefonso Pueblo beginning in August-September 2001 (the canyon has been a nesting ground for the endangered spotted owl). The multi-barrier system is designed for in situ treatment of natural and manmade colloidal materials that can capture metals and radionuclides, soluble metals and radionuclides, inorganic contaminants, and organic compounds. The barrier is intended to immobilize metals and radionuclides (and other contaminants) in the shallow, alluvial plume by intercepting the groundwater plume downstream of the source (a wastewater treatment facility). The barrier materials are intended to be relatively resistant to degradation over time, but will require long-term stewardship.

The local communities are, in contrast to Oak Ridge, more distrustful of LANL due to the secrecy that has surrounded the isolated community, as well as issues of safety and management, weapons production, environmental impacts, and the economic dominance of the region. The Los Alamos region is also demographically more diverse with greater ethnic and income diversity.

\section{Los Alamos Maps}

Maps of the national laboratory and of the general area are presented in Figures 5 and 6. 


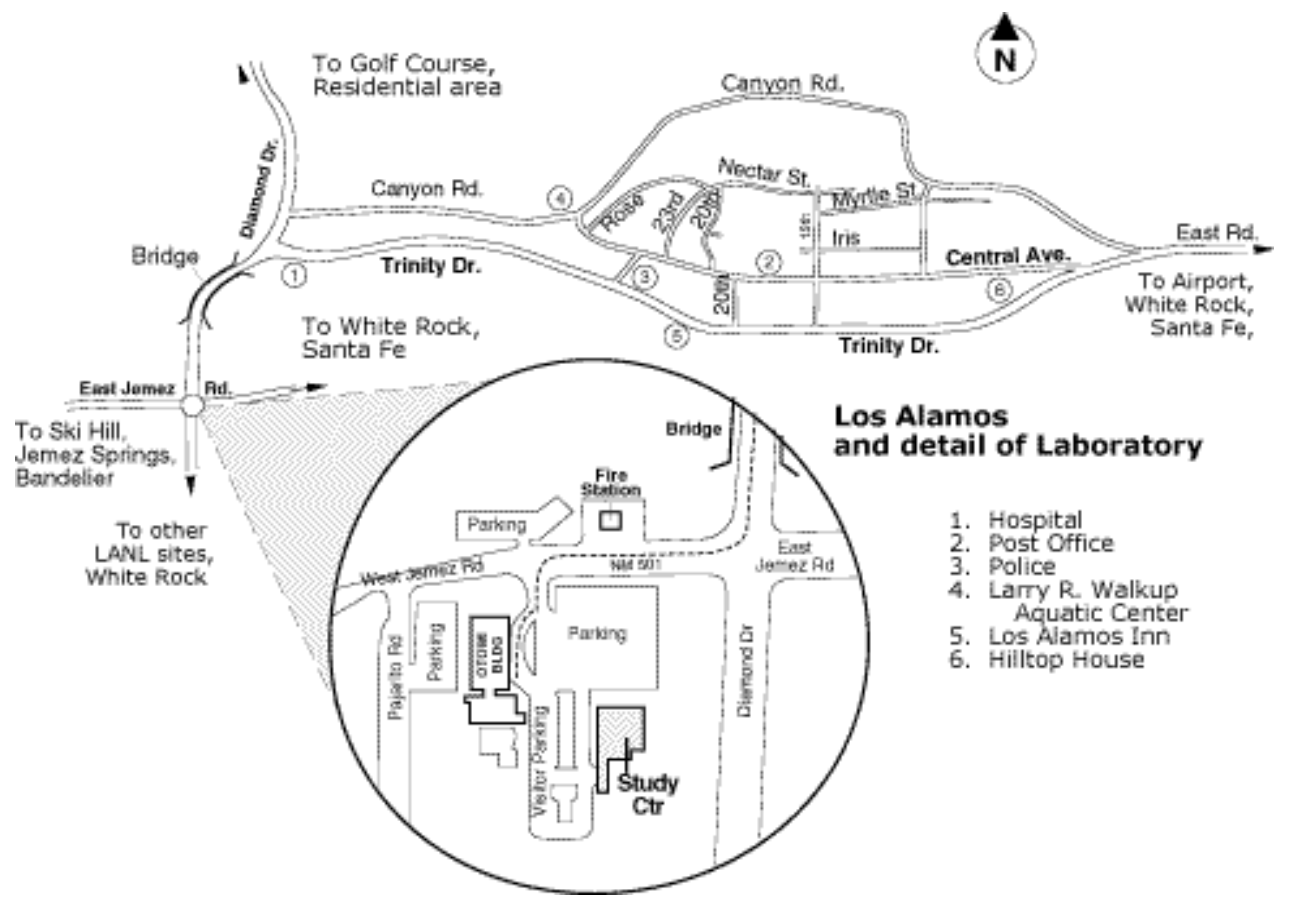

Figure 5. Map of the Los Alamos National Laboratory 


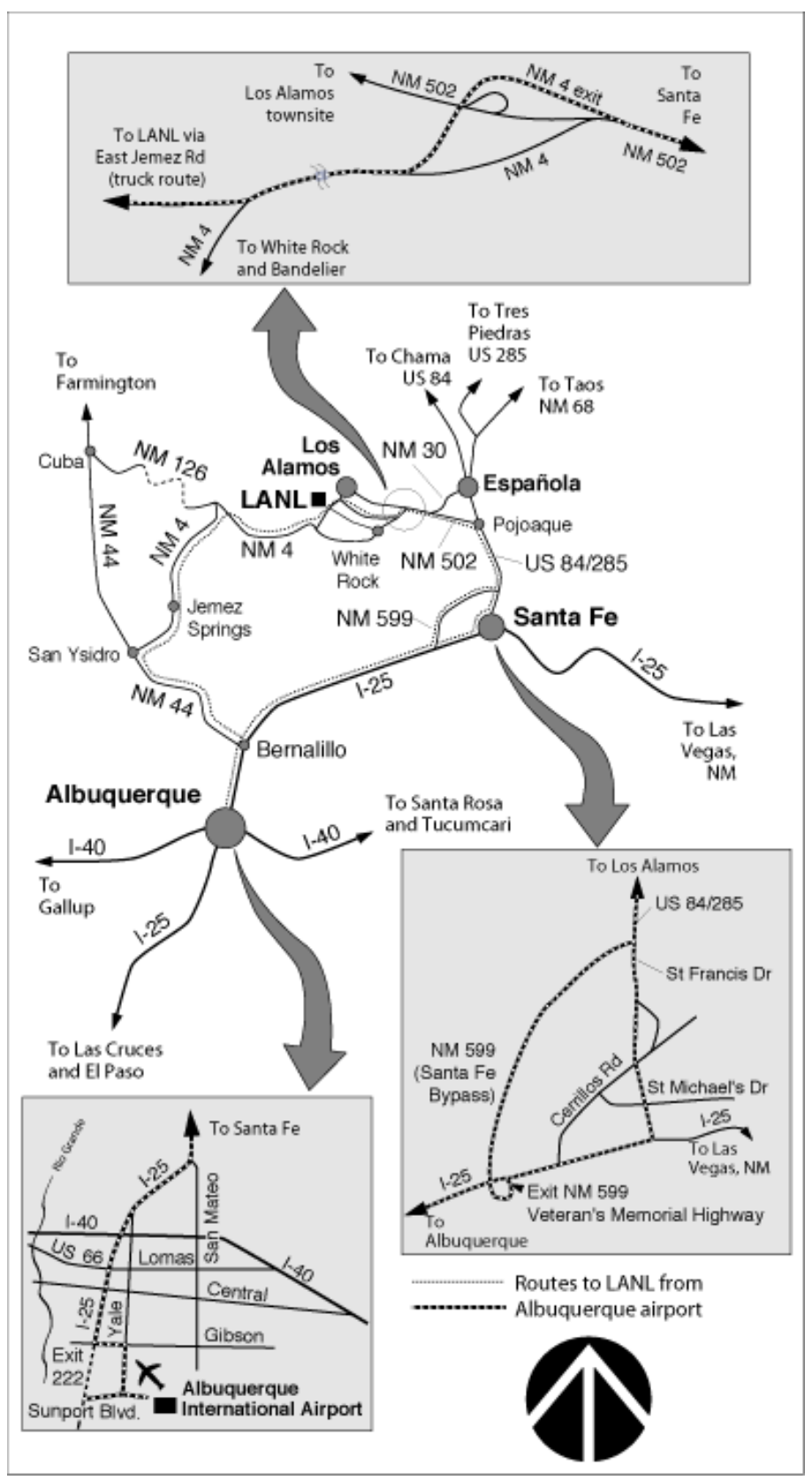

Figure 6. Map of the Area of Los Alamos, New Mexico 


\section{CHAPTER 3 \\ STAKEHOLDER INTERVIEWS: BIOREMEDIATION AND PARTICIPATION THEMES}

\section{Identification of Participants}

During the summer and fall of 2002, researchers conducted 30 face-to-face stakeholder interviews in the Oak Ridge area; 29 interviews in the Hanford area; and 20 interviews in the Los Alamos area. The interviews were conducted with community leaders, governmental officials, interest group representatives, and other local stakeholders. The interviewers used "snowballing" to identify those who had different perspectives on site remediation and participation in decision-making.

Snowballing was conducted using a variety of methods. In Oak Ridge, a "gatekeeper" was used to develop initial contacts. Amy Wolfe, a social scientist at Oak Ridge National Laboratory who has extensive experience working in the local community, supplied a list of people to contact. From this original list of ten, references to those holding different opinions expanded this list of interviewees to 30 . In Hanford, the interviewer developed her initial list from the Hanford Advisory Board. Using the Internet and references by the board, the number of interviewees grew from 12 to 29. In Los Alamos, the interviewer used the Internet and Citizen Advisory Board to develop the initial list. References by the Board resulted in 20 interviews. Table 1 presents selected demographic characteristics of the 79 stakeholders who were interviewed.

Table 1. Stakeholder Interviewee Demographic Characteristics

\begin{tabular}{|c|c|c|c|c|}
\hline GENDER & EDUCATION & $\begin{array}{c}\text { AGE } \\
\text { RANGE }\end{array}$ & CAREER & $\begin{array}{l}\text { INCOME } \\
\text { RANGE }\end{array}$ \\
\hline $\mathrm{F}$ & BS & $40-44$ & Chemical Engineering Consultant \& Activist & $90-110$ \\
\hline $\mathrm{M}$ & MS & $45-49$ & State Environmental Director & $70-90$ \\
\hline $\mathrm{M}$ & BS & $30-34$ & Convention \&Visitor Bureau & $30-50$ \\
\hline $\mathrm{M}$ & PhD & $70-74$ & Retired Nuclear Physicist & $110-129$ \\
\hline M & BS & $60-64$ & Retired Scientist & $70-90$ \\
\hline $\mathrm{M}$ & BS & $55-59$ & DOE Analyst \& Activist & $30-50$ \\
\hline $\mathrm{F}$ & MS & $45-49$ & Environmental Science Contractor & $70-90$ \\
\hline $\mathrm{F}$ & MS & $50-54$ & Ecology Contractor & $150-170$ \\
\hline $\mathrm{F}$ & BS & $40-44$ & Chemist Contractor & $70-90$ \\
\hline $\mathrm{F}$ & PhD & $40-44$ & Municipal Government & $130-150$ \\
\hline $\mathrm{M}$ & MS & $60-64$ & Retired Gov't Environmental Director & Unknown \\
\hline $\mathrm{M}$ & PhD & $75+$ & Retired Government Chemist & $30-50$ \\
\hline $\mathrm{F}$ & $\mathrm{PhD}$ & $45-49$ & Scientist/Dir Non-profit & $130-150$ \\
\hline $\mathrm{F}$ & PhD & $70-74$ & Retired Gov't Research Scientist & $50-70$ \\
\hline $\mathrm{M}$ & MBA & $45-49$ & Manager- Local Gov & $170+$ \\
\hline $\mathrm{M}$ & MS & $40-44$ & DOE Environmental Scientist & $50-70$ \\
\hline $\mathrm{F}$ & MS & $45-49$ & Environmental Engineering Contractor & $90-110$ \\
\hline $\mathrm{F}$ & Non-Degree & $50-54$ & Activist & Unknown \\
\hline $\mathrm{F}$ & BS & $50-54$ & Manager, Radiation Lab Contractor & $50-70$ \\
\hline $\mathrm{M}$ & BS & $50-54$ & Retired Mechanical Engineer \&Activist & $30-50$ \\
\hline $\mathrm{M}$ & $\mathrm{PhD}$ & $55-59$ & Lab Director & $90-110$ \\
\hline $\mathrm{M}$ & BS & $30-34$ & Real Estate Developer & $90-110$ \\
\hline $\mathrm{M}$ & MS & $45-49$ & DOE Hydrologist & $90-110$ \\
\hline $\mathrm{M}$ & MS & $35-39$ & City Manager & $110-130$ \\
\hline
\end{tabular}




\begin{tabular}{|c|c|c|c|c|}
\hline GENDER & EDUCATION & $\begin{array}{c}\text { AGE } \\
\text { RANGE }\end{array}$ & CAREER & $\begin{array}{l}\text { INCOME } \\
\text { RANGE }\end{array}$ \\
\hline $\mathrm{M}$ & BS & $45-49$ & Civil Engineering Project Manager & $90-110$ \\
\hline M & BS & $45-49$ & DOE Manager, Environmental Engineering & $70-90$ \\
\hline $\mathrm{F}$ & Non-Degree & $60-64$ & Real Estate Agent & $150-170$ \\
\hline $\mathrm{M}$ & BS & $75+$ & Retired Contractor Executive & $150-170$ \\
\hline $\mathrm{M}$ & BS & $55-59$ & Security Contractor & $50-70$ \\
\hline $\mathrm{M}$ & Non-Degree & $40-44$ & Firefighter & $50-70$ \\
\hline $\mathrm{F}$ & BS & $65-69$ & Civil Engineer & $120-130$ \\
\hline $\mathrm{M}$ & MS & $50-54$ & Civil Engineering Manager & $140-150$ \\
\hline $\mathrm{M}$ & MS & $45-49$ & Engineering Manager & $100-110$ \\
\hline $\mathrm{F}$ & $\mathrm{PhD}$ & $45-49$ & Hydrologist & $100-110$ \\
\hline $\mathrm{F}$ & MS & $50-54$ & Environmental Specialist & $40-50$ \\
\hline $\mathrm{F}$ & BS & $50-54$ & Environmental Restoration Contractor & Unknown \\
\hline $\mathrm{F}$ & BS & $35-39$ & Environmental Scientist & $60-70$ \\
\hline $\mathrm{M}$ & BS & $70-74$ & Retired Scientist & $90-100$ \\
\hline $\mathrm{M}$ & MS & $45-49$ & State Environmental Geologist & $100-110$ \\
\hline $\mathrm{M}$ & PhD & $60-64$ & Environmental Scientist & $40-50$ \\
\hline $\mathrm{M}$ & MS & $30-34$ & Geologist & $40-50$ \\
\hline $\mathrm{M}$ & MS & $55-59$ & Gov't Environmental Dept. Director & $100-110$ \\
\hline $\mathrm{F}$ & $\mathrm{PhD}$ & $75+$ & Retired Materials Scientist & Unknown \\
\hline $\mathrm{M}$ & MS & $65-69$ & Retired CEO/CFO & Unknown \\
\hline $\mathrm{F}$ & BS & $45-49$ & Environmental Scientist & $40-50$ \\
\hline $\mathrm{F}$ & MS & $40-44$ & Director, $A B$ & $150-160$ \\
\hline $\mathrm{M}$ & MS & $35-39$ & Environmental Manager & $50-60$ \\
\hline $\mathrm{F}$ & PhD & $40-44$ & Communications Consultant & $60-70$ \\
\hline $\mathrm{M}$ & BS & $40-44$ & Technical Advisor & $120-130$ \\
\hline $\mathrm{M}$ & BS & $30-34$ & Fishery Director & Unknown \\
\hline $\mathrm{M}$ & PhD & $55-59$ & Bioremediation Engineering Contractor & $90-110$ \\
\hline $\mathrm{F}$ & BS & $55-59$ & Teacher & $30-50$ \\
\hline $\mathrm{M}$ & BS & $45-49$ & Manager, Communications Contractor & $70-90$ \\
\hline $\mathrm{F}$ & MS & $45-49$ & City Manager & $130-150$ \\
\hline $\mathrm{M}$ & MS & $50-54$ & PNL Contractor & $90-110$ \\
\hline $\mathrm{F}$ & BS & $50-54$ & State Ecology Manager & $110-130$ \\
\hline $\mathrm{M}$ & BS & $45-49$ & EPA Scientist & $70-90$ \\
\hline $\mathrm{M}$ & BS & $75+$ & Retired DOE Chemical Engineer & $30-50$ \\
\hline $\mathrm{M}$ & MS & $35-39$ & DOE Public Affairs Officer & $70-90$ \\
\hline $\mathrm{F}$ & BS & $45-49$ & Graphic Artist & $70-90$ \\
\hline $\mathrm{M}$ & Non-Degree & $45-49$ & Trade Council Executive & $90-110$ \\
\hline $\mathrm{M}$ & BS & +75 & Retired DOE Mechanical Engineer & $30-50$ \\
\hline $\mathrm{M}$ & $\mathrm{BS}$ & $35-39$ & Public Relations Contractor & $130-150$ \\
\hline $\mathrm{F}$ & Non-Degree & $55-59$ & Winery Owner & $90-110$ \\
\hline $\mathrm{M}$ & MS & $35-39$ & Environmental Restoration Contractor & Unknown \\
\hline $\mathrm{M}$ & MS & $40-44$ & Engineer & $70-90$ \\
\hline $\mathrm{F}$ & MS & $30-34$ & Systems Engineer & $90-110$ \\
\hline $\mathrm{M}$ & $\mathrm{JD}$ & $35-40$ & DOE Attorney & $70-90$ \\
\hline $\mathrm{M}$ & BS & $45-49$ & City Civil Engineer & $110-130$ \\
\hline $\mathrm{M}$ & $\mathrm{BS}$ & $40-44$ & DOE Environmental Engineering Manager & $90-110$ \\
\hline
\end{tabular}




\begin{tabular}{|c|c|c|c|c||}
\hline GENDER & EdUCATION & $\begin{array}{c}\text { AGE } \\
\text { RANGE }\end{array}$ & CAREER & $\begin{array}{c}\text { INCOME } \\
\text { RANGE }\end{array}$ \\
\hline \hline M & MS & $50-54$ & DOE Physical Science & Unknown \\
\hline M & BS & $45-49$ & Stakeholder Relations Contractor & $70-90$ \\
\hline F & BS & $20-24$ & Environmental Justice Intern & $10-30$ \\
\hline M & MS & $40-44$ & Tribal Geophysicist & Unknown \\
\hline M & BS & $50-54$ & Director of Non-Profit Organization & $150-170$ \\
\hline M & BS & $35-39$ & Non-Profit Environmental Outreach Officer & $50-70$ \\
\hline F & Non-Degree & $45-49$ & Director of Non-Profit Organization & $50-70$ \\
\hline F & BS & $25-29$ & Non-Profit Organization Worker & $10-30$ \\
\hline
\end{tabular}

\section{Interview Methodology}

Interviewees were contacted by telephone to schedule an appointment for the interview. A brief description of the purpose of the study was provided and the respondent asked if he or she would be willing to participate. The telephone contact form is included in Appendix A.

Interviews were conducted at locations convenient to the interviewees, such as their offices, homes, hotels, restaurants, and public buildings. Interviews lasted from one to three hours, averaging two hours. The interviewer began by asking the respondent to sign a consent form (see Appendix A). The interview began with the respondent reading a brief description of bioremediation of radioactive and toxic heavy metals in groundwater (see Appendix A). The interview continued with an open-ended discussion of the concerns that the respondent had about contamination, health risks, trust, and participation preferences. Selected demographic characteristics (location, gender, level of education, age, occupation, and income) were also gathered.

The interviews were tape-recorded and later professionally transcribed. Seventy-two useable transcripts were analyzed (seven Los Alamos interviews tapes could not be transcribed due to inaudible recording).

\section{Methodology for Narrative Analysis of Transcripts}

Qualitative analysis of the transcripts was performed using a Computer-Assisted Qualitative Data Analysis Software (CAQDAS) package known as NUD*IST Vivo (NVivo) 2.0, produced by Qualitative Solutions and Research International (QSR). This package provides flexibility in coding and theme identification by allowing us to browse documents, create nodes, and set attributes for each document, thus creating a much simpler method by which to identify themes. Following data entry, the researcher can identify relationships between demographic characteristics and themes.

The research was conducted in the field by four interviewers, producing seventy-two transcripts from Los Alamos, Oak Ridge, and Hanford. Using NVivo, the transcripts were imported into the program in a richtext format, which allows the investigator to edit and format them. Additionally, NVivo allows the user to assign attributes of passages included in each document to facilitate later analysis. Demographic characteristics of each participant (age, education, annual household income, profession, gender, and race) were added after the transcripts were imported, which informed subsequent interpretation of findings. For example, NVivo makes it easy to select comments from interviewees who are female, between the ages of 18-24, residents of Oak Ridge, and government employees. Later, the demographic data can be cross-referenced with the themes to identify those participants and their views on risk management and trust of DOE.

Next, the transcripts were read thoroughly two to three times to identify common themes between the interviews and throughout the project. While reviewing the data, codes were applied to represent themes, patterns, categories, and links. "Coding [using the NVivo program] involves identifying an interesting passage of text and saving references to that passage of text in a database item called a node. A node can contain multiple references and can code many passages from any number of documents." ${ }^{1}$ NVivo

\footnotetext{
${ }^{1}$ NVivo manual, pg. 89.
} 
allows the researcher an opportunity to reorder, duplicate, merge, copy, or remove coding and nodes from the project. This is integral to finding and assigning clear, concise levels of relation, as well as refinement of the data.

Several thematic categories emerged from the analysis relating to trust, risk management, bioremediation, and participation. Valences within the themes are also apparent, such as trust/distrust of DOE, high/low risk perceptions, intensity of participation, and acceptability/unacceptability of bioremediation. Throughout the progressive analysis, themes were identified by coding in hierarchical nodes as well as free nodes and sets.

It is important to note that although the wording of interview questions and questionnaires were consistent, four researchers performed the interviews, each with his/her own unique style. Moreover, the research assistant performing the NVivo coding was not present at any of the interviews conducted in the field. Nevertheless, this enabled the assistant to view the data in a more objective manner, focusing on the recurrence of themes and the relation(s) between certain patterns and codes.

Upon completion of theme identification, a table of hierarchical nodes was created. ${ }^{2}$ Parent themes are justified using "child," "sibling," and even "grandchild" nodes, with the statements associated with them. In addition, demographic attributes of the interviewees are added to allow a more nuanced interpretation. To produce the table, the "modeler" and "search tool" were utilized in NVivo. Using the modeler, connections between ideas and concepts were created, layered, and labeled. The search tool created a matrix of attribute data and coding. These tools made it possible to locate and isolate text associated with certain themes, as well as produce analytic patterns of demographic attribute, trust, and participation preference. The discussion below summarizes the results of this analysis of transcripts.

\section{Narrative Analysis Results I: Themes Related to Bioremediation}

Three thematic categories were identified from discussions concerning bioremediation: risk construction (how is risk defined; three themes), risk management (how risks should be reduced; five themes), and risk managers (who should be responsible for reducing and controlling risks; five themes).

- Risk Construction Themes
o Risk acceptance
o Risk familiarity
o Risk control

- Risk Management Themes
o Action urgency
o Money versus risk
o Long-term stewardship
o Effectiveness
o Efficiency

- Risk Manager Themes
o Administration
o DOE competency
- DOE values
o Expert trust
o Risk communication

\section{Risk Construction Themes}

\section{Risk Acceptance}

Interviews fell into two distinct camps on this issue. Respondents felt that they were at either minimal or serious risk from groundwater contamination. This issue split individuals from all three sites, all genders,

\footnotetext{
${ }^{2}$ See Table of Themes and Nodes in Appendix B.
} 
and all occupations - although a preponderance of the minimal risk individuals are current or former lab employees and scientists.

\section{Risk Familiarity}

The level and extent of groundwater contamination are major concerns. The complexity of the measurement, cleanup levels, and possible technologies are not well understood by the public. A concerted effort to educate the public on these issues is probably needed; educating only Citizens Advisory Board (CAB) is not sufficient. All citizens should be aware of the scope of the issue along with the possible technologies that are being tested (or those already in use).

\section{Risk Control}

People hold divergent views over their control of risks from groundwater contamination. Again, the thread of education (information) ran through the interviews. Several interviewees believe that the lack of information causes them to be exposed to risk from groundwater contamination without their consent. They believe that if people know more about risks, they could avoid them (e.g., not drink the water, avoid body contact, or move away). Many express a feeling of a loss of control over the continuing risk of groundwater contamination.

\section{Risk Management Themes}

\section{Action Urgency}

A general feeling of inaction about the groundwater cleanup (as with other large cleanups) pervades the views expressed in many interviews. One group commented, "It seems like things are studied to death before any action is taken." Others expressed concern that a legion of interviewers, university students, and contractors take unknown reams of data, talk to endless groups of people, and do nothing to solve the problem. General frustration is evidenced by the statement, "I don't care how it is cleaned up, just do it." On the other hand, a small group that believes that "nothing needs to be done at this time."

\section{Money versus Action}

Groundwater contamination promises to be the most expensive, extensive, and contentious environmental problem at these sites. It appears that a reduction in cleanup funds coupled with an accelerated timeline for site cleanup has caused a general unease among those interviewed. One interviewee stated, "It looks like reducing risk means that money comes first and people come second." On the other hand, a concern was expressed by some that money not be wasted on political fixes, unproven technologies, and unreasonable cleanup levels.

\section{Long-Term Stewardship}

Long-term stewardship will be required due to the nature and extent of the contamination. Concern over the ability of DOE to take responsibility for long-term care was expressed by more than half of the respondents. They believe that DOE will not fulfill cleanup requirements or that they will leave the site in a state in which the community cannot assume responsibility. One individual asserted that, "we will be here after the DOE leaves." There was also a strong feeling that federal funds will run out long before the cleanup is accomplished. This undercurrent of distrust over long-term care has been heightened by DOE's accelerated cleanup schedule, which suggests to some that DOE wishes to apply quick but inadequate solutions to get the problem behind it.

\section{Effectiveness}

Due to a lack of knowledge about bioremediation of subsurface radioactive and toxic metals, most individuals are unsure of its effectiveness. Most people couched their answers within their limited knowledge on bioremediation of hydrocarbons. This led to a mixture of feelings about using bioremediation that ranged from the positive - "as close you can come to following nature's lead, the better off you are;" to the negative - "bioremediation will not take care of the contamination." Once again, a lack of knowledge of the process leads to widespread speculation. Fear is also expressed concerning the possible adverse health effects of bioremediation. 


\section{Efficiency}

Insufficient knowledge leads also to divergent opinions on the efficiency of bioremediation. Questions about the time required before bioremediation can be initiated, time required to complete bioremediation, and its cost-effectiveness lead to negative opinions. Reasonable cost as well as quick deployment and implementation will no doubt lead to positive opinions. Most respondents support bioremediation "if it was proven to work without major side-effects."

Risk Manager Themes

Administration and Responsibility

About a third of the interviewees believe that the cleanup process has become politicized with a focus on cost in lieu of protection. Issues about whether the government will take responsibility for off-site contamination persist. Doubts about DOE's ability to administer bioremediation, adequate cleanup of groundwater, and long-term stewardship were also expressed.

\section{DOE Competence}

Interviewees questioned the DOE competence to implement a complex, long-term bioremediation program due to political interference, changing administration, regulations, and funding. About a third of the respondents believe that a multi-agency approach is best while another third believe that DOE is able to implement groundwater bioremediation alone.

\section{DOE Values}

Respondents wonder if managers who change jobs every few years (or sooner) and who shift with political winds really share the values of the local citizens. They also wonder if they have been told the "whole truth" and if the government will really interested in protecting them.

\section{Expert Trust}

Expert trust was also split into thirds, with one-third heavily relying on experts to make their bioremediation judgments, one-third moderately trusting only outside experts, and one-third expressing distrust of experts because they are motivated by their own agendas and money rather that what is best.

\section{Risk Communication}

Risk communication (information) is believed to be a serious problem. Questions on the validity, completeness, correctness, truthfulness, and the quality of risk communication are frequent. Some believed that they were not told the entire truth, some believed that data is slanted or incomplete, while others believed that DOE holds back information that they do not want the public to know. One individual opined that DOE risk communication is coercive: "I don't think any agency should be talking people into accepting risk."

\section{Narrative Analysis Results II: Themes Related to Stakeholder Participation}

Six themes were revealed from analysis of the transcripts: interest in participation, knowledge required for effective participation, the role of values in decision-making, participation processes, trust of other participants, and time required for participation.

\section{Interest in Participation}

Respondents are split into two distinct groups - those who want to actively participate and those who do not. Those who want to participate believe that they could make a difference and the community wants to be involved in environmental decisions. Those who don't believe that the process takes too long, elected officials and citizen advisory boards should represent their interests, and most of the public has little concern about or interest in cleanup activities.

\section{Knowledge Required for Effective Participation}

The amount and type of information that DOE has provided to the public elicits a wide variety of responses. Respondents split over whether they have been told the whole truth or only part of the story. Some believe that DOE deliberately "talks over their heads" to discourage participation and that DOE 
continues to manifest an "ongoing legacy of a culture of secrecy." More than a third of the respondents equate education and information sharing with lowering risk perceptions and building trust.

Role of Values

A question of values arises in discussions about DOE oversight. Some believe that political appointees and upper level DOE managers might not have the "same" values as the local citizens. Moreover, some believe that $C A B$ representatives might not represent the values of the public. One individual stated, "They [CAB members] have their own agendas that don't really focus on the real issues of the time. Therefore, I feel that perhaps as a citizen, my best interests and my concerns are not really addressed." Another respondent countered, "The perception of risk and significance of risk is very badly understood by the public; emotion takes over rather than logic.

\section{Participation Process}

Though most respondents believe that the public should to be involved in bioremediation decisionmaking, their preference for degree of involvement varies. Consultation and deliberation is preferred by more than two-thirds of the respondents with a quarter preferring only information exchange. Some want to be involved "but only after the preliminary data are collected." Others believe that "listening to all sides will help make the decision more effective and comprehensive; public input gives the government more credibility." A very small group believes that "decisions are the authority of regulators working under the laws passed by elected officials; you can't leave decisions to stakeholders because the buck stops with the people doing the work and paying the money."

\section{Trust}

A major area of inquiry concerns trust: trust of DOE, trust of the local community, trust of experts, and trust of local, state, and federal government. Who people trusted and why they trusted them is a major factor in determining how stakeholders want to be involved in decision-making. More than half of the respondents either moderately or strongly trust local citizens. About two-thirds moderately or strongly trust state government, while half moderately or strongly trust the federal government. Nearly two-thirds moderately or strongly trust experts. Half of the respondents distrust or only slightly trust DOE.

\section{Time and Effort}

A variety of citizen involvement projects have been initiated at the three sites. All have a CAB and other citizen involvement groups. One group noted that "sitting through a meeting is pretty tough; life is too short to engage in a year-long process." Another group reported that "very few people want to be involved because it's too time consuming and there are personal cost as well - no one wants to be seen as biting the hand that feeds them." A common belief exists that there is not enough time to be involved in all aspects of any DOE decision. This is evidenced by the frequent preference for consultation over deliberation.

\section{Conclusions}

Three important conclusions can be drawn from this analysis of interview transcripts.

First, DOE should do more to educate the public about groundwater contamination risks and its plans to reduce these risks. The belief that the public is not capable of understanding risks and their mitigation undermines trust and exacerbates opposition to bioremediation. It is also important to keep in mind that while education and forthright risk communication alone may not reduce public opposition, the failure to educate and communicate will almost certainly increase opposition.

Second, DOE should provide ample assurances that it will not abandon the remediation effort before these risks are reduced to safe levels. Gaining public trust will not be easy, given the legacy of secrecy and widespread contamination over the last several decades. Trust must be earned through transparency, shared values, and demonstrated competence.

Third, DOE is also advised not to substitute public meetings for trust building. Citizens can become fatigued - and frustrated - from meetings that never seem to produce obvious results. We recommend that meeting agendas be oriented around concrete actions that demonstrate progress in risk reduction. 


\section{CHAPTER 4}

\section{STAKEHOLDER PERSPECTIVES ON BIOREMEDIATION AND PARTICIPATION}

This chapter presents results of a $\mathrm{Q}$ methodological survey of stakeholders who were familiar with radionuclide and heavy metal contamination and DOE efforts to remediate that contamination at the Los Alamos, Oak Ridge, and Hanford reservations. The $\mathrm{Q}$ study allows the research team to diagnose conflict among stakeholders concerning radionuclide remediation and discover opportunities for reaching consensus.

\section{Q Methodology}

The research team was interested in discovering stakeholder perspectives about two issues: site remediation (including bioremediation) to reduce risks and stakeholder participation preferences in remediation decision-making. To allow stakeholders to reveal their perspectives on these two issues, two sets of 47 statements each were selected from the concourse of statements contained in the interview transcripts based on the themes identified in the narrative analysis. These "Q samples" addressed the themes revealed from the text analysis and captured the breadth of sentiment expressed in the interviews. Table 2 presents the statements that were included in the bioremediation Q sample.

\section{Table 2. Bioremediation Q Sample}

\begin{tabular}{|c|c|}
\hline No. & STATEMENT \\
\hline 1 & We've regulated ourselves to the point of not being able to do anything. \\
\hline 2 & I assume that we have been told the truth and the locations of the contamination are correct. \\
\hline 3 & Cleanup needs to be protective of all life forms. Period! \\
\hline 4 & As much as it is a great thing to have zero risk, realistically, I don't see us getting anywhere near there. \\
\hline 5 & DOE is not being held liable for any health effects, because they have no base line testing. \\
\hline 6 & Technologies are studied to death before action is taken. \\
\hline 7 & $\begin{array}{l}\text { I believe that if people understood risks better, they would be more willing to accept small risks and spend the } \\
\text { money on large risks. }\end{array}$ \\
\hline 8 & $\begin{array}{l}\text { If there was a more concerted public education campaign on bioremediation, you would have more people } \\
\text { understand and be willing to accept the use of it. }\end{array}$ \\
\hline 9 & DOE has a problem talking about risk with stakeholders. \\
\hline 10 & I want the site to be as clean as it can possibly be; I don't care about the money. \\
\hline 11 & As long as you are aware of the contamination, you can control your risk. \\
\hline 12 & I do not trust the government to develop and oversee bioremediation. \\
\hline 13 & Just because I am calm about the contamination does not mean that I accept it. \\
\hline 14 & I rely heavily on people who are experts in their field and make judgments based on those experts. \\
\hline 15 & Though bioremediation may be a short-term fix, it certainly is not a long-term fix. \\
\hline 16 & It's very hard to get the pure scientific analysis that isn't quirked in some way by outside interest. \\
\hline 17 & I don't think any agency should be talking people into accepting risks. \\
\hline 18 & There is no question that the data is accurate; it's the interpretation of the data that we have concern with. \\
\hline 19 & DOE shouldn't waste resources on bioremediation just for political gain. \\
\hline 20 & With the regulations that are in place, I just don't see how anybody could be put in harm's way. \\
\hline 21 & You have to look at a cost-benefit analysis to decide how clean is clean. \\
\hline 22 & If anyone is so concerned that they are affected by contamination, they should move. \\
\hline 23 & I don't believe I am at risk from subsurface contamination. \\
\hline 24 & Just because it's there, doesn't mean it is bad. \\
\hline 25 & The perceived risks are much higher than the actual risks. \\
\hline 26 & DOE is not out to get me; they're probably going to look out for my best interests. \\
\hline 27 & The problem is not politics as much as limited competence in DOE. \\
\hline 28 & To DOE, reducing risks means that money comes first and people come second. \\
\hline 29 & The volumes are so great that bioremediation will not have a great deal of impact. \\
\hline 30 & People basically are able to avoid risks if they want to. \\
\hline 31 & DOE has a habit of acting in a way that would be perceived by local communities as being arrogant. \\
\hline 32 & There is more here than just economics and risk. It is our way of life that is at stake. \\
\hline 33 & The risk of contamination is not something we will be able to live with calmly. \\
\hline
\end{tabular}


$34 \quad$ DOE is overconfident that they understand all the risks.

35 I support bioremediation because that's the only way we're going to get this thing taken care of.

36 We know enough about the site to take action now, we don't need more studies.

37 The only risk associated with bioremediation is spending a lot of money on something that can't possibly work.

38 Putting manpower and dollars into making automobiles, trains, and planes safer is better than trying to reduce the theoretical "one death in a million" from contaminant exposure.

39 If DOE management didn't turn over so often, they would care more about long-term protection.

$40 \quad$ I don't completely trust DOE but I can't see anybody being able to do a better job.

41 We feel like it is going to be left to us to deal with what is left behind.

42 To me solving the problem on-site makes a lot more sense than just sending it off site.

43 DOE doesn't provide all of the data, or the data is slanted in such a way that they don't openly say that we

43 have a problem.

44 The assessment of health risks from exposure to contaminants is an exact science.

45 It's hard for me to see how we have a little bug that can do a better job than what we are doing now.

46 For right now, leaving the contamination alone is the best answer.

47 The only way we're going to get any kind of cleanup that will provide long-term protection is to remove DOE.

Table 3 presents the statements that were included in the stakeholder participation Q sample.

Table 3. Stakeholder Participation Q Sample

\begin{tabular}{|c|c|}
\hline No. & STATEMENT \\
\hline 1 & $\begin{array}{l}\text { The voices you hear are such a small fraction of all the voices out there that it's foolish to make decisions } \\
\text { based on the input from a fraction of one percent of the people }\end{array}$ \\
\hline 2 & Very few people are interested enough to really follow through and learn the facts. \\
\hline 3 & Emotions take over with most citizens groups; they don't listen to the science. \\
\hline 4 & Stakeholders can't get enough information to influence the course of events \\
\hline 5 & If they're going to leave the decision process to a committee, the decision will never be made \\
\hline 6 & DOE's words are there but the action is not. \\
\hline 7 & The State folks don't have enough knowledge or resources to adequately manage bioremediation \\
\hline 8 & The officials don't take into consideration the values of the people who live in the region \\
\hline 9 & There is currently no real mechanism to actually get public input. \\
\hline 10 & They're going to leave the decision process to a committee, the decision will never be made \\
\hline 11 & Decision-making should be done using deliberation \\
\hline 12 & DOE should be overseeing the cleanup-not a third party. \\
\hline 13 & A multi-organizational approach is much better than letting one government agency try to do it all. \\
\hline 14 & The advisory board doesn't express what l'm personally concerned about since they have different concerns. \\
\hline 15 & It is essential that stakeholders be involved in everything, including analysis, discussion, and decision-making. \\
\hline 16 & I always think that the more people involved in decision-making, the better. \\
\hline 17 & Decisions should be based only on facts, not on opinions. \\
\hline 18 & $\begin{array}{l}\text { The state does not historically have ownership of the problem. They are not wedded to it the same way DOE } \\
\text { is. }\end{array}$ \\
\hline 19 & There is an issue of whether the government has fully and honestly informed the public. \\
\hline 20 & From everything I've seen, DOE is committed to seeing it through. \\
\hline 21 & If it were not part of my job, I would not attend public meetings. \\
\hline 22 & $\begin{array}{l}\text { We've got more Ph.D.'s and top-notch scientists than probably any place on Earth, but they're not allowed to } \\
\text { practice good science. They practice political science. }\end{array}$ \\
\hline 23 & $\begin{array}{l}\text { I feel that you can't leave it to stakeholders to make the decision. The buck stops with the people who are } \\
\text { paying the money and doing the work. }\end{array}$ \\
\hline 24 & I expect the DOE to educate us so that we really understand bioremediation. \\
\hline 25 & We can't overcome the politics of DOE; they have too much money to throw around. \\
\hline 26 & Being a company town, people are not willing to be perceived as biting the hand that feeds them. \\
\hline 27 & The problem is that the people really don't have the knowledge base they need to make informed decisions. \\
\hline 28 & The DOE is competent to manage the site only with the regulatory agencies by their side. \\
\hline 29 & People just want to be told whether it is safe or not; they really don't want any of the details. \\
\hline 30 & I trust consultants more than I trust the government to manage bioremediation. \\
\hline 31 & $\begin{array}{l}\text { The public should be brought into the process only after sufficient information has been gathered to } \\
\text { communicate a complete picture to the public. }\end{array}$ \\
\hline 32 & I believe that it is the citizen's responsibility to keep the scientists under control. \\
\hline
\end{tabular}




\begin{tabular}{||l|l||}
\hline 33 & The decision maker should listen to all sides before making a decision. \\
\hline 34 & Consultation with stakeholders is how we are going to make the best use of resources. \\
\hline 35 & DOE will take your comments for the record and will do what they want to do anyway. \\
\hline 36 & I feel I have a voice whenever I want to use it. \\
\hline 37 & I would expect the DOE to somehow educate us so that we really understand bioremediation. \\
\hline 38 & Overall, DOE is doing a good job on public involvement. \\
\hline 39 & $\begin{array}{l}\text { We have elected officials, advisory boards, and public comment periods, which satisfy my need to be involved } \\
\text { in DOE cleanup decisions. }\end{array}$ \\
\hline 40 & Life is too short to be engaged in yearlong stakeholder processes. \\
\hline 41 & All experts care about is personal gain. \\
\hline 42 & If you try to do anything by consensus, you will never get anything done. \\
\hline 43 & $\begin{array}{l}\text { If DOE does not involve stakeholders then there will be unnecessary expense, unnecessary displeasure, and } \\
\text { unnecessary problems. }\end{array}$ \\
\hline 44 & Regardless of what stakeholders say, most people do not want to participate in the whole process. \\
\hline 45 & Someone just needs to step up to the plate and make a decision. \\
\hline 46 & I don't have the time to participate; I have to make a living. \\
\hline 47 & Trusting the Federal Government is like trusting an illusion. \\
\hline
\end{tabular}

Q sort questions were selected that reflected the NVivo themes in a balanced manner. Tables 4 and 5 show how the statements are arranged across the themes.

Table 4. Distribution of Bioremediation Q Sample Items across Interview Themes

\begin{tabular}{|c|c|c|c|c|c|c|c|c|c|c|c|c|c|}
\hline & 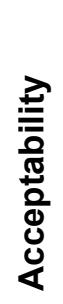 & 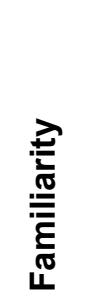 & 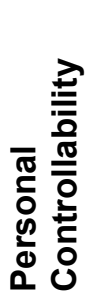 & $\frac{\text { 동 }}{\frac{0}{0}}$ & 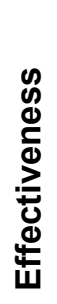 & 茂 & 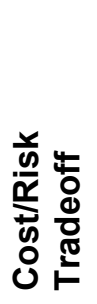 & 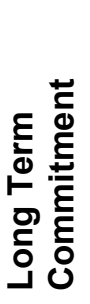 & 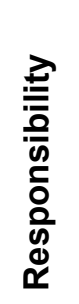 & 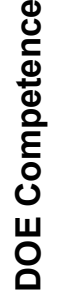 & 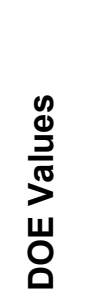 & 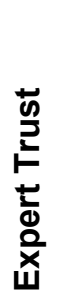 & 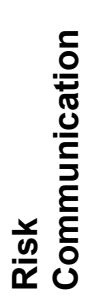 \\
\hline $\begin{array}{c}\text { Risk } \\
\text { Construction }\end{array}$ & $\begin{array}{l}7 \\
13 \\
24 \\
33\end{array}$ & $\begin{array}{l}8,17 \\
23 \\
2544\end{array}$ & $\begin{array}{l}11, \\
20, \\
22, \\
30\end{array}$ & & & & & & & & & & \\
\hline $\begin{array}{c}\text { Risk } \\
\text { Management }\end{array}$ & & & & $\begin{array}{c}6,34 \\
36\end{array}$ & $\begin{array}{l}15, \\
29 \\
35 \\
42 \\
45\end{array}$ & $\begin{array}{l}19 \\
37 \\
38\end{array}$ & $\begin{array}{c}4,10 \\
21 \\
28 \\
32\end{array}$ & $\begin{array}{c}3,41 \\
47\end{array}$ & & & & & \\
\hline $\begin{array}{c}\text { Risk } \\
\text { Managers }\end{array}$ & & & & & & & & & $\begin{array}{l}1,5 \\
39 \\
40\end{array}$ & $\begin{array}{l}12 \\
27 \\
34\end{array}$ & 2,26 & $\begin{array}{l}14 \\
16 \\
18\end{array}$ & $\begin{array}{c}9,31 \\
43\end{array}$ \\
\hline
\end{tabular}

Table 5. Distribution of Stakeholder Participation Items across Interview Themes

\begin{tabular}{|l|c|c|c|c|c|c|}
\hline & $\begin{array}{c}\text { Interest in } \\
\text { Participation }\end{array}$ & Knowledge & Values & $\begin{array}{c}\text { Participation } \\
\text { Process }\end{array}$ & Trust & \multicolumn{1}{c|}{ Time } \\
\hline \hline Stakeholder & $11,15,16,36,39$ & $2,4,27,31$, & $3,26,32$ & $5,10,34,43$ & $20,30,41$ & $40,44,46$ \\
\hline Decision Maker & $1,9,13,25,33$ & $7,17,22,24,37$ & 8,14 & $18,23,42,45$ & $\begin{array}{c}6,12,19,28,35, \\
38,47\end{array}$ & 21,29 \\
\hline
\end{tabular}

Formboards (Figures 7 and 8) were developed to guide the two Q sorting exercises. 
What is your view of the use of subsurface bioremediation

to treat radioactive and heavy metals contamination?

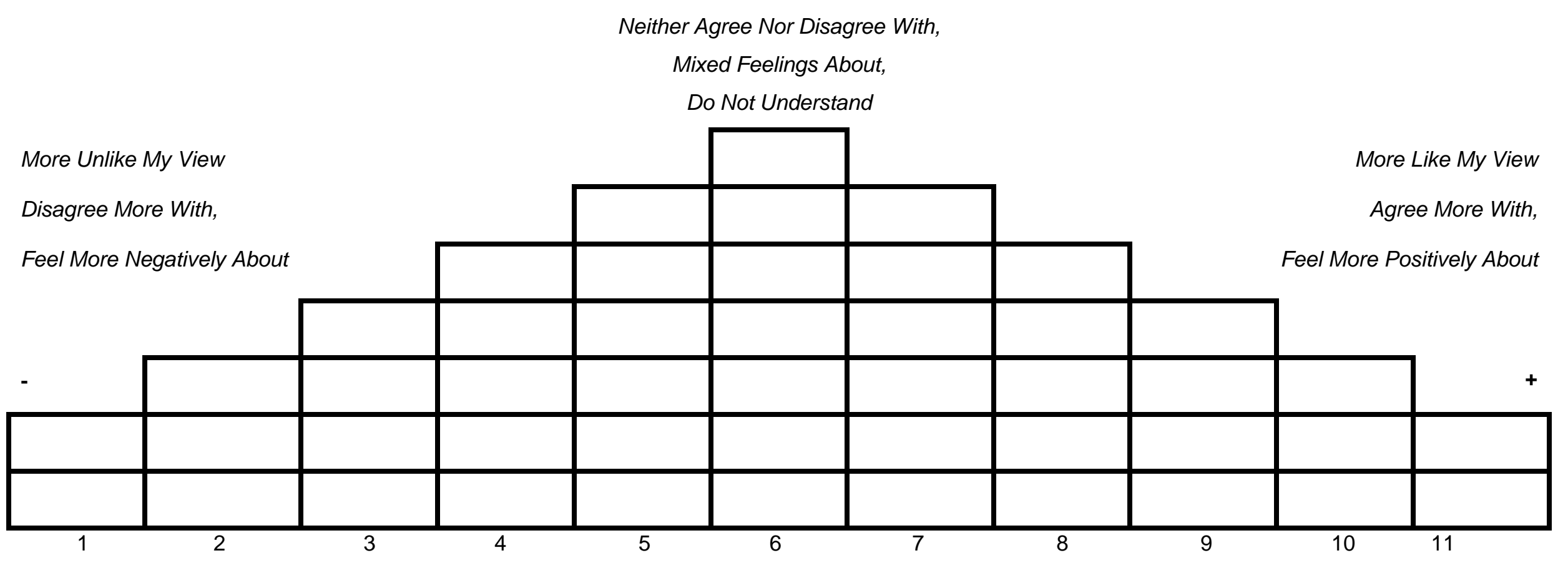

Summary of My View:

Figure 7. Bioremediation Formboard 
What is your view on involving stakeholders in decision-making about subsurface bioremediation to treat radioactive and heavy metal contamination?

Neither Agree Nor Disagree With,

Mixed Feelings About,

Do Not Understand

More Unlike My View

Disagree More With,

Feel More Negatively About
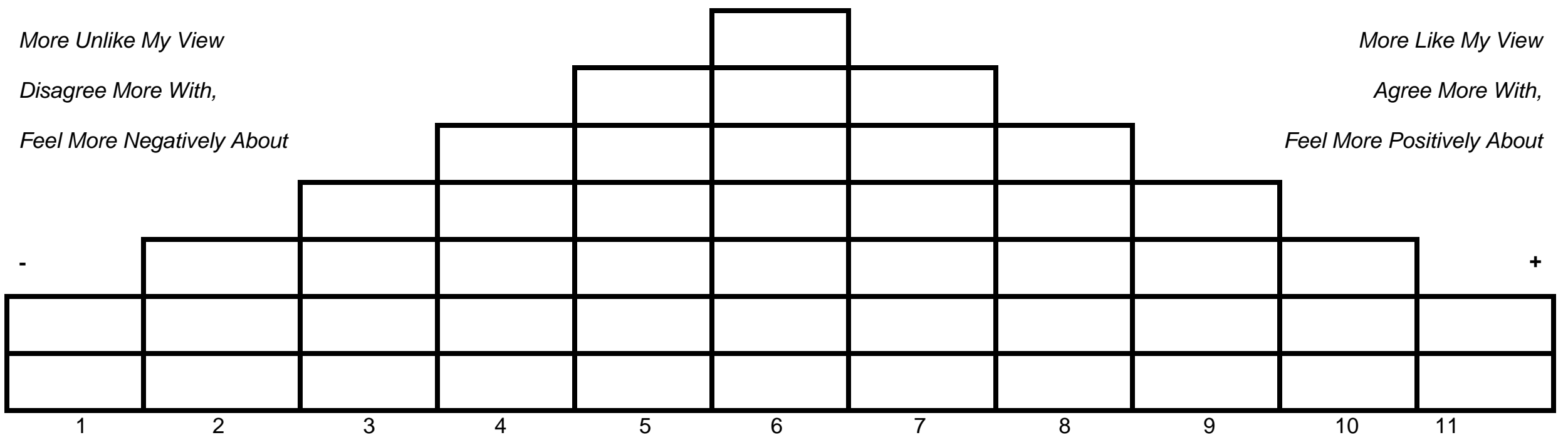

Summary of My View:

Figure 8. Stakeholder Participation Formboard 
The formboards and Q samples were mailed to the 72 stakeholders for whom we were able to develop transcripts. Thirty-six pairs of $\mathrm{Q}$ sorts were returned (after one follow-up mailing and one follow-up telephone call) - a 50\% response rate. However, three of the 36 returned sort pairs were unusable, leaving 33 sort pairs for analysis. Table 6 presents selected demographic characteristics of those who returned usable Q sort pairs.

Table 6. Q Respondent Demographic Characteristics

\begin{tabular}{|c|c|c|c|c|}
\hline GENDER & EDUCATION & AgE RANGE & CAREER & $\begin{array}{l}\text { INCOME } \\
\text { RANGE }\end{array}$ \\
\hline $\mathrm{M}$ & MS & $45-49$ & State Environmental Director & $70-90$ \\
\hline $\mathrm{M}$ & PhD & $70-74$ & Retired Nuclear Physicist & $110-129$ \\
\hline $\mathrm{F}$ & MS & $45-49$ & DOE Analyst \& Activist & $70-90$ \\
\hline $\mathrm{F}$ & MS & $50-54$ & Ecology Contractor & $150-170$ \\
\hline $\mathrm{M}$ & PhD & $75+$ & Retired Government Chemist & $30-50$ \\
\hline $\mathrm{F}$ & $\mathrm{PhD}$ & $70-74$ & Retired Gov't Environmental Director & $50-70$ \\
\hline $\mathrm{M}$ & MBA & $45-49$ & City Manager & $170+$ \\
\hline $\mathrm{M}$ & MS & $40-44$ & DOE Environmental Scientist & $50-70$ \\
\hline $\mathrm{F}$ & MS & $45-49$ & Environmental Engineering Contractor & $90-110$ \\
\hline $\mathrm{M}$ & $\mathrm{PhD}$ & $55-59$ & Lab Director & $90-110$ \\
\hline $\mathrm{M}$ & MS & $35-39$ & City Manager & $110-130$ \\
\hline $\mathrm{M}$ & BS & $75+$ & Retired Contractor Executive & $150-170$ \\
\hline $\mathrm{M}$ & BS & $55-59$ & Security Contractor & $50-70$ \\
\hline $\mathrm{F}$ & BS & $65-69$ & Civil Engineer & $120-130$ \\
\hline $\mathrm{M}$ & MS & $50-54$ & Civil Engineering Manager & $140-150$ \\
\hline $\mathrm{M}$ & MS & $45-49$ & Engineering Manager & $100-110$ \\
\hline $\mathrm{M}$ & PhD & $60-64$ & Environmental Scientist & $40-50$ \\
\hline $\mathrm{M}$ & MS & $30-34$ & Geologist & $40-50$ \\
\hline $\mathrm{M}$ & MS & $55-59$ & Gov't Environmental Department Director & $100-110$ \\
\hline $\mathrm{F}$ & PhD & $40-44$ & Communications Consultant & $60-70$ \\
\hline $\mathrm{M}$ & $\mathrm{PhD}$ & $55-59$ & & $90-110$ \\
\hline $\mathrm{F}$ & BS & $55-59$ & Teacher & $30-50$ \\
\hline $\mathrm{M}$ & BS & $45-49$ & Contract Communications Manager & $70-90$ \\
\hline $\mathrm{M}$ & MS & $50-54$ & PNL Contractor & $90-110$ \\
\hline $\mathrm{F}$ & BS & $50-54$ & State Ecology Manager & $110-130$ \\
\hline $\mathrm{M}$ & BS & $45-49$ & EPA Scientist & $70-90$ \\
\hline $\mathrm{M}$ & BS & $75+$ & Retired DOE Chemical Engineer & $30-50$ \\
\hline $\mathrm{F}$ & BS & $45-49$ & Graphic Artist & $70-90$ \\
\hline $\mathrm{F}$ & Non-Degree & $55-59$ & Winery Owner & $90-110$ \\
\hline $\mathrm{M}$ & MS & $40-44$ & Engineer & $70-90$ \\
\hline $\mathrm{M}$ & $\mathrm{BS}$ & $45-49$ & City Civil Engineer & $110-130$ \\
\hline $\mathrm{M}$ & BS & $45-49$ & Stakeholder Relations Contractor & $70-90$ \\
\hline $\mathrm{F}$ & BS & $20-24$ & Environmental Justice Intern & $10-30$ \\
\hline
\end{tabular}

The Q sort data from the 33 usable sort pairs were entered into PQMethod, Version 2.11, a software program available from http://www.rz.unibw-muenchen.de/ p41bsmk/qmethod/. Orthogonal Q factors were obtained using principal components extraction and varimax rotation. Each retained factor had at least two sorts significantly loaded on it (at $p<0.001)$. To validate our interpretations, we asked respondents to provide a written summary of their perspectives captured by the Q sort. Though most of 
these summaries were quite brief, those provided by the high-pure loaders provided sufficient information for validation of our interpretations.

\section{Perspectives on Bioremediation}

Six perspectives on bioremediation were revealed from the $\mathrm{Q}$ factor analysis. These six factors accounted for all 33 sorts and $64 \%$ of the total variance among sorts. The factor correlations are presented in Table 7.

Table 7. Bioremediation Factor Correlations

\begin{tabular}{|c||c|c|c|c|c|}
\hline FACTORS & B & C & D & E & F \\
\hline \hline A & 0.14 & $\mathbf{0 . 6 0}$ & 0.05 & $\mathbf{0 . 3 6}$ & -0.01 \\
\hline B & & 0.16 & $\mathbf{0 . 3 2}$ & 0.09 & $\mathbf{0 . 4 5}$ \\
\hline C & & & 0.00 & $\mathbf{0 . 3 2}$ & -0.14 \\
\hline D & & & & 0.03 & $\mathbf{0 . 2 3}$ \\
\hline E & & & & & -0.02 \\
\hline
\end{tabular}

This table demonstrates that the perspectives captured by factors $A, C$, and $E$ are moderately correlated and $B, D$, and $F$ are moderately correlated, but these two groups are quite independent of each other. This suggests that the six perspectives can be divided into two groups of three perspectives each. Note further, that within the ACE group, factors $A$ and $C$ are correlated most highly $(r=0.60)$ and within the BDF group, factors $B$ and $F$ are correlated most highly $(r=0.45)$. This suggests that two subgroups within each group can be identified as well. The following diagram (Figure 9) illustrates these relationships. The names of the perspectives, both composite and individual, are also shown and will be discussed in the next section.
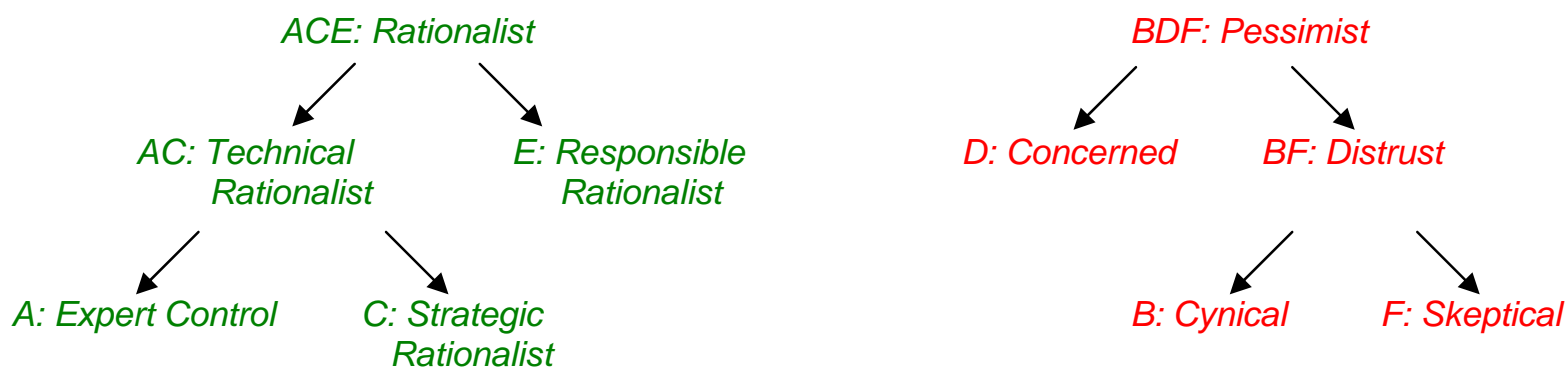

Figure 9. Relationships among Bioremediation Perspectives

\section{Factor Loadings}

Table 8 presents the factor loadings for each of the 33 stakeholders who submitted Q sorts for analysis. At a significance level of 0.001 , the critical loading value is 0.451 . Therefore, a loading exceeding this value indicates that that stakeholder's sort is significantly correlated with the common sort represented by the factor (indicated by boldface type). Note that OR represents an Oak Ridge stakeholder, HA represents a Hanford stakeholder, and LA represents a Los Alamos stakeholder. 
Table 8. Bioremediation Factor Loadings

\begin{tabular}{|c|c|c|c|c|c|c|}
\hline QSORT & $\bar{A}$ & B & $\bar{C}$ & $\bar{D}$ & $\bar{E}$ & $\overline{\mathbf{F}}$ \\
\hline OR14 & 0.827 & -0.096 & 0.252 & 0.030 & 0.107 & -0.035 \\
\hline HA09 & 0.751 & 0.080 & 0.137 & -0.061 & 0.110 & 0.195 \\
\hline HA17 & 0.724 & -0.111 & 0.426 & 0.062 & 0.123 & -0.064 \\
\hline LA03 & 0.669 & -0.125 & -0.201 & 0.117 & 0.048 & -0.080 \\
\hline LA24 & 0.654 & 0.223 & 0.388 & 0.059 & 0.043 & 0.285 \\
\hline OR16 & 0.635 & -0.068 & 0.121 & -0.174 & -0.109 & 0.048 \\
\hline OR21 & 0.577 & -0.133 & 0.403 & 0.016 & 0.235 & -0.157 \\
\hline OR02 & 0.576 & 0.196 & 0.166 & -0.084 & 0.158 & -0.178 \\
\hline OR12 & 0.595 & 0.128 & 0.514 & -0.094 & 0.309 & 0.034 \\
\hline OR07 & 0.550 & 0.393 & 0.285 & 0.365 & 0.270 & 0.038 \\
\hline OR24 & 0.474 & 0.083 & -0.040 & -0.441 & 0.050 & -0.198 \\
\hline LA17 & -0.028 & 0.806 & -0.094 & -0.073 & 0.033 & 0.037 \\
\hline LA18 & -0.069 & 0.774 & 0.189 & -0.138 & 0.232 & 0.179 \\
\hline OR17 & -0.102 & 0.732 & 0.163 & -0.019 & 0.203 & -0.252 \\
\hline HA07 & 0.242 & 0.729 & 0.177 & 0.127 & -0.143 & 0.114 \\
\hline HA06 & -0.203 & 0.714 & -0.150 & 0.261 & -0.119 & 0.219 \\
\hline HA11 & -0.180 & 0.645 & 0.138 & 0.092 & 0.032 & 0.370 \\
\hline OR29 & 0.419 & 0.602 & -0.086 & 0.175 & 0.024 & 0.085 \\
\hline OR08 & 0.242 & 0.527 & 0.189 & 0.465 & 0.373 & -0.029 \\
\hline OR04 & 0.458 & 0.471 & 0.138 & 0.017 & 0.400 & 0.203 \\
\hline HA23 & 0.203 & 0.059 & 0.733 & 0.043 & 0.084 & -0.102 \\
\hline LA01 & -0.001 & -0.034 & 0.722 & 0.289 & 0.062 & 0.161 \\
\hline HA2O & 0.260 & 0.219 & 0.682 & -0.235 & -0.079 & -0.162 \\
\hline LA02 & 0.165 & 0.183 & 0.677 & -0.347 & 0.012 & -0.075 \\
\hline OR15 & 0.430 & -0.190 & 0.584 & 0.030 & 0.296 & -0.124 \\
\hline HA02 & -0.150 & 0.057 & -0.126 & 0.732 & -0.177 & -0.114 \\
\hline HA24 & 0.214 & 0.221 & 0.044 & 0.610 & 0.118 & 0.417 \\
\hline HA04 & 0.242 & 0.153 & -0.061 & -0.026 & 0.613 & 0.283 \\
\hline HA08 & 0.313 & 0.453 & 0.006 & 0.128 & -0.612 & 0.089 \\
\hline LA16 & 0.196 & 0.320 & 0.207 & 0.145 & 0.590 & -0.300 \\
\hline OR28 & 0.368 & 0.067 & 0.252 & -0.136 & 0.570 & 0.070 \\
\hline HA15 & 0.021 & 0.192 & -0.101 & 0.145 & 0.057 & 0.773 \\
\hline HA03 & -0.102 & 0.495 & -0.144 & -0.190 & -0.000 & 0.547 \\
\hline \# of Significant Loaders & 12 & 11 & 6 & 3 & 4 & 2 \\
\hline Explained Variance (\%) & 18 & 16 & 11 & 6 & 7 & 6 \\
\hline
\end{tabular}

Note that all 33 stakeholders significantly loaded on at least one factor. Five of the 33 stakeholders' sorts loaded on two factors, meaning that their perspective is a composite of those represented by the two factors.

\section{Factor Interpretations}

To explain the perspectives represented by the factors, the factor score arrays are consulted. Table 9 presents the factor score arrays for the six bioremediation factors. Those statements ranking at the extremes (highly positive or highly negative) are most salient (positively or negatively) to the stakeholders who loaded most significantly on the common factor. These highly salient statements (z-scores highlighted in bold) are most important in developing factor interpretations that represent the perspective shared by the significant loaders. 
Table 9. Bioremediation Factor Score Arrays

\begin{tabular}{|c|c|c|c|c|c|c|c|}
\hline No. & STATEMENT & $\overline{\mathbf{A}}$ & $\mathbf{B}$ & $\bar{C}$ & $\bar{D}$ & $\bar{E}$ & $\overline{\mathbf{F}}$ \\
\hline 1 & $\begin{array}{l}\text { We've regulated ourselves to the point of not being able to } \\
\text { do anything. }\end{array}$ & -0.48 & -1.08 & 1.64 & -0.46 & -0.81 & -1.32 \\
\hline 2 & $\begin{array}{l}\text { I assume that we have been told the truth and the locations } \\
\text { of the contamination are correct. }\end{array}$ & 0.90 & 0.29 & 0.30 & 1.36 & -0.28 & 0.24 \\
\hline 3 & Cleanup needs to be protective of all life forms. Period! & 0.31 & 1.28 & -2.20 & 1.80 & -0.63 & 1.26 \\
\hline 4 & $\begin{array}{l}\text { As much as it is a great thing to have zero risk, realistically, } \\
\text { I don't see us getting anywhere near there. }\end{array}$ & 0.07 & 0.11 & 0.02 & 0.06 & 0.01 & -0.06 \\
\hline 5 & $\begin{array}{l}\text { DOE is not being held liable for any health effects, because } \\
\text { they have no base line testing. }\end{array}$ & -1.00 & -0.22 & -0.66 & 0.90 & -0.11 & -0.82 \\
\hline 6 & Technologies are studied to death before action is taken. & -0.10 & 0.08 & 0.29 & -1.21 & 1.05 & 0.68 \\
\hline 7 & $\begin{array}{l}\text { I believe that if people understood risks better, they would } \\
\text { be more willing to accept small risks and spend the money } \\
\text { on large risks. }\end{array}$ & 2.20 & 0.66 & 0.68 & 0.28 & 0.26 & -1.19 \\
\hline 8 & $\begin{array}{l}\text { If there was a more concerted public education campaign } \\
\text { on bioremediation, you would have more people } \\
\text { understand and be willing to accept the use of it. }\end{array}$ & 1.14 & 0.78 & 0.23 & -0.01 & 1.13 & 1.31 \\
\hline 9 & DOE has a problem talking about risk with stakeholders. & 0.87 & 1.83 & 1.73 & -0.91 & -0.07 & 1.13 \\
\hline 10 & $\begin{array}{l}\text { I want the site to be as clean as it can possibly be; I don't } \\
\text { care about the money. }\end{array}$ & -1.78 & 1.08 & -2.23 & 0.62 & -1.89 & 2.07 \\
\hline 11 & $\begin{array}{l}\text { As long as you are aware of the contamination, you can } \\
\text { control your risk. }\end{array}$ & 0.76 & -0.61 & 0.53 & 0.24 & -1.34 & 1.38 \\
\hline 12 & $\begin{array}{l}\text { I do not trust the government to develop and oversee } \\
\text { bioremediation. }\end{array}$ & -1.30 & -0.44 & -0.57 & -0.69 & -0.01 & -0.19 \\
\hline 13 & $\begin{array}{l}\text { Just because I am calm about the contamination does not } \\
\text { mean that I accept it. }\end{array}$ & 0.57 & 1.08 & 0.99 & 0.28 & 1.03 & 1.63 \\
\hline 14 & $\begin{array}{l}\text { I rely heavily on people who are experts in their field and } \\
\text { make judgments based on those experts. }\end{array}$ & 1.36 & 0.63 & 0.18 & 0.37 & 0.84 & -0.32 \\
\hline 15 & $\begin{array}{l}\text { Though bioremediation may be a short-term fix, it certainly } \\
\text { is not a long-term fix. }\end{array}$ & -1.24 & -0.45 & -0.09 & 1.36 & -0.33 & 0.15 \\
\hline 16 & $\begin{array}{l}\text { It's very hard to get the pure scientific analysis that isn't } \\
\text { quirked in some way by outside interest. }\end{array}$ & -0.03 & 0.50 & -0.22 & -0.69 & -0.13 & 0.95 \\
\hline 17 & $\begin{array}{l}\text { I don't think any agency should be talking people into } \\
\text { accepting risks. }\end{array}$ & -1.14 & 0.34 & -0.37 & 2.14 & 0.56 & 1.07 \\
\hline 18 & $\begin{array}{l}\text { There is no question that the data is accurate; it's the } \\
\text { interpretation of the data that we have concern with. }\end{array}$ & -0.25 & -0.17 & -0.68 & 0.04 & -1.18 & 0.31 \\
\hline 19 & $\begin{array}{l}\text { DOE shouldn't waste resources on bioremediation just for } \\
\text { political gain. }\end{array}$ & 0.62 & 0.37 & 0.58 & -2.29 & 0.18 & 0.20 \\
\hline 20 & $\begin{array}{l}\text { With the regulations that are in place, I just don't see how } \\
\text { anybody could be put in harm's way. }\end{array}$ & 0.02 & -1.61 & -1.33 & -0.03 & -0.52 & -1.26 \\
\hline 21 & $\begin{array}{l}\text { You have to look at a cost-benefit analysis to decide how } \\
\text { clean is clean. }\end{array}$ & 0.97 & -1.16 & 1.09 & -0.62 & 1.12 & -2.07 \\
\hline 22 & $\begin{array}{l}\text { If anyone is so concerned that they are affected by } \\
\text { contamination, they should move. }\end{array}$ & -1.52 & -1.96 & -0.22 & -0.49 & -0.68 & 0.12 \\
\hline 23 & I don't believe I am at risk from subsurface contamination. & 1.23 & -1.04 & -0.02 & -1.14 & 0.38 & -0.19 \\
\hline 24 & Just because it's there, doesn't mean it is bad. & 0.58 & -1.02 & 1.07 & 0.06 & 0.10 & 0.24 \\
\hline 25 & The perceived risks are much higher than the actual risks. & 1.69 & 0.06 & 2.30 & -1.64 & -0.68 & -1.63 \\
\hline 26 & $\begin{array}{l}\text { DOE is not out to get me; they're probably going to look out } \\
\text { for my best interests. }\end{array}$ & 0.87 & -1.45 & -0.08 & -0.19 & 0.14 & 0.26 \\
\hline 27 & $\begin{array}{l}\text { The problem is not politics as much as limited competence } \\
\text { in DOE. }\end{array}$ & -.056 & 0.03 & 0.89 & 1.00 & -0.44 & -0.75 \\
\hline 28 & $\begin{array}{l}\text { To DOE, reducing risks means that money comes first and } \\
\text { people come second. }\end{array}$ & -0.77 & 1.41 & -0.94 & 0.38 & -0.75 & -1.82 \\
\hline 29 & $\begin{array}{l}\text { The volumes are so great that bioremediation will not have } \\
\text { a great deal of impact. }\end{array}$ & -0.65 & -0.28 & -0.49 & 0.29 & -0.73 & -1.25 \\
\hline 30 & People basically are able to avoid risks if they want to. & -0.01 & -1.17 & -0.30 & -0.44 & 0.71 & -1.38 \\
\hline 31 & $\begin{array}{l}\text { DOE has a habit of acting in a way that would be perceived } \\
\text { by local communities as being arrogant. }\end{array}$ & 0.48 & 1.97 & 1.27 & 2.23 & 1.05 & 0.31 \\
\hline
\end{tabular}




\begin{tabular}{|c|c|c|c|c|c|c|c|}
\hline 32 & $\begin{array}{l}\text { There is more here than just economics and risk. It is our } \\
\text { way of life that is at stake. }\end{array}$ & 0.54 & 0.94 & -0.49 & -1.40 & 1.81 & 0.69 \\
\hline 33 & $\begin{array}{l}\text { The risk of contamination is not something we will be able } \\
\text { to live with calmly. }\end{array}$ & -0.90 & 0.60 & -0.41 & 0.53 & 0.30 & -0.37 \\
\hline 34 & DOE is overconfident that they understand all the risks. & 0.09 & 1.46 & 0.55 & 0.40 & 0.59 & 0.34 \\
\hline 35 & $\begin{array}{l}\text { I support bioremediation because that's the only way we're } \\
\text { going to get this thing taken care of. }\end{array}$ & -0.31 & -0.23 & -1.36 & -1.30 & -0.41 & 0.00 \\
\hline 36 & $\begin{array}{l}\text { We know enough about the site to take action now, we } \\
\text { don't need more studies. }\end{array}$ & 0.25 & -0.52 & 0.26 & 0.21 & 0.33 & 0.36 \\
\hline 37 & $\begin{array}{l}\text { The only risk associated with bioremediation is spending a } \\
\text { lot of money on something that can't possibly work. }\end{array}$ & -1.04 & -0.75 & -0.72 & -0.53 & -1.02 & -0.19 \\
\hline 38 & $\begin{array}{l}\text { Putting manpower and dollars into making automobiles, } \\
\text { trains, and planes safer is better than trying to reduce the } \\
\text { theoretical "one death in a million" from contaminant } \\
\text { exposure. }\end{array}$ & 0.69 & -0.74 & 0.72 & 0.34 & 0.53 & -0.81 \\
\hline 39 & $\begin{array}{l}\text { If DOE management didn't turn over so often, they would } \\
\text { care more about long-term protection. }\end{array}$ & 0.36 & 0.15 & -0.32 & 0.59 & -0.59 & 1.19 \\
\hline 40 & $\begin{array}{l}\text { I don't completely trust DOE but I can't see anybody being } \\
\text { able to do a better job. }\end{array}$ & 1.36 & -1.09 & -0.11 & -0.10 & 1.95 & 0.94 \\
\hline 41 & $\begin{array}{l}\text { We feel like it is going to be left to us to deal with what is } \\
\text { left behind. }\end{array}$ & -0.25 & 0.79 & 0.02 & -0.81 & 0.47 & 0.38 \\
\hline 42 & $\begin{array}{l}\text { To me, solving the problem on-site makes a lot more sense } \\
\text { than just sending it off site. }\end{array}$ & 1.15 & 1.05 & 0.82 & 1.18 & -2.52 & 1.63 \\
\hline 43 & $\begin{array}{l}\text { DOE doesn't provide all of the data, or the data is slanted } \\
\text { in such a way that they don't openly say that we have a } \\
\text { problem. }\end{array}$ & -0.69 & 1.17 & -0.28 & 0.44 & 0.72 & 0.43 \\
\hline 44 & $\begin{array}{l}\text { The assessment of health risks from exposure to } \\
\text { contaminants is an exact science. }\end{array}$ & -0.32 & -1.26 & -1.13 & 0.03 & 0.84 & 0.44 \\
\hline 45 & $\begin{array}{l}\text { It's hard for me to see how we have a little bug that can do } \\
\text { a better job than what we are doing now. }\end{array}$ & -1.14 & -0.88 & -0.64 & -0.62 & 0.48 & -0.13 \\
\hline 46 & $\begin{array}{l}\text { For right now, leaving the contamination alone is the best } \\
\text { answer. }\end{array}$ & -1.65 & 1 & 2 & 37 & -1.74 & -1.07 \\
\hline 47 & $\begin{array}{l}\text { The only way we're going to get any kind of cleanup that } \\
\text { will provide long-term protection is to remove DOE. }\end{array}$ & -1.93 & 0.48 & -0.87 & -1.45 & -1.77 & 0.00 \\
\hline
\end{tabular}

The perspectives captured by the individual factors, as well as the composite perspectives shared across factors that were most highly correlated, are interpreted below.

ACE Composite Perspective: "Rationalist"

Interestingly, 18 of the 22 stakeholders who share this composite perspective are male (compared with only 7 of 16 stakeholders who identify with the Pessimist perspective). They also are more technically trained. Rationalists share the view that zero risk is impossible and that remediation benefits (risk reduction) must be balanced against remediation costs. In addition, they believe that the public exaggerates risks and thus education is required to correct their risk misperceptions. Finally, they share the view that DOE and its contractors can lead the remediation effort but that they should be less arrogant and more open with stakeholders. The label Rationalist is adopted because this composite perspective shares an optimistic view toward DOE's risk assessments and their ability to reduce these risks to safe levels.

\section{AC Composite Perspective: "Technical Rationalist"}

The composite perspective shared by those who significantly loaded on factors $A$ and $C$, of course, share the view represented above. However, they differ from the factor $E$ perspective below in that they are less motivated by a concern for the welfare of the community (see factor $E$ discussion below). The label Technical Rationalists is adopted because these stakeholders share a stronger belief than do factor $\mathrm{E}$ stakeholders that objectively assessed risks are real and that subjective risk views are less legitimate. 


\section{Perspective A: "Expert Control"}

Perspective A is shared by twelve stakeholders. These stakeholders tend to be more technically trained - especially in the physical and applied sciences, have advanced degrees, are predominantly male, and work for DOE or other government agency.

Expert Controllers share the view that the public exaggerates risk and education is the remedy. They believe that zero risk is not necessary. They also believe that bioremediation is necessary and works, but must be balanced against cost. They support the position that remediation decisions should be left to experts at DOE and its contractors; they are competent and can be trusted. The label Expert Control was chosen because this perspective manifests an abiding faith that radionuclide and heavy metal contamination can be controlled effectively by those who are familiar with the risks and risk management technologies.

\section{Perspective C: "Strategic Rationalist"}

Perspective $C$ is shared by six stakeholders. This group is dominated by males and engineers.

Strategic Rationalists believe that the public exaggerates risk and that zero risk is impossible. They believe that DOE and its contractors are not arrogant, but they do have compliance and communications problems. Benefit-cost analysis should govern remediation decisions because cost matters. Nevertheless, they do believe that a sense of urgency exists and that all options (not just bioremediation) should be examined. They do not favor more regulation as a solution. Strategic Rationalist was chosen as the label for this perspective because this view embraces rational decision-making as the appropriate strategy for remediation decisions.

\section{Perspective E: "Responsible Rationalist"}

Perspective $E$ is shared by four stakeholders. This group is entirely male and is represented primarily by environmental professionals and managers. One of the significant loaders was negatively loaded on this factor, indicating that he held a perspective nearly opposite of the one reported here.

Responsible Rationalist believe that DOE and its contractors can be trusted to conduct site remediation despite what some believe is arrogance. Zero risk is not possible; benefit-cost analysis and risk analysis must be considered. Somewhat differently from the A and C perspectives, Responsible Rationalists believe that these sites are the community's lifeblood so they argue that the public should not over-react. They believe that education can help people understand the real risks and thus act more rationally. Also uniquely, they prefer that the problem not be transported elsewhere but rather dealt with onsite. Responsible Rationalist was selected as the most appropriate label because this perspective is most sympathetic to site remediation on behalf of the host communities and thus are most willing to defend the communities' health and environmental interests.

\section{BDF Composite Perspective: "Pessimists"}

As previously stated, those sharing this composite perspective are dominated by females - particularly when compared to Rationalists. They also include fewer engineers and physical scientists and more environmental professionals and activists.

This composite perspective endorses the view that current risks are quite unacceptable and that DOE and its contractors should be held accountable for the contamination. Pessimists also believe that DOE should be much more open and communicative with the public. This composite perspective reflects a much more pessimistic view of DOE's ability to remediate radioactive and heavy metal contamination properly at the sites.

\section{BF Composite Perspective: "Distrust"}

Distrusters share the pessimism of the BDF composite perspective but differ somewhat from their factor D colleagues. Distrusters are more distrusting of DOE and its contractors and are less willing to consider remediation cost as a legitimate decision criterion than those who share the perspective represented by factor D. 


\section{Perspective B: "Cynical"}

Perspective $B$ is shared by eleven stakeholders, primarily environmental professionals.

Perspective B adherents believe that DOE and its contractors cannot be trusted because of their bias, arrogance, secrecy, and incompetence; site remediation must be managed by an independent organization. Given the high risk, they believe in total and immediate risk reduction, regardless of cost. Moreover, risk and benefit-cost analyses are inexact sciences and should not govern decisions. What should be paramount is protection of human health, community welfare, and the environment. This perspective is the most pessimistic of the three, and is stimulated by a strong reaction to the contamination and DOE's approach to risk reduction.

\section{Perspective F: "Skeptical"}

Perspective $F$ is shared by only two stakeholders, both of whom live some distance from the DOE reservation and have no direct affiliation with DOE or its contractors.

The individuals in this perspective believe that risk to the human health and environment is unacceptable, unavoidable, not exaggerated, and in urgent need of reduction. They believe that the public needs more information about risk, but caution that education is no substitute for real risk reduction. Though turnover seems to be a problem, DOE and its contractors must be held accountable. They also believe that bioremediation can be a useful technology. The label of Skeptical is appropriate given their concern about risks, but contrary to Cynical, they are not as antagonistic toward site managers.

\section{Perspective D: "Concerned"}

Three stakeholders share this perspective. All share a professional interest in environmental issues.

"Concerned" stakeholders believe that DOE and its contractors are arrogant and their incompetence and inadequate communication with the public are problems. However, they believe that they tell the truth. As a result, they believe that DOE should not waste resources for political gain. DOE must be held liable - especially for long-term care. Bioremediation may not be the best long-term solution; more study may be necessary. Unlike the other Pessimists, Concerned recognize that zero risk is not possible and cost is a concern. Their perspective can be characterized as pragmatic.

\section{Perspectives on Stakeholder Participation}

In the previous part, we explored stakeholders' perspectives on remediation of the sites. In this part, we explore stakeholders' perspectives on how they prefer to participate in remediation decision-making.

Four perspectives on stakeholder participation were revealed from the $\mathrm{Q}$ factor analysis. These four factors accounted for 30 of the 33 sorts and $52 \%$ of the total variance among sorts. The factor correlations are presented in Table 10.

Table 10. Stakeholder Participation Factor Correlations

\begin{tabular}{|c||c|c|c|}
\hline FACTORS & B & C & D \\
\hline \hline A & 0.09 & 0.07 & 0.45 \\
\hline B & & 0.09 & 0.13 \\
\hline C & & & 0.11 \\
\hline
\end{tabular}

This table demonstrates that the perspectives captured by factors A and D are moderately correlated. B and $C$ factors are not correlated with each other or with factors $A$ and $D$. This suggests that the perspective associated with factor $D$ shares some of its aspects with the perspective associated with factor A. However, contrary to the bioremediation perspectives, the factor $D$ perspective is not a strict subset of factor $A$ because the significant loaders on factor $D$ came from both factors $A$ (with which they remain confounded, that is, significantly loaded on both factors $A$ and $D$ ) and $C$. Thus, we did not find composite perspectives. 


\section{Factor Loadings}

Table 11 presents the factor loadings for the 33 stakeholders who submitted Q sorts for analysis. Again, the critical loading value is 0.451 . Loadings exceeding this value are considered statistically significant and are indicated by boldface type. We note that three of the significant loaders were bipolarly loaded on three factors (A, C, and D), which indicates that they held nearly opposite views from those reported in the next section.

Table 11. Stakeholder Participation Factor Loadings

\begin{tabular}{|c|c|c|c|c|}
\hline "QSORT & $\overline{\bar{A}}$ & $\bar{B}$ & $\bar{c}$ & $\overline{\mathbf{D}}$ \\
\hline OR17 & 0.766 & -0.027 & -0.026 & -0.170 \\
\hline RL06 & 0.739 & -0.330 & -0.163 & 0.128 \\
\hline OR04 & 0.723 & 0.072 & -0.088 & 0.301 \\
\hline RL03 & 0.699 & -0.327 & 0.182 & 0.093 \\
\hline LA17 & 0.690 & -0.015 & 0.150 & -0.115 \\
\hline OR08 & 0.684 & 0.009 & 0.162 & 0.054 \\
\hline OR29 & 0.675 & 0.138 & 0.069 & 0.350 \\
\hline LA16 & 0.656 & 0.163 & -0.337 & -0.107 \\
\hline LA18 & 0.624 & 0.028 & 0.372 & 0.066 \\
\hline RL11 & 0.604 & -0.009 & 0.365 & 0.344 \\
\hline RL04 & 0.568 & 0.146 & -0.144 & 0.615 \\
\hline LA24 & 0.549 & 0.273 & -0.051 & 0.565 \\
\hline RL07 & 0.532 & 0.121 & -0.155 & 0.269 \\
\hline OR12 & 0.518 & 0.436 & 0.175 & -0.339 \\
\hline OR07 & 0.504 & 0.323 & 0.237 & 0.362 \\
\hline OR24 & 0.462 & 0.155 & -0.056 & -0.087 \\
\hline LA03 & -0.474 & 0.409 & 0.426 & 0.143 \\
\hline OR14 & 0.198 & 0.852 & -0.018 & 0.215 \\
\hline RL09 & -0.217 & 0.698 & -0.192 & 0.344 \\
\hline RL02 & -0.145 & 0.663 & 0.153 & 0.105 \\
\hline OR21 & -0.086 & 0.622 & 0.275 & 0.246 \\
\hline OR28 & 0.300 & 0.561 & -0.196 & 0.041 \\
\hline LA01 & 0.361 & 0.553 & -0.308 & 0.005 \\
\hline RL17 & -0.005 & 0.534 & 0.174 & -0.089 \\
\hline OR15 & -0.353 & 0.465 & 0.019 & -0.139 \\
\hline RL15 & 0.135 & 0.464 & 0.072 & -0.144 \\
\hline OR16 & 0.097 & 0.356 & 0.681 & -0.083 \\
\hline RL08 & 0.014 & 0.237 & -0.684 & -0.147 \\
\hline RL24 & 0.194 & 0.171 & 0.313 & 0.509 \\
\hline RL20 & -0.012 & 0.286 & 0.003 & -0.699 \\
\hline RL23 & 0.022 & 0.441 & -0.047 & 0.056 \\
\hline LA02 & 0.215 & 0.329 & 0.339 & 0.107 \\
\hline OR02 & -0.104 & 0.192 & 0.143 & 0.435 \\
\hline \# Significant Loaders & 17 & 9 & 2 & 4 \\
\hline Explained Variance (\%) & 22 & 15 & 7 & 8 \\
\hline
\end{tabular}

Factor Interpretations

Table 12 presents the factor score arrays for the four stakeholder participation factors. As in the bioremediation factor interpretations, those statements ranking at either extreme (bolded z-scores) are most salient to stakeholders and most relevant to factor interpretation. 
Table 12. Stakeholder Participation Factor Score Arrays

\begin{tabular}{|c|c|c|c|c|c|}
\hline No. & STATEMENT & $\overline{\mathbf{A}}$ & $\overline{\mathrm{B}}$ & $\bar{C}$ & $\bar{D}$ \\
\hline 1 & $\begin{array}{l}\text { The voices you hear are such a small fraction of all the voices out } \\
\text { there that it's foolish to make decisions based on the input from a } \\
\text { fraction of one percent of the people }\end{array}$ & -1.72 & -0.35 & 1.26 & -0.77 \\
\hline 2 & $\begin{array}{l}\text { Very few people are interested enough to really follow through } \\
\text { and learn the facts. }\end{array}$ & -0.20 & 2.33 & -1.26 & -1.06 \\
\hline 3 & $\begin{array}{l}\text { Emotions take over with most citizens groups; they don't listen to } \\
\text { the science. }\end{array}$ & -0.60 & 1.57 & -1.01 & -1.32 \\
\hline 4 & $\begin{array}{l}\text { Stakeholders can't get enough information to influence the course } \\
\text { of events }\end{array}$ & -0.67 & -1.27 & 0.51 & -0.55 \\
\hline 5 & $\begin{array}{l}\text { If they're going to leave the decision process to a committee, the } \\
\text { decision will never be made }\end{array}$ & -1.22 & 0.01 & 0.51 & 0.12 \\
\hline 6 & DOE's words are there but the action is not. & 0.73 & -0.14 & 0.76 & -0.62 \\
\hline 7 & $\begin{array}{l}\text { The State folks don't have enough knowledge or resources to } \\
\text { adequately manage bioremediation }\end{array}$ & -0.44 & -0.12 & -0.01 & -1.30 \\
\hline 8 & $\begin{array}{l}\text { The officials don't take into consideration the values of the people } \\
\text { who live in the region }\end{array}$ & 0.73 & -0.79 & -1.50 & 0.33 \\
\hline 9 & There is currently no real mechanism to actually get public input. & -0.75 & -1.53 & -2.51 & -1.69 \\
\hline 10 & $\begin{array}{l}\text { They're going to leave the decision process to a committee, the } \\
\text { decision will never be made }\end{array}$ & -0.93 & 0.18 & -1.01 & 0.62 \\
\hline 11 & Decision-making should be done using deliberation & 0.83 & 0.65 & 0.49 & 1.07 \\
\hline 12 & DOE should be overseeing the cleanup-not a third party. & -0.72 & -0.08 & 0.00 & -0.06 \\
\hline 13 & $\begin{array}{l}\text { A multi-organizational approach is much better than letting one } \\
\text { government agency try to do it all. }\end{array}$ & 1.28 & -0.83 & -0.49 & 1.87 \\
\hline 14 & $\begin{array}{l}\text { The advisory board doesn't express what I'm personally } \\
\text { concerned about since they have very different concerns. }\end{array}$ & -0.92 & -0.01 & 0.00 & -0.94 \\
\hline 15 & $\begin{array}{l}\text { It is essential that stakeholders be involved in everything, } \\
\text { including analysis, discussion, and decision-making. }\end{array}$ & 2.18 & -0.62 & 0.75 & 2.10 \\
\hline 16 & $\begin{array}{l}\text { I always think that the more people involved in decision-making, } \\
\text { the better. }\end{array}$ & 0.92 & -0.81 & 0.00 & 1.36 \\
\hline 17 & Decisions should be based only on facts, not on opinions. & -0.09 & 1.47 & 1.75 & -0.21 \\
\hline 18 & $\begin{array}{l}\text { The state does not historically have ownership of the problem. } \\
\text { They are not wedded to it the same way DOE is. }\end{array}$ & -0.72 & -0.07 & -0.75 & -1.05 \\
\hline 19 & $\begin{array}{l}\text { There is an issue of whether the government has fully and } \\
\text { honestly informed the public. }\end{array}$ & 1.53 & -0.64 & 0.26 & -0.24 \\
\hline 20 & $\begin{array}{l}\text { From everything l've seen, DOE is committed to seeing it } \\
\text { through. }\end{array}$ & -1.00 & 0.43 & 0.26 & 0.69 \\
\hline 21 & If it were not part of my job, I would not attend public meetings. & -1.01 & -1.02 & 0.01 & -0.74 \\
\hline 22 & $\begin{array}{l}\text { We've got more Ph.D.'s and top-notch scientists than probably } \\
\text { any place on Earth, but they're not allowed to practice good } \\
\text { science. They practice political science. }\end{array}$ & 0.07 & -1.26 & 1.00 & -0.95 \\
\hline 23 & $\begin{array}{l}\text { I feel that you can't leave it to stakeholders to make the decision. } \\
\text { The buck stops with the people who are paying the money and } \\
\text { doing the work. }\end{array}$ & -1.40 & 0.76 & -0.50 & 0.51 \\
\hline 24 & $\begin{array}{l}\text { I expect the DOE to educate us so that we really understand } \\
\text { bioremediation. }\end{array}$ & 1.15 & 0.53 & 0.24 & 1.74 \\
\hline 25 & $\begin{array}{l}\text { We can't overcome the politics of DOE; they have too much } \\
\text { money to throw around. }\end{array}$ & 0.49 & -0.63 & -1.76 & -1.14 \\
\hline 26 & $\begin{array}{l}\text { Being a company town, people are not very willing to be } \\
\text { perceived as biting the hand that feeds them. }\end{array}$ & 1.25 & -0.38 & 0.50 & -0.62 \\
\hline 27 & $\begin{array}{l}\text { The problem is that the people really don't have the knowledge } \\
\text { base they need to make informed decisions. }\end{array}$ & 0.35 & 1.42 & -0.26 & 0.05 \\
\hline
\end{tabular}




\begin{tabular}{|c|c|c|c|c|c|}
\hline 28 & $\begin{array}{l}\text { The DOE is competent to manage the site only with the } \\
\text { regulatory agencies by their side. }\end{array}$ & 0.44 & 0.98 & -2.26 & 1.80 \\
\hline 29 & $\begin{array}{l}\text { People just want to be told whether it is safe or not; they really } \\
\text { don't want any of the details. }\end{array}$ & -0.78 & -0.38 & 0.25 & -0.22 \\
\hline 30 & $\begin{array}{l}\text { I trust consultants more than I trust the government to manage } \\
\text { bioremediation. }\end{array}$ & -0.21 & -1.27 & -0.99 & -0.57 \\
\hline 31 & $\begin{array}{l}\text { The public should be brought into the process only after sufficient } \\
\text { information has been gathered to communicate a complete } \\
\text { picture to the public. }\end{array}$ & -0.98 & 0.55 & -0.26 & -0.51 \\
\hline 32 & $\begin{array}{l}\text { I believe that it is the citizen's responsibility to keep the scientists } \\
\text { under control. }\end{array}$ & -0.09 & -1.71 & 0.26 & 1.03 \\
\hline 33 & $\begin{array}{l}\text { The decision maker should listen to all sides before making a } \\
\text { decision. }\end{array}$ & 1.74 & 1.69 & 1.25 & -0.58 \\
\hline 34 & $\begin{array}{l}\text { Consultation with stakeholders is how we are going to make the } \\
\text { best use of resources. }\end{array}$ & 1.35 & -0.14 & -1.00 & 1.17 \\
\hline 35 & $\begin{array}{l}\text { DOE will take your comments for the record and will do what they } \\
\text { want to do anyway. }\end{array}$ & 1.05 & -0.58 & 0.25 & 0.05 \\
\hline 36 & I feel I have a voice whenever I want to use it. & 0.05 & 1.58 & 0.50 & 1.23 \\
\hline 37 & $\begin{array}{l}\text { I would expect the DOE to somehow educate us so that we really } \\
\text { understand bioremediation. }\end{array}$ & 1.09 & 1.20 & 0.75 & 1.07 \\
\hline 38 & Overall, DOE is doing a good job on public involvement. & -0.59 & 0.67 & 0.76 & 1.14 \\
\hline 39 & $\begin{array}{l}\text { We have elected officials, advisory boards, and public comment } \\
\text { periods, which satisfy my need to be involved in DOE cleanup } \\
\text { decisions. }\end{array}$ & -0.65 & 1.41 & -0.25 & 0.06 \\
\hline 40 & $\begin{array}{l}\text { Life is too short to be engaged in year-long stakeholder } \\
\text { processes. }\end{array}$ & -1.10 & -0.76 & 2.01 & -0.10 \\
\hline 41 & All experts care about is personal gain. & -1.16 & -1.93 & -1.00 & -0.45 \\
\hline 42 & $\begin{array}{l}\text { If you try to do anything by consensus, you will never get anything } \\
\text { done. }\end{array}$ & -0.77 & 0.46 & -1.01 & -1.14 \\
\hline 43 & $\begin{array}{l}\text { If DOE does not involve stakeholders then there will be } \\
\text { unnecessary expense, unnecessary displeasure, and } \\
\text { unnecessary problems. }\end{array}$ & 1.79 & 0.43 & 0.51 & 1.57 \\
\hline 44 & $\begin{array}{l}\text { Regardless of what stakeholders say, most people do not want to } \\
\text { participate in the whole process. }\end{array}$ & 0.62 & 0.90 & 1.76 & -0.47 \\
\hline 45 & Someone just needs to step up to the plate and make a decision. & -0.89 & -0.46 & 0.75 & -0.85 \\
\hline 46 & I don't have the time to participate; I have to make a living. & -0.83 & -0.90 & 1.00 & -0.27 \\
\hline 47 & Trusting the federal government is like trusting an illusion. & 0.79 & -0.56 & -0.50 & -1.14 \\
\hline
\end{tabular}

\section{Perspective A: "Everyone Decides Together"}

Seventeen stakeholders substantially agree with this perspective. One of these stakeholders (the only non-environmental engineer) opposes this view. Almost all others are environmental professionals and non-technical stakeholders. Gender distribution is balanced, with ten males and seven females. (Note: only eleven females are included among the $33 \mathrm{Q}$ respondents.)

Those sharing this perspective adopt a "we should decide together" view. They believe that all parties should be involved throughout the entire decision-making process, learning as they go - even if it takes a long time. They want to hear all sides and to be fully and honestly informed. They prefer a committee decision process with representatives from multiple organizations, including DOE, and wish to avoid politicization of site remediation decisions. Because DOE and its contractors will be conducting remediation doesn't mean that they alone should make decisions. Indeed, failure to consult with stakeholders will lead to trouble, both for the site managers and for the community. 


\section{Perspective B: "Elected Officials Decide"}

Nine stakeholders loaded significantly on this factor: six males and three females. Most are engineers. Two are scientists and one works for local government. Interestingly, one is a non-degreed winery owner who lives some distance away.

Given the very low correlation with factor $A$, we would expect that this perspective has very little in common with factor $A$. This is indeed the case. The adherents to the factor B perspective believe that elected government officials have the authority to make decisions and we should trust them. Though all sides should be given an opportunity to be heard, decisions should not be made by the public because they can be influenced by emotions rather than facts. In addition, experts should not make these decisions either though they can be relied upon to provide relevant facts. Finally, DOE should also not be delegated decision authority but they should be expected to provide information to the public on bioremediation so that the public better understands the technology.

\section{Perspective C: "DOE Decides"}

Only two stakeholders, both male, load significantly on this factor - and one of these is bipolar. The positive loader is a DOE environmental scientist. Ironically, the bipolar loader is an EPA environmental scientist.

Factor $\mathrm{C}$ has very little in common with either factor $\mathrm{B}$ or $\mathrm{C}$, based on the near-zero correlations. Our interpretation confirms this. Factor $\mathrm{C}$ adherents believe that decisions should be made by DOE, with input from a broadly constituted advisory committee. There isn't time for a long process and people don't have time for long processes anyway. Those who demand participation are not representative of the views that are held in the community as a whole; we need to listen to all sides. DOE can be trusted; they do consider the interests of the community at large, not just those who yell the loudest. In any case, decisions should be based on facts, not politics.

\section{Perspective D: "Stakeholders Oversee Decisions"}

Four stakeholders significantly load on this factor. Two are male and two are female. The three stakeholders who load positively are non-technically trained. The lone bipolar loader is an engineer.

This perspective is rather independent from those represented by factors $B$ and $C$. However, it does share commonalities with factor $A$. Both factor $A$ and $D$ perspectives believe that stakeholders should be involved throughout the decision process, though this perspective is much stronger in its preference for multi-organizational involvement. Factor $A$ and $D$ perspectives also agree that consultation with stakeholders is the best use of resources and that not involving stakeholders will mean trouble.

This perspective differs, however, from that represented by factor $A$ in that these adherents feel that they are empowered and citizens will commit to see the process through. Citizens have an obligation to exert oversight of site remediation decisions and activities by both experts and DOE and can be counted on not to let emotions interfere. Government can be trusted to conduct bioremediation; after all, they are the ones who are doing the work. So far, those sharing this perspective believe that DOE is doing a good job in involving stakeholders.

\section{Conclusions}

\section{With Respect to Site Remediation}

The results of the Q-study over the use of bioremediation resulted six orthogonal factors (with only a single bipolar loader on one factor), suggesting that a remediation solution for these three sites that will enjoy widespread stakeholder support is possible.

Areas of consensus among stakeholders relating to site remediation are:

- The contamination must be remediated

- Education of stakeholders on bioremediation (without appearing arrogant)

- Communications and openness in DOE actions 
- Efficiency is important - do not waste money and resources

- Trust should be built among DOE, its contractors, experts, state and local agencies, and the public so that it is clear that public health and community welfare are important values that will be protected

Other areas are orthogonally related; that is, were important to some perspectives and not to others (and therefore were not opposed by any perspective). These include:

- Bioremediation is not the only technique available to remediate subsurface contamination

- Bioremediation could work and government can be trusted to conduct it, especially over the long term, though DOE management turnover is a problem and they appear overconfident and arrogant in dealing with stakeholders

- Experts are trusted

- Something should be done soon, though risk cannot be reduced to zero

- Education can reduce the public's risk perceptions

- People who are concerned shouldn't have to move away

- Regulation does not protect against risk

The following areas are controversial

- The public is at risk from subsurface contamination

- Bioremediation is a long-term solution

- Technologies are studied to death

- Cost of remediation is important and cost-benefit analysis should govern decisions

- DOE is not trusted: it has limited competence, its findings are biased or held secret, its risk assessments are uncertain, and it is not being held liable; therefore, independent oversight is needed

- People can avoid risk if they want to, especially if they are more knowledgeable

Despite these controversies, we are optimistic that bioremediation can be acceptable. Our recommendations to enhance its acceptability are:

- Experts should reach consensus on the effectiveness of bioremediation, and if selected, it should be implemented as soon as feasible.

- DOE should commit to long-term management of the site.

- Stakeholders should become more familiar with bioremediation and it and not see it as only a cost-cutting measure.

- DOE should expend significant resources in building trust among stakeholders by being more open, communicative, responsible, humble, and inclusive of stakeholders in decision-making. More regulation is not the answer; fiduciary responsibility is.

With Respect to Stakeholder Participation

Similarly, the existence of four orthogonal factors, with only a single bipolar loader on three of the factors, suggests that a stakeholder participation strategy may be designed that will enjoy widespread stakeholder support.

Areas of consensus among stakeholders relating to their participation in decision-making are:

- Consultation is more important than deliberation

- Education on bioremediation is important 
Areas of orthogonality (no bipolar disagreements) are:

- Stakeholders should be involved throughout, all points of view should be considered before a decision is made, and access to information should be guaranteed; not involving stakeholders will bring trouble

- Stakeholders cannot be trusted with these decisions; decisions should be based on facts only, most people will not participate over the long term, and consensus decision-making doesn't work

- Stakeholders cannot overcome the political power of DOE

Areas of bipolar controversy are:

- Multi-organizational approaches are best

- Citizen groups suffer from non-representativeness and emotional interference with rational decision-making; in any event, stakeholders don't have time to participate

- Consultation is the best use of resources; committee decisions don't work

- Government cannot be trusted because it is secretive, it ignores citizen's concerns and values, and it allows politics to unduly influence science; therefore, citizens should oversee government and its experts

- Communities are dependent on the sites for their economic welfare

Based on these findings, we offer the following recommendations regarding the involvement of stakeholders in bioremediation decision-making.

- Stakeholders should be involved throughout the decision-making process but in a consultancy role. A multi-organizational advisory committee that is broadly representative and includes elected officials may be the best strategy.

- To improve the effectiveness and acceptability of this strategy, DOE should provide participants with complete, timely, succinct, and easy-to-comprehend information.

- DOE should also be willing to consider seriously the suggestions made by the committee.

- DOE should work to build trust with the community - not only through its willingness to involve stakeholders - but also through its willingness to consider the welfare of the community in its deliberations. 


\section{CHAPTER 5}

\section{TELEPHONE SURVEY: SAMPLE DESCRIPTION AND DEMOGRAPHIC ANALYSIS}

\section{Introduction}

This chapter presents the results and findings from a large-scale telephone survey of 1950 respondents living near the Oak Ridge, Hanford, and Los Alamos reservations. The survey was conducted November 5 through November 16, 2003, during the evening hours by NSON Corporation based in Salt Lake City.

The purpose of this survey was to determine to what extent the preliminary results of the face-to-face interviews and mail survey are generalizable to the wider stakeholder population.

\section{Questionnaire}

These questions are similar to those asked in the personal interviews. Results from the Q-sort were also used to develop questions for the telephone survey. The questionnaire is included in Appendix A.

\section{Respondent Sampling Protocol}

We began the survey with one screening question to determine eligibility as a stakeholder. We asked whether the respondent was aware that radioactive contamination existed at the site, and if not, we terminated the interview. We also included a "quota" question concerning trust of DOE to ensure that we obtained a balance of those who trust and distrust in the sample population.

The study population was divided into non-overlapping strata (zip codes) that define areas adjacent to the three DOE reservations. Screening questions were used to select respondents (see appendix A) to ensure awareness of contamination. Those that were not aware of contamination were not included in the phone survey. Then the respondents were stratified by trust of DOE (the number was equally split between those who trust DOE and those that did not trust DOE). The above steps were taken to get the most complete set of results possible. The respondents had to be aware of contamination and half of them trusted DOE and the other half did not.

Zip codes were selected in each area of the phone survey using data supplied by the individuals that conducted the personal interviews. All three sites were selected for the Manhattan Project due to their remoteness (Los Alamos) or access to electrical power (Hanford and Oak Ridge). This has resulted in small towns near the reservations and thus a need to include larger population bases some distance away. It also resulted in a need to include down-stream populations (Hanford and Oak Ridge) also resulting in population bases some distance from the reservations.

Respondents answered the question "in what direction from the site is your residence located?"' with one of the following eight directions: north, south, east, west, northwest, northeast, southwest, or southeast. Wind roses from the national weather service were used to average the direction of prevailing winds for the preceding eight directions. Then these wind directions were matched to the direction of residence and the percentage of time exposed to winds from the site was tabulated.

\section{Respondent Characteristics}

This section presents a summary of 10 demographic characteristics of the respondent sample (gender, proximity of residence from the site, frequency of exposure to wind blowing from the site, home ownership, length of household residence, length of community residence, personal site employment, family site employment, education level, and occupation. These characteristics will later help us interpret judgments of risk, trust, acceptability of bioremediation, and public participation preference because they relate to degree of stake, familiarity, and knowledge. We present both single variable analyses and bivariate correlations. Each analysis includes a table of descriptive statistics and a pie chart. The pie charts sometimes display recoded (usually aggregated data) to enhance visualization. Reported correlations are statistically significant at $p<0.01$. 


\section{Gender}

Table 13 and Figure 10 present the results of the gender distribution of the sample. The gender distribution of our sample was essentially equal.

Table 13. Respondent Gender

\begin{tabular}{|c|c|c|c|c|}
\hline RESPONSES & FREQUENCY & Percent & VALID PERCent & Cumulative Percent \\
\hline Male & 987 & 50.6 & 50.6 & 50.6 \\
\hline Female & 963 & 49.4 & 49.4 & 100.0 \\
\hline Total & 1950 & 100.0 & 100.0 & \\
\hline
\end{tabular}

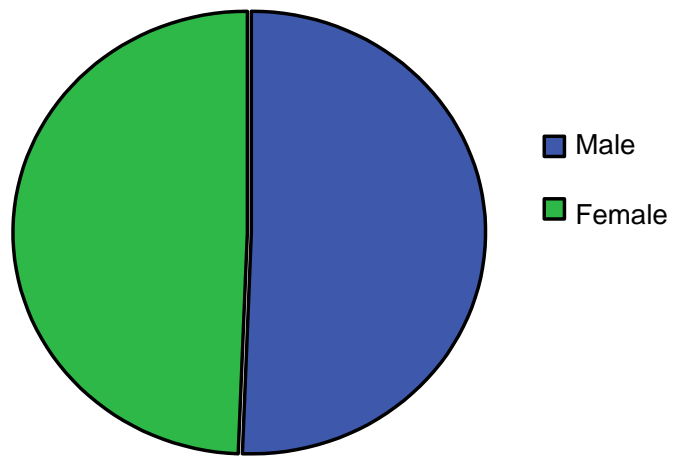

Slightly more males (50.6\%) than females (49.4\%) responded to the survey.

Gender correlated negatively with site employment $(r=-0.271)$. More males work at these sites than females.

Figure 10. Gender Distribution

\section{Proximity to DOE Facility}

Table 14 and Figure 11 show the proximity of respondents to DOE facilities.

Table 14. Responses to "As the crow flies, in miles, about how far away from the site do you live?"

\begin{tabular}{|c|c|c|c|c|c|}
\hline RESPONSE & Distance & FREQUENCY & Percent & $\begin{array}{c}\text { VALID } \\
\text { PERCENT }\end{array}$ & $\begin{array}{c}\text { Cumulative } \\
\text { PERCENT }\end{array}$ \\
\hline \multirow[t]{18}{*}{ Valid } & Less than $1 / 2$ mile & 33 & 1.7 & 1.7 & 1.7 \\
\hline & 1 & 43 & 2.2 & 2.2 & 4.0 \\
\hline & 2 & 63 & 3.2 & 3.3 & 7.3 \\
\hline & 3 & 59 & 3.0 & 3.1 & 10.3 \\
\hline & 4 & 50 & 2.6 & 2.6 & 12.9 \\
\hline & 5 & 88 & 4.5 & $\overline{4.6}$ & 17.5 \\
\hline & 6 & 30 & 1.5 & 1.6 & 19.1 \\
\hline & 7 & 34 & 1.7 & 1.8 & 20.9 \\
\hline & 8 & 43 & 2.2 & 2.2 & 23.1 \\
\hline & 9 & 8 & 0.4 & 0.4 & 23.5 \\
\hline & 10 & 130 & 6.7 & 6.8 & 30.3 \\
\hline & 11 & 5 & 0.3 & 0.3 & 30.6 \\
\hline & 12 & 31 & 1.6 & 1.6 & 32.2 \\
\hline & 13 & 12 & 0.6 & 0.6 & 32.8 \\
\hline & 14 & 8 & 0.4 & 0.4 & 33.2 \\
\hline & 15 & 120 & 6.2 & 6.3 & 39.5 \\
\hline & 16 & 10 & 0.5 & 0.5 & 40.0 \\
\hline & 17 & 14 & 0.7 & 0.7 & 40.7 \\
\hline
\end{tabular}




\begin{tabular}{|c|c|c|c|c|c|}
\hline & 18 & 20 & 1.0 & 1.0 & 41.8 \\
\hline & 19 & 2 & 0.1 & 0.1 & 41.9 \\
\hline & 20 & 173 & 8.9 & 9.0 & 50.9 \\
\hline & 21 & 1 & 0.1 & 0.1 & 51.0 \\
\hline & 22 & 6 & 0.3 & 0.3 & 51.3 \\
\hline & 23 & 5 & 0.3 & 0.3 & 51.5 \\
\hline & 25 & 100 & 5.1 & 5.2 & 56.8 \\
\hline & 26 & 5 & 0.3 & 0.3 & 57.0 \\
\hline & 27 & 4 & 0.2 & 0.2 & 57.2 \\
\hline & 28 & 1 & 0.1 & 0.1 & 57.3 \\
\hline & 30 & 164 & 8.4 & 8.6 & 65.8 \\
\hline & 32 & 6 & 0.3 & 0.3 & 66.1 \\
\hline & 34 & 2 & 0.1 & 0.1 & 66.2 \\
\hline & 35 & 73 & 3.7 & 3.8 & 70.1 \\
\hline & 36 & 1 & 0.1 & 0.1 & 70.1 \\
\hline & 37 & 4 & 0.2 & 0.2 & 70.3 \\
\hline & 38 & 3 & 0.2 & 0.2 & 70.5 \\
\hline & 40 & 117 & 6.0 & 6.1 & 76.6 \\
\hline & 42 & 1 & 0.1 & 0.1 & 76.6 \\
\hline & 43 & 1 & 0.1 & 0.1 & 76.7 \\
\hline & 44 & 1 & 0.1 & 0.1 & 76.7 \\
\hline & 45 & 58 & 3.0 & 3.0 & 79.8 \\
\hline & 47 & 1 & 0.1 & 0.1 & 79.8 \\
\hline & 50 & 111 & 5.7 & 5.8 & 85.6 \\
\hline & 54 & 2 & 0.1 & 0.1 & 85.7 \\
\hline & 55 & 12 & 0.6 & 0.6 & 86.3 \\
\hline & 58 & 1 & 0.1 & 0.1 & 86.4 \\
\hline & 60 & 68 & 3.5 & 3.5 & 89.9 \\
\hline & 62 & 2 & 0.1 & 0.1 & 90.0 \\
\hline & 65 & 12 & 0.6 & 0.6 & 90.7 \\
\hline & 70 & 30 & 1.5 & 1.6 & 92.2 \\
\hline & 71 & 1 & 0.1 & 0.1 & 92.3 \\
\hline & 75 & 26 & 1.3 & 1.4 & 93.6 \\
\hline & 78 & 1 & 0.1 & 0.1 & 93.7 \\
\hline & 80 & 29 & 1.5 & 1.5 & 95.2 \\
\hline & 85 & 2 & 0.1 & 0.1 & 95.3 \\
\hline & 90 & 24 & 1.2 & 1.3 & 96.6 \\
\hline & 95 & 2 & 0.1 & 0.1 & 96.7 \\
\hline & 100 & 42 & 2.2 & 2.2 & 98.9 \\
\hline & 110 & 2 & 0.1 & 0.1 & 99.0 \\
\hline & 114 & 1 & 0.1 & 0.1 & 99.0 \\
\hline & 116 & 1 & 0.1 & 0.1 & 99.1 \\
\hline & 120 & 5 & 0.3 & 0.3 & 99.3 \\
\hline & 125 & 3 & 0.2 & 0.2 & 99.5 \\
\hline & 130 & 1 & 0.1 & 0.1 & 99.5 \\
\hline & 140 & 1 & 0.1 & 0.1 & 99.6 \\
\hline & 150 & 4 & 0.2 & 0.2 & 99.8 \\
\hline & 200 & 4 & 0.2 & 0.2 & 100.0 \\
\hline & Total & 1917 & 98.3 & 100.0 & \\
\hline Missing & Don't Know/Refused & 33 & 1.7 & & \\
\hline & Total & 1950 & 100.0 & & \\
\hline
\end{tabular}


For ease of viewing, distances in Table 14 were recoded in Figure 5 as follows: from 0-1 mile $=1$, from 25 miles $=5$, from 6-10 $=10$, from $11-15=15$, from $16-20=20$, from $21-25=25$, from $26-20=30$, from $31-50=50$, from $51-75=75$, and from76 $-200=200$.

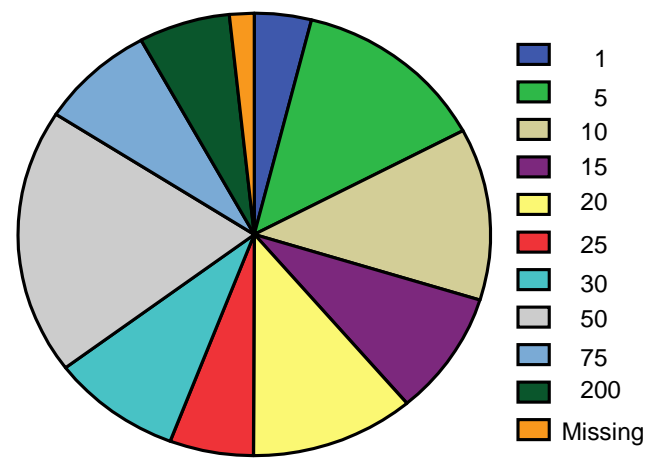

Mean distance from the site is 38.5 miles and median distance is 20 miles. Respondents who live closer to the site have a greater chance of not working at the site $(r=-0.353)$ nor have family members working at the site $(r=-0.256)$. They also have a greater chance of being exposed to the prevailing wind $(r=0.225)$. They also tend not to have technical occupations.

\section{Figure 11. Proximity Distribution} (Recoded)

\section{Exposure to Prevailing Winds}

Table 15 and Figure 12 report the percentage of time respondents are exposed to prevailing winds from the DOE facilities.

Table 15. Respondents Percent of Time Exposed to Prevailing Winds

\begin{tabular}{|c|c|c|c|c|c|}
\hline \multicolumn{2}{|c|}{$\begin{array}{c}\text { PERCENT OF TIME EXPOSED TO } \\
\text { WINDS FROM THE SITE }(\%) \\
\end{array}$} & FREQUENCY & Percent & $\begin{array}{c}\text { VALID } \\
\text { PERCENT }\end{array}$ & $\begin{array}{c}\text { Cumulative } \\
\text { PERCENT }\end{array}$ \\
\hline \multirow{15}{*}{ Valid } & 4 & 92 & 4.7 & 4.8 & 4.8 \\
\hline & 5 & 126 & 6.5 & 6.6 & 11.5 \\
\hline & 6 & 350 & 17.9 & 18.4 & 29.9 \\
\hline & 7 & 133 & 6.8 & 7.0 & 36.9 \\
\hline & 8 & 259 & 13.3 & 13.6 & 50.6 \\
\hline & 10 & 31 & 1.6 & 1.6 & 52.2 \\
\hline & 12 & 108 & 5.5 & 5.7 & 57.9 \\
\hline & 15 & 65 & 3.3 & 3.4 & 61.3 \\
\hline & 17 & 37 & 1.9 & 1.9 & 63.3 \\
\hline & 18 & 48 & 2.5 & 2.5 & 65.8 \\
\hline & 19 & 79 & 4.1 & 4.2 & 70.0 \\
\hline & 20 & 197 & 10.1 & 10.4 & 80.3 \\
\hline & 22 & 186 & 9.5 & 9.8 & 90.1 \\
\hline & 23 & 187 & 9.6 & 9.9 & 100.0 \\
\hline & Total & 1898 & 97.3 & 100.0 & \\
\hline \multirow[t]{2}{*}{ Missing } & Don't Know/Refused & 52 & 2.7 & & \\
\hline & Total & 1950 & 100.0 & & \\
\hline
\end{tabular}




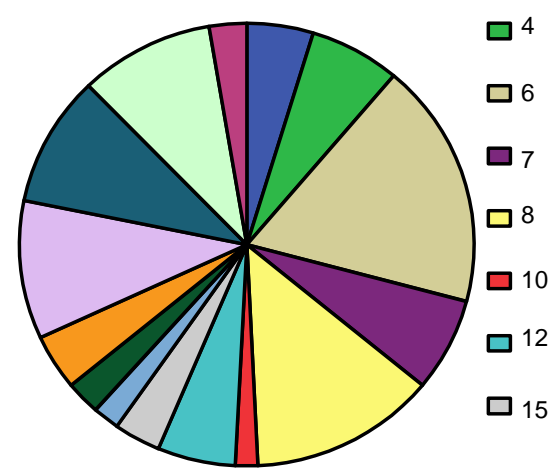

Figure 12. Wind Exposure Distribution
The mean frequency of exposure to prevailing winds from the site is $12.7 \%$; median exposure is $8 \%$. Those individuals who live closer to the site are exposed more often to the prevailing winds $(r=0.225)$.

\section{Own or Rent}

Table 16 and Figure 13 show the percentage of individuals that either own or rent their primary residence.

Table 16. Responses to "Do you own or rent your current residence?"

\begin{tabular}{|c|c|c|c|c|c|}
\hline \multicolumn{2}{|c|}{ RESPONSES } & FREQUENCY & PERCENT & $\begin{array}{c}\text { VALID } \\
\text { PERCENT }\end{array}$ & $\begin{array}{c}\text { CUMULATIVE } \\
\text { PERCENT }\end{array}$ \\
\hline \hline \multirow{3}{*}{ Valid } & Rent & 308 & 15.8 & 16.0 & 16.0 \\
\cline { 2 - 6 } & Own & 1623 & 83.2 & 84.0 & 100.0 \\
\cline { 2 - 6 } & Total & 1931 & 99.0 & 100.0 & \\
\hline Missing & Refused & 19 & 1.0 & & \\
\hline \hline \multicolumn{2}{|c|}{ Total } & $\mathbf{1 9 5 0}$ & $\mathbf{1 0 0 . 0}$ & & \\
\hline
\end{tabular}

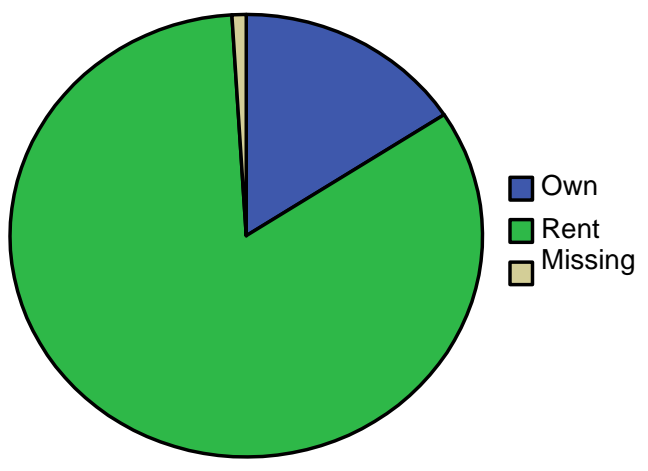

Figure 13. Home Ownership Distribution
The median and mean values are ownership. More than $80 \%$ of respondents own their current residence, while just $16 \%$ rented. Those who own their residence stay in their residence longer $(r=0.371)$ and stay in the community longer $(r=0.265)$. 
Length of Household Residence

Table 17 and Figure 8 present the amount of time respondents have lived at their current residences.

Table 17. Responses to "How long have you lived at your present residence?"

\begin{tabular}{|c|c|c|c|c|c|}
\hline RESPONSE & DURATION & FREQUENCY & Percent & $\begin{array}{c}\text { VALID } \\
\text { PERCENT }\end{array}$ & $\begin{array}{c}\text { CUMulative } \\
\text { PERCENT }\end{array}$ \\
\hline \multirow[t]{41}{*}{ Valid } & $<6$ months & 46 & 2.4 & 2.4 & 2.4 \\
\hline & 1 & 157 & 8.1 & 8.1 & 10.5 \\
\hline & 2 & 179 & 9.2 & 9.2 & 19.7 \\
\hline & 3 & 132 & 6.8 & 6.8 & 26.5 \\
\hline & 4 & 93 & 4.8 & 4.8 & 31.3 \\
\hline & 5 & 89 & 4.6 & 4.6 & 35.9 \\
\hline & 6 & 75 & 3.8 & 3.9 & 39.7 \\
\hline & 7 & 71 & 3.6 & 3.7 & 43.4 \\
\hline & 8 & 63 & 3.2 & 3.2 & 46.6 \\
\hline & 9 & 44 & 2.3 & 2.3 & 48.9 \\
\hline & 10 & 113 & 5.8 & 5.8 & 54.7 \\
\hline & 11 & 29 & 1.5 & 1.5 & 56.2 \\
\hline & 12 & 54 & 2.8 & 2.8 & 59.0 \\
\hline & 13 & 50 & 2.6 & 2.6 & 61.6 \\
\hline & 14 & 25 & 1.3 & 1.3 & 62.9 \\
\hline & 15 & 65 & 3.3 & 3.3 & 66.2 \\
\hline & 16 & 24 & 1.2 & 1.2 & 67.4 \\
\hline & 17 & 29 & 1.5 & 1.5 & 68.9 \\
\hline & 18 & 32 & 1.6 & 1.6 & 70.6 \\
\hline & 19 & 17 & 0.9 & 0.9 & 71.5 \\
\hline & 20 & 88 & 4.5 & 4.5 & 76.0 \\
\hline & 21 & 14 & 0.7 & 0.7 & 76.7 \\
\hline & 22 & 20 & 1.0 & 1.0 & 77.7 \\
\hline & 23 & 23 & 1.2 & 1.2 & 78.9 \\
\hline & 24 & 20 & 1.0 & 1.0 & 80.0 \\
\hline & 25 & 43 & 2.2 & 2.2 & 82.2 \\
\hline & 26 & 13 & 0.7 & 0.7 & 82.8 \\
\hline & 27 & 15 & 0.8 & 0.8 & 83.6 \\
\hline & 28 & 21 & 1.1 & 1.1 & 84.7 \\
\hline & 29 & 6 & 0.3 & 0.3 & 85.0 \\
\hline & 30 & 67 & 3.4 & 3.5 & 88.5 \\
\hline & 31 & 10 & 0.5 & 0.5 & 89.0 \\
\hline & 32 & 11 & 0.6 & 0.6 & 89.5 \\
\hline & 33 & 10 & 0.5 & 0.5 & 90.1 \\
\hline & 34 & 3 & 0.2 & 0.2 & 90.2 \\
\hline & 35 & 26 & 1.3 & 1.3 & 91.6 \\
\hline & 36 & 12 & 0.6 & 0.6 & 92.2 \\
\hline & 37 & 10 & 0.5 & 0.5 & 92.7 \\
\hline & 38 & 6 & 0.3 & 0.3 & 93.0 \\
\hline & 39 & 3 & 0.2 & 0.2 & 93.1 \\
\hline & 40 & 34 & 1.7 & 1.8 & 94.9 \\
\hline
\end{tabular}




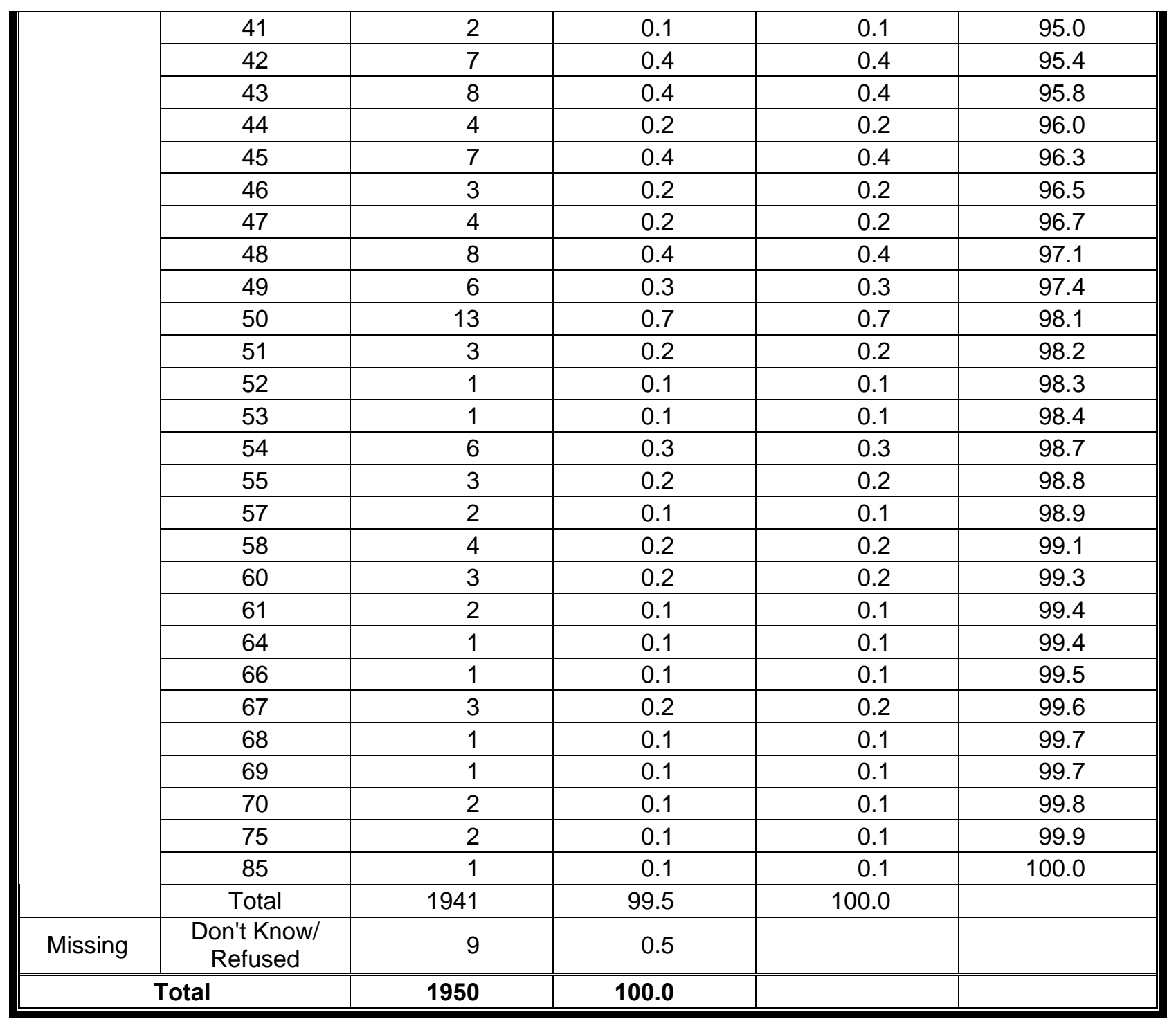

Distances in Table 17 were recoded in Figure 14 as follows: from 0-1 mile $=1$, from 2-5 miles $=5$, from 610 miles $=10$, from $11-15$ miles $=15$, from $16-20$ miles $=20$, from $21-30$ miles $=30$, from $31-50$ miles $=$ 50 , and from 51-100 miles $=100$.

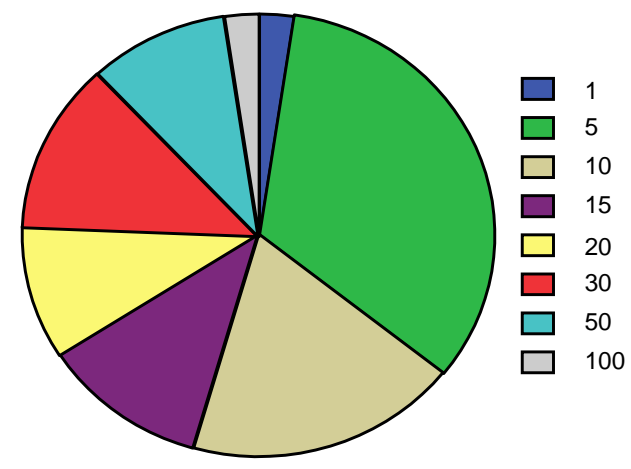

Mean residence time is 14 years and median residence time is 10 years. Longer home residents tend to own their residences $(r=0.371)$, live in the community longer $(r=0.568)$, and are more likely to work at the site $(r=0.168)$.

Figure 14. Household Residence Time Distribution (Recoded) 


\section{Length of Community Residence}

Table 18 and Figure 9 show how long respondents lived in their communities.

Table 18. Responses to "How long have you lived in the area?"

\begin{tabular}{|c|c|c|c|c|c|}
\hline RESPONSE & DURATION & FREQUENCY & Percent & $\begin{array}{c}\text { VALID } \\
\text { PERCENT }\end{array}$ & $\begin{array}{l}\text { Cumulative } \\
\text { Percent } \\
\end{array}$ \\
\hline \multirow[t]{46}{*}{ Valid } & $<<6$ months & 11 & 0.6 & 0.6 & 0.6 \\
\hline & 1 & 31 & 1.6 & 1.6 & 2.2 \\
\hline & 2 & 55 & 2.8 & 2.8 & 5.0 \\
\hline & 3 & 43 & 2.2 & 2.2 & 7.2 \\
\hline & 4 & 45 & 2.3 & 2.3 & 9.6 \\
\hline & 5 & 40 & 2.1 & 2.1 & 11.6 \\
\hline & 6 & 39 & 2.0 & 2.0 & 13.7 \\
\hline & 7 & 37 & 1.9 & 1.9 & 15.6 \\
\hline & 8 & 36 & 1.8 & 1.9 & 17.4 \\
\hline & 9 & 27 & 1.4 & 1.4 & 18.8 \\
\hline & 10 & 60 & 3.1 & 3.1 & 21.9 \\
\hline & 11 & 26 & 1.3 & 1.3 & 23.3 \\
\hline & 12 & 31 & 1.6 & 1.6 & 24.9 \\
\hline & 13 & 34 & 1.7 & 1.8 & 26.6 \\
\hline & 14 & 26 & 1.3 & 1.3 & 28.0 \\
\hline & 15 & 51 & 2.6 & 2.6 & 30.6 \\
\hline & 16 & 17 & 0.9 & 0.9 & 31.5 \\
\hline & 17 & 19 & 1.0 & 1.0 & 32.5 \\
\hline & 18 & 20 & 1.0 & 1.0 & 33.5 \\
\hline & 19 & 21 & 1.1 & 1.1 & 34.6 \\
\hline & 20 & 92 & 4.7 & 4.8 & 39.4 \\
\hline & 21 & 9 & 0.5 & 0.5 & 39.8 \\
\hline & 22 & 27 & 1.4 & 1.4 & 41.2 \\
\hline & 23 & 32 & 1.6 & 1.7 & 42.9 \\
\hline & 24 & 17 & 0.9 & 0.9 & 43.8 \\
\hline & 25 & 80 & 4.1 & 4.1 & 47.9 \\
\hline & 26 & 22 & 1.1 & 1.1 & 49.0 \\
\hline & 27 & 29 & 1.5 & 1.5 & 50.5 \\
\hline & 28 & 26 & 1.3 & 1.3 & 51.9 \\
\hline & 29 & 7 & 0.4 & 0.4 & 52.3 \\
\hline & 30 & 92 & 4.7 & 4.8 & 57.0 \\
\hline & 31 & 22 & 1.1 & 1.1 & 58.1 \\
\hline & 32 & 25 & 1.3 & 1.3 & 59.4 \\
\hline & 33 & 22 & 1.1 & 1.1 & 60.6 \\
\hline & 34 & 15 & 0.8 & 0.8 & 61.4 \\
\hline & 35 & 47 & 2.4 & 2.4 & 63.8 \\
\hline & 36 & 16 & 0.8 & 0.8 & 64.6 \\
\hline & 37 & 18 & 0.9 & 0.9 & 65.5 \\
\hline & 38 & 15 & 0.8 & 0.8 & 66.3 \\
\hline & 39 & 9 & 0.5 & 0.5 & 66.8 \\
\hline & 40 & 69 & 3.5 & 3.6 & 70.4 \\
\hline & 41 & 9 & 0.5 & 0.5 & 70.8 \\
\hline & 42 & 14 & 0.7 & 0.7 & 71.5 \\
\hline & 43 & 16 & 0.8 & 0.8 & 72.4 \\
\hline & 44 & 13 & 0.7 & 0.7 & 73.0 \\
\hline & 45 & 50 & 2.6 & 2.6 & 75.6 \\
\hline
\end{tabular}




\begin{tabular}{|c|c|c|c|c|c|}
\hline & 46 & 17 & 0.9 & 0.9 & 76.5 \\
\hline & 47 & 21 & 1.1 & 1.1 & 77.6 \\
\hline & 48 & 22 & 1.1 & 1.1 & 78.7 \\
\hline & 49 & 18 & 0.9 & 0.9 & 79.7 \\
\hline & 50 & 82 & 4.2 & 4.2 & 83.9 \\
\hline & 51 & 20 & 1.0 & 1.0 & 84.9 \\
\hline & 52 & 14 & 0.7 & 0.7 & 85.7 \\
\hline & 53 & 17 & 0.9 & 0.9 & 86.5 \\
\hline & 54 & 15 & 0.8 & 0.8 & 87.3 \\
\hline & 55 & 31 & 1.6 & 1.6 & 88.9 \\
\hline & 56 & 10 & 0.5 & 0.5 & 89.4 \\
\hline & 57 & 17 & 0.9 & 0.9 & 90.3 \\
\hline & 58 & 19 & 1.0 & 1.0 & 91.3 \\
\hline & 59 & 6 & 0.3 & 0.3 & 91.6 \\
\hline & 60 & 54 & 2.8 & 2.8 & 94.4 \\
\hline & 61 & 4 & 0.2 & 0.2 & 94.6 \\
\hline & 62 & 6 & 0.3 & 0.3 & 94.9 \\
\hline & 63 & 3 & 0.2 & 0.2 & 95.1 \\
\hline & 64 & 8 & 0.4 & 0.4 & 95.5 \\
\hline & 65 & 9 & 0.5 & 0.5 & 96.0 \\
\hline & 66 & 5 & 0.3 & 0.3 & 96.2 \\
\hline & 67 & 7 & 0.4 & 0.4 & 96.6 \\
\hline & 68 & 7 & 0.4 & 0.4 & 96.9 \\
\hline & 69 & 1 & 0.1 & 0.1 & 97.0 \\
\hline & 70 & 11 & 0.6 & 0.6 & 97.6 \\
\hline & 71 & 6 & 0.3 & 0.3 & 97.9 \\
\hline & 73 & 2 & 0.1 & 0.1 & 98.0 \\
\hline & 74 & 3 & 0.2 & 0.2 & 98.1 \\
\hline & 75 & 10 & 0.5 & 0.5 & 98.7 \\
\hline & 76 & 2 & 0.1 & 0.1 & 98.8 \\
\hline & 77 & 4 & 0.2 & 0.2 & 99.0 \\
\hline & 78 & 4 & 0.2 & 0.2 & 99.2 \\
\hline & 79 & 1 & 0.1 & 0.1 & 99.2 \\
\hline & 80 & 7 & 0.4 & 0.4 & 99.6 \\
\hline & 81 & 1 & 0.1 & 0.1 & 99.6 \\
\hline & 82 & 2 & 0.1 & 0.1 & 99.7 \\
\hline & 83 & 1 & 0.1 & 0.1 & 99.8 \\
\hline & 84 & 1 & 0.1 & 0.1 & 99.8 \\
\hline & 85 & 2 & 0.1 & 0.1 & 99.9 \\
\hline & 89 & 1 & 0.1 & 0.1 & 100.0 \\
\hline & Total & 1933 & 99.1 & 100.0 & \\
\hline Missing & Don't Know/Refused & 17 & 0.9 & & \\
\hline & Total & 1950 & 100.0 & & \\
\hline
\end{tabular}

Distances in Table 18 were recoded in Figure 15 as follows: from 0-1 mile $=1$, from 2-5 miles $=5$, from 610 miles $=10$, from $11-15$ miles $=15$, from $16-20$ miles $=20$, from $21-30$ miles $=30$, from $31-50$ miles $=$ 50 , and from 51-100 miles $=100$. 


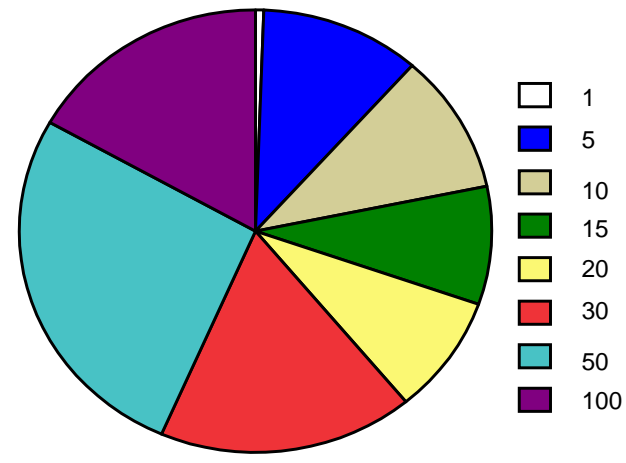

Mean community residence time is 29.6 years and the median time is 27 years. Those who lived in the community longer tend to own their residence $(r=0.265)$ and stay longer in that residence $(r=0.568)$. Longer residents tend to have a lower level of education $(r=-0.261)$.

Figure 15. Community Residence Time Distribution (Recoded)

\section{Personal Site Employment}

Table 19 and Figure 16 report the number of individuals who have worked or are working at the DOE facility.

Table 19. Response to "Have you ever worked or are you now working at the site?"

\begin{tabular}{|c|c|c|c|c|c|}
\hline \multicolumn{2}{|c|}{ RESPONSES } & FREQUENCY & Percent & VALID PERCENT & Cumulative Percent \\
\hline \multirow{3}{*}{ Valid } & No & 1408 & 72.2 & 72.4 & 72.4 \\
\hline & Yes & 538 & 27.6 & 27.6 & 100.0 \\
\hline & Total & 1946 & 99.8 & 100.0 & \\
\hline Missing & Refused & 4 & 0.2 & & \\
\hline \multicolumn{2}{|c|}{ Total } & 1950 & 100.0 & & \\
\hline
\end{tabular}

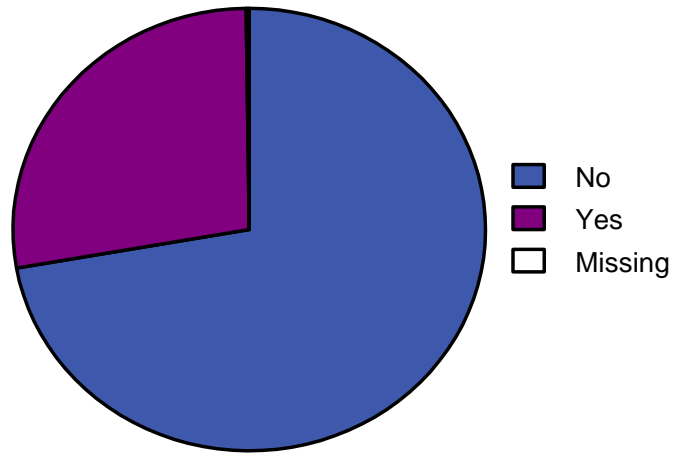

The mean and median values are not working (or never worked) at the site. Only $27.6 \%$ have ever worked at the site. Site workers are more likely to be male $(r=0.271)$, work in technical occupations $(r=0.308)$, and live further away from the site $(r=0.353)$.

Figure 16. Site Employment Distribution 
Family Site Employment

Table 20 and Figure 17 report the number of individuals whose immediate family worked or are working at the DOE facility.

Table 20. Responses to "Other than you, has any one in your immediate family worked at the site?"

\begin{tabular}{|c|c|c|c|c|c||}
\hline \multicolumn{2}{|c|}{ Responses } & Frequency & PERCENT & VAlid PERCENT & Cumulative PeRCENT \\
\hline \multirow{3}{*}{ Valid } & No (=1) & 1173 & 60.2 & 60.3 & 60.3 \\
\cline { 2 - 6 } & Yes (=2) & 771 & 39.5 & 39.7 & 100.0 \\
\cline { 2 - 6 } & Total & 1944 & 99.7 & 100.0 & \\
\hline Missing & Refused & 6 & .3 & & \\
\hline \multicolumn{2}{|c|}{ Total } & 1950 & 100.0 & & \\
\hline
\end{tabular}

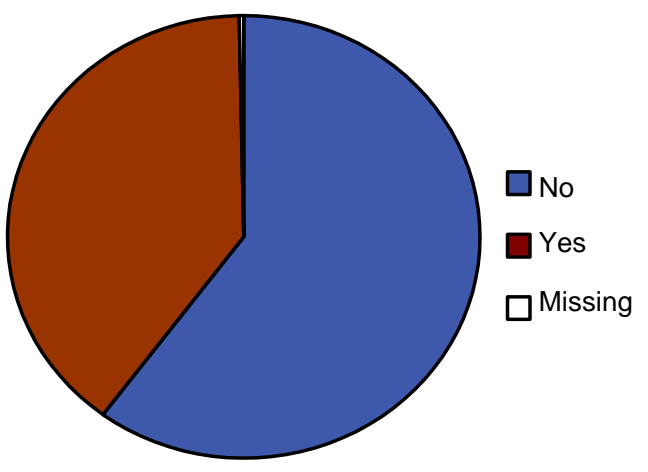

The mean and median values are no family site employment $(39.5 \%$ of respondents have family members who worked at the site). Those families that have members who work at the site tend to live further away $(r=0.256)$ and live in the community longer $(r=0.262)$.

Figure 17. Family Site Employment Distribution

\section{Education Level}

Table 21 and Figure 18 show the education level of respondents.

Table 21. Responses to "What is the highest education level that you achieved?"

\begin{tabular}{|c|c|r|r|r|c|}
\hline \multicolumn{2}{|c|}{ ReSPONSES } & \multirow{2}{*}{ FREQUENCY } & PERCENT & $\begin{array}{c}\text { VALID } \\
\text { PERCENT }\end{array}$ & $\begin{array}{c}\text { CUMULATIVE } \\
\text { PERCENT }\end{array}$ \\
\hline \hline \multirow{4}{*}{ Valid } & Did not graduate from High School & 53 & 2.7 & 2.7 & 2.7 \\
\cline { 2 - 5 } & High School Diploma & 311 & 15.9 & 16.1 & 18.8 \\
\cline { 2 - 5 } & Some College (but no degree) & 402 & 20.6 & 20.8 & 39.6 \\
\cline { 2 - 6 } & Associate Degree & 199 & 10.2 & 10.3 & 49.9 \\
\cline { 2 - 6 } & Undergraduate College Degree & 345 & 17.7 & 17.8 & 67.7 \\
\cline { 2 - 6 } & Some Graduate/Professional School & 161 & 8.3 & 8.3 & 76.1 \\
\cline { 2 - 6 } & Masters Degree & 335 & 17.2 & 17.3 & 93.4 \\
\cline { 2 - 6 } & Doctoral or Professional Degree & 128 & 6.6 & 6.6 & 100.0 \\
\cline { 2 - 6 } & Total & 1934 & 99.2 & 100.0 & \\
\hline Missing & Refused & 16 & 0.8 & & \\
\hline \hline
\end{tabular}




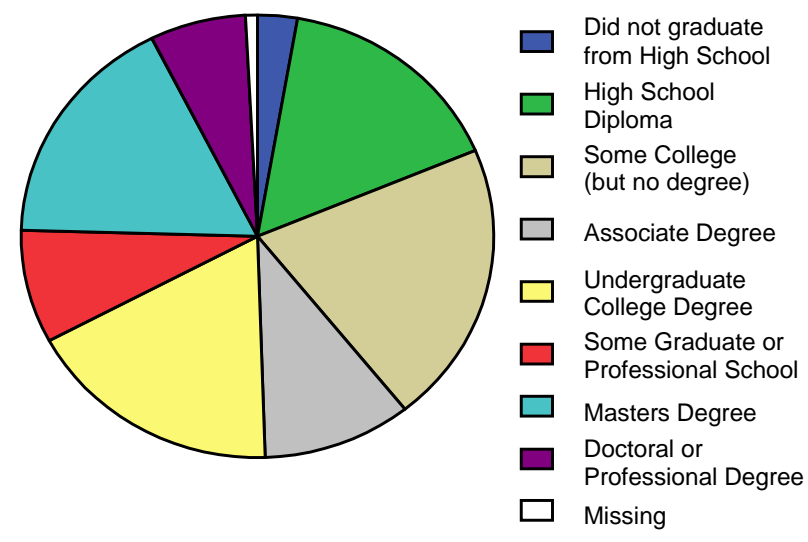

Figure 18. Education Level Distribution
Mean education level is between an associate and undergraduate degree. The median education level is an undergraduate degree.

The higher the level of education a respondent has, the shorter their community residence time $(r=-0.261)$. Also, the higher the level of education the more likely they are to work in a technical occupation $(r=0.407)$.

\section{Occupation}

Table 22 and Figure 19 present the results of our recode of respondents' occupations into technical and non-technical groups. Occupations were recoded as technical if, in our judgment, they would likely involve an understanding of radioactive contamination in either education or job performance. For example, we listed technical occupations as doctors, nurses, engineers, educators, researchers, x-ray technicians, fire service, site employees, etc. and non-technical occupations as homemakers, secretaries, repairmen, students, farmers, salesman, fast food workers, counter help, truck drivers, mechanics, manual laborers, etc.

Table 22. Technical and Non-Technical Occupations

\begin{tabular}{|c|c|c|c|c|c|}
\hline \multicolumn{2}{|c|}{ RESPONSES } & FREQUENCY & PERCENT & $\begin{array}{c}\text { VALID } \\
\text { PERCENT }\end{array}$ & $\begin{array}{c}\text { CUMULATIVE } \\
\text { PERCENT }\end{array}$ \\
\hline \multirow{3}{*}{ Valid } & Non-Technical & 1412 & 72.4 & 78.9 & 78.9 \\
\cline { 2 - 6 } & Technical & 378 & 19.4 & 21.1 & 100.0 \\
\cline { 2 - 6 } & Total & 1790 & 91.8 & 100.0 & \\
\hline Missing & Unknown/Refused & 160 & 8.2 & & \\
\hline \hline \multicolumn{2}{|c|}{ Total } & $\mathbf{1 9 5 0}$ & $\mathbf{1 0 0 . 0}$ & & \\
\hline
\end{tabular}

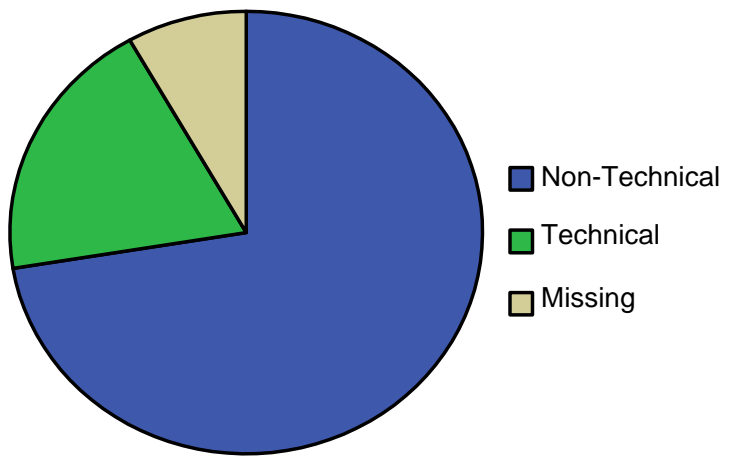

The mean and median values represent nontechnical occupations. Those who work in a technical occupation have a higher level of education ( $r=0.407)$ and lived in their community longer $(r=0.261)$. They also live further away from the site than other respondents $(r=-0.148)$.

Figure 19. Occupation Distribution 


\section{Summary of Single Variable Statistics}

Table 23 presents the measures of central tendency for the 10 demographic variables. The typical stakeholder near these sites is male, lives 20 miles away and owns his home, has lived in his residence for 14 years and in the community for 30 years, has a non-technical occupation with an undergraduate degree, has not worked at the site nor has any member of his family, and is exposed to wind blowing from the site 3 hours per day.

Table 23. Descriptive Demographic Statistics

\begin{tabular}{|c||c|c|c|c|c||}
\hline \multicolumn{1}{|c||}{ VARIABLE } & $\begin{array}{c}\text { NUMBER } \\
\text { REPORTING }\end{array}$ & MEAN & MEDIAN & MODE & $\begin{array}{c}\text { STANDARD } \\
\text { DEVIATION }\end{array}$ \\
\hline \hline Gender & 1950 & & & male & \\
\hline Proximity & 1917 & $19.3 \mathrm{mi}$ & $20 \mathrm{mi}$ & $20 \mathrm{mi}$ & $26.7 \mathrm{mi}$ \\
\hline Own/Rent & 1931 & & & own & \\
\hline House Residence Time & 1941 & $14.0 \mathrm{yrs}$ & $10 \mathrm{yrs}$ & $2 \mathrm{yrs}$ & $13.6 \mathrm{yrs}$ \\
\hline Community Residence Time & 1933 & $29.6 \mathrm{yrs}$ & $27 \mathrm{yrs}$ & $20 \mathrm{yrs}$ & $19.7 \mathrm{yrs}$ \\
\hline Technical Occupation & 1790 & & & non-technical & \\
\hline Education Level & 1934 & & undergrad & some college & \\
\hline Your Site Employment & 1946 & $28 \%$ & & & $4.8 \%$ \\
\hline Family Site Employment & 1944 & $40 \%$ & & & $4.9 \%$ \\
\hline Wind Exposure & 1898 & $\sim 3$ hours & $\sim 2$ hours & $\sim 1.5$ hours & $\sim 1.5$ hours \\
\hline
\end{tabular}

\section{Summary of Bivariate Correlations}

Table 24 summarizes the strengths of the correlations between demographic characteristics.

Table 24. Demographic Correlations

\begin{tabular}{|c|c|c|c|c|c|c|c|c|c|c|}
\hline VARIABLE & GENDER & $\begin{array}{c}\% \\
\text { WIND } \\
\text { DIR } \\
\end{array}$ & $\begin{array}{l}\text { RENT/ } \\
\text { OWN }\end{array}$ & $\begin{array}{c}\text { ProxIMITY } \\
\text { TO SITE } \\
\end{array}$ & $\begin{array}{c}\text { HOUSE } \\
\text { RESIDENCE } \\
\text { TIME } \\
\end{array}$ & $\begin{array}{c}\text { COMMUNITY } \\
\text { RESIDENCE } \\
\text { TIME } \\
\end{array}$ & $\begin{array}{l}\text { YOUR } \\
\text { SITE } \\
\text { EMPLOY }\end{array}$ & $\begin{array}{l}\text { FAMILY } \\
\text { SITE } \\
\text { EMPLOY }\end{array}$ & $\begin{array}{c}\text { TECH } \\
\text { JOB } \\
\end{array}$ & $\begin{array}{l}\text { EdUC } \\
\text { LEVEL } \\
\end{array}$ \\
\hline PROXIMITY & & + & -0 & & & & $\overline{-1}$ & $\overline{-1}$ & & \\
\hline $\begin{array}{c}\text { HOUSE } \\
\text { RESIDENCE TIME }\end{array}$ & & & +0 & & & ++ & + & & & \\
\hline $\begin{array}{c}\text { COMMUNITY } \\
\text { RESIDENCE TIME }\end{array}$ & & & +0 & & ++ & & + & + & + & - \\
\hline $\begin{array}{c}\text { YOUR } \\
\text { EMPLOYMENT AT } \\
\text { THE SITE } \\
\end{array}$ & M & & +0 & - & + & + & & & + & \\
\hline $\begin{array}{c}\text { FAMILY } \\
\text { EMPLOYMENT AT } \\
\text { THE SITE }\end{array}$ & & & & - & & + & & & & \\
\hline $\begin{array}{l}\text { TECHNICAL } \\
\text { OCCUPATION }\end{array}$ & & & & - & & + & + & & & ++ \\
\hline EDUCATION LEVEL & & & & & & - & & & ++ & \\
\hline
\end{tabular}

Here are our findings.

- More men than women worked at the sites and worked in technical occupations.

- People who live close by have not worked at these sites or in a technical occupation, nor did members of their families. This, coupled with a mild negative correlation of home ownership, suggests that property in close proximity is less desirable to people who work at the sites and that a higher proportion of rental property is located closer to the sites.

- Homeowners are more likely to stay in that home, stay in the community, and work for the site. As pointed out earlier in the response to proximity, those who own live further away from the site. 
- The longer people live in their communities, the more likely they are to own their homes, stay in their homes, and work and have a family member work at the site. Community residence time, however, correlates negatively with education level. This suggests that those who have lived longer in the community, and thus are older, are likely to be less educated than younger residents are.

- Those in technical occupations have higher levels of education. But higher education also correlates with shorter community residence times. Apparently, those with higher education are either younger on average than those with lower education or else they are more mobile.

- The closer that people live to the facility, the more often they are exposed to wind blowing from the site.

\section{Sample Representativeness}

Using data from the US Census of 2000, we can evaluate the representativeness of the phone survey in the following five areas: females (gender), living in the same house (household residence time), high school and college graduates (education level), and home ownership (rent/own). Census data for counties and cities adjacent to the sites is shown in Table 25.

Table 25. 2000 Census Data

\begin{tabular}{|c|c|c|c|c|c|c||}
\hline \multirow{3}{*}{ StATE } & Counties AND CITIES & FEMALE & $\begin{array}{c}\text { LIVING IN } \\
\text { SAME HOUSE } \\
\text { (5+ YEARS) }\end{array}$ & $\begin{array}{c}\text { HIGH SCHOOL } \\
\text { GRADUATE } \\
\text { (AGE 25+) }\end{array}$ & $\begin{array}{c}\text { BACHELOR } \\
\text { DEGREE } \\
\text { (AGE 25+) }\end{array}$ & $\begin{array}{c}\text { OWN HOME } \\
\text { (\%) }\end{array}$ \\
\hline \hline \multirow{4}{*}{ TN } & Anderson County & 53.3 & 61.5 & 78.9 & 20.0 & 72.5 \\
\cline { 2 - 7 } & Roane County & 51.6 & 62.3 & 74.8 & 14.8 & 77.6 \\
\cline { 2 - 7 } & Knox County & 51.7 & 52.0 & 82.5 & 29.0 & 66.9 \\
\cline { 2 - 7 } & Loudon County & 51.3 & 57.9 & 75.6 & 17.0 & 79.1 \\
\cline { 2 - 7 } & Oak Ridge & 53.2 & 58.7 & 89.3 & 37.9 & 68.4 \\
\hline \multirow{4}{*}{ WA } & Benton County & 50.3 & 51.2 & 85.1 & 26.3 & 68.7 \\
\cline { 2 - 7 } & Franklin County & 47.8 & 49.0 & 63.5 & 13.6 & 65.6 \\
\cline { 2 - 7 } & Grant County & 48.9 & 50.0 & 72.2 & 13.7 & 66.7 \\
\cline { 2 - 7 } & Pasco & 48.4 & 44.8 & 55.9 & 10.6 & 60.0 \\
\cline { 2 - 7 } & Kennewick & 50.4 & 46.9 & 83.3 & 22.1 & 59.7 \\
\cline { 2 - 7 } & Richland & 51.0 & 51.4 & 92.6 & 38.9 & 66.3 \\
\hline \multirow{3}{*}{ NM } & Rio Arriba County & 50.5 & 71.3 & 73.0 & 15.4 & 81.6 \\
\cline { 2 - 7 } & Los Alamos & 49.7 & unknown & 96.4 & 62.1 & 71.5 \\
\cline { 2 - 7 } & White Rock & 49.6 & unknown & 96.7 & 69.9 & 94.5 \\
\hline
\end{tabular}

Female

The census bureau reports that females make up $51 \%$ of the population in these areas. Our survey matched this distribution well (males $=50.6 \%$ ).

\section{Living in the Same House}

The 2000 census, $54.8 \%$ of citizens living near our study sites have lived in their residences for at least five years. In our survey, respondents lived in their current residence an average of 14 years. These results are consistent.

\section{High School Graduates and College Graduates}

According to the 2000 census, $80 \%$ of citizens over the age of 25 in the areas near our study sites are high school graduates and $28 \%$ are college graduates. In our survey, $97.3 \%$ of respondents are high school graduates and $50 \%$ are college graduates. Our sample is more educated than the population as a whole, which is consistent with telephone survey respondents conducted generally. 


\section{Own Residence}

In the areas surrounding our study sites, $71.4 \%$ own their own homes according to the 2000 census. In our survey, $83 \%$ own their own homes. Our sample is a bit over-represented with homeowners.

\section{Conclusions}

Our sample is fairly representative of the areas' populations, which lends validity to our results. The population is relatively stable and well invested in their communities. About a quarter of these populations have worked at the DOE facilities and $40 \%$ of the families have had another member work there. Our sample is well educated, especially those in technical occupations. However, those who worked at the sites and well educated tend to live further away. Therefore, less well-educated persons without technical training and experience in working at the sites live closer to them. This could present a challenge to DOE in risk communication and gaining their support for bioremediation. 


\section{CHAPTER 6}

\section{FINDINGS ON RISK JUDGMENTS}

\section{Introduction}

Because stakeholders' acceptance of bioremediation depends in part on their risk perceptions and judgments, the second major investigation conducted by our telephone survey involves respondents' views toward risk in general and bioremediation risk in particular. We review their responses below.

\section{Analysis of Risk Judgments}

Belief about Being at Risk

Table 26 and Figure 20 show respondent beliefs about the risk that they face personally from exposure to subsurface contamination at the sites.

Table 26. Responses to Questions about Whether the Respondents Believe They Are at Risk of Suffering, or Could Suffer, Adverse Health Effects

\begin{tabular}{|c|c|c|c|c|}
\hline ResPonse & FREQUENCY & PERCENT & VALID PERCENT & $\begin{array}{c}\text { CUMULATIVE } \\
\text { PERCENT }\end{array}$ \\
\hline \hline Not at Risk & 638 & 32.7 & 32.7 & 32.7 \\
\hline Potentially at Risk & 1058 & 54.3 & 54.3 & 87.0 \\
\hline Actually at Risk & 254 & 13.0 & 13.0 & 100.0 \\
\hline \hline Total & $\mathbf{1 9 5 0}$ & $\mathbf{1 0 0 . 0}$ & $\mathbf{1 0 0 . 0}$ & \\
\hline
\end{tabular}

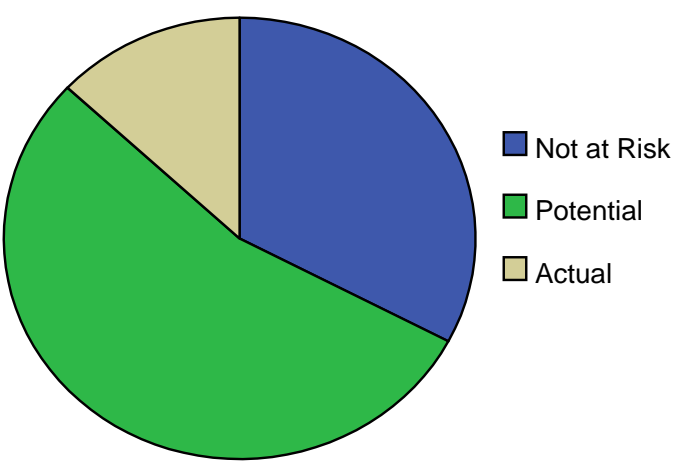

Figure 20. At Risk Distribution
The median belief is that they are potentially suffering adverse health effects. Based on a sample size of 1950, the confidence interval about the mean is $1.80 \pm 0.03$ at $95 \%$ confidence level $(p<0.05)$, where not at risk $=1$, potential risk $=2$, and actual risk $=3$. Few respondents believe that they have actually suffered harm from exposure to subsurface contamination. Most believe that they could suffer adverse effects, however. 


\section{Risk Magnitude}

Table 27 and Figure 21 show respondents beliefs about the severity of health risks that they potentially or actually face. Note that the 642 respondents who believe that they are not at risk (listed below as "Other") are no included in the valid percentages.

Table 27. Responses to "How significant do you believe these health risks are?"

\begin{tabular}{|c|c|c|c|c|c|}
\hline \multicolumn{2}{|c|}{ RESPONSES } & FREQUENCY & PERCENT & VAlid Percent & $\begin{array}{c}\text { Cumulative } \\
\text { PERCENT }\end{array}$ \\
\hline \multirow{6}{*}{ Valid } & Very Low & 113 & 5.8 & 8.9 & 8.9 \\
\hline & Somewhat Low & 213 & 10.9 & 16.9 & 25.8 \\
\hline & Moderate & 384 & 19.7 & 30.4 & 56.2 \\
\hline & Somewhat High & 311 & 15.9 & 24.6 & 80.8 \\
\hline & Very High & 242 & 12.4 & 19.2 & 100.0 \\
\hline & Total & 1263 & 64.8 & 100.0 & \\
\hline \multirow{4}{*}{ Missing } & Don't Know & 42 & 2.2 & & \\
\hline & Refused & 3 & 0.2 & & \\
\hline & Other $^{3}$ & 642 & 32.9 & & \\
\hline & Total & 687 & 35.2 & & \\
\hline \multicolumn{2}{|r|}{ Total } & 1950 & 100.0 & & \\
\hline
\end{tabular}

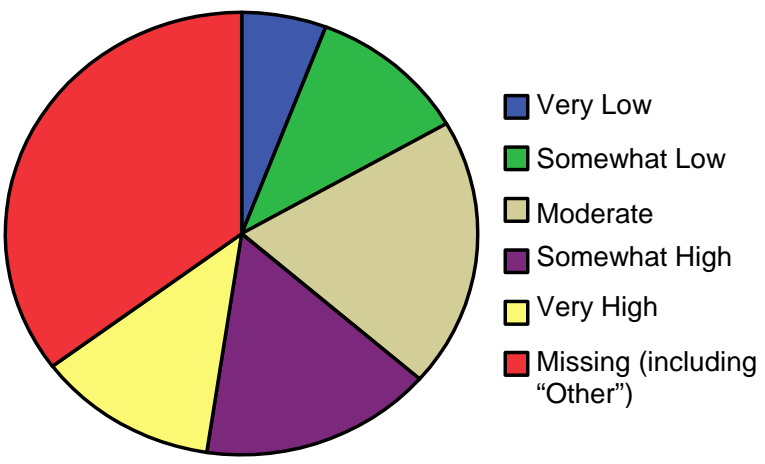

Median = moderate risk magnitude (value $=$ 3 ) confidence interval $=3.28 \pm 0.07$. Nearly $3 / 4$ of those who believe they are at potential or actual health risk believe that this risk is moderate, high, or very high. Risk magnitude is correlated with respondents' perceptions that the risk is dreadful $(r=0.538)$.

Figure 21. Risk Magnitude Estimate Distribution

3 This question was not included because these respondents believed that they were not actually or potentially exposed. 


\section{Contamination Knowledge}

Table 28 and Figure 22 report how long that stakeholders have known about subsurface contamination and its associated risks.

Table 28. Responses to "How long have you known about the subsurface radioactive contamination at the site and the health risks that this contamination may pose?"

\begin{tabular}{|c|c|c|c|c|c|}
\hline \multicolumn{2}{|c|}{$\begin{array}{c}\text { RESPONSES: KNOWN ABOUT } \\
\text { CONTAMINATION AND ASSOCIATED RISKS... }\end{array}$} & \multirow{2}{*}{$\begin{array}{c}\text { FREQUENCY } \\
657 \\
\end{array}$} & \multirow{2}{*}{$\begin{array}{c}\text { PERCENT } \\
33.7 \\
\end{array}$} & \multirow{2}{*}{$\begin{array}{c}\begin{array}{c}\text { VALID } \\
\text { PERCENT }\end{array} \\
50.7 \\
\end{array}$} & \multirow{2}{*}{$\begin{array}{c}\begin{array}{c}\text { Cumulative } \\
\text { PERCENT }\end{array} \\
50.7\end{array}$} \\
\hline \multirow{6}{*}{ Valid } & For A Very Long Time & & & & \\
\hline & For A Somewhat Long Time & 356 & 18.3 & 27.4 & 78.1 \\
\hline & Not Recently, but Not a Long Time & 133 & 6.8 & 10.3 & 88.4 \\
\hline & Somewhat Recently & 121 & 6.2 & 9.3 & 97.7 \\
\hline & Very Recently & 30 & 1.5 & 2.3 & 100.0 \\
\hline & Total & 1297 & 66.5 & 100.0 & \\
\hline \multirow{4}{*}{ Missing } & Don't Know & 10 & 0.5 & & \\
\hline & Refused & 1 & 0.1 & & \\
\hline & Other $^{4}$ & 642 & 32.9 & & \\
\hline & Total & 653 & 33.5 & & \\
\hline \multicolumn{2}{|r|}{ Total } & 1950 & 100.0 & & \\
\hline
\end{tabular}

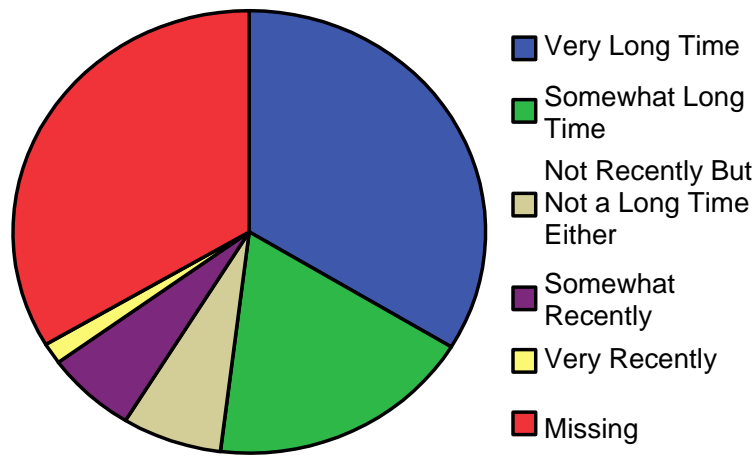

Figure 22. Contamination Awareness Distribution
Median value $=$ known about risks for a very long time (value $=1$ ); confidence interval = 1.85 \pm 0.06 . Nearly $80 \%$ of the respondents reported that they have known about site contamination for a long time. Less than 12\% reported that they learned about the contamination recently. Familiarity correlates positively with length of time they have lived in the community $(r=0.303)$, indicating that the longer people live in the community, the more they know about subsurface radioactive contamination. It is also correlated with health effects knowledge $(r=0.226)$ and exposure knowledge $(r=0.234)$, suggesting that knowledge about site contamination, exposure pathways, and health effects are coincident.

\footnotetext{
${ }^{4}$ This question was asked of those respondents who reported in the previous question that they were not actually or
} potentially exposed. 


\section{Exposure Knowledge}

Table 29 and Figure 23 report respondents' rating of their knowledge about subsurface contamination exposure.

Table 29. Responses to "How would you rate your knowledge of how you are exposed to subsurface radioactive contamination?"

\begin{tabular}{|c|c|c|c|c|c|}
\hline \multicolumn{2}{|c|}{ RESPONSES } & FREQUENCY & PERCENT & $\begin{array}{c}\text { VALID } \\
\text { PERCENT }\end{array}$ & $\begin{array}{c}\text { CUMULATIVE } \\
\text { PERCENT }\end{array}$ \\
\hline \hline \multirow{4}{*}{ Valid } & Very Low & 107 & 5.5 & 8.3 & 8.3 \\
\cline { 2 - 6 } & Somewhat Low & 242 & 12.4 & 18.7 & 27.0 \\
\cline { 2 - 6 } & Moderate & 467 & 23.9 & 36.1 & 63.2 \\
\cline { 2 - 6 } & Somewhat High & 309 & 15.8 & 23.9 & 87.1 \\
\cline { 2 - 6 } & Very High & 167 & 8.6 & 12.9 & 100.0 \\
\cline { 2 - 6 } & Total & 1292 & 66.3 & 100.0 & \\
\hline \multirow{3}{*}{ Missing } & Don't Know & 15 & 0.8 & & \\
\cline { 2 - 6 } & Refused & 1 & 0.1 & & \\
\cline { 2 - 6 } & Other & 642 & 32.9 & & \\
\cline { 2 - 6 } & Total & 658 & 33.7 & & \\
\hline \hline \multicolumn{1}{|l}{} & $\mathbf{1 9 5 0}$ & $\mathbf{1 0 0 . 0}$ & & \\
\hline
\end{tabular}

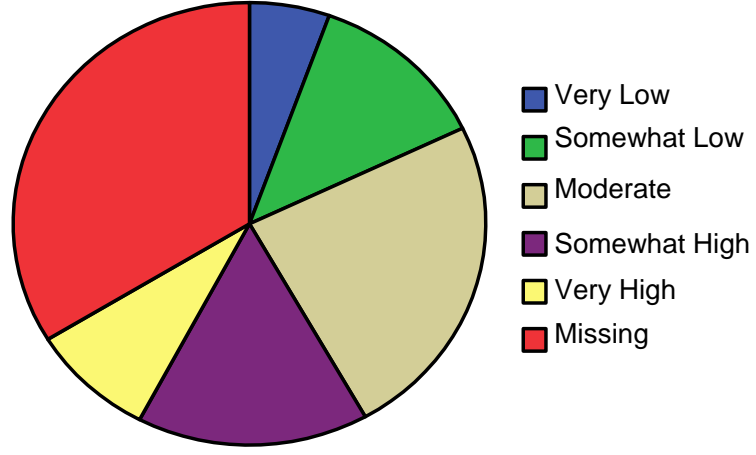

Figure 23. Exposure Knowledge Distribution
Median value $=$ moderate exposure knowledge (value $=3$ ); confidence interval $=3.14 \pm 0.06$. Of those who believe that they are suffering or could suffer adverse health effects, the sample divides itself into approximately equal divisions of low knowledge, moderate knowledge, high knowledge of how they are exposed to subsurface radioactive contamination. This response correlates quite highly with health effects knowledge $(r=0.653)$ and somewhat less so with working at the site $(r=0.300)$. Those who are or have worked at the site know more about both health effects and exposure pathways.

\footnotetext{
${ }^{5}$ Again, this question was not asked of those respondents who reported that they were not at risk.
} 


\section{Health Effects Knowledge}

Table 30 and Figure 24 report respondents' rating of their knowledge of health effects that could result from exposure to subsurface contamination.

Table 30. Responses to "How would you rate your knowledge of the health effects of exposure to subsurface radioactive contamination?"

\begin{tabular}{|c|c|c|c|c|c||}
\hline \multicolumn{2}{|c|}{ RESPONSES } & FREQUENCY & PERCENT & $\begin{array}{c}\text { VALID } \\
\text { PERCENT }\end{array}$ & $\begin{array}{c}\text { CUMULATIVE } \\
\text { PERCENT }\end{array}$ \\
\hline \multirow{4}{*}{ Valid } & Very Low & 98 & 5.0 & 7.6 & 7.6 \\
\cline { 2 - 6 } & Somewhat Low & 233 & 11.9 & 18.0 & 25.6 \\
\cline { 2 - 6 } & Moderate & 504 & 25.8 & 39.0 & 64.6 \\
\cline { 2 - 6 } & Somewhat High & 294 & 15.1 & 22.8 & 87.4 \\
\cline { 2 - 6 } & Very High & 163 & 8.4 & 12.6 & 100.0 \\
\cline { 2 - 6 } & Total & 1292 & 66.3 & 100.0 & \\
\hline \multirow{3}{*}{ Missing } & Don't Know & 16 & 0.8 & & \\
\cline { 2 - 6 } & Other & 642 & 32.9 & & \\
\cline { 2 - 6 } & Total & 658 & 33.7 & & \\
\hline \hline \multicolumn{2}{|c|}{} & $\mathbf{1 9 5 0}$ & $\mathbf{1 0 0 . 0}$ & & \\
\hline
\end{tabular}

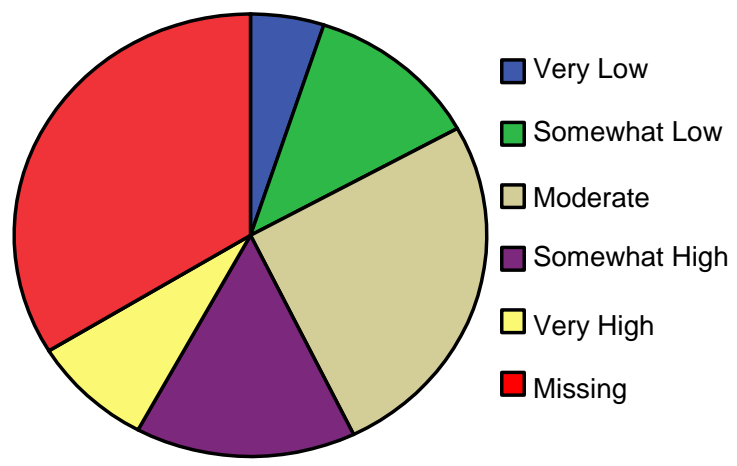

Median value $=$ moderate knowledge $($ value $=3$; confidence interval $=3.15 \pm 0.06$. Among those who believe that they are potentially or actually at risk, their mean health risk knowledge rating is essentially the same as their rating of exposure knowledge. Again, the sample is divided into approximately equal divisions among low, moderate, and high risk knowledge. Its correlation with site employment $(r=0.249)$ suggests that working at the site increases confidence in health effects knowledge, which is not surprising.

Figure 24. Health Effects Knowledge Distribution

\footnotetext{
${ }^{6}$ Those who believe that they are not at risk were not asked this question.
} 


\section{Exposure Control}

Table 31 and Figure 25 report respondents' answers to their beliefs about their ability to control their exposure to subsurface contamination.

Table 31. Responses to "In your opinion, how much choice do you have whether you are exposed to subsurface radioactive contamination?"

\begin{tabular}{|c|c|c|c|c|c|}
\hline \multicolumn{2}{|c|}{ RESPONSES } & FREQUENCY & PERCENT & $\begin{array}{c}\text { VALID } \\
\text { PERCENT }\end{array}$ & $\begin{array}{c}\text { CUMULATIVE } \\
\text { PERCENT }\end{array}$ \\
\hline \hline \multirow{4}{*}{ Valid } & Very Low & 487 & 25.0 & 39.1 & 39.1 \\
\cline { 2 - 6 } & Somewhat Low & 248 & 12.7 & 19.9 & 58.9 \\
\cline { 2 - 6 } & Moderate & 232 & 11.9 & 18.6 & 77.5 \\
\cline { 2 - 6 } & Somewhat High & 167 & 8.6 & 13.4 & 90.9 \\
\cline { 2 - 6 } & Very High & 113 & 5.8 & 9.1 & 100.0 \\
\cline { 2 - 6 } & Total & 1247 & 63.9 & 100.0 & \\
\hline \multirow{4}{*}{ Missing } & Don't Know & 55 & 2.8 & & \\
\cline { 2 - 6 } & Refused & 6 & 0.3 & & \\
\cline { 2 - 6 } & Other & 642 & 32.9 & & \\
\cline { 2 - 6 } & Total & 703 & 36.1 & & \\
\hline \hline \multicolumn{1}{|l}{} & 1950 & 100.0 & & \\
\hline
\end{tabular}

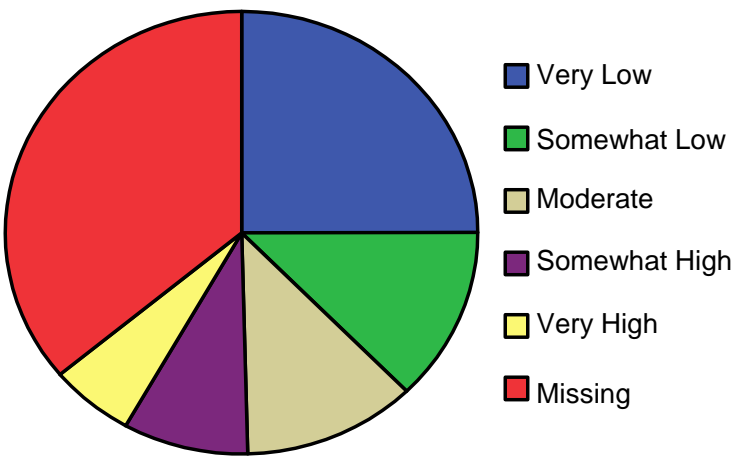

Median value $=$ somewhat low (value $=2$ ); confidence interval $=2.34 \pm 0.07$. Of those who believe that they are at risk), nearly $60 \%$ believe that they have low control over whether they are exposed; less than a 1/4 believe that they have high control. People living near the sites generally do not believe that they can control their exposure to subsurface radioactive contamination ( $r=-0.149)$, a weak but statistically significant correlation.

Figure 25. Exposure Controllability Distribution

\footnotetext{
${ }^{7}$ Question not presented to those who do not believe that they are at risk.
} 


\section{Dread Risk}

Table 32 and Figure 26 show respondents' answers to dread of the risk posed by subsurface contamination.

Table 32. Responses to "In your opinion, how ghastly or awful are the health risks from subsurface radioactive contamination?"

\begin{tabular}{|c|c|c|c|c|c|}
\hline \multicolumn{2}{|r|}{ RESPONSES } & FREQUENCY & Percent & $\begin{array}{c}\text { VALID } \\
\text { PERCENT }\end{array}$ & $\begin{array}{c}\text { Cumulative } \\
\text { PERCENT }\end{array}$ \\
\hline \multirow{6}{*}{ Valid } & Terrifying & 168 & 8.6 & 13.1 & 13.1 \\
\hline & Of Major Concern & 513 & 26.3 & 40.0 & 53.0 \\
\hline & Of Moderate Concern & 346 & 17.7 & 26.9 & 80.0 \\
\hline & Of Some Concern & 203 & 10.4 & 15.8 & 95.8 \\
\hline & No Big Deal & 54 & 2.8 & 4.2 & 100.0 \\
\hline & Total & 1284 & 65.8 & 100.0 & \\
\hline \multirow{4}{*}{ Missing } & Don't Know & 20 & 1.0 & & \\
\hline & Refused & 4 & 0.2 & & \\
\hline & Other $^{8}$ & 642 & 32.9 & & \\
\hline & Total & 666 & 34.2 & & \\
\hline \multicolumn{2}{|r|}{ Total } & 1950 & 100.0 & & \\
\hline
\end{tabular}

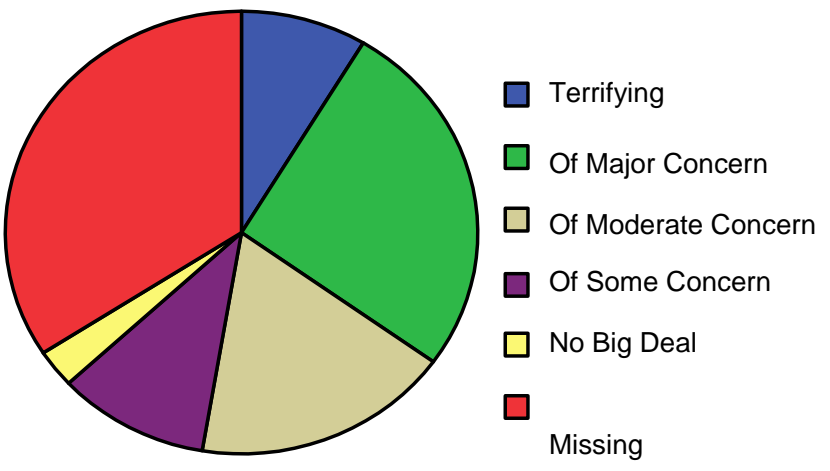

Figure 26. Dread Perception Distribution
Median value $=$ of major concern $($ value $=2)$; confidence interval $=2.58 \pm 0.06$. More than half of those who state that they are at risk believe that these risks are at least a major concern and 8 out of 10 believe that the risks are at least a moderate concern. Only $4 \%$ believe that these risks are "no big deal." Clearly, respondents are quite concerned about these risks.

Dread is correlated with risk magnitude $(r=0.538)$ and inversely with beliefs that the existence of contamination does not mean that health risks are posed $(r=-0.484)$. This suggests that the higher the perceived risks, the more these risks are dreaded, and the more the mere presence of contamination indicates that these risks are real.

\footnotetext{
${ }^{8}$ This question was asked of those who believe that they are not at risk.
} 
Correspondence between Contamination and Risk

Table 33 and 27 report respondents' reactions to the proposition that the presence of contamination necessarily means that a health risk is posed.

Table 33. Responses to "Just because there is contamination doesn't mean we are at risk."

\begin{tabular}{|c|c|c|c|c|c||}
\hline \multicolumn{2}{|c|}{ Responses } & FREQUENCY & PERCENT & $\begin{array}{c}\text { VALID } \\
\text { PERCENT }\end{array}$ & $\begin{array}{c}\text { CUMULATIVE } \\
\text { PERCENT }\end{array}$ \\
\hline \hline \multirow{4}{*}{ Valid } & Strongly Disagree & 666 & 34.2 & 34.5 & 34.5 \\
\cline { 2 - 6 } & Somewhat Disagree & 414 & 21.2 & 21.4 & 55.9 \\
\cline { 2 - 6 } & Neither Disagree nor Agree & 59 & 3.0 & 3.1 & 58.9 \\
\cline { 2 - 6 } & Somewhat Agree & 447 & 22.9 & 23.1 & 82.0 \\
\cline { 2 - 6 } & Strongly Agree & 347 & 17.8 & 18.0 & 100.0 \\
\cline { 2 - 6 } & Total & 1933 & 99.1 & 100.0 & \\
\hline \hline \multirow{3}{*}{ Missing } & Don't Know & 14 & 0.7 & & \\
\cline { 2 - 6 } & Refused & 17 & 0.2 & & \\
\cline { 2 - 6 } & Total & $\mathbf{1 9 5 0}$ & $\mathbf{1 0 0 . 0}$ & & \\
\hline \hline
\end{tabular}

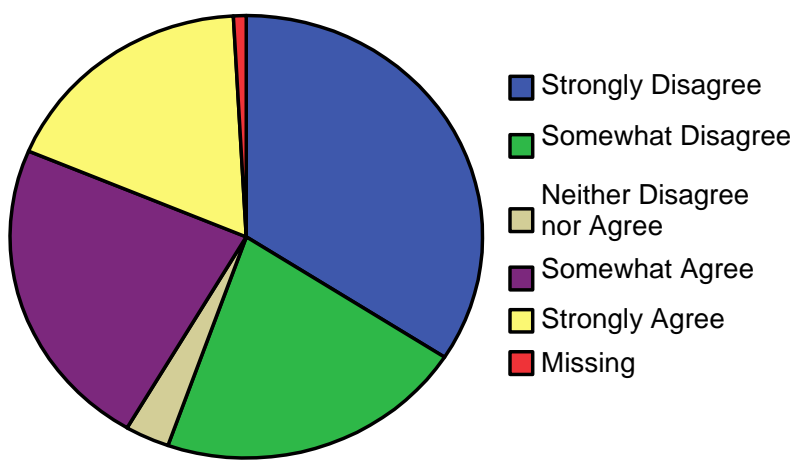

Figure 27. Contamination-Risk Correspondence Distribution
Median value $=$ somewhat agree that the presence of contamination means that risks are posed (value $=2$ ); confidence interval = $2.69 \pm 0.07$. More than half of the respondents disagree that contamination equals risk whereas 4 in 10 agree. Only 3\% have no opinion. This belief is positively correlated with whether respondents believe that they are at risk $(r=0.486)$, their estimates of risk magnitude $(r=0.511)$, and their dread of risks $(r=0.459)$. This suggests that beliefs about risk and its severity are motivated, at least in part, by beliefs about the close relationship between contamination and risks. 


\section{Risk Perception Validity}

Table 34 and Figure 28 show respondents' responses to the proposition that risk perceptions need to be better calibrated to actual risk through education.

Table 34. Responses to "Since many people perceive that there is a higher risk than is actually present, they should become better educated so that their risk perceptions would be better calibrated."

\begin{tabular}{|c|c|c|c|c|c|}
\hline \multicolumn{2}{|c|}{ Responses } & \multirow{2}{*}{ FREQUENCY } & PERCENT & $\begin{array}{c}\text { VALID } \\
\text { PERCENT }\end{array}$ & $\begin{array}{c}\text { CUMULATIVE } \\
\text { PERCENT }\end{array}$ \\
\hline \multirow{4}{*}{ Valid } & Strongly Disagree & 156 & 8.0 & 8.1 & 8.1 \\
\cline { 2 - 6 } & Somewhat Disagree & 110 & 5.6 & 5.7 & 13.9 \\
\cline { 2 - 6 } & Neither Disagree nor Agree & 73 & 3.7 & 3.8 & 17.7 \\
\cline { 2 - 6 } & Somewhat Agree & 566 & 29.0 & 29.6 & 47.3 \\
\cline { 2 - 6 } & Strongly Agree & 1010 & 51.8 & 52.7 & 100.0 \\
\cline { 2 - 6 } & Total & 1915 & 98.2 & 100.0 & \\
\hline \hline \multirow{3}{*}{ Missing } & Don't Know & 30 & 1.5 & & \\
\cline { 2 - 6 } & Refused & 5 & 0.3 & & \\
\cline { 2 - 6 } & Total & $\mathbf{1 9 5 0}$ & 100.0 & & \\
\hline & Total & & 1.8 & & \\
\hline
\end{tabular}

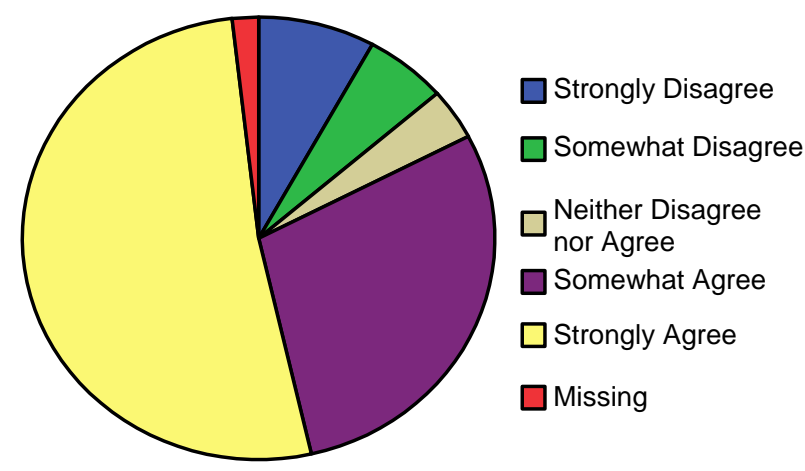

Figure 28. Risk Perception Calibration Distribution
Median Value $=$ somewhat agree $($ value $=4) ;$ confidence interval $=4.13 \pm 0.06$. More than $4 / 5$ of the respondents agree that more education is needed to better calibrate risk perception. Only $14 \%$ disagree. This finding acknowledges that public risk perception may be higher than actual risk and thus is reflected in a strong desire for accurate risk knowledge. Since this variable correlates positively with views toward DOE [trust (trust $1 \quad(r=0.246)$, trust $2 \quad(r=0.274)$, deference $(r=0.272)$, and value similarity $(r=0.260)]$, as well as the correspondence between the presence of contamination and concomitant risk ( $r=0.231)$ and the belief that the cost of risk reduction should be balanced against its benefits $(r=0.254)$, part of the explanation for this result is that DOE defenders judge public risk aversion as ill informed and correctable through education. 


\section{Co-optation}

Table 35 and Figure 29 report responses to the proposition that agencies having the right to talk citizens into accepting risk.

Table 35. Responses to "No agency has the right to talk anyone into accepting risk."

\begin{tabular}{|c|c|c|c|c|c|}
\hline \multicolumn{2}{|c|}{ Responses } & FREQUENCY & PERCENT & $\begin{array}{c}\text { VALID } \\
\text { PERCENT }\end{array}$ & $\begin{array}{c}\text { CUMULATIVE } \\
\text { PERCENT }\end{array}$ \\
\hline \multirow{4}{*}{ Valid } & Strongly Disagree & 157 & 8.1 & 8.2 & 8.2 \\
\cline { 2 - 6 } & Somewhat Disagree & 156 & 8.0 & 8.2 & 16.4 \\
\cline { 2 - 6 } & Neither Disagree nor Agree & 107 & 5.5 & 5.6 & 22.0 \\
\cline { 2 - 6 } & Somewhat Agree & 341 & 17.5 & 17.9 & 39.9 \\
\cline { 2 - 6 } & Strongly Agree & 1146 & 58.8 & 60.1 & 100.0 \\
\cline { 2 - 6 } & Total & 1907 & 97.8 & 100.0 & \\
\hline \multirow{3}{*}{ Missing } & Don't Know & 32 & 1.6 & & \\
\cline { 2 - 6 } & Refused & 11 & 0.6 & & \\
\cline { 2 - 6 } & Total & 1950 & 100.0 & & \\
\hline \hline
\end{tabular}

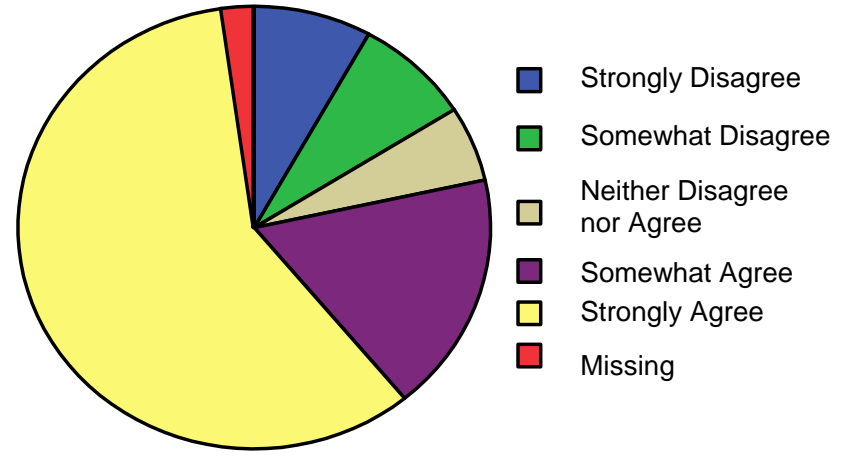

Figure 29. Cooptation Distribution
Median Value $=$ strongly agree with the unacceptability of cooptation (value $=5$ ); confidence interval $=4.13 \pm 0.06$. Almost 4 out of 5 respondents agree that no agency has the right to talk anyone into accepting risk. About $1 / 6$ of the respondent sample disagree. Clearly, voluntary and informed consent to risk exposure is preferred. The reason for its negative correlation with the correspondence between contamination and risk ( $r=-0.216)$ [i.e., the more one agrees that cooptation is unacceptable, the more one agrees that contamination does not imply risk] is unclear. 


\section{Cost Balanced Against Benefits}

Table 36 and Figure 30 show respondents' answers to the proposition that the cost of remediation must be balanced against its benefits.

\section{Table 36. Responses to "The costs of site cleanup must be balanced against the benefits."}

\begin{tabular}{|c|c|c|c|c|c||}
\hline \multicolumn{2}{|c|}{ Responses } & FREQUENCY & PERCENT & $\begin{array}{c}\text { VALID } \\
\text { PERCENT }\end{array}$ & $\begin{array}{c}\text { CUMULATIVE } \\
\text { PERCENT }\end{array}$ \\
\hline \hline \multirow{4}{*}{ Valid } & Strongly Disagree & 524 & 26.9 & 27.6 & 27.6 \\
\cline { 2 - 6 } & Somewhat Disagree & 233 & 11.9 & 12.3 & 39.9 \\
\cline { 2 - 6 } & Neither Disagree nor Agree & 89 & 4.6 & 4.7 & 44.6 \\
\cline { 2 - 6 } & Somewhat Agree & 438 & 22.5 & 23.1 & 67.7 \\
\cline { 2 - 6 } & Strongly Agree & 612 & 31.4 & 32.3 & 100.0 \\
\cline { 2 - 6 } & Total & 1896 & 97.2 & 100.0 & \\
\hline \hline \multirow{3}{*}{ Missing } & Don't Know & 49 & 2.5 & & \\
\cline { 2 - 6 } & Refused & 5 & 0.3 & & \\
\cline { 2 - 6 } & Total & 1950 & 100.0 & & \\
\hline \hline
\end{tabular}

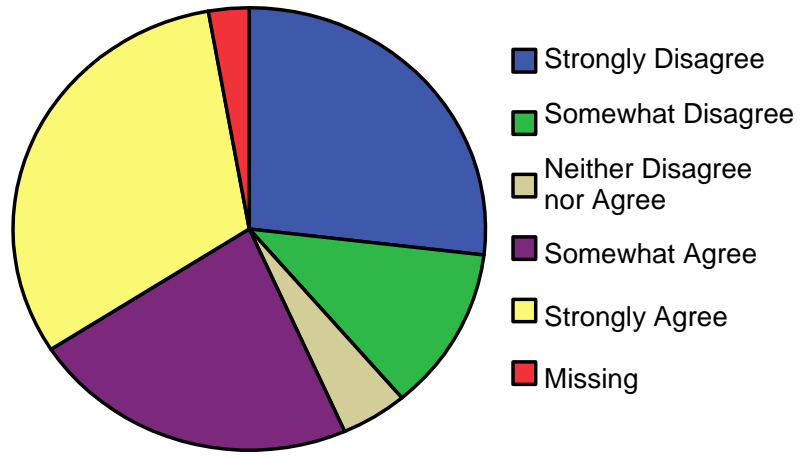

Figure 30. Cost-Benefit Balance Distribution
Median Value $=$ somewhat agree with cost balanced with benefits (value $=4$ ); confidence interval $=3.20 \pm 0.07$. These results suggest that respondents tend to have extreme opinions of this proposition (28\% strongly disagree and $32 \%$ strongly agree, for a total of $60 \%$ ). The overall judgment is about equally divided: $40 \%$ disagree and $45 \%$ agree. This variable correlates positively with the contamination-risk correspondence $(r=0.367)$ and risk perception calibration $(r=0.254)$ variables and negatively with belief of being at risk $(r=-0.202)$ and dread risk (-0.240), suggests that those who exaggerate risk need to recognize that risk must be balanced against cost. 


\section{Analysis of Risk Judgments}

Figure 31 presents, in diagrammatic form, the relationships among risk judgment heuristics as indicated by their bivariate correlations. Note that the heuristics have been grouped into three heuristic categories: risk familiarity, risk estimate, and risk management. The dashed relationships indicated those between heuristic categories. Table 37 presents a tally of these same results, also organized by heuristic category.

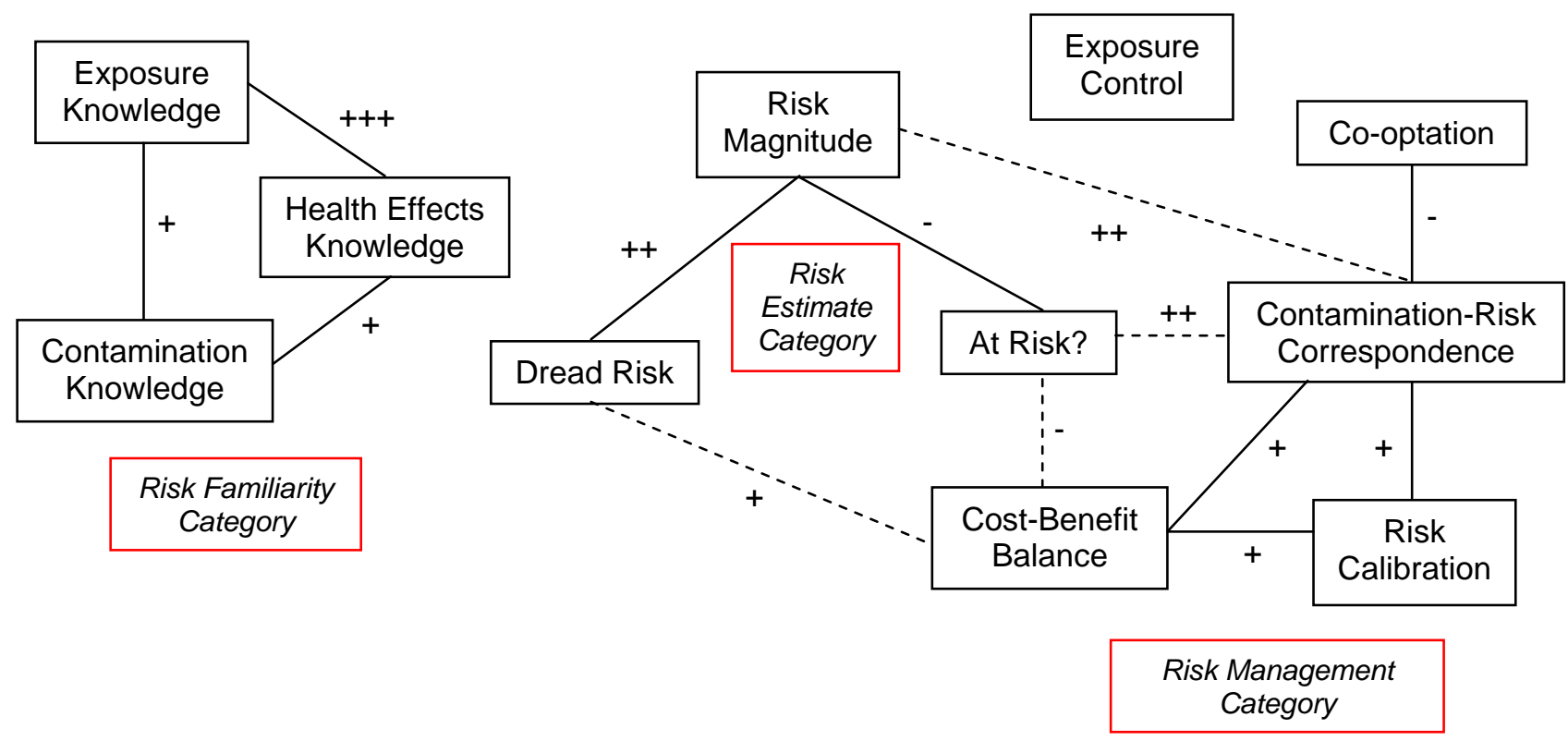

Figure 31. Risk Judgment Correlations

It is immediately obvious that the risk familiarity category is isolated from all other heuristics. Apparently, perceived familiarity with contamination, exposure, and associated health risks is judged independently of the magnitudes of these risks and how these risks should be managed. The focus of risk communication therefore need not be on the qualitative identification of sources, exposure routes, or risk but rather on the quantitative assessment of these risks and how they can best be managed.

Within the familiarity category, we find that its three heuristics are related. The correlation between health effects and exposure knowledge is particularly strong, which demonstrates that stakeholders rate their knowledge of these two areas similarly, probably because they often think of exposure and risks jointly. The weaker, though still significant correlations of these two knowledge ratings with contamination knowledge can be explained by recalling that the latter concerns knowledge history rather than knowledge per se.

Within the risk estimate heuristic category, dread risk is correlated only with the magnitude. It is intuitively obvious that the more people view a risk as dreadful, the greater they tend to judge the risk to be. It also makes sense that dread need not predict whether one believes that they are actually at risk. The other two risk estimate heuristics (belief in being at risk and risk magnitude) are also correlated, though weakly, suggesting that belief in being at risk tends to elevate the perception of the severity of that risk.

The risk management category is more complexly related. We see that stakeholders' belief in their ability to control exposure is not related to any other heuristic; this is the only heuristic that is judged completely independently of all others. This may be explained by the differentiation that stakeholders see in responsibility: the burden of risk reduction does not lie with them but with the DOE and its contractors.

We also find that judgments about the propriety of relating the presence of contamination with health risk are correlated with five other heuristics, three of which are other heuristics within the risk management 
category. The more that stakeholders judge the correspondence to be true, the more they desire education to calibrate their perceptions. This is an encouraging sign because it indicates that stakeholders are concerned enough to learn more rather than so certain of their risk that they desire no new information. Also, the more that stakeholders judge the correspondence to be true, the more they believe that the costs of remediation should be balanced against its benefits, which suggests that stakeholders may recognize that removal of all contamination is cost prohibitive (and therefore exposure controls may be acceptable if they are used in conjunction with source mitigation).

The weakly negative association between contamination-risk correspondence and stakeholders' judgments about the propriety of co-optation (talking people into accepting risks) can be explained through the moderately strong correlations between correspondence and both being at risk and risk magnitude. The more that stakeholders perceive the risks to be high, the less willing they are willing to be talked into accepting them.

We also found associations between the risk estimate and risk management heuristic categories (represented by dashed lines). Moderately strong relationships between judgments of the contaminationrisk correspondence and two of the three risk estimate heuristics suggests that the presence of contamination is a sufficient signal to indicate that risk is present and that it is possibly severe. The weakly negative correlation between dread and the propriety of balancing the cost of remediation against the benefit of reducing risk is intuitively obvious: the more a person dreads a risk, the more demanding they will be in reducing it at any cost. However, the weakly positive relationship between belief in being at risk and cost-benefit balance is harder to explain. Perhaps, the best explanation can be discerned by noting that the risk magnitude heuristic is not related to the cost-benefit balance heuristic, suggesting that merely being at risk is not sufficient justification for risk reduction at any cost.

Table 37. Risk Judgment Correlations

\begin{tabular}{|c|c|c|c|c|c|c|c|c|c|c|c|}
\hline \multirow{2}{*}{$\begin{array}{l}\text { RISK JUDGMENT } \\
\text { HEURISTIC }\end{array}$} & \multicolumn{3}{|c|}{ FAMILIARITY CATEGORY } & \multicolumn{3}{|c|}{$\begin{array}{l}\text { RISK EstIMATE } \\
\text { CATEGORY }\end{array}$} & \multicolumn{5}{|c|}{ Risk Management Category } \\
\hline & $\begin{array}{l}\text { Health } \\
\text { Effects } \\
\text { Know }\end{array}$ & $\begin{array}{c}\text { Exp } \\
\text { Know }\end{array}$ & $\begin{array}{l}\text { Contam } \\
\text { Know }\end{array}$ & Dread & $\begin{array}{l}\text { Risk } \\
\text { Mag }\end{array}$ & $\begin{array}{l}\text { At } \\
\text { Risk }\end{array}$ & $\begin{array}{l}\text { Exp } \\
\text { Contr }\end{array}$ & $\begin{array}{l}\text { Contam- } \\
\text { Risk } \\
\text { Corresp }\end{array}$ & $\begin{array}{l}\text { Risk } \\
\text { Calib }\end{array}$ & $\begin{array}{l}\text { Co- } \\
\text { opt }\end{array}$ & $\begin{array}{l}\text { Cost- } \\
\text { Ben } \\
\text { Balance }\end{array}$ \\
\hline $\begin{array}{l}\text { Health Effects } \\
\text { Knowledge }\end{array}$ & & +++ & + & & & & & & & & \\
\hline $\begin{array}{l}\text { Exposure } \\
\text { Knowledge }\end{array}$ & & & + & & & & & & & & \\
\hline \multicolumn{12}{|l|}{$\begin{array}{l}\text { Contamination } \\
\text { Knowledge }\end{array}$} \\
\hline Dread Risk & & & & & ++ & & & & & & + \\
\hline $\begin{array}{c}\text { Risk } \\
\text { Magnitude }\end{array}$ & & & & & & + & & ++ & & & \\
\hline At Risk & & & & & & & & ++ & & & - \\
\hline \multicolumn{12}{|l|}{ Exposure Control } \\
\hline $\begin{array}{l}\text { Contam-Risk } \\
\text { Correspondence }\end{array}$ & & & & & & & & & + & - & + \\
\hline $\begin{array}{c}\text { Risk } \\
\text { Calibration }\end{array}$ & & & & & & & & & & & + \\
\hline \multicolumn{12}{|l|}{$\begin{array}{l}\text { Risk Accept } \\
\text { Cooptation }\end{array}$} \\
\hline $\begin{array}{l}\text { Benefit-Cost } \\
\text { Balance }\end{array}$ & & & & & & & & & & & \\
\hline
\end{tabular}




\section{Risk Demographics}

We next investigated the possibility of correlation between demographic characteristics of stakeholder respondents and risk judgment heuristics (see Table 38). Note that the only statistically significant correlations (which were weak) were found in the five columns that are shaded (personal site employment, technical occupation, proximity of residence to site, and community residence time).

\section{Table 38. Risk Demographics}

\begin{tabular}{|c|c|c|c|c|c|c|c|c|c|c|}
\hline VARIABLE & GENDER & $\begin{array}{c}\text { YouR } \\
\text { SITE } \\
\text { EMPL }\end{array}$ & $\begin{array}{c}\text { FAMILY } \\
\text { SITE } \\
\text { EMPL } \\
\end{array}$ & $\begin{array}{l}\text { TECH } \\
\text { OcC }\end{array}$ & Prox & $\begin{array}{c}\text { COMM } \\
\text { RESIDENT } \\
\text { TIME } \\
\end{array}$ & $\begin{array}{c}\text { HOME } \\
\text { RESIDENT } \\
\text { TIME } \\
\end{array}$ & $\begin{array}{l}\text { Educ } \\
\text { LEVEL }\end{array}$ & $\begin{array}{c}\text { RENT } \\
I \\
\text { OWN } \\
\end{array}$ & $\begin{array}{c}\% \\
\text { WIND } \\
\text { DIR }\end{array}$ \\
\hline $\begin{array}{l}\text { Contamination } \\
\text { Knowledge }\end{array}$ & & + & + & & & + & & & & \\
\hline $\begin{array}{c}\text { Exposure } \\
\text { Knowledge }\end{array}$ & & + & & & & & & & & \\
\hline $\begin{array}{c}\text { Health Effects } \\
\text { Knowledge }\end{array}$ & & + & & & & & & & & \\
\hline $\begin{array}{c}\text { Contamination-Risk } \\
\text { Correspondence }\end{array}$ & & + & & + & + & & & & & \\
\hline
\end{tabular}

The correlation between the length of time that a person has lived in the community and the length of time that they have known about subsurface contamination needs no explanation. Similarly, family member site employment and working in a technical occupation correlates with contamination knowledge.

The correlation between proximity of residences to the sites and the correspondence between contamination and risk suggests that people living close by tend to believe that they are at risk simply because they are close to the contamination - a finding that is not surprising.

The correlation of site employment with health effects knowledge, exposure knowledge, contamination knowledge, and the correspondence between contamination and risk is also intuitively obvious: site workers are trained to work in and around contamination.

\section{Risk Judgment Summary and Conclusions}

The following conclusions can be drawn from this investigation into risk perception and judgment. Almost than $4 / 5$ of the population residing near these three facilities have know about subsurface contamination for a long time and more than $2 / 3$ of the population believes that they are at least potentially at risk from this contamination. Moreover, 4/10 of the population believes that the presence of contamination necessarily poses risk to them. More than $4 / 5$ believes that more information about risks is needed to better calibrate their perceptions of risk to the actual risk posed by the contamination.

Of those believing that they are at risk, $3 / 4$ believes that the risk is moderate to very high. In fact, more than $1 / 2$ believes that the risk is of major concern or terrifying. Less than $1 / 20$ of this group believes that the risk is "no big deal." About $1 / 3$ believe that they have high knowledge of how they are exposed and the health risks that result from these exposures. Another $1 / 3$ believe that they have moderate knowledge and the remaining $1 / 3$ low knowledge. Less than $1 / 4$ of the population believes that they have any significant ability to control their exposures.

Almost $4 / 5$ of the population believes that no agency has the right to co-opt the public into accepting risk. Informed and voluntary consent are required. The population is fairly equally divided between those recognizing that the costs of risk reduction should be balanced against its benefits and those believing that cost should not play a role in reducing risk to safe levels.

In considering the relationships among 11 risk judgment heuristics, we found that the three risk familiarity heuristics (pertaining to knowledge of contamination, exposure, and health risk) are considered in tandem but not in relation to the other heuristics. The remaining 8 heuristics (three in the risk estimate category and 5 in the risk management category) are inter-related. In particular, the correspondence between contamination and risk is related to 5 of the 8 heuristics and cost-benefit balance is related to 4 of them. 
We can conclude from these findings that most of the population residing near these sites is aware and concerned about the health risks from subsurface contamination. They want more information about these risks but don't want to be talked into accepting them. Instead, they want DOE and its contractors to take responsibility for reducing the risk to safe levels. The division on cost-benefit balance suggests that a combination of exposure controls with source reduction may be acceptable. 


\section{CHAPTER 7}

\section{FINDINGS ON TRUST JUDGMENTS}

\section{Introduction}

Our next investigation into the beliefs and opinions of stakeholders residing near these sites concerns the trust they have of DOE and each other. An investigation into trust is important to understanding how stakeholders feel about bioremediation because trust necessarily involves risk acceptance.

\section{Analysis of Trust Judgments}

Trust of DOE Decision-Making

Table 39 and Figure 32 show respondent answers to trust of DOE to make decisions about remediation of contamination.

Table 39. Responses to "How much do you trust DOE to make decisions about the cleanup of contamination at the site?"

\begin{tabular}{|c|c|c|c|c|}
\hline RESPONSES & FREQUENCY & Percent & VALID PERCENT & Cumulative Percent \\
\hline Strongly Distrust & 448 & 23.0 & 23.0 & 23.0 \\
\hline Somewhat Distrust & 527 & 27.0 & 27.0 & 50.0 \\
\hline Somewhat Trust & 611 & 31.3 & 31.3 & 81.3 \\
\hline Strongly Trust & 364 & 18.7 & 18.7 & 100.0 \\
\hline Total & 1950 & 100.0 & 100.0 & \\
\hline
\end{tabular}

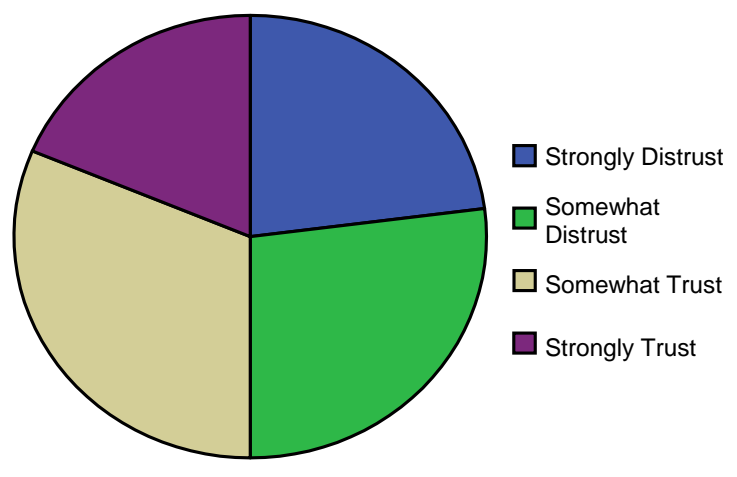

Figure 32. DOE Decision-Making Trust Distribution
Median value $=$ between somewhat trust and distrust and somewhat distrust (value $=2.5$ ); confidence interval $=2.46 \pm 0.05$. Stakeholders' trust of DOE to make an appropriate decision perform an adequate site cleanup is equally divided between those who trust and those who distrust. However, fewer strongly trust DOE than any other measure of trust (see below).

DOE decision-making trust correlates negatively with four of the eight risk judgment measures: beliefs about being at risk $(r=-0.400)$, risk magnitude $(r=-$ 0.452), dread $(r=-0.414)$, contamination-risk correspondence ( $r=-0.558)$, and, more weakly, site employment $(r=-0.256)$. This implies that trustbuilding efforts are also important to reducing stakeholders' risk judgments. 


\section{Trust of DOE Management of the Site}

Table 40 and Figure 33 report respondent answers to trust of DOE to make decision on behalf of stakeholders regarding site management.

Table 40. Responses to "How much do you trust DOE officials to make decisions on your behalf to manage the site properly?"

\begin{tabular}{|c|c|c|c|c|c|}
\hline \multicolumn{2}{|r|}{ RESPONSES } & FREQUENCY & Percent & $\begin{array}{c}\text { VALID } \\
\text { PERCENT }\end{array}$ & $\begin{array}{c}\text { Cumulative } \\
\text { PERCENT }\end{array}$ \\
\hline \multirow{6}{*}{ Valid } & Strongly Distrust & 469 & 24.1 & 24.3 & 24.3 \\
\hline & Somewhat Distrust & 479 & 24.6 & 24.8 & 49.0 \\
\hline & Neither Trust or Distrust & 218 & 11.2 & 11.3 & 60.3 \\
\hline & Somewhat Trust & 489 & 25.1 & 25.3 & 85.6 \\
\hline & Strongly Trust & 279 & 14.3 & 14.4 & 100.0 \\
\hline & Total & 1934 & 99.2 & 100.0 & \\
\hline \multirow{3}{*}{ Missing } & Don't Know & 15 & 0.8 & & \\
\hline & Refused & 1 & 0.1 & & \\
\hline & Total & 16 & 0.8 & & \\
\hline \multicolumn{2}{|r|}{ Total } & 1950 & 100.0 & & \\
\hline
\end{tabular}

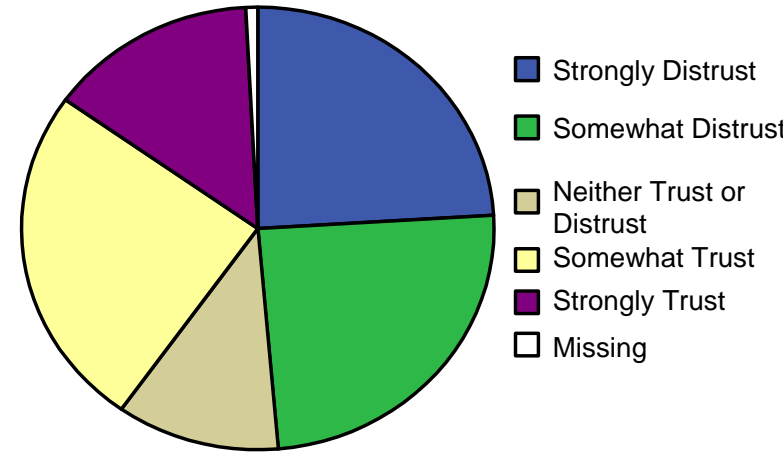

Figure 33. DOE Site Management Trust Distribution
Median value $=$ neither trust nor distrust (value $=3$ ); confidence interval $=2.81 \pm 0.06$. Again, about half of the respondents distrust DOE to act on their behalf and the other half either trust or have no opinion.

Site management trust correlates quite strongly with the decision trust measure $(r=0.805)$. It is no surprise then that site management trust correlates the same five risk judgment variables: beliefs about being at risk $(r=0.427)$, risk magnitude $(r=0.453)$, dread $(r=0.431)$, contamination-risk correspondence $(r=0.560)$, exposure controllability $(\mathrm{r}=0.202)$, and, weakly, site employment $(r=0.204)$. This confirms our previous recommendation that trust building is necessary to reduce stakeholders' risk judgments. 


\section{Deference to DOE}

Table 41 and Figure 34 show respondent answers to willingness to defer to DOE officials.

Table 41. Responses to "How would you rate your willingness to defer to DOE officials to make decisions on your behalf to manage these risks properly?"

\begin{tabular}{|c|c|c|c|c|c|}
\hline \multicolumn{2}{|c|}{ RESPONSES } & \multirow{2}{*}{$\frac{\text { FREQUENCY }}{4333}$} & \multirow{2}{*}{$\begin{array}{r}\text { PERCENT } \\
22.2\end{array}$} & \multirow{2}{*}{$\begin{array}{c}\text { VALID PERCENT } \\
22.7\end{array}$} & \multirow{2}{*}{$\begin{array}{c}\begin{array}{c}\text { Cumulative } \\
\text { Percent }\end{array} \\
22.7\end{array}$} \\
\hline \multirow{6}{*}{ Valid } & Very Low & & & & \\
\hline & Low & 343 & 17.6 & 18.0 & 40.7 \\
\hline & Moderate & 660 & 33.8 & 34.6 & 75.4 \\
\hline & High & 272 & 13.9 & 14.3 & 89.7 \\
\hline & Very High & 197 & 10.1 & 10.3 & 100.0 \\
\hline & Total & 1905 & 97.7 & 100.0 & \\
\hline \multirow{3}{*}{ Missing } & Don't Know & 40 & 2.1 & & \\
\hline & Refused & 5 & 0.3 & & \\
\hline & Total & 45 & 2.3 & & \\
\hline \multicolumn{2}{|c|}{ Total } & 1950 & 100.0 & & \\
\hline
\end{tabular}

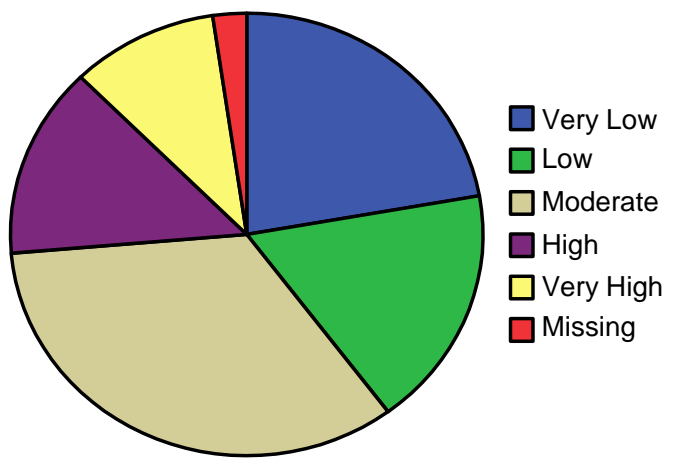

Figure 34. DOE Deference Distribution
Median value $=$ moderate willingness to defer to DOE's remediation decisions (value $=3$ ); confidence interval $=2.71 \pm 0.06$. Less than $25 \%$ of the respondents are highly willing to defer to DOE. Slightly more than $40 \%$ are unwilling to defer. The variable correlates with several other trust measures: decision trust $(r=0.635)$, site management trust $(r=0.698)$, technical competence $(r=0.526)$, value similarity $(r=0.652)$, and efficacy $(r=0.423)$, suggesting that stakeholders view these various measures of trust similarly. Deference also correlates, but more weakly, with social deference $(r=0.222)$.

This deference measure correlates negatively with four risk judgment heuristics: belief about being at risk ( $r=-0.351)$, risk magnitude $(r=-0.345)$, dread $(\mathrm{r}=-0.316)$, and contamination-risk correspondence $(r=-0.474)$. Those who trust DOE tend to view health risks of contamination as less a problem. This finding lends support for our proposition that trust and risk acceptance are tapping into the same sentiment. 


\section{Technical Competence of DOE}

Table 42 and Figure 34 report respondents' judgments of DOE managers' technical competence.

Table 42. Responses to "How would you judge the technical competence of DOE managers to manage these risks properly?"

\begin{tabular}{|c|c|c|c|c|c|}
\hline \multicolumn{2}{|c|}{ RESPONSES } & FREQUENCY & Percent & VAlid PERcent & $\begin{array}{c}\text { Cumulative } \\
\text { PERCENT }\end{array}$ \\
\hline \multirow{6}{*}{ Valid } & Very Low & 187 & 9.6 & 10.3 & 10.3 \\
\hline & Low & 212 & 10.9 & 11.6 & 21.9 \\
\hline & Moderate & 662 & 33.9 & 36.4 & 58.3 \\
\hline & High & 486 & 24.9 & 26.7 & 85.0 \\
\hline & Very High & 273 & 14.0 & 15.0 & 100.0 \\
\hline & Total & 1820 & 93.3 & 100.0 & \\
\hline \multirow{3}{*}{ Missing } & Don't Know & 127 & 6.5 & & \\
\hline & Refused & 3 & 0.2 & & \\
\hline & Total & 130 & 6.7 & & \\
\hline \multicolumn{2}{|c|}{ Total } & 1950 & 100.0 & & \\
\hline
\end{tabular}

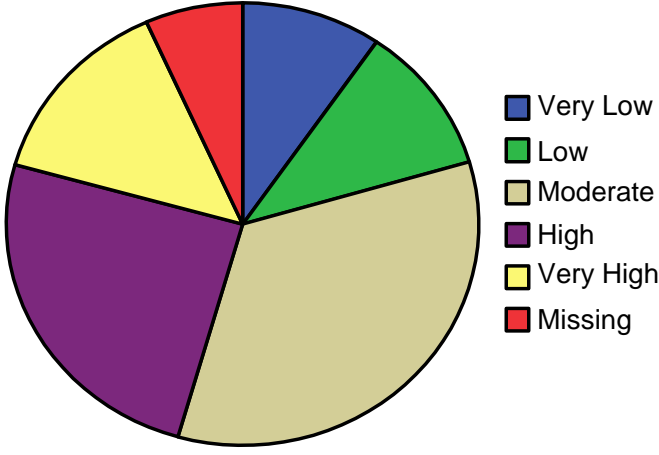

Figure 35. DOE Technical Competence Distribution
Median value $=$ moderate judgment of the technical competence of DOE managers (value = 3); confidence interval $=3.25 \pm 0.05$. Though nearly $22 \%$ of respondents judged the DOE managers technically incompetent to manage contamination risks, twice that number judge them as competent.

Technical competence correlates well with other trust measures: decision trust $(r=0.475)$, site management trust $(r=0.526)$, deference $(r=0.526)$, value similarity $(r=0.508)$, and efficacy $(r=0.333)$. Again, this demonstrates the similarity of these various trust measures in stakeholders' trust judgments of DOE.

Technical competence also correlates weakly with social technical competence $(r=0.233)$, indicating a tendency of stakeholders to group their judgments of technical competence both parties.

Technical competence correlates negatively with four risk judgment heuristics: belief about being at risk $(r=-0.284)$, risk magnitude $(r=-0.256)$, dread $(r=-0.200)$, and contamination-risk correspondence $(r=-0.353)$. This result confirms the relationship between trust and risk judgments. 
DOE Value Similarity

Table 43 and Figure 36 report respondents' judgments of the similarity of public and DOE values.

Table 43. Responses to "How would you rate the degree to which DOE managers share your values when it comes to managing these risks properly?"

\begin{tabular}{|c|c|c|c|c|c|}
\hline \multicolumn{2}{|r|}{ RESPONSES } & FREQUENCY & Percent & $\begin{array}{c}\text { VALID } \\
\text { PERCENT }\end{array}$ & $\begin{array}{c}\text { CUMULATIVE } \\
\text { PERCENT }\end{array}$ \\
\hline \multirow{6}{*}{ Valid } & Very Different & 452 & 23.2 & 24.5 & 24.5 \\
\hline & Somewhat Different & 328 & 16.8 & 17.8 & 42.3 \\
\hline & Mixed & 405 & 20.8 & 21.9 & 64.2 \\
\hline & Somewhat Similar & 395 & 20.3 & 21.4 & 85.6 \\
\hline & Very Similar & 266 & 13.6 & 14.4 & 100.0 \\
\hline & Total & 1846 & 94.7 & 100.0 & \\
\hline \multirow{3}{*}{ Missing } & Don't Know & 97 & 5.0 & & \\
\hline & Refused & 7 & 0.3 & & \\
\hline & Total & 104 & 5.3 & & \\
\hline \multicolumn{2}{|r|}{ Total } & 1950 & 100.0 & & \\
\hline
\end{tabular}

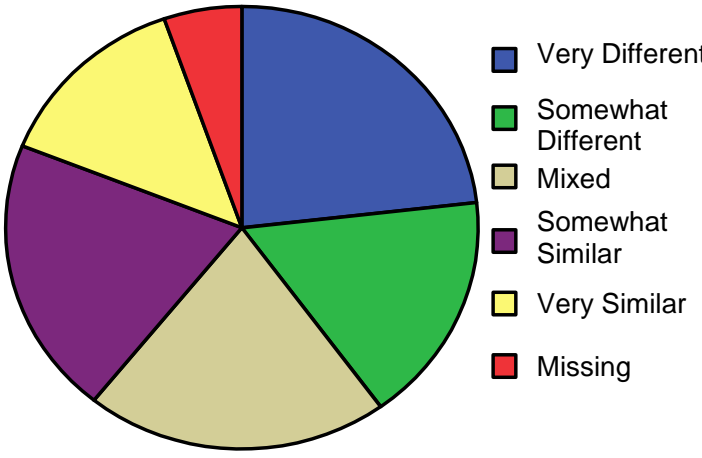

Figure 36. DOE Value Similarity Distribution
Median Value $=\mathrm{a}$ mixed of shared and not shared values (value $=3$ ); confidence interval $=$ $2.83 \pm 0.06$. Though about $36 \%$ of respondents believe that DOE share their values, $42 \%$ disagree.

Value similarity correlates positively with decision trust $(r=0.670)$, site management $(r=0.705)$, deference $(r=0.652)$, technical competence $(r=0.508)$, and efficacy $(r=0.448)$, similar to other measures of trust.

It also weakly correlates with social value similarity $(r=0.200)$, social technical competence $(r=0.200)$, and overall social trust $(r=0.244)$.

Value similarity correlates negatively with four risk judgment variables: at risk $(r=-0.360)$, risk magnitude ( $r=-0.380)$, dread $(r=-0.200)$, and contamination-risk correspondence $(r=-0.506)$. 


\section{DOE Efficacy}

Table 44 and Figure 37 show respondents' belief in the degree of their influence over DOE's risk management.

\section{Table 44. Responses to "How would you rate the degree of influence that you have over how DOE manages these risks?"}

\begin{tabular}{|c|c|c|c|c|c|}
\hline \multicolumn{2}{|c|}{ RESPONSES } & FREQUENCY & PERCENT & VALid PeRcent & $\begin{array}{c}\text { Cumulative } \\
\text { PFRCFNT }\end{array}$ \\
\hline \multirow{6}{*}{ Valid } & Very Low & 1016 & 52.1 & 52.8 & 52.8 \\
\hline & Low & 446 & 22.9 & 23.2 & 75.9 \\
\hline & Moderate & 306 & 15.7 & 15.9 & 91.8 \\
\hline & High & 106 & 5.4 & 5.5 & 97.4 \\
\hline & Very High & 51 & 2.6 & 2.6 & 100.0 \\
\hline & Total & 1925 & 98.7 & 100.0 & \\
\hline \multirow{3}{*}{ Missing } & Don't Know & 21 & 1.1 & & \\
\hline & Refused & 4 & 0.3 & & \\
\hline & Total & 25 & 1.3 & & \\
\hline \multicolumn{2}{|c|}{ Total } & 1950 & 100.0 & & \\
\hline
\end{tabular}

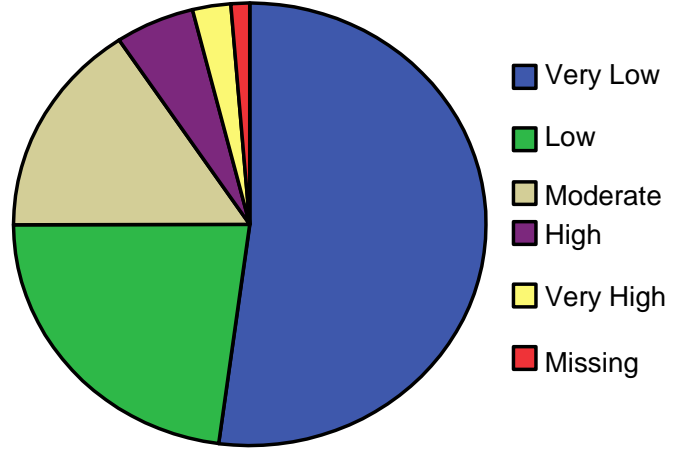

Figure 37. DOE Efficacy Distribution
Median Value = low influence (value $=2$ ); confidence interval $=1.82 \pm 0.05$. Almost $76 \%$ of respondents believe that they have low or very low influence. Only slightly over $8 \%$ believe that they have high influence. This finding, we believe, presents a serious challenge to DOE in gaining public acceptance of bioremediation. The public apparently feels more like a hapless victim than a change agent participation in the reduction of risk.

Efficacy correlates with decision trust $(r=0.414)$, site management trust $(r=0.482)$, deference $(r=0.423)$, technical competence $(r=0.333)$, and value similarity $(r=0.448)$, once again confirming the apparent similarity of these various trust measures.

Efficacy correlates negatively, but relatively weakly, with two of the risk perception heuristics: belief of being at risk $(r=-0.213)$ and contamination-risk correspondence $(r=-0.317)$. This suggests a problematic connection between fear of risk and powerlessness to influence its reduction. 


\section{Social Trust}

Table 45 and Figure 38 reports respondents' trust of other stakeholders.

Table 45. Responses to "How much do you trust other stakeholders to make decisions on your behalf to manage the risks of subsurface radioactive contamination properly?"

\begin{tabular}{|c|c|c|c|c|c|}
\hline \multicolumn{2}{|r|}{ RESPONSES } & FREQUENCY & PERCENT & $\begin{array}{c}\text { VALID } \\
\text { PERCENT }\end{array}$ & $\begin{array}{c}\text { Cumulative } \\
\text { PERCENT }\end{array}$ \\
\hline \multirow{6}{*}{ Valid } & Strongly Distrust & 271 & 13.9 & 14.5 & 14.5 \\
\hline & Distrust & 483 & 24.8 & 25.9 & 40.4 \\
\hline & Neither Trust nor Distrust & 419 & 21.5 & 22.4 & 62.8 \\
\hline & Trust & 576 & 29.5 & 30.8 & 93.6 \\
\hline & Strongly Trust & 119 & 6.1 & 6.4 & 100.0 \\
\hline & Total & 1868 & 95.8 & 100.0 & \\
\hline \multirow{3}{*}{ Missing } & Don't Know & 68 & 3.5 & & \\
\hline & Refused & 14 & 0.7 & & \\
\hline & Total & 82 & 4.2 & & \\
\hline \multicolumn{2}{|r|}{ "Total } & 1950 & 100.0 & & \\
\hline
\end{tabular}

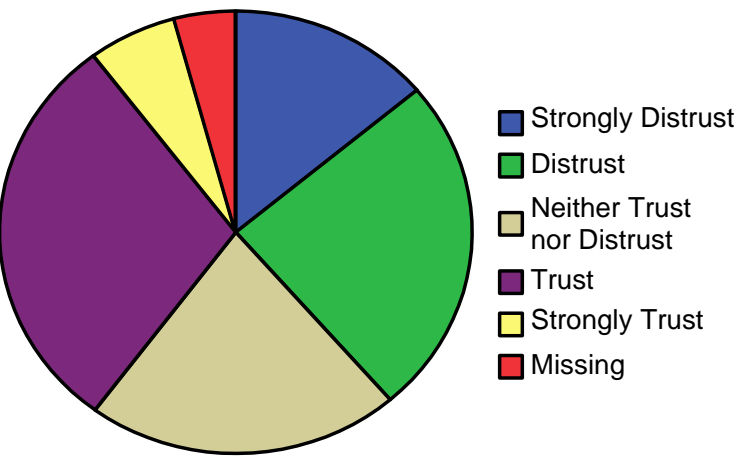

Figure 38. Social Trust Distribution
Median Value $=$ neither trust of distrust other stakeholders (value $=3$ ); confidence interval $=$ 2.89 \pm 0.05 . Respondents are about equally divided on this trust measure, with about $40 \%$ of respondents trusting and $40 \%$ distrusting other stakeholders to make decisions on their behalf.

Social trust correlates positively with social deference $(r=0.548)$, social technical competence $(r=0.531)$, and social value similarity $(r=0.432))$. As in the case of DOE trust measures, stakeholders tend to group social trust measures as well.

Social trust correlates much more weakly with DOE decision trust $(r=0.260)$, DOE site management trust $(r=0.310)$, DOE technical competence $(r=0.220)$, and DOE value similarity $(r=0.244)$.

Social trust correlates negatively with risk magnitude $(r=-0.227)$. The more stakeholders judge risk as high, the more they distrust each other to manage it. Based on the relatively high correlation of social trust with social technical competence, this correlation may be based on their judgments that expert technical knowledge is required to mitigate these risks. 


\section{Social Deference}

Table 46 and Figure 39 reports respondents' willingness to defer to other stakeholders.

Table 46. Responses to "How would you rate your willingness to defer to other stakeholders to make decision on your behalf to manage the risks of subsurface radioactive contamination properly?"

\begin{tabular}{|c|c|c|c|c|c|}
\hline \multicolumn{2}{|c|}{ RESPONSES } & FREQUENCY & Percent & VAlid Percent & $\begin{array}{c}\text { Cumulative } \\
\text { PERCENT }\end{array}$ \\
\hline \multirow{6}{*}{ Valid } & Very Low & 321 & 16.5 & 17.4 & 17.4 \\
\hline & Low & 377 & 19.3 & 20.4 & 37.9 \\
\hline & Moderate & 845 & 43.3 & 45.8 & 83.7 \\
\hline & High & 216 & 11.1 & 11.7 & 95.4 \\
\hline & Very High & 85 & 4.4 & 4.6 & 100.0 \\
\hline & Total & 1844 & 94.6 & 100.0 & \\
\hline \multirow{3}{*}{ Missing } & Don't Know & 92 & 4.7 & & \\
\hline & Refused & 14 & 0.7 & & \\
\hline & Total & 106 & 5.4 & & \\
\hline \multicolumn{2}{|c|}{ Total } & 1950 & 100.0 & & \\
\hline
\end{tabular}

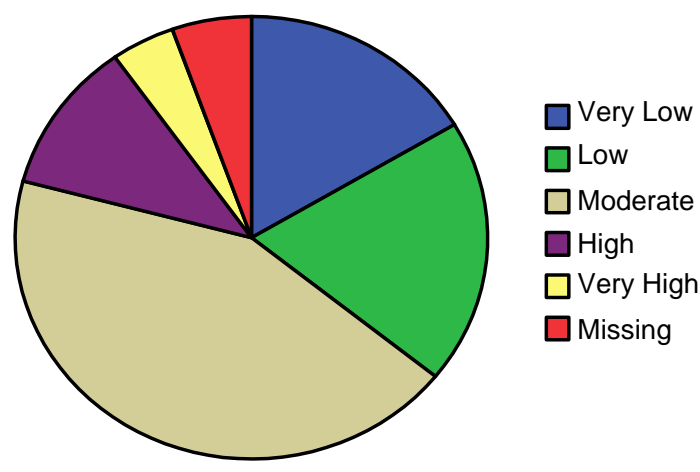

Figure 39. Social Deference Distribution
Median Value $=$ moderate willingness to defer to other stakeholders (value $=3$ ); confidence interval $=2.66 \pm 0.05$. Almost $38 \%$ of respondents are unwilling to defer whereas less than $16 \%$ are willingness.

Social deference correlates with social trust $(r=0.548)$, social technical competence $(r=0.567)$, and value similarity $(r=0.374))$.

Social deference weakly correlates with DOE deference $(r=0.222)$. 


\section{Social Technical Competence}

Table 47 and Figure 40 reports respondents' judgments of the technical competence of other stakeholders.

Table 47. Response to "How would you judge the technical competence of other stakeholders to make decision on your behalf to manage the risks of subsurface radioactive contamination properly?"

\begin{tabular}{|c|c|c|c|c|c|}
\hline \multicolumn{2}{|c|}{ RESPONSES } & FREQUENCY & PERCENT & VALID PERCENT & $\begin{array}{c}\text { Cumulative } \\
\text { PERCENT }\end{array}$ \\
\hline \multirow{6}{*}{ Valid } & Very Low & 240 & 12.3 & 14.2 & 14.2 \\
\hline & Low & 338 & 17.3 & 20.0 & 34.2 \\
\hline & Moderate & 774 & 39.7 & 45.8 & 80.0 \\
\hline & High & 242 & 12.4 & 14.3 & 94.3 \\
\hline & Very High & 96 & 4.9 & 5.7 & 100.0 \\
\hline & Total & 1690 & 86.7 & 100.0 & \\
\hline \multirow{3}{*}{ Missing } & Don't Know & 235 & 12.1 & & \\
\hline & Refused & 25 & 1.3 & & \\
\hline & Total & 260 & 13.3 & & \\
\hline \multicolumn{2}{|c|}{ Total } & 1950 & 100.0 & & \\
\hline
\end{tabular}

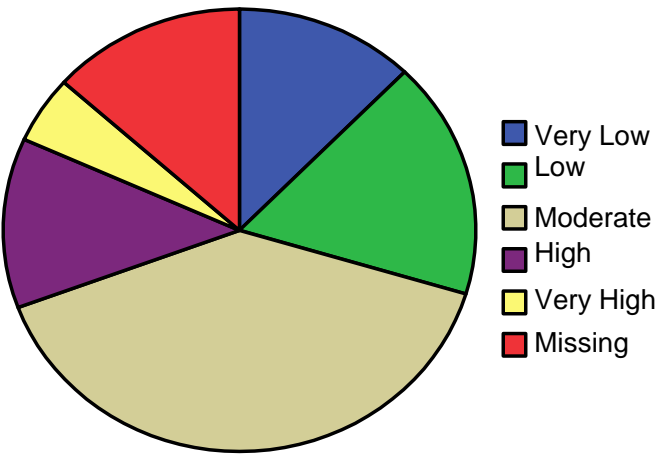

Figure 40. Social Technical Competence Distribution
Median Value $=$ moderate technical competence stakeholders (value $=3$ ); confidence interval = $2.77 \pm 0.05$. More than $34 \%$ of respondents rate the technical competence of fellow stakeholders as low; less than $16 \%$ believe that other stakeholders are competent.

Social technical competence correlates with social trust $(r=0.531)$, deference $(r=0.567)$, and value similarity $(r=0.398)$.

It also correlates weakly with DOE technical competence $(r=0.233)$ and value similarity $(r=0.200)$. 


\section{Social Value Similarity}

Table 48 and Figure 41 report respondents' judgments of the degree to which they share values with other stakeholders.

Table 48. Responses to "How would you rate the degree to which other stakeholders share your values when it comes to managing the risks of subsurface radioactive contamination properly?"

\begin{tabular}{|c|c|c|c|c|c||}
\hline \multicolumn{2}{|c|}{ Responses } & \multirow{2}{*}{ FREQUENCY } & PERCENT & $\begin{array}{c}\text { VALID } \\
\text { PERCENT }\end{array}$ & $\begin{array}{c}\text { CUMULATIVE } \\
\text { PERCENT }\end{array}$ \\
\hline \hline \multirow{4}{*}{ Valid } & Very Different & 179 & 9.2 & 10.3 & 10.3 \\
\cline { 2 - 6 } & Somewhat Different & 246 & 12.6 & 14.1 & 24.4 \\
\cline { 2 - 6 } & Mixed & 640 & 32.8 & 36.7 & 61.1 \\
\cline { 2 - 6 } & Somewhat Similar & 461 & 23.6 & 26.4 & 87.6 \\
\cline { 2 - 6 } & Very Similar & 217 & 11.1 & 12.4 & 100.0 \\
\cline { 2 - 6 } & Total & 1743 & 89.4 & 100.0 & \\
\hline \multirow{3}{*}{ Missing } & Don't Know & 189 & 9.7 & & \\
\cline { 2 - 6 } & Refused & 18 & 0.9 & & \\
\cline { 2 - 6 } & Total & 207 & 10.6 & & \\
\hline \hline \multicolumn{2}{|c|}{} & Total & 100.0 & & \\
\hline
\end{tabular}

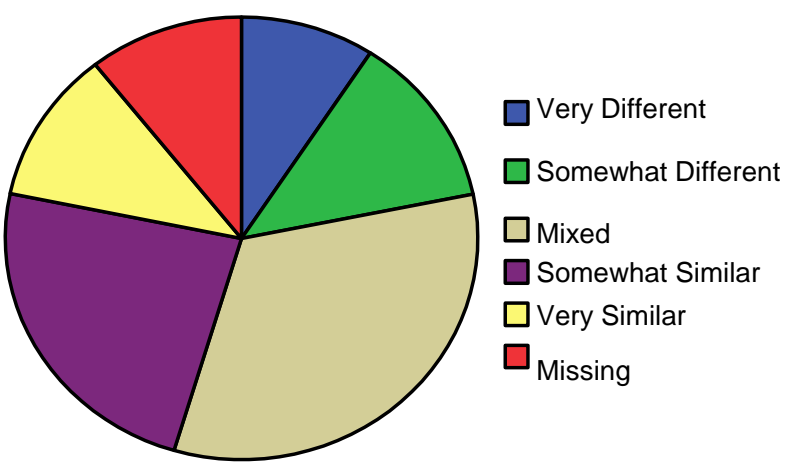

Figure 41. Social Value Similarity Distribution
Median Value $=$ mixed shared and not shared values (value $=3$ ); confidence interval = $3.17 \pm 0.05$. Almost $39 \%$ of respondents judge that they share values with other stakeholders but 24\% disagree.

Social value similarity correlates with social trust $(r=0.432)$, social deference $(r=0.374)$, and social technical competence $(r=0.398)$ ).

It also correlates weakly with DOE value similarity $(r=0.200)$. 


\section{DOE Trust Statistics and Correlations}

Tables 49 and 50 summarize DOE trust statistics and correlations, respectively.

Table 49. DOE Trust Statistics

\begin{tabular}{|c||c|c|c|c|c|}
\hline Trust MEAsuRE & $\begin{array}{c}\text { \# OF } \\
\text { RESPONSES }\end{array}$ & MEAN & MEDIAN & MoDE & $\begin{array}{c}\text { STANDARD } \\
\text { DEVIATION }\end{array}$ \\
\hline \hline Technical Competence & 1820 & 3.25 & 3 (moderate) & 3 (moderate) & 1.16 \\
\hline Value Similarity & 1846 & 2.83 & 3 (mixed) & 1 (very low) & 1.39 \\
\hline Trust & 1950 & 2.46 & 2.5 (slight distrust) & 3 (between)) & 1.04 \\
\hline Deference & 1905 & 2.71 & 3 (moderate) & 3 (moderate) & 1.25 \\
\hline Efficacy & 1925 & 1.82 & 1 (very low influence) & 1 (very low) & 1.05 \\
\hline
\end{tabular}

These results reinforce our previous findings that stakeholders' trust of DOE is mixed. Not surprisingly, judgments of its technical competence exceed judgments of value similarity. In fact, the mode proves that more people judge DOE as having very low value similarity than any other single judgment. Likewise, stakeholders generally believe that they have very little influence over DOE site remediation decisions and operations.

Table 50. DOE Trust Correlations

\begin{tabular}{|c|c|c|c|c|c|}
\hline \multirow{2}{*}{ TRUST MEASURE } & \multicolumn{3}{|c|}{ TRUST } & \multirow{2}{*}{ DEFERENCE } & \multirow{2}{*}{ EFFICACY } \\
\hline & $\begin{array}{c}\text { Technical } \\
\text { Competence }\end{array}$ & $\begin{array}{c}\text { Value } \\
\text { Similarity }\end{array}$ & $\begin{array}{l}\text { Overall } \\
\text { Trust }\end{array}$ & & \\
\hline Technical Competence & & ++ & ++ & ++ & + \\
\hline Value Similarity & & & +++ & +++ & ++ \\
\hline Overall Trust & & & & +++ & ++ \\
\hline Deference & & & & & ++ \\
\hline
\end{tabular}

Figure 42 diagramitically illustrates these correlations.

$+++$

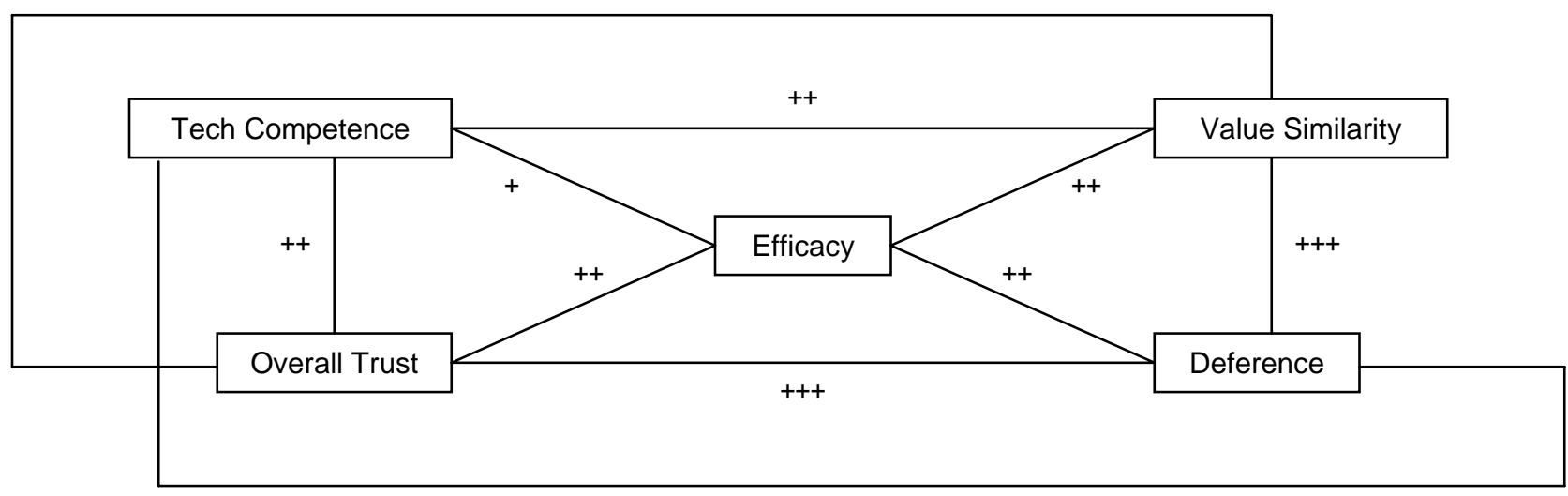

$++$

Figure 42. DOE Trust Correlations 
This diagram makes clear that the entire trust network is symmetrical and centered on efficacy. Stakeholders' beliefs that they can influence DOE risk management decision is tied to all other trust measures. To avoid feelings of haplessness and powerlessness (and concomitant frustration and fear), DOE should do more to build trust.

The correlation results also demonstrate that the various measures of DOE trust covary and essentially measure the same phenomenon. Value similarity influences the trust network slightly more than technical competence.

Moreover, DOE trust and stakeholders willingness to trust DOE also covary, suggesting that deference requires trust. Conversely, those who don't trust DOE also believe that they little influence over DOE but yet are unwilling to defer. This is a bad situation that could lead to frustration and anger. It is plain to see that if DOE wants stakeholders to defer to their discretion and expertise, it must build trust.

\section{Social Trust Statistics and Correlations}

Tables 51 and Table 52 summarize social trust statistics and correlations, respectively.

Table 51. Social Trust Statistics

\begin{tabular}{|c||c|c|c|c|c|}
\hline TRUST MEASURE & NUMBER & MEAN & MEDIAN & MODE & $\begin{array}{c}\text { STANDARD } \\
\text { DEVIATION }\end{array}$ \\
\hline \hline Social Technical Competence & 1690 & 2.77 & 3 & 3 & 1.04 \\
\hline Social Value Similarity & 1743 & 3.17 & 3 & 3 & 1.13 \\
\hline Social Trust & 1868 & 2.89 & 3 & 4 & 1.18 \\
\hline Social Deference & 1844 & 2.66 & 3 & 3 & 1.04 \\
\hline
\end{tabular}

As anticipated, stakeholders view their value similarity as more trustworthy than their technical competence, which is the reverse of their judgments of DOE. It is also noteworthy that their willingness to defer to other stakeholders is about the same as their willingness to defer to DOE. This can be explained by the importance of shared values. Therefore, DOE must not only demonstrate its technical competence but also that it cares about contamination and risks in the same ways as the public.

Table 52. Social Trust Correlations

\begin{tabular}{|c||c|c|c|c|c||}
\hline \multirow{2}{*}{ TRUST MEASURE } & \multicolumn{3}{|c||}{ TRUST } & DEFERENCE & EfFICACY \\
\cline { 2 - 6 } & $\begin{array}{c}\text { Technical } \\
\text { Competence }\end{array}$ & $\begin{array}{c}\text { Value } \\
\text { Similarity }\end{array}$ & $\begin{array}{c}\text { Overall } \\
\text { Trust }\end{array}$ & Deference & Efficacy \\
\hline \hline Technical Competence & & + & $\mathbf{+ +}$ & $\mathbf{+ +}$ & \\
\hline Value Similarity & & & ++ & + & \\
\hline Overall Trust & & & & +++ & \\
\hline Deference & & & & & \\
\hline
\end{tabular}

It is also worth noting that the strength of the correlations among social trust measures is weaker than it is among DOE trust measures, though the symmetry still holds. This suggests that social trust is a more complex and subtle phenomenon among stakeholders near these sites than it is toward DOE itself.

A somewhat surprising finding is that social deference is correlated slightly more strongly with technical competence than to value similarity. We are unable to explain this finding.

Figure 37 presents a diagram of the correlative relationships. Here we see no connections to efficacy, which can be interpreted as stakeholders do not equate their ability to influence DOE as connected to trust of their fellow stakeholders. Efficacy is thus judged purely in terms of their feelings about DOE. 


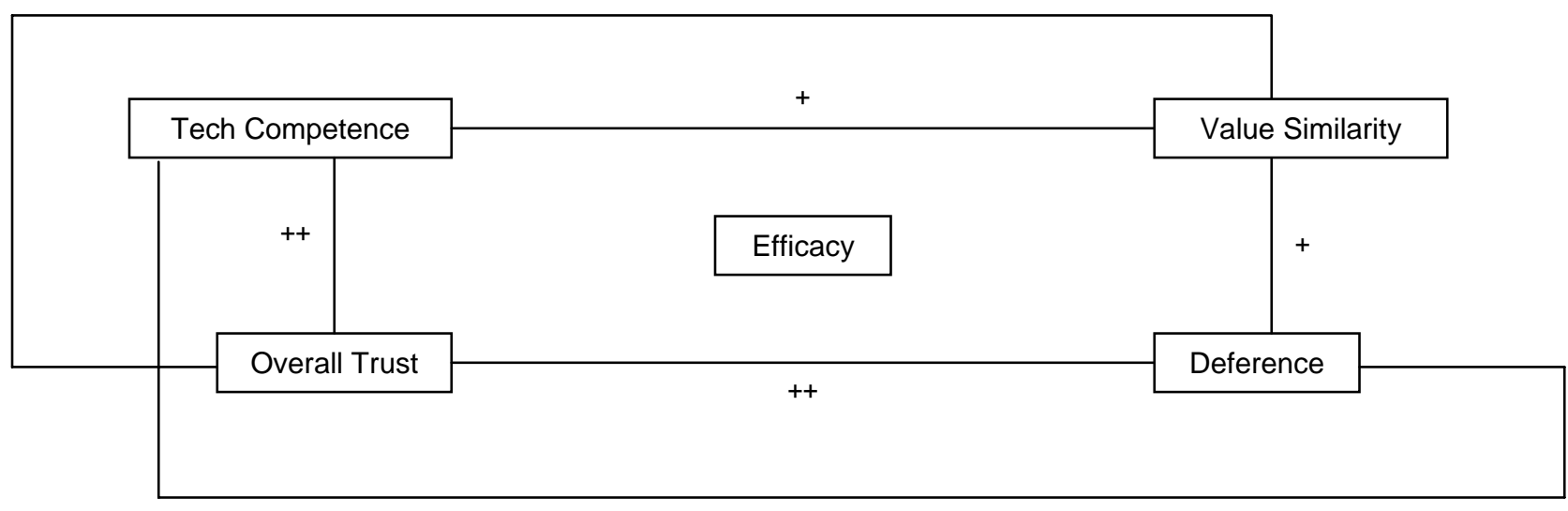

$++$

Figure 43. Social Trust Correlations

\section{DOE and Social Trust Correlations}

Table 53 and Figure 38 summarize the correlations between DOE and social trust measures.

Table 53. DOE and Social Trust Correlations

\begin{tabular}{|c||c|c|c|c|}
\hline TRUST MEASURE & $\begin{array}{c}\text { DOE Technical } \\
\text { Competence }\end{array}$ & $\begin{array}{c}\text { DOE Value } \\
\text { Similarity }\end{array}$ & $\begin{array}{c}\text { DOE Overall } \\
\text { Trust }\end{array}$ & DOE Deference \\
\hline \hline Social Technical Competence & + & + & & \\
\hline Social Value Similarity & & + & & \\
\hline Social Trust & + & + & + & \\
\hline Social Deference & & & & + \\
\hline
\end{tabular}

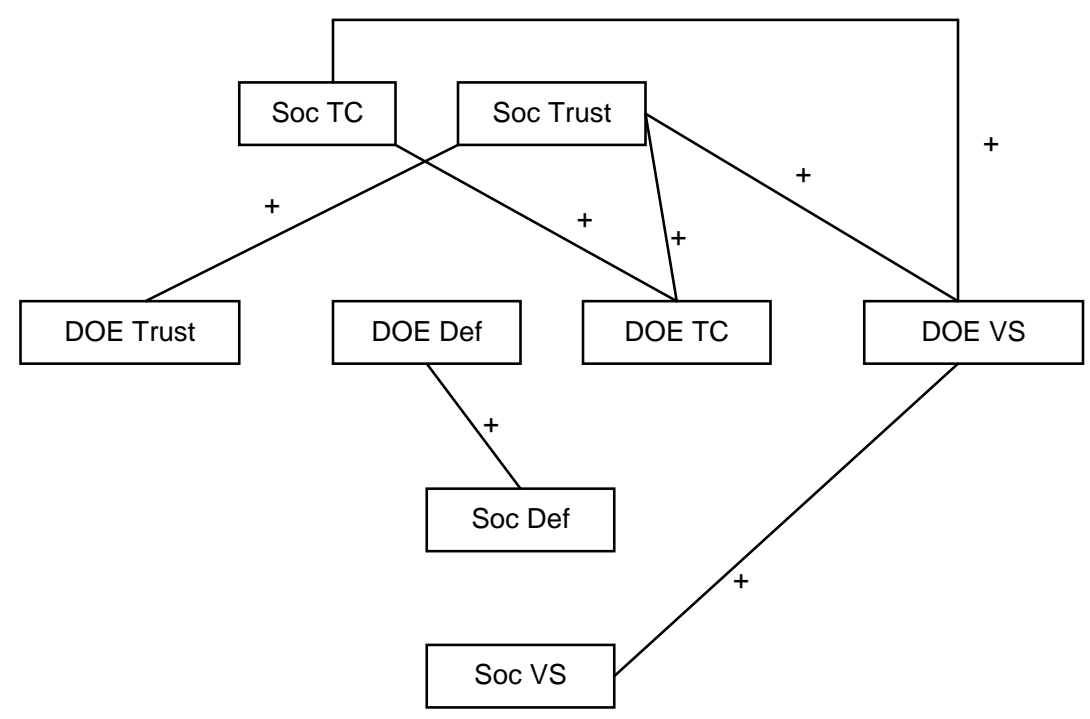

Figure 44. DOE and Social Trust Correlations 
First, we can see that all cross target (DOE and social) trust correlations are relatively weak. This is not surprising.

Second, as indicated by the shaded cells, we find that companion measures of trust (competence, value similarity, deference, and overall trust are correlated between DOE and social targets. Respondents tend to judge the four trust variables similarly between DOE and themselves, which is perhaps has an ontological explanation.

Third, stakeholders' willingness to defer is not related to any of the other target's trust measures except willingness to defer to that target.

Three of the 12 possible cross-measure correlations are significant: DOE value similarity is correlated with social trust and social technical competence, and social trust is correlated with DOE technical competence. We have no explanation for the DOE value similarity and social technical competence or the social trust and DOE technical competence. The correlation between DOE value similarity and social trust may be interpreted as stakeholders incorporating DOE personnel's values as part of the social trust fabric.

\section{DOE Trust - Risk Correlations}

Table 54 shows the relationship between DOE trust and risk judgment heuristics.

Table 54. DOE Trust Judgment - Risk Judgment Correlations

\begin{tabular}{|c|c|c|c|c|c|}
\hline \multirow{2}{*}{$\begin{array}{l}\text { RISK JUDGMENT } \\
\text { HEURISTIC }\end{array}$} & \multicolumn{5}{|c|}{ DOE TRUST MEASURE } \\
\hline & $\begin{array}{c}\text { Technical } \\
\text { Competence }\end{array}$ & $\begin{array}{l}\text { Value } \\
\text { Similarity }\end{array}$ & $\begin{array}{c}\text { Overall } \\
\text { Trust }\end{array}$ & Deference & Efficacy \\
\hline \multicolumn{6}{|l|}{ Contamination Knowledge } \\
\hline \multicolumn{6}{|l|}{ Exposure Knowledge } \\
\hline \multicolumn{6}{|l|}{ Health Effects Knowledge } \\
\hline Belief in Being at Risk & - & - & -- & - & - \\
\hline Risk Magnitude & - & - & - & & \\
\hline Dread & - & - & - & - & \\
\hline Contamination-Risk Correspondence & - & -- & -- & -- & - \\
\hline Exposure Control & & + & + & + & \\
\hline Risk Calibration & & + & + & + & \\
\hline Co-optation & & - & & & \\
\hline Cost-Benefit Balance & & + & + & + & + \\
\hline
\end{tabular}

The first result than can be noticed is the lack of correlation between the three risk familiarity heuristics and trust (shaded cells). What stakeholders believe they know about contamination, exposure, and health risk is independent of their trust. We hypothesized no such relationships and none were found.

Stakeholders' judgments concerning the three risk estimate heuristics (belief in being at risk, risk magnitude, and dread) are adversely affected by their trust of DOE and their judgment of their ability to influence DOE decision-making.

With respect to the five risk management heuristics, we note the following. The more that stakeholders view DOE as not sharing their values, the more they reject co-optation. Though this correlation is weak, it reinforces our hypothesis that gaining public acceptance of bioremediation will be made easier if DOE demonstrates that it empathizes with public concerns about its commitment to protecting public health from risks of exposure to contamination. In addition, we note that the more that stakeholders trust DOE and are willing to defer to its discretion, the more they believe that they can exercise some level of control over exposure, believe that public risk perceptions should be calibrated against scientific risk 
assessments, believe that the costs of remediation should be balanced against its benefits. Our interpretation of these three correlations is that trust encourages confidence and empowerment. Finally, those who perceiver risk to be higher, dreadful, and associated with contamination trust DOE less.

\section{DOE Trust Demographics}

Table 55 reports demographic correlations between DOE trust and proximity as well as site employment.

Table 55. DOE Trust Demographics

\begin{tabular}{|c||c|c|}
\hline TRUST MEASURE & PROXIMITY & SITE EMPLOYMENT \\
\hline \hline Overall DOE Trust (decision and site management) & - & $\mathbf{+}$ \\
\hline DOE Value Similarity & - & $\mathbf{+}$ \\
\hline DOE Deference & & \\
\hline DOE Technical Competence & & \\
\hline Efficacy & & \\
\hline
\end{tabular}

Only overall DOE trust and value similarity is correlated with DOE trust. More specifically, proximity to the site correlates negatively with both DOE trust and value similarity, suggesting that those individuals who live closer to the sites don't trust DOE and believe that DOE doesn't share their values. In addition, stakeholders who work or have worked at these sites have higher trust in DOE and believe that DOE shares their values more than those who have never worked there.

\section{Trust Judgment Conclusions}

Not surprisingly, both DOE trust and social trust judgments are highly correlated with judgments of technical competence and value similarity. One of the authors (Focht) has found this before, and this finding is consistent with the conceptions of trust by Benjamin Barber and others.

We have also seen that stakeholders' trust of DOE and of each other is mixed. DOE enjoys slightly higher ratings of technical competence whereas stakeholders enjoy slightly higher ratings of value similarity. In addition, we found that stakeholders' trust of DOE correlates with their judgments of their efficacy. This finding suggests that DOE should do much more to build trust and build efficacy in stakeholders, which will likely improve both reflexively.

Finally, in examining correlations between trust and risk judgments, we found evidence that trust of DOE lowers stakeholder vigilance. Higher trust means more deference, increased sense of control, lower risk estimates, greater willingness to endorse economic rationality as a basis for decision-making. This confirms that trust is indeed a form of social capital that DOE should work hard to build and protect. 


\section{CHAPTER 8}

\section{FINDINGS ON BIOREMEDIATION ACCEPTANCE}

\section{Introduction}

In this chapter, we consider the results of our telephone survey regarding stakeholders' judgments of the acceptance of bioremediation as the approach to addressing subsurface contamination.

\section{Analysis of Bioremediation Acceptance}

Bioremediation Support

Table 56 and Figure 45 report respondents' support of bioremediation.

Table 56. Responses to "How much do you support or oppose the use of bioremediation to reduce these risks?"

\begin{tabular}{|c|c|c|c|c|c||}
\hline \multicolumn{2}{|c|}{ Responses } & FREQUENCY & PERCENT & $\begin{array}{c}\text { VALID } \\
\text { PERCENT }\end{array}$ & $\begin{array}{c}\text { CUMULATIVE } \\
\text { PERCENT }\end{array}$ \\
\hline \hline \multirow{4}{*}{ Valid } & Strongly Oppose & 86 & 4.4 & 5.0 & 5.0 \\
\cline { 2 - 6 } & Oppose & 142 & 7.3 & 8.3 & 13.3 \\
\cline { 2 - 6 } & Neither Oppose nor Support & 573 & 29.4 & 33.5 & 46.8 \\
\cline { 2 - 6 } & Support & 571 & 29.3 & 33.4 & 80.1 \\
\cline { 2 - 6 } & Strongly Support & 340 & 17.4 & 19.9 & 100.0 \\
\cline { 2 - 6 } & Total & 1712 & 87.8 & 100.0 & \\
\hline \multirow{3}{*}{ Missing } & Don't Know & 228 & 11.7 & & \\
\cline { 2 - 6 } & Refused & 10 & 0.5 & & \\
\cline { 2 - 6 } & Total & $\mathbf{1 9 5 0}$ & $\mathbf{1 0 0 . 0}$ & & \\
\hline
\end{tabular}

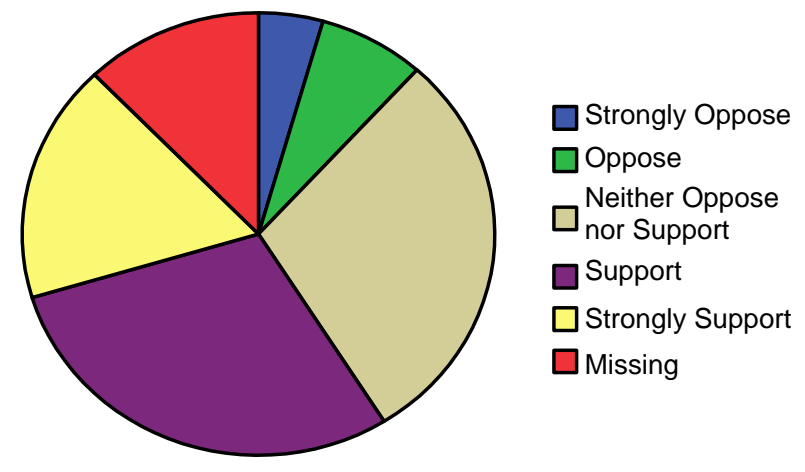

Figure 45. Bioremediation Support Distribution
Median Value $=$ support of the use of bioremediation (value $=4$ ); confidence interval $=$ $3.55 \pm 0.05$. More than $46 \%$ of respondents support the use of bioremediation to reduce risk and only slightly more than $13 \%$ oppose it. However, most interestingly, $41 \%$ have no opinion.

Bioremediation support correlates weakly with DOE decision trust $(r=0.201)$, DOE site management trust $(r=0.225)$, DOE technical competence $(r=0.217)$, and DOE value similarity $(r=0.241)$. 


\section{Bioremediation Dichotomy}

Table 57 and Figure 46 show our dichotomization recode of respondents' support of bioremediation. "Strongly oppose" and "oppose" were recoded as "oppose" and "strongly support" and "support" were recoded as "support." "Neither support or oppose," "don't know," and "refuse" were recoded as "missing."

Table 57. Bioremediation Acceptability Dichotomy

\begin{tabular}{|c|c|c|c|c|c|}
\hline \multicolumn{2}{|c|}{ Responses } & \multirow{2}{*}{ FREQUENCY } & PERCENT & $\begin{array}{c}\text { VAlid } \\
\text { PERCENT }\end{array}$ & $\begin{array}{c}\text { CUMULATIVE } \\
\text { PERCENT }\end{array}$ \\
\hline \multirow{3}{*}{ Valid } & Oppose (=1,2) & 228 & 11.7 & 20.0 & 20.0 \\
\cline { 2 - 6 } & Support (=4,5) & 911 & 46.7 & 80.0 & 100.0 \\
\cline { 2 - 6 } & Total & 1139 & 58.4 & 100.0 & \\
\hline Missing & Neither, don't know, refuse (=3,6,7) & 810 & 41.5 & & \\
\hline \multicolumn{2}{|c|}{ Total } & $\mathbf{1 9 5 0}$ & $\mathbf{1 0 0 . 0}$ & & \\
\hline
\end{tabular}

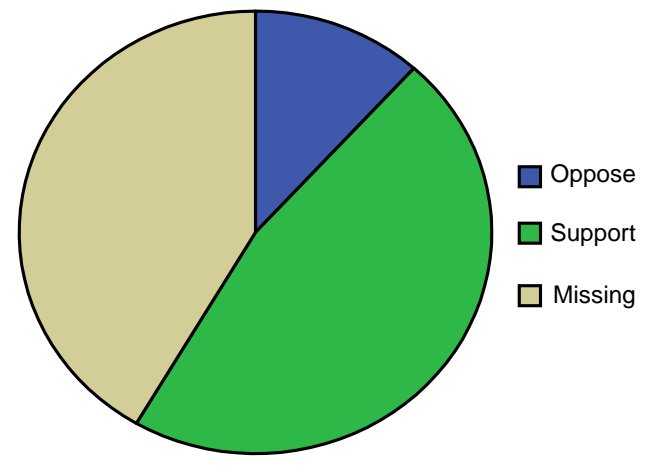

Figure 40. Dichotomized Bioremediation Support Distribution
$80 \%$ of those with an opinion support bioremediation; however more than $40 \%$ have no opinion. We suspect that this support is explainable, in part, by stakeholders' desires to do something about reducing risk despite their ignorance about bioremediation. This presents a challenge to DOE: bioremediation education could either move those with no opinion toward acceptance or move them and prior supporters to opposition. 


\section{Bioremediation as a Short Term Fix}

Table 58 and Figure 47 report respondents' beliefs about whether bioremediation is a short-term fix.

Table 58. Responses to "I believe that bioremediation is a short term fix at best; therefore, other technologies will be required to complete the cleanup"

\begin{tabular}{|c|c|c|c|c|c|}
\hline \multicolumn{2}{|r|}{ RESPONSES } & FREQUENCY & Percent & $\begin{array}{c}\text { VALID } \\
\text { PERCENT }\end{array}$ & $\begin{array}{c}\text { Cumulative } \\
\text { PERCENT }\end{array}$ \\
\hline \multirow{6}{*}{ Valid } & Strongly Disagree & 84 & 4.3 & 5.1 & 5.1 \\
\hline & Somewhat Disagree & 127 & 6.5 & 7.7 & 12.8 \\
\hline & Neither Disagree nor Agree & 279 & 14.3 & 16.9 & 29.7 \\
\hline & Somewhat Agree & 558 & 28.6 & 33.8 & 63.5 \\
\hline & Strongly Agree & 603 & 30.9 & 36.5 & 100.0 \\
\hline & Total & 1651 & 84.7 & 100.0 & \\
\hline \multirow{3}{*}{ Missing } & Don't Know & 288 & 14.8 & & \\
\hline & Refused & 11 & 0.6 & & \\
\hline & Total & 299 & 15.3 & & \\
\hline \multicolumn{2}{|r|}{ Total } & 1950 & 100.0 & & \\
\hline
\end{tabular}

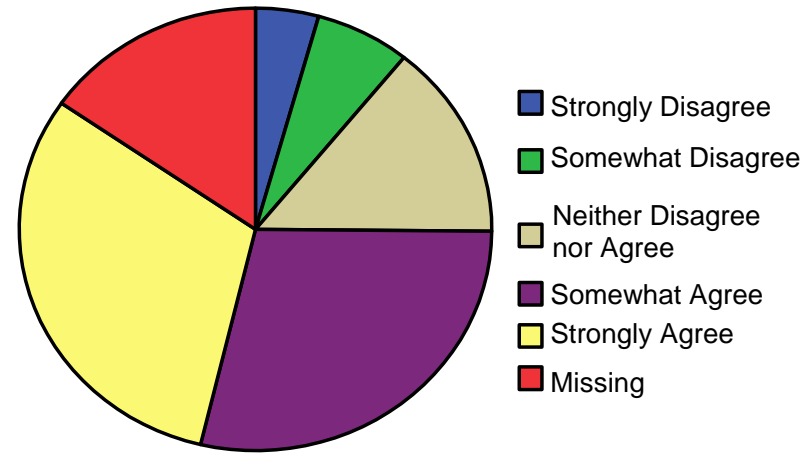

Figure 47. Bioremediation as a Short-Term Fix Distribution
Median Value $=$ somewhat agree with bioremediation is a short-term fix (value $=4$ ); confidence interval $=3.89 \pm 0.05$. More than $70 \%$ of respondents believe that bioremediation is a short-term fix while only $12 \%$ disagree.

Bioremediation as a short-term fix weakly correlates with beliefs of being at risk $(r=0.205)$ and co-optation $(r=0.206)$, and negatively with contamination-risk correspondence $(r=-0.220)$. 
Need More Study

Table 59 and Figure 48 report responses to the need to rush into bioremediation.

Table 59. Responses to "We have the time to investigate technologies and pick the ones that will best protect us and the environment.

We need not rush into bioremediation."

\begin{tabular}{|c|c|c|c|c|c||}
\hline \multicolumn{2}{|c|}{ RESPONSES } & \multirow{2}{*}{ FREQUENCY } & PERCENT & $\begin{array}{c}\text { VALID } \\
\text { PERCENT }\end{array}$ & $\begin{array}{c}\text { CUMULATIVE } \\
\text { PERCENT }\end{array}$ \\
\hline \hline \multirow{4}{*}{ Valid } & Strongly Disagree & 270 & 13.8 & 15.3 & 15.3 \\
\cline { 2 - 6 } & Somewhat Disagree & 355 & 18.2 & 20.2 & 35.5 \\
\cline { 2 - 6 } & Neither Disagree nor Agree & 257 & 13.2 & 14.6 & 50.1 \\
\cline { 2 - 6 } & Somewhat Agree & 545 & 27.9 & 31.0 & 81.1 \\
\cline { 2 - 6 } & Strongly Agree & 333 & 17.1 & 18.9 & 100.0 \\
\cline { 2 - 6 } & Total & 1760 & 90.3 & 100.0 & \\
\hline \multirow{3}{*}{ Missing } & Don't Know & 182 & 9.3 & & \\
\cline { 2 - 6 } & Refused & 8 & 0.4 & & \\
\cline { 2 - 6 } & Total & 190 & 9.7 & & \\
\hline \hline \multicolumn{2}{|c|}{} & Total & $\mathbf{1 9 0 . 0}$ & & \\
\hline
\end{tabular}

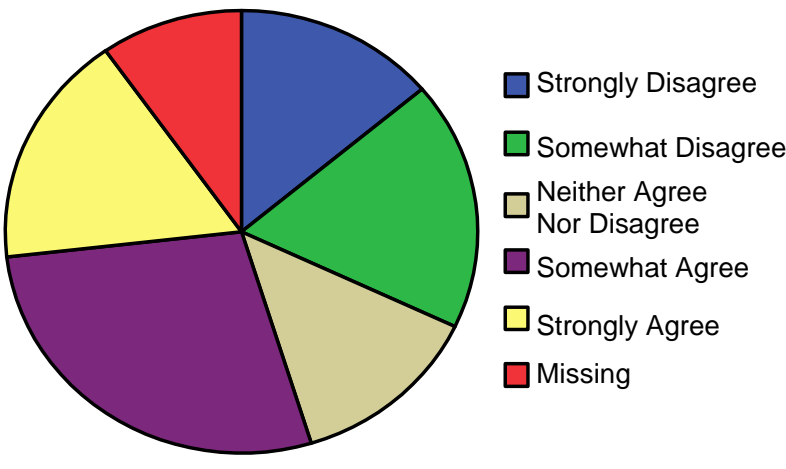

Figure 48. Need More Study Distribution
Median Value $=$ neither disagree nor agree (value = 3); confidence interval = 3.18 \pm 0.06 . Almost half of the respondent sample agrees that more study of alternative remediation technologies is needed, while 1/3 disagrees. 


\section{Bioremediation Support Statistics and Correlations}

Tables 60 and 61 summarize bioremediation support statistics and correlations among the four variables associated with bioremediation.

Table 60. Bioremediation Support Statistics

\begin{tabular}{|c||c|c|c|c|c||}
\hline SUPPORT VARIABLE & NUMBER & MEAN & MEDIAN & MODE & STD DEV \\
\hline \hline Bioremediation Support & 1712 & 3.55 & 4 (support) & 3 & 1.05 \\
\hline Bioremediation Dichotomy & 1139 & 1.80 & 2 (support) & 2 & 0.40 \\
\hline Bioremediation Is Short-Term Fix & 1651 & 3.89 & 4 (somewhat agree) & 5 & 1.13 \\
\hline More Study & 1760 & 3.18 & 3 (neither disagree/agree) & 4 & 1.36 \\
\hline
\end{tabular}

Though a large majority of stakeholders holding an opinion express support for bioremediation, more than $40 \%$ have no opinion. Moreover, they tend to view bioremediation as a short-term fix at best and that half of the respondents believe that DOE should not rush into bioremediation without first looking at other alternatives. For these reasons, we believe that bioremediation support is soft and could change with more information.

Table 61. Internal Bioremediation Support Correlations

\begin{tabular}{|c|c|c|c|c||}
\hline SUPPORT VARIABLE & $\begin{array}{c}\text { Bioremediation } \\
\text { Support }\end{array}$ & $\begin{array}{c}\text { Bioremediation } \\
\text { Dichotomy }\end{array}$ & $\begin{array}{c}\text { Bioremediation } \\
\text { Is Short-Term Fix }\end{array}$ & $\begin{array}{c}\text { More } \\
\text { Study }\end{array}$ \\
\hline \hline Bioremediation Is Short-Term Fix & & - & & \\
\hline
\end{tabular}

We see here evidence that those who oppose bioremediation tend to look at it as a short-term fix at best. No relationship between was found, however, between those who believe that bioremediation is only a short-term fix and those who want more study. This suggests that those wanting more study are not necessarily inclined against bioremediation.

By the way, we also found that neither stakeholder deference to DOE nor their judgments of efficacy influences bioremediation support. We believe that this adds support to our suspicion that bioremediation support is soft because it has not yet gain sufficient salience to trigger trust operationalization.

Table 62 shows bioremediation correlations with non-bioremediation variables associated with risk and trust.

Table 62. External Bioremediation Correlations

\begin{tabular}{|c|c|c|c|c||}
\hline RISK AND TRUST MEASURES & $\begin{array}{c}\text { Bioremediation } \\
\text { Support }\end{array}$ & $\begin{array}{c}\text { Bioremediation } \\
\text { Dichotomy }\end{array}$ & $\begin{array}{c}\text { Bioremediation is } \\
\text { Short-Term Fix }\end{array}$ & $\begin{array}{c}\text { More } \\
\text { Study }\end{array}$ \\
\hline Belief of Being at Risk & & & + & \\
\hline Risk Magnitude & & - & & \\
\hline Dread & & - & & \\
\hline Contamination-Risk Correspondence & & $\mathbf{+}$ & - & \\
\hline DOE Trust & $\mathbf{+}$ & $\mathbf{+}$ & & \\
\hline DOE Tech Competence & $\mathbf{+}$ & $\mathbf{+}$ & & \\
\hline DOE Value Similarity & $\mathbf{+}$ & $\mathbf{+}$ & & \\
\hline DOE Deference & $\mathbf{+}$ & $\mathbf{+}$ & & \\
\hline Social Trust & & $\mathbf{+}$ & & \\
\hline Co-optation & & & & + \\
\hline Efficacy & & & & \\
\hline
\end{tabular}


We first note that stakeholders' desires for more study is not correlated with any risk or trust variable. Moreover, all correlations with risk and trust variables are weak, if they exist at all. Again, we interpret this as a result of the low salience of bioremediation at the time of the survey.

Second, dichotomization of bioremediation support provides better correlations than the nondichotomized version of support. We can see that dichotomized support correlates positively with all DOE trust measures and with overall social trust. Again, we find that trust stimulates acceptance. However, we find no correlation between bioremediation support and efficacy because, we believe, the support is soft.

Third, we find that bioremediation supporters are more likely to judge site risks lower and less dreadful than do opponents. We suspect that a lower stake (less risk) encourages a greater willingness to accept risk.

Fourth, those who see bioremediation as only a short-term fix are more likely to believe that they are at risk and are opposed to co-optation. We suspect that risk aversion and defensive vigilance undermine unqualified support. We cannot explain the weak correlation with this variable and seeing risk as concomitant with contamination.

\section{Conclusions}

We suspect that though support for bioremediation is expressed by nearly half of all respondents, this support is soft and subject to change with more information. We recommend that stakeholders be provided with substantially more information about bioremediation effectiveness, timeliness, and cost, especially when compared to alternative methodologies for subsurface remediation. We also recommend here, as we have repeatedly elsewhere in this report, that DOE engage in efforts to build trust, which we believe will also build support for bioremediation. 


\section{CHAPTER 9}

\section{FINDINGS ON STAKEHOLDERS' PARTICIPATION PREFERENCES}

\section{Introduction}

In this chapter, we consider stakeholders' preferences for their participation in bioremediation decisionmaking. We asked respondents to indicate their preferences for four participation strategies, which are defined in Table 63. It should be evident that decision-making power shifts toward the public as one moves down the table from feedback (minimum public influence) to independent facilitation (maximum public influence).

Table 63. Stakeholder Participation Strategies

\begin{tabular}{|c|l||}
\hline STRATEGY & \multicolumn{1}{c|}{ PARTICIPATION DESCRIPTION } \\
\hline \hline Feedback & $\begin{array}{l}\text { DOE officials make a tentative decision and then submit it to stakeholders for their } \\
\text { feedback before making a final decision }\end{array}$ \\
\hline Consultation & $\begin{array}{l}\text { DOE officials consult with stakeholders first before making a decision that considers } \\
\text { stakeholders' preferences }\end{array}$ \\
\hline $\begin{array}{c}\text { DOE } \\
\text { Facilitation }\end{array}$ & DOE officials sponsor and moderate a discussion with stakeholders to make a decision \\
\hline $\begin{array}{c}\text { Independent } \\
\text { Facilitation }\end{array}$ & $\begin{array}{l}\text { In a negotiation moderated by an independent mediator and assisted by independent } \\
\text { analysts, DOE officials participate as equal partners with stakeholders to make a } \\
\text { decision }\end{array}$ \\
\hline
\end{tabular}

\section{Analysis of Participation Preferences}

Feedback Strategy

Table 64 and Figure 49 report stakeholders' preferences for the feedback participation strategy.

Table 64. Responses to "DOE officials make a tentative decision and then submit it to stakeholders for their feedback before making a final decision (Feedback Strategy)"

\begin{tabular}{|c|c|c|c|c|c|}
\hline \multicolumn{2}{|c|}{ RESPONSES } & FREQUENCY & PERCENT & $\begin{array}{c}\text { VALID } \\
\text { PERCENT }\end{array}$ & $\begin{array}{c}\text { CUMULATIVE } \\
\text { PERCENT }\end{array}$ \\
\hline \multirow{4}{*}{ Valid } & Strongly Oppose & 343 & 17.6 & 17.9 & 17.9 \\
\cline { 2 - 6 } & Somewhat Oppose & 272 & 13.9 & 14.2 & 32.2 \\
\cline { 2 - 6 } & Tolerate & 392 & 20.1 & 20.5 & 52.7 \\
\cline { 2 - 6 } & Somewhat Support & 519 & 26.6 & 27.1 & 79.8 \\
\cline { 2 - 6 } & Strongly Support & 386 & 19.8 & 20.2 & 100.0 \\
\cline { 2 - 6 } & Total & 1912 & 98.1 & 100.0 & \\
\hline \multirow{3}{*}{ Missing } & Don't Know & 32 & 1.6 & & \\
\cline { 2 - 6 } & Refused & 6 & 0.3 & & \\
\cline { 2 - 6 } & Total & $\mathbf{3 8}$ & 1.9 & & \\
\hline \hline \multicolumn{2}{|c|}{} & Total & $\mathbf{1 0 0 . 0}$ & & \\
\hline
\end{tabular}




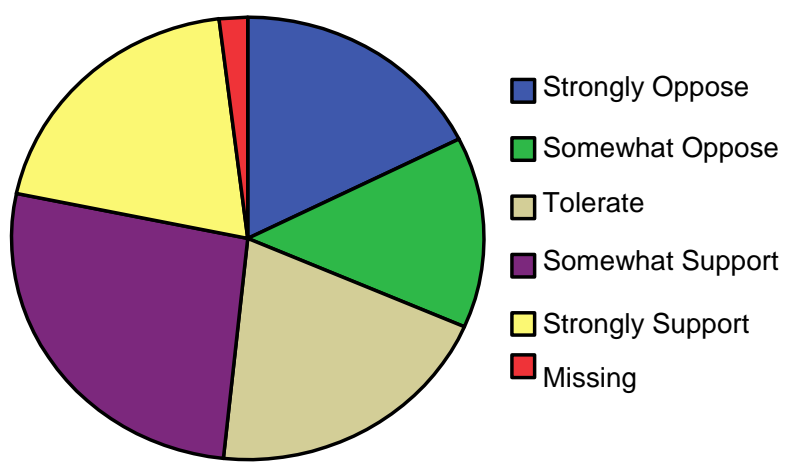

Figure 49. Feedback Strategy Preference Distribution
Median Value $=$ tolerate $($ value $=3$ ); confidence interval $=3.17 \pm 0.06$. More than $47 \%$ of respondents support the feedback strategy. Slightly more than $32 \%$ are opposed.

Feedback preference correlates with DOE decision trust $(r=0.295), \quad D O E$ site management trust $(r=0.329)$, DOE deference $(r=0.296)$, DOE technical competence $(r=0.206)$, and DOE value similarity $(r=0.297)$.

Feedback preference also correlates with the contamination-risk correspondence $(r=0.246)$ and preference for the consultation strategy $(r=0.446)$.

\section{Consultation Strategy}

Table 65 and Figure 50 show stakeholders' preferences for the stakeholder consultation strategy.

Table 65. Responses to "DOE officials consult with stakeholders first before making a decision that considers stakeholders' preferences (Consultation Strategy)"

\begin{tabular}{|c|c|c|c|c|c|}
\hline \multicolumn{2}{|c|}{ Responses } & FREQUENCY & PERCENT & $\begin{array}{c}\text { VALID } \\
\text { PERCENT }\end{array}$ & $\begin{array}{c}\text { CUMULATIVE } \\
\text { PERCENT }\end{array}$ \\
\hline \hline \multirow{4}{*}{ Valid } & Strongly Oppose & 205 & 10.5 & 10.8 & 10.8 \\
\cline { 2 - 6 } & Somewhat Oppose & 278 & 14.3 & 14.7 & 25.5 \\
\cline { 2 - 6 } & Tolerate & 361 & 18.5 & 19.1 & 44.6 \\
\cline { 2 - 6 } & Somewhat Support & 594 & 30.5 & 31.4 & 75.9 \\
\cline { 2 - 6 } & Strongly Support & 456 & 23.4 & 24.1 & 100.0 \\
\cline { 2 - 6 } & Total & 1894 & 97.1 & 100.0 & \\
\hline \multirow{3}{*}{ Missing } & Don't Know & 50 & 2.6 & & \\
\cline { 2 - 6 } & Refused & 6 & 0.3 & & \\
\cline { 2 - 6 } & Total & $\mathbf{1 9 5 0}$ & $\mathbf{1 0 0 . 0}$ & & \\
\hline \hline \multicolumn{2}{|c|}{} & Total & & & \\
\hline
\end{tabular}

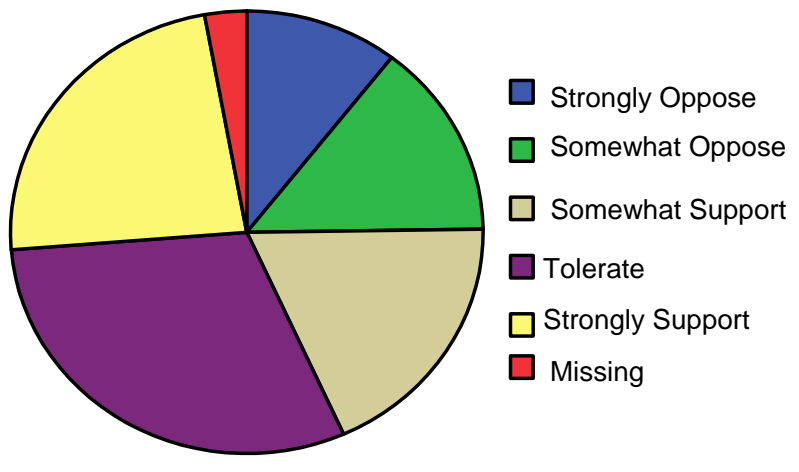

Figure 50. Consultation Strategy Preference Distribution
Median Value $=$ tolerate $($ value $=3)$; confidence interval $=3.43 \pm 0.06$. More than $55 \%$ support the use of consultation as a participation strategy. Slightly more than $25 \%$ of respondents oppose it.

Consultation preference correlates with the participation strategies of feedback $(r=0.446)$ and DOE facilitation $(r=0.447)$. 


\section{DOE Facilitation Strategy}

Table 66 and Figure 51 show respondents' preferences for use of the DOE facilitation strategy.

Table 66. Responses to "DOE officials sponsor and moderate a discussion with stakeholders to make a decision (DOE Facilitation Strategy)"

\begin{tabular}{|c|c|c|c|c|c|}
\hline \multicolumn{2}{|c|}{ RESPONSES } & FREQUENCY & Percent & $\begin{array}{c}\text { VALID } \\
\text { PERCENT }\end{array}$ & $\begin{array}{l}\text { CumUlative } \\
\text { PERCENT }\end{array}$ \\
\hline \multirow{6}{*}{ Valid } & Strongly Oppose & 171 & 8.8 & 9.0 & 9.0 \\
\hline & Somewhat Oppose & 267 & 13.7 & 14.1 & 23.2 \\
\hline & Tolerate & 368 & 18.9 & 19.5 & 42.6 \\
\hline & Somewhat Support & 598 & 30.7 & 31.6 & 74.2 \\
\hline & Strongly Support & 488 & 25.0 & 25.8 & 100.0 \\
\hline & Total & 1892 & 97.0 & 100.0 & \\
\hline \multirow{3}{*}{ Missing } & Don't Know & 55 & 2.8 & & \\
\hline & Refused & 3 & 0.2 & & \\
\hline & Total & 58 & 3.0 & & \\
\hline \multicolumn{2}{|r|}{ Total } & 1950 & 100.0 & & \\
\hline
\end{tabular}

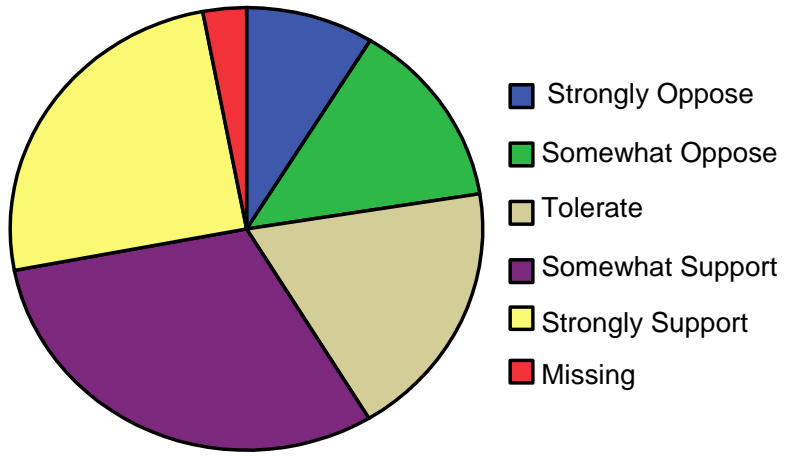

Figure 51. DOE Facilitation Strategy Preference Distribution
Median Value $=$ tolerate $($ value $=3$ ); confidence interval $=3.51 \pm 0.06$. More than $57 \%$ support the use of the DOE facilitation strategy. Slightly more than $23 \%$ of respondents oppose it.

DOE facilitation preference correlates with all other stakeholder participation strategies, especially consultation: feedback $(r=0.226)$, consultation $(r=0.447)$ and independent facilitation $(r=0.289)$. 
Independent Facilitation Strategy

Table 67 and Figure 52 show respondents' preferences for the use of an independent facilitation strategy.

Table 67. Combined Responses to "In a negotiation moderated by an independent mediator and assisted by independent analysts, DOE officials participate as equal partners with stakeholders to make a decision (Independent Facilitation Strategy)"

\begin{tabular}{|c|c|c|c|c|c|}
\hline \multicolumn{2}{|c|}{ Responses } & FREQUENCY & PERCENT & $\begin{array}{c}\text { VALID } \\
\text { PERCENT }\end{array}$ & $\begin{array}{c}\text { CUMULATIVE } \\
\text { PERCENT }\end{array}$ \\
\hline \multirow{4}{*}{ Valid } & Strongly Oppose & 221 & 11.3 & 11.7 & 11.7 \\
\cline { 2 - 6 } & Somewhat Oppose & 200 & 10.3 & 10.6 & 22.2 \\
\cline { 2 - 6 } & Tolerate & 194 & 9.9 & 10.2 & 32.5 \\
\cline { 2 - 6 } & Somewhat Support & 414 & 21.2 & 21.8 & 54.3 \\
\cline { 2 - 6 } & Strongly Support & 866 & 44.4 & 45.7 & 100.0 \\
\cline { 2 - 6 } & Total & 1895 & 97.2 & 100.0 & \\
\hline \multirow{3}{*}{ Missing } & Don't Know & 50 & 2.6 & & \\
\cline { 2 - 6 } & Refused & 5 & 0.3 & & \\
\cline { 2 - 6 } & Total & $\mathbf{1 9 5 0}$ & $\mathbf{1 0 0 . 0}$ & & \\
\hline \hline \multicolumn{2}{|c|}{} & Total & & & \\
\hline
\end{tabular}

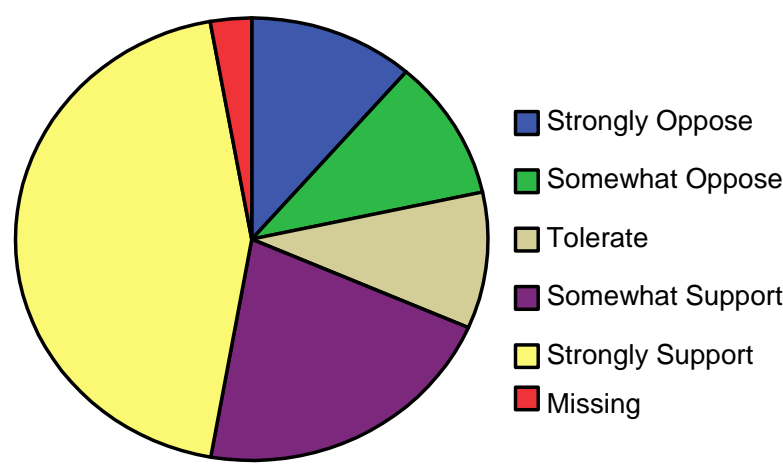

Figure 52. Independent Facilitation Strategy Preference Distribution
Median Value $=$ somewhat support $($ value $=4)$; confidence interval $=3.79 \pm 0.06$. More than $67 \%$ support the use of the independent facilitation strategy. Slightly more than $22 \%$ of respondents oppose it.

Independent facilitation correlates with the DOE facilitation strategy $(r=0.289)$.

Independent facilitation correlates negatively with DOE decision trust $(r=-0.264)$, DOE site management trust $(r=-0.275)$, DOE value similarity $(r=-0.264)$, DOE deference $(r=-0.273)$, co-optation $(r=0.211)$, and contamination-risk correspondence $(r=-0.307) . \quad$ It correlates positively with risk magnitude $(r=0.211)$. 


\section{Participation Statistics and Correlations}

Tables 68 and 69 show respondents' participation preference statistics and correlations, respectively.

Table 68. Participation Strategy Statistics

\begin{tabular}{|c||c|c|c|c|c||}
\hline VARIABLE & $\begin{array}{c}\text { \# OF } \\
\text { RESPONSES }\end{array}$ & MEAN & MEDIAN & MODE & $\begin{array}{c}\text { STANDARD } \\
\text { DEVIATION }\end{array}$ \\
\hline \hline Feedback Strategy & 1912 & 3.17 & 3 & 4 & 1.38 \\
\hline Consultation Strategy & 1894 & 3.43 & 4 & 4 & 1.29 \\
\hline DOE Facilitation Strategy & 1892 & 3.51 & 4 & 4 & 1.26 \\
\hline Independent Facilitation Strategy & 1895 & 3.79 & 4 & 5 & 1.41 \\
\hline
\end{tabular}

It is apparent that the more decision-making power that is accorded to the public vis-à-vis DOE, the more stakeholders like it. The two facilitation strategies are, on average, somewhat supported whereas the feedback and consultation strategies are only tolerated, on average. In fact, in the case of independent facilitation, the most popular response was "strongly support."

Table 69. Participation Strategy Correlations

\begin{tabular}{|c||c|c|c|c|}
\hline $\begin{array}{c}\text { PARTICIPATION } \\
\text { STRATEGY }\end{array}$ & Feedback & Consultation & DOE Facilitation & Independent Facilitation \\
\hline \hline Feedback & & $\mathbf{+ +}$ & $\mathbf{+}$ & $\mathbf{+ +}$ \\
\hline Consultation & & & & $\mathbf{+}$ \\
\hline DOE Facilitation & & & & \\
\hline Independent Facilitation & & & & \\
\hline
\end{tabular}

These results demonstrate that adjoining strategies in the hierarchy fare more closely in terms of preference. For example, consultation correlates more strongly with feedback (less public power) and DOE facilitation (more public power) but feedback only weakly correlates with DOE facilitation (much more difference in public power). Independent facilitation is seen by stakeholders as most different; it enjoys only weak correlation with DOE facilitation and no correlation with any other strategy.

Insofar as demographic characteristics are concerned, site employment correlates negatively with independent facilitation. Persons who are or have worked at the site do not prefer independent facilitation.

\section{Relationship between Trust Judgments and Participation Preferences}

Table 70 shows the significant correlations between trust and participation strategy preference.

Table 70. Stakeholder Participation Preference and DOE Trust Correlations

\begin{tabular}{||c||c|c|c|c||}
\hline DOE TRUST MEASURE & Feedback & Consultation & DOE Facilitation & $\begin{array}{c}\text { Independent } \\
\text { Facilitation }\end{array}$ \\
\hline \hline Decision and Site Management Trust & + & & & - \\
\hline Technical Competence & + & & & \\
\hline Value Similarity & + & & & - \\
\hline Deference & + & & & - \\
\hline
\end{tabular}


Two findings immediately leap out from this table. First, the feedback strategy is preferred by those stakeholders who trust DOE. The second is that the independent facilitation strategy is preferred by those who don't (with the sole exception of those who focus on technical competence). In between these two strategies, no significant correlation with trust is apparent.

\section{Participation Preference Conclusions}

It is clear that stakeholders most prefer independent facilitation, which affords them the most influence over remediation decisions at the site. We believe that this bias toward increased public power can be explained by the distrust that stakeholders have of DOE. The important relationship between trust and participation preference is explored further in the next chapter. 


\section{CHAPTER 10}

\section{PREDICTION OF STAKEHOLDERS' PARTICIPATION PREFERENCES}

\section{Introduction}

In this chapter, we explore the important relationship between stakeholders' public participation strategy preferences and their trust of DOE. We will develop and test a model that relates trust to participation preference.

\section{Model of the Relationship between DOE Trust and Participation Preference}

We postulate that stakeholders' trust of DOE and each other can predict their remediation decisionmaking participation preference. Table 71 summarizes our postulated relationships between the level of DOE and social trust with the role in decision-making that stakeholders want to adopt.

Table 71. Hypothesized Stakeholder Participation Roles Related to Level of Trust

\begin{tabular}{|c|c|l||}
\hline $\begin{array}{c}\text { TRUST } \\
\text { DIMENSION }\end{array}$ & $\begin{array}{c}\text { LEVEL OF } \\
\text { TRUST }\end{array}$ & \multicolumn{1}{|c||}{ PREDICTED STAKEHOLDER PARTICIPATION ROLE PREFERENCE } \\
\hline \hline \multirow{3}{*}{ Social } & Trust & $\begin{array}{l}\text { Cooperative role: Stakeholders are willing to cooperate in the decision- } \\
\text { making process }\end{array}$ \\
\cline { 2 - 3 } DOE & Distrust & $\begin{array}{l}\text { Defensive role: Stakeholders want to participate defensively to protect their } \\
\text { interests }\end{array}$ \\
\hline & Trust & $\begin{array}{l}\text { Subdued role: Stakeholders are willing to allow DOE officials to lead the } \\
\text { decision-making process }\end{array}$ \\
\cline { 2 - 3 } & Distrust & $\begin{array}{l}\text { Enhanced role: Stakeholders want to participate vigilantly in the decision- } \\
\text { making process }\end{array}$ \\
\hline
\end{tabular}

When stakeholders trust each other, we predict that they will be willing to cooperate; but when they don't, they will want to defend their interests from attack. When stakeholders trust DOE, we predict they will be willing to allow it to lead the decision-making process; but when they don't, they will want to again defend their interests energetically. In summary, trust encourages deference and distrust encourages vigilance.

Table 72 presents our predictions of which of the four participation strategies will be preferred given stakeholders' trust judgments.

Table 72. Stakeholder Participation Strategy Predictions

\begin{tabular}{|c|c|c|c|}
\hline \multicolumn{2}{|c|}{ TRUST JUDGMENT } & SocIAL TRUST & SOCIAL DISTRUST \\
\cline { 2 - 4 } DOE TRUST & Subdued role & Cooperative role & Defensive role \\
\hline DOE DISTRUST & Enhanced role & Consultation strategy & $\begin{array}{c}\text { Independent Facilitation } \\
\text { strategy }\end{array}$ \\
\hline
\end{tabular}

By combining social trust and DOE trust dimensions, and the roles that we believe stakeholders prefer to adopt, we can map our four participation strategies onto these trust combinations. We predict that the low public-power feedback strategy will be preferred only if trust of both DOE and fellow stakeholders is high because then stakeholders are willing to defer to both DOE and each other - thus, aggressive participation is not necessary. When both trust dimensions are low however, we predict that stakeholders will want to participate energetically, which calls for the highest power strategy of independent facilitation. Mixed trust judgments call for intermediate power strategies: low DOE but high social trust should result in a preference for consultation whereas the reverse calls for DOE facilitation. 
Table 73 summarizes our predictions. Figure 53 depicts a graphical representation of these predictions.

Table 73. Context-Specific Stakeholder Participation Strategy Predictions

\begin{tabular}{|c|c||c|c||}
\hline $\begin{array}{c}\text { SOCIAL } \\
\text { TRUST } \\
\text { (PREFERRED } \\
\text { ROLE) }\end{array}$ & $\begin{array}{c}\text { DOE TRUST } \\
\text { (PREFERRED } \\
\text { ROLE) }\end{array}$ & $\begin{array}{c}\text { PARTICIPATION } \\
\text { STRATEGY } \\
\text { PREFERENCE }\end{array}$ & PARTICIPATION STRATEGY DESCRIPTION \\
\hline \hline $\begin{array}{c}\text { Trust } \\
\text { (cooperative) }\end{array}$ & $\begin{array}{c}\text { Trust } \\
\text { (subdued) }\end{array}$ & Feedback & $\begin{array}{l}\text { DOE officials make a tentative decision and then } \\
\text { submit it to stakeholders for their feedback before } \\
\text { making a final decision. }\end{array}$ \\
\hline $\begin{array}{c}\text { Trust } \\
\text { (cooperative) }\end{array}$ & $\begin{array}{c}\text { Distrust } \\
\text { (enhanced) }\end{array}$ & Consultation & $\begin{array}{l}\text { DOE officials consult with stakeholders first } \\
\text { before making a decision that considers } \\
\text { stakeholders' preferences. }\end{array}$ \\
\hline $\begin{array}{c}\text { Distrust } \\
\text { (defensive) }\end{array}$ & $\begin{array}{c}\text { Trust } \\
\text { (subdued) }\end{array}$ & DOE Facilitation & $\begin{array}{l}\text { DOE officials sponsor and moderate a discussion } \\
\text { with stakeholders to make a decision. }\end{array}$ \\
\hline $\begin{array}{c}\text { Distrust } \\
\text { (defensive) }\end{array}$ & $\begin{array}{c}\text { Distrust } \\
\text { (enhanced) }\end{array}$ & Independent \\
Facilitation & $\begin{array}{l}\text { In a negotiation moderated by an independent } \\
\text { mediator and assisted by independent analysts, } \\
\text { DOE officials participate as equal partners with } \\
\text { stakeholders to make a decision. }\end{array}$ \\
\hline
\end{tabular}

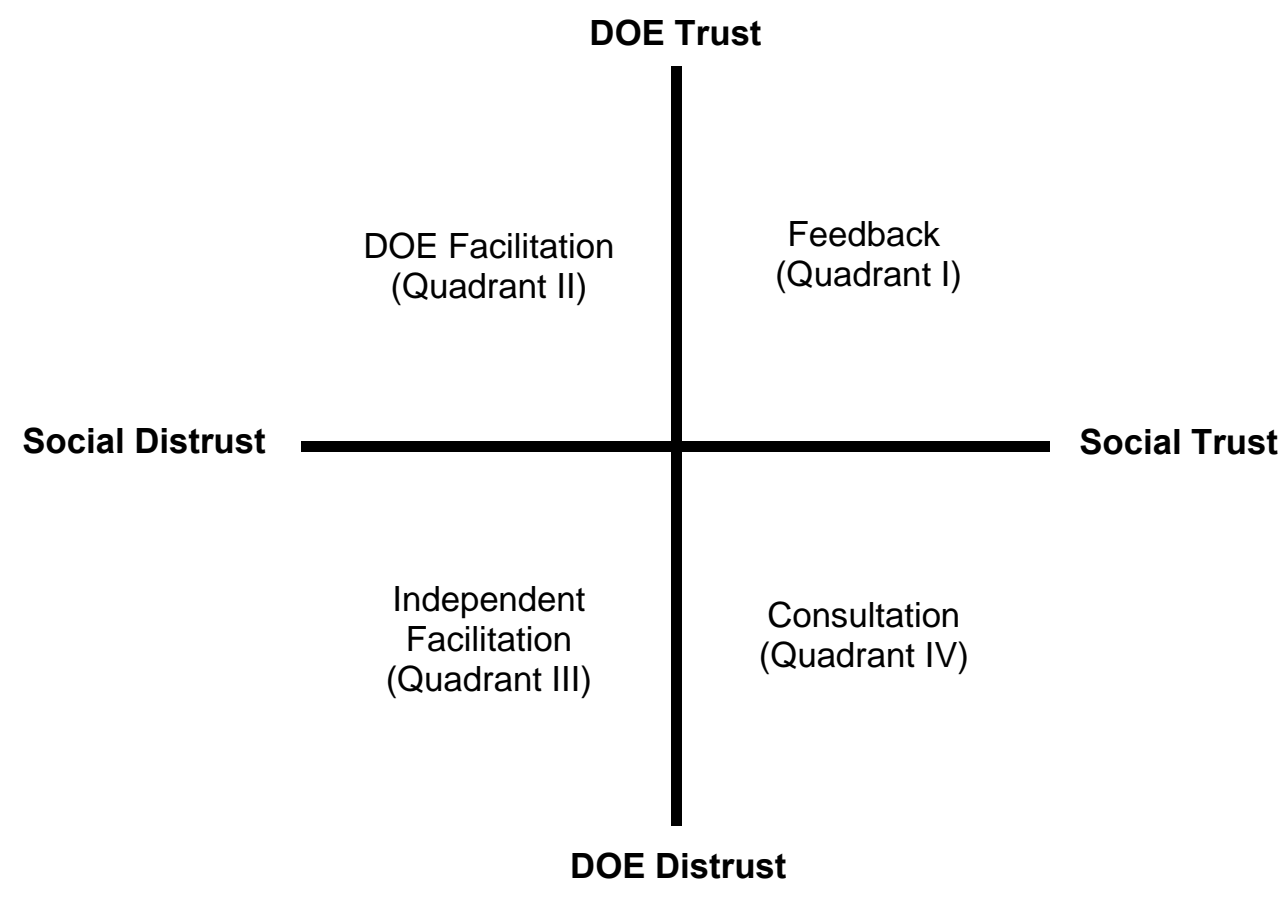

Figure 53. Stakeholder Participation Graph 


\section{Relationship between Trust Asymmetry and Threshold of Participation Acceptability}

To test our model, we must define the division between trust and distrust. It has been variously reported that trust is hard to get and easy to lose; therefore, the division between trust and distrust should be biased. In other words, deference requires a lot of trust and vigilance is triggered by very little distrust. To test how much trust is required for deference, we varied the division between trust and distrust on the five-point Likert scale responses used in the telephone survey. First, we assumed high asymmetry by equating deference to only high trust responses $(=5)$. Then, we assumed moderate asymmetry by equating deference to somewhat trust and high trust $(=4,5)$. Finally, we assumed low asymmetry by equating deference to neither trust nor distrust through high trust $(=3,4,5)$.

Similarly, we must determine how much preference is required before a participation strategy will be acceptable. Will a strategy be acceptable only if it is not strongly opposed, tolerated, or at least somewhat supported? To determine this, we tested all three of these options by recoding participation strategy acceptability as equal to 2, 3, 4 or 5 (not strongly opposed); 3, 4 or 5 (at least tolerated), and 4 or 5 (supported and highly supported).

We conducted two tests of our participation preference model across the nine combinations of three trust asymmetries and three strategy acceptabilities. The first test, conducted in two ways, evaluates the popularity of our predictions. The second test evaluates the acceptability of our predictions.

\section{Popularity Test}

Tables 74, 75 and 76 show the results of stakeholders' preferences for the four participation strategies based on variations in varying the trust-distrust dichotomy and the acceptable-unacceptable participation preference dichotomy.

The bolded numbers in these tables represent the predictions of participation strategy preferences made by our model. Shaded cells represent the most popular strategy given a particular trust asymmetry definition. If the model's prediction (bolded number) lies within a shaded cell (strategy that is most preferred by those stakeholders who judged social and trust judgments according to the particularly trustdistrust dichotomy specified in columns 3 and 4), then the prediction was a success. For example, in the top row of Table 74, we can see that 1391 of the 1526 respondents who highly distrusted both DOE and fellow stakeholders reported that they did not strongly oppose DOE facilitation. This strategy is the most popular choice among these respondents as indicated by the shaded cell. The predicted strategy for this group of respondents however is independent facilitation, which ranks second in popularity (see last column). Similarly, we ranked the popularity of our predicted strategy for the other three combinations of DOE and social trust within that particular definition of trust asymmetry. We then summed the ranks of the four DOE-social trust combinations to reach an overall prediction score for that particular trust asymmetry and strategy acceptability context. We can see that the prediction score for high trust asymmetry and not strongly opposed participation strategy acceptability is 10 . The best possible score is 4 , corresponding to the outcome in which all predicted strategies were most popular. The worst possible score is 16 , corresponding to the outcome in which all predicted strategies were least popular.

As can be seen in these three tables, the 12 prediction scores varied within a small range, from 10 to 13. The best performing contexts are high trust asymmetry - not opposed acceptability, high trust asymmetry - tolerated acceptability, moderate trust asymmetry - tolerated acceptability, and moderate-trust asymmetry - supported acceptability. This suggests that our model performs best in high trust asymmetry contexts (deference requires substantial trust) but not as well across varying definitions of strategy acceptability. 
Table 74. Trust Asymmetries versus "Not Strongly Opposed" Strategy Acceptability

\begin{tabular}{|c|c|c|c|c|c|c|c|c|}
\hline \multirow{6}{*}{$\begin{array}{c}\text { HIGH TRUST } \\
\text { AsYMMETRY } \\
\text { (Deference } \\
=\text { "Strong } \\
\text { Trust") }\end{array}$} & \multirow{2}{*}{ \# } & \multicolumn{2}{|c|}{ TRUST TARGET } & \multicolumn{4}{|c|}{ PARTICIPATION StRATEgy PREFERENCES } & \multirow{2}{*}{$\begin{array}{c}\text { RANK OF } \\
\text { PREDICTION }\end{array}$} \\
\hline & & DOE & SOCIAL & FEEDBACK & CONSULT & DOE FAC & INDEP FAC & \\
\hline & 1526 & distrust & distrust & 1253 & 1369 & 1391 & 1387 & 2 \\
\hline & 59 & distrust & trust & 50 & 52 & 56 & 56 & 3 \\
\hline & 207 & trust & distrust & 167 & 188 & 185 & 152 & 2 \\
\hline & 60 & trust & trust & 50 & 54 & 57 & 48 & 3 \\
\hline Total & 1852 & & & 1510 & 1663 & 1689 & 1643 & \\
\hline \multicolumn{8}{|c|}{ PREDICTION SCORE } & 10 \\
\hline \multirow{6}{*}{$\begin{array}{l}\text { MODERATE } \\
\text { TRUST } \\
\text { AsYMMETRY } \\
\text { (Deference } \\
\text { = "Trust") }\end{array}$} & \# & \multicolumn{2}{|c|}{ TRUST TARGET } & \multicolumn{4}{|c|}{ PaRticipation StRategy PREFERENCES } & RANK OF \\
\hline & H & DOE & SOCIAL & FEEDBACK & CONSULT & DOE FAC & INDEP FAC & Prediction \\
\hline & 818 & distrust & distrust & 676 & $\overline{7710}$ & 729 & 611 & $\overline{44}$ \\
\hline & 291 & distrust & trust & 234 & 265 & 271 & 291 & 3 \\
\hline & 347 & trust & distrust & 280 & 316 & 308 & 286 & 2 \\
\hline & 396 & trust & trust & 330 & 372 & 372 & 396 & 4 \\
\hline Total & 1852 & & & 1520 & 1663 & 1680 & 1584 & \\
\hline \multicolumn{8}{|c|}{ PREDICTION SCORE } & 13 \\
\hline \multirow{6}{*}{$\begin{array}{c}\text { Low TRUST } \\
\text { AsYMMETRY } \\
\text { (“Neither } \\
\text { Trust Nor } \\
\text { Distrust") }\end{array}$} & $\#$ & \multicolumn{2}{|c|}{ TRUST TARGET } & \multicolumn{4}{|c|}{ PARTICIPATION StRATEgy Preferences } & RANK OF \\
\hline & & DOE & SOCIAL & FEEDBACK & CONSULT & DOE FAC & INDEP FAC & Prediction \\
\hline & 479 & distrust & distrust & 399 & 396 & 409 & 284 & 4 \\
\hline & 416 & distrust & trust & 338 & 378 & 388 & 416 & 3 \\
\hline & 268 & trust & distrust & 222 & 238 & 234 & 195 & 2 \\
\hline & 689 & trust & trust & 561 & 651 & 658 & 689 & 4 \\
\hline Total & 1852 & & & 1520 & 1663 & 1689 & 1584 & \\
\hline \multicolumn{8}{|c|}{ PREDICTION SCORE } & 13 \\
\hline
\end{tabular}


Table 75. Trust Asymmetries versus "Tolerated" Strategy Acceptability

\begin{tabular}{|c|c|c|c|c|c|c|c|c|}
\hline \multirow{6}{*}{$\begin{array}{l}\text { HIGH TRUST } \\
\text { AsYMmETRY } \\
\text { (Deference } \\
\text { = "Strong } \\
\text { Trust") }\end{array}$} & \multirow{2}{*}{ \# } & \multicolumn{2}{|c|}{ TRUST TARGET } & \multicolumn{4}{|c|}{ PARTICIPATION STRATEGY PREFERENCES } & \multirow{2}{*}{$\begin{array}{l}\text { RANK OF } \\
\text { PREDICTION }\end{array}$} \\
\hline & & $\mathrm{DOE}$ & SOCIAL & FEEDBACK & CONSULT & DOE FAC & INDEP FAC & \\
\hline & 1526 & distrust & distrust & 476 & 1139 & 1190 & 1241 & 1 \\
\hline & 59 & distrust & trust & 20 & 44 & 47 & 49 & 3 \\
\hline & 207 & trust & distrust & 72 & 168 & 151 & 117 & 2 \\
\hline & 60 & trust & trust & 17 & 50 & 51 & 42 & 4 \\
\hline \multirow{2}{*}{\multicolumn{8}{|c|}{\begin{tabular}{c|c}
1439 & 1449 \\
PREDICTION SCORE \\
\end{tabular}}} & \\
\hline & & & & & & & & 10 \\
\hline \multirow{6}{*}{$\begin{array}{l}\text { MODERATE } \\
\text { TRUST } \\
\text { AsYMMETRY } \\
\text { (Deference } \\
\text { = "Trust") }\end{array}$} & \# & \multicolumn{2}{|c|}{ TRUST TARGET } & \multicolumn{4}{|c|}{ PARTICIPATION STRATEgy PREFERENCES } & RANK OF \\
\hline & H & DOE & SOCIAL & FEEDBACK & CONSULT & DOE FAC & INDEP FAC & PREDICTION \\
\hline & 818 & distrust & distrust & 561 & 576 & 621 & 686 & 1 \\
\hline & 291 & distrust & trust & 195 & 227 & 234 & 253 & 3 \\
\hline & 347 & trust & distrust & 229 & 267 & 251 & 207 & 2 \\
\hline & 396 & trust & trust & 282 & 331 & 333 & 303 & 4 \\
\hline Total & 1852 & & & 1257 & 1401 & 1439 & 1449 & \\
\hline \multicolumn{8}{|c|}{ PREDICTION SCORE } & 10 \\
\hline \multirow{6}{*}{$\begin{array}{c}\text { Low TRUST } \\
\text { AsYMMETRY } \\
\text { ("Neither } \\
\text { Trust Nor } \\
\text { Distrust") }\end{array}$} & \# & \multicolumn{2}{|c|}{ TRUST TARGET } & \multicolumn{4}{|c|}{ PARTICIPATION StRATEgy PREFERENCES } & RANK OF \\
\hline & \# & DOE & SOCIAL & FEEDBACK & CONSULT & DOE FAC & INDEP FAC & PREDICTION \\
\hline & 479 & distrust & distrust & 334 & 310 & 346 & 403 & 1 \\
\hline & 416 & distrust & trust & 280 & 314 & 335 & 372 & 3 \\
\hline & 268 & trust & distrust & 189 & 204 & 184 & 159 & 3 \\
\hline & 689 & trust & trust & 464 & 573 & 574 & 515 & 4 \\
\hline Total & 1852 & & & 1267 & 1401 & 1439 & 1449 & \\
\hline \multicolumn{8}{|c|}{ PREDICTION SCORE } & 11 \\
\hline
\end{tabular}


Table 76. Trust Asymmetries versus "Supported" Strategy Acceptability

\begin{tabular}{|c|c|c|c|c|c|c|c|c|}
\hline \multirow{6}{*}{$\begin{array}{l}\text { HIGH TRUST } \\
\text { AsYMMETRY } \\
\text { (Deference } \\
=\text { "Strong } \\
\text { Trust") }\end{array}$} & \multirow{2}{*}{ \# } & \multicolumn{2}{|c|}{ TRUST TARGET } & \multicolumn{4}{|c|}{ PARTICIPATION STRATEGY PREFERENCES } & \multirow{2}{*}{$\begin{array}{c}\text { RANK OF } \\
\text { PREDICTION }\end{array}$} \\
\hline & & DOE & SOCIAL & FEEDBACK & CONSULT & DOE FAC & INDEP FAC & \\
\hline & 1526 & distrust & distrust & 1090 & 892 & 855 & 689 & 4 \\
\hline & 59 & distrust & trust & 41 & 39 & 37 & 29 & 2 \\
\hline & 207 & trust & distrust & 94 & 109 & 116 & 139 & 2 \\
\hline & 60 & trust & trust & 39 & 44 & 43 & 43 & 4 \\
\hline Total & 1852 & & & 1264 & 1084 & 1051 & 900 & \\
\hline \multicolumn{8}{|c|}{ PREDICTION SCORE } & 12 \\
\hline \multirow{6}{*}{$\begin{array}{l}\text { MODERATE } \\
\text { TRUST } \\
\text { AsYMMETRY } \\
\text { (Deference } \\
\text { = "Trust") }\end{array}$} & $\#$ & \multicolumn{2}{|c|}{ TRUST TARGET } & \multicolumn{4}{|c|}{ PARTICIPATION STRATEgY PREFERENCES } & RANK OF \\
\hline & & $\mathrm{DOE}$ & SOCIAL & FEEDBACK & CONSULT & DOE FAC & INDEP FAC & PREDICTION \\
\hline & 818 & distrust & distrust & 332 & 415 & 465 & 609 & 1 \\
\hline & 291 & distrust & trust & 109 & 179 & 176 & 233 & 2 \\
\hline & 347 & trust & distrust & 216 & 201 & 184 & 172 & 3 \\
\hline & 396 & trust & trust & 244 & 256 & 259 & 256 & 4 \\
\hline Total & 1852 & & & 901 & 1051 & 1084 & 1270 & \\
\hline \multicolumn{8}{|c|}{ PREDICTION SCORE } & 10 \\
\hline \multirow{6}{*}{$\begin{array}{c}\text { Low TRUST } \\
\text { AsYMMETRY } \\
\text { ("Neither } \\
\text { Trust Nor } \\
\text { Distrust") }\end{array}$} & $\#$ & \multicolumn{2}{|c|}{ TRUST TARGET } & \multicolumn{4}{|c|}{ PARTICIPATION StRATEgy PREFERENCES } & RANK OF \\
\hline & \# & $\mathrm{DOE}$ & SOCIAL & FEEDBACK & CONSULT & DOE FAC & INDEP FAC & Prediction \\
\hline & 479 & distrust & distrust & 172 & 226 & 262 & 358 & 1 \\
\hline & 416 & distrust & trust & 157 & 241 & 246 & 343 & 3 \\
\hline & 268 & trust & distrust & 153 & 147 & 131 & 131 & 3 \\
\hline & 689 & trust & trust & 409 & 437 & 445 & 432 & 4 \\
\hline Total & 1852 & & & 891 & 1051 & 1084 & 1264 & \\
\hline \multicolumn{8}{|c|}{ PREDICTION SCORE } & 11 \\
\hline
\end{tabular}

Another way to evaluate popularity is to compare rankings across trust asymmetries and strategy acceptabilities for each particular social and DOE trust combination. Table 77 shows these results.

Table 77. Popularity Test of the Participation Preference Model

\begin{tabular}{|c|c|c|c|c|c|c|c|c|c|c|c|c|}
\hline \multirow{3}{*}{\multicolumn{2}{|c|}{ TRUST TARGET }} & \multicolumn{9}{|c|}{ STRATEGY ACCEPTABILITY } & \multirow{4}{*}{$\begin{array}{c}\text { TOTAL OF } \\
\text { PREDICTION } \\
\text { RANKS }\end{array}$} & \multirow{4}{*}{$\begin{array}{c}\text { AVERAGE } \\
\text { PREDICTION } \\
\text { RANK }\end{array}$} \\
\hline & & \multicolumn{3}{|c|}{ NOT OPPOSED } & \multicolumn{3}{|c|}{$\begin{array}{c}\text { TOLERATED } \\
\end{array}$} & \multicolumn{3}{|c|}{ SUPPORTED } & & \\
\hline & & \multicolumn{9}{|c|}{ TRUST ASYMMETRY } & & \\
\hline DOE & SOCIAL & $\mathrm{HIGH}$ & MOD & Low & $\mathrm{HIGH}$ & MOD & Low & $\mathrm{HIGH}$ & MOD & Low & & \\
\hline Distrust & Distrust & 2 & 4 & 4 & 1 & 1 & 1 & 4 & 1 & 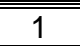 & 19 & 2.1 \\
\hline Trust & Distrust & 2 & 2 & 2 & 2 & 2 & 3 & 2 & 3 & 3 & 21 & 2.3 \\
\hline Distrust & Trust & 3 & 3 & 3 & 3 & 3 & 3 & 2 & 2 & 3 & 25 & 2.8 \\
\hline Trust & Trust & 3 & 4 & 4 & 4 & 4 & 4 & 4 & 4 & 4 & 35 & 3.9 \\
\hline
\end{tabular}

Looking across contexts, we can see that the model performs most poorly in high trust contexts. Stakeholders reject DOE feedback strategies even when trust is high. The model performs better in low social trust contexts, and best when both social and DOE trust are low. Stakeholders particularly like facilitation strategies in these contexts, with independent facilitation somewhat outperforming DOE facilitation. 


\section{Acceptability Test}

A second test of the model's predictions using the same data was conducted by calculating the percentage of respondents who preferred a strategy as predicted given their DOE and social trust judgments. In Table 78, we show the percentages of respondents who preferred a strategy according to the model's predictions for each combination of strategy acceptability and trust asymmetry.

Table 78. Acceptability Test of the Participation Preference Model

\begin{tabular}{|c|c|c|c|c|c|c|}
\hline \multirow{2}{*}{$\begin{array}{l}\text { STRATEGY } \\
\text { ACCEPTABILITY }\end{array}$} & \multirow{2}{*}{$\begin{array}{l}\text { TRUST } \\
\text { ASYMMETRY }\end{array}$} & \multicolumn{4}{|c|}{$\begin{array}{l}\text { PERCENT OF ReSPONDENTS SELECTING } \\
\text { PREDICTED PARTICIPATION StRATEGy }\end{array}$} & \multirow[t]{2}{*}{$\begin{array}{l}\text { WEIGHTED } \\
\text { AVERAGE }\end{array}$} \\
\hline & & Feedback & Consult & DOE Fac & Indep Fac & \\
\hline \multirow{4}{*}{$\begin{array}{l}\text { NOT STRONGLY } \\
\text { OPPOSED }\end{array}$} & High & 83.3 & 88.1 & 89.4 & 90.9 & 87.9 \\
\hline & Moderate & 83.3 & 91.1 & 88.8 & 74.7 & 84.5 \\
\hline & Low & 81.4 & 90.9 & 87.3 & 59.3 & 79.7 \\
\hline & Overall & 83.1 & 90.8 & 88.5 & 66.4 & 81.7 \\
\hline \multirow{4}{*}{ TOLERATED } & High & 28.3 & 74.6 & 73.0 & 81.3 & 64.3 \\
\hline & Moderate & 71.2 & 78.0 & 72.3 & 83.9 & 76.4 \\
\hline & Low & 67.3 & 75.5 & 68.7 & 84.1 & 74.0 \\
\hline & Overall & 47.7 & 76.4 & 71.4 & 84.0 & 61.4 \\
\hline \multirow{4}{*}{ SUPPORTED } & High & 65.0 & 66.1 & 56.0 & 84.2 & 67.8 \\
\hline & Moderate & 61.6 & 61.5 & 53.0 & 74.4 & 62.7 \\
\hline & Low & 59.4 & 58.0 & 48.9 & 74.7 & 60.2 \\
\hline & Overall & 62.5 & 60.1 & 52.6 & 75.1 & 63.5 \\
\hline ALL & $\begin{array}{l}\text { WEIGHTED } \\
\text { AVERAGE }\end{array}$ & 64.5 & 77.8 & 73.8 & 74.5 & 69.7 \\
\hline
\end{tabular}

These results demonstrate that the model generally performs quite well in predicting the acceptability of stakeholders' preferences. Altogether, the model correctly predicted the acceptability of $70 \%$ of all preferences. As in the popularity test however, the model performs better in predicting high power strategies. As expected, the model does better when acceptability is relaxed ( $82 \%$ for not strongly opposed as compared to low 60s for tolerated and supported). It also does better when deference is accorded in very high trust contexts. Nevertheless, the model does much better than would be the case if participation preferences were assigned to the model randomly.

\section{Conclusions}

We have seen that low power strategies under-performed in our model and high power strategies do better than expected. We also found that the model does best when the threshold for strategy acceptance is relaxed and the trust required for deference is quite high.

Moreover, the participation preference model performs better in predicting the acceptability of stakeholders' participation preferences though it does in predicting the popularity of participation strategies. We posit two explanations for the sub-optimal performance of our model.

The first explanation is methodological. A telephone interview has two serious limitations in asking respondents to rate the acceptability of four alternatives. First, since stakeholders are read only one strategy at a time (though we randomly varied their order), they have a difficult time keeping in mind the previous strategies as they judge successive ones. A face-to-face interview in which the strategies are written on cards and compared against each other would have yielded more validity to our findings.

The second explanation is political. It is quite likely that the frustration, misinformation, and fatigue that has accumulated over the several years that remediation of these sites has been discussed has created a bias against low power strategies such as feedback, despite trust judgments. On one hand, stakeholders want something done soon. On the other hand, they want to be involved and are unwilling to let DOE and its contractors to "go it alone." We suspect that if these same stakeholders had been asked about their participation preferences at the beginning of public discussions about remediation, their aversion to low power strategies would have been lower and our model would have performed better. 


\title{
CHAPTER 11 \\ STAKEHOLDER DIALOGUE ON BIOREMEDIATION ACCEPTANCE
}

\begin{abstract}
Introduction
Preliminary findings of the research project were presented to the Site Specific Advisory Board at the Oak Ridge Reservation. The presentation began with an explanation of the purpose of the study and a description of the research protocol used in it. This proved useful because the participants better appreciated the national scope of bioremediation at DOE sites and that their views were shared by others.
\end{abstract}

Next, we reviewed the bioremediation and public participation themes that were identified from our personal interviews. Then we described the stakeholder perspectives on bioremediation and participation preferences identified the $\mathrm{Q}$ method factor analyses.

Finally, we gave a brief summary of the telephone survey with an emphasis on risk and trust judgments, bioremediation acceptance, and participation preferences.

A copy of our PowerPoint presentation is included in Appendix C. [Appendix D contains a copy of our presentation to DOE personnel at the end of our project.] Note that these presentations were first converted to handouts within MS PowerPoint $₫$, then saved as a pdf file, then converted into MS Word $₫$, then pasted into this report. As a result, the slides do not look as nice as they do in the original presentations.

\section{Group Dialogue}

After the presentation, the group was engaged in a dialogue about how the bioremediation should proceed and what role they should play in the process. This discussion lasted about one hour.

Initially, participants were frustrated that little progress had been made despite months and months of meetings. This frustration occurred on two fronts. First, DOE made very little progress on bioremediation and thus the participants wondered why they kept meeting. Second, attendance at these meetings was sporadic, which caused them to cover the same topics over and over. It became apparent that the group had not benefited from either presentation of technical information or the deliberations. This led to the lead presenter's (Focht) offer to consider the National Research Council's (1996) framework for coupling analysis and deliberation.

This unplanned presentation was fortuitous because it stimulated the group to engage in productive discussion rather than an opportunity for airing frustrations.

\section{Findings}

Figure 54 presents the outcome of the group's discussion of the NRC's analysis and deliberation framework.

The discussion started with a simple drawing that showed only the recursive relationship between analysis and deliberation, with an arrow coming into "analysis" from "data" and an arrow coming out of "deliberation" to "decision." As the figure shows, the group replaced "data" with five specific types of data, relabeled "decision" as "timely decision" (thereby emphasizing that they were frustrated with the lack of progress toward a decision), and added "timely implementation" after "timely decision" to make plain their desire for action on the ground to reduce risk. They also relabeled "analysis" as "competent analysis" and "deliberation" as "democratic deliberation" to emphasize that they have doubts about DOE being able to bioremediate effectively and to accept seriously public participation in the decision-making process.

As can be seen in the diagram however, they added several other features that deserve comment.

The data they want considered in analyses that are conducted concerning bioremediation include the time required to complete treatment, the costs and benefits of treatment, the effectiveness of treatment (level of residual risk that will remain after treatment), the scope of treatment (physical, chemical, and geographical), and a comparison of bioremediation in these areas against other remediation 
technologies. In sum, the group agreed that they were not being provided with enough information to reach an informed opinion about the viability of bioremediation and thus remained unconvinced that it should be adopted as the preferred treatment methodology.

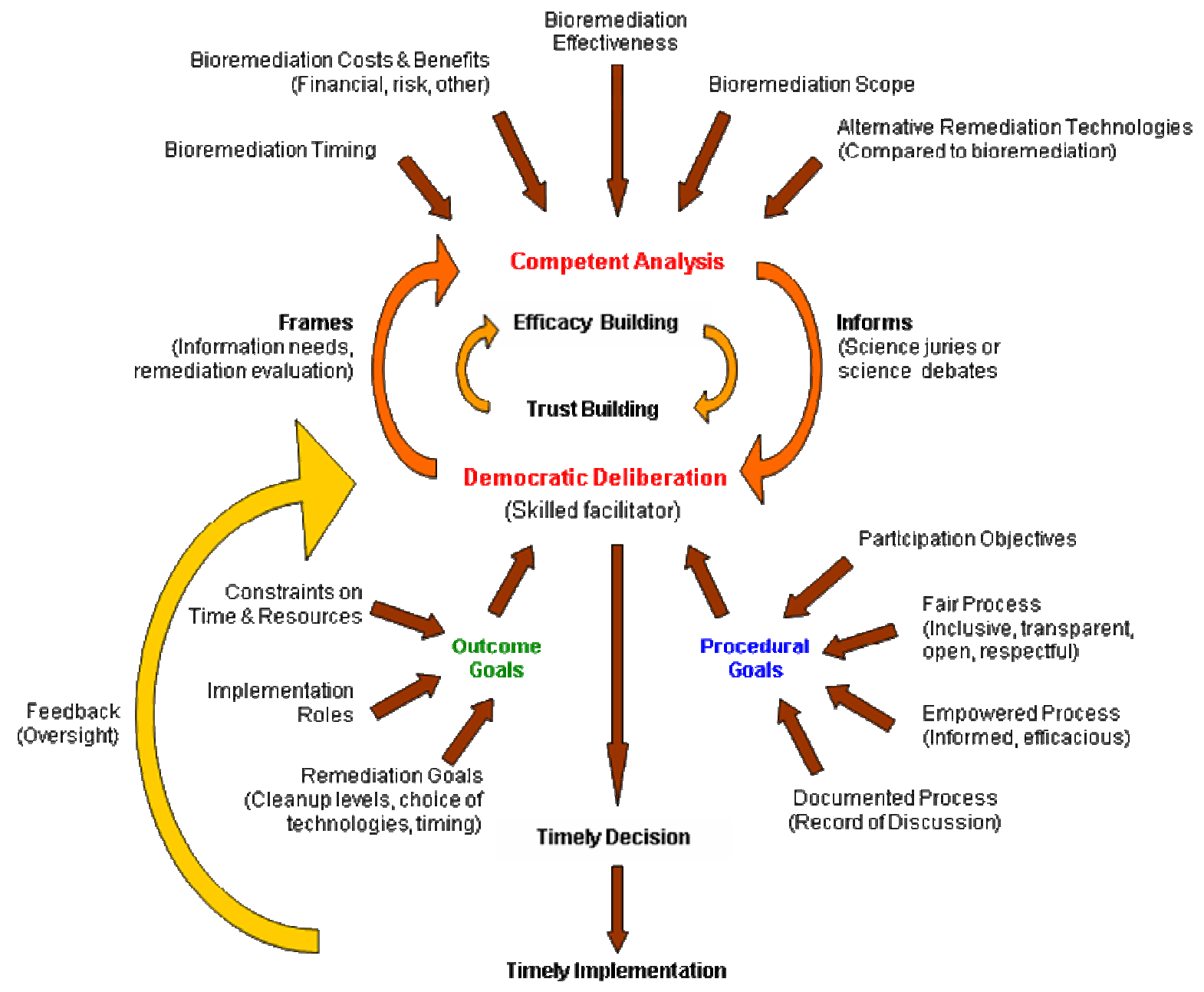

Figure 54. Augmented Analysis and Deliberation Framework

Because the group distrusts DOE, they wanted analytic findings presented to them so that they don't receive just DOE's point of view. They thus prefer independent analyses, science juries, or scientist debates. This would provide more confidence to the group that the information being conveyed is reliable.

With respect to framing, the group wanted to make sure that its information needs will be addressed and that it wanted to be involved in the evaluation of the effectiveness of the bioremediation, should it be implemented. In other words, the group wanted to be involved not only in the remediation decisions but also in tracking and evaluation the remediation itself.

The group added quite a bit of detail to the deliberation agenda. With respect to outcome goals, the group wanted to discuss constraints on the time to complete remediation and its cost (including agreement on who pays). They also wanted to discuss remediation goals (residual risks), choice of technologies, and timing. Finally, they wanted to discuss how the remediation would proceed and their role in tracking remediation. 
With respect to procedural goals, the group wanted to decide for itself how subsequent meetings would be run. They wanted to control the objectives of their participation. They also thought that it was important to develop a "record of discussion" that would publish the minutes of each meeting on the Internet and include a searchable database of all questions asked and answers provided. This record would serve two purposes: it would avoid wasting time reviewing information that had already been covered and it would ensure that all questions are answered. Finally, the group wanted to make sure that the deliberations were fair, open, transparent inclusive, respectful, and informed. The point of deliberation, in their view, was to empower citizens to make informed judgments about bioremediation. They did not want to be manipulated, co-opted, or coerced. As a result, they wanted the group meetings to be professionally facilitated to ensure that participation is fair to all and that progress is achieved.

Perhaps the most innovative change to the original analysis and deliberation framework is the insertion of another recursive relationship inside of the analysis and deliberation relationship. This addition concerned the building of trust and political efficacy. The group recognized that their distrust of DOE and its contractors is significant and that building trust - both between DOE and the public, as well as between members of the public itself, is important. Moreover, participation analysis and deliberation will also build skills in both, and thereby improve the ability of the public to influence decision-making. Though participation is important in getting to a bioremediation decision, the group also views participation as a valuable end in itself. This insight demonstrates that the group values its role in decision-making, which should be respected by DOE personnel.

\section{Conclusion}

Though we were not able to engage the SSABs at Hanford and Los Alamos, the dialogue that we had with the Oak Ridge board was quite productive. We had initially planned to engage the group in deliberation on a list of topics that we had prepared before the meeting. Instead, quite surprisingly, the group wanted to talk about the larger picture: the role that they wanted to have in the bioremediation decision process. The group instinctively knew that they didn't just want to be passively educated by experts nor did they just want to talk about what should be done. Seeing that the group wanted to discuss how they should couple technical information with democratic deliberation, we proposed the NRC framework as a starting point for their discussion. The group accepted this framework and then "ran" with it to develop a sophisticated version with which they were happy. 


\section{CHAPTER 12}

\section{ENHANCEMENT OF PUBLIC SUPPORT FOR BIOREMEDIATION}

\section{Introduction}

In this final chapter, we present our overall conclusions from this study and propose recommendations for how DOE can enhance public support for its subsurface bioremediation programs at the Oak Ridge, Hanford, and Los Alamos facilities.

\section{Summary of Conclusions}

We used a variety of methodologies to investigate how stakeholders living near these sites think about contamination, the risks its poses, and how these risks should be reduced. Those findings that are consistent across methods are considered robust, leading to our confidence that they are internally valid and externally reliable across sites and across the entire population. Table 79 presents a summary of these findings and the methods used to reveal them. The table demonstrates that most findings are supported by more than one methodology.

We can conclude from this evidence summary that bioremediation support is the outcome of a complex interplay of risk perceptions, trust, commitment, efficacy, education, communication, welfare, training, fairness, cost, effectiveness, timeliness, vigilance, and patience. In the next section, we examine the apparent relationship between risk, trust, deference, participation, and bioremediation acceptance. 
Table 79. Summary of Findings and Methods

\begin{tabular}{|c|c|c|c|}
\hline CATEGORY & TOPIC & METHOD & EVIDENCE \\
\hline \multirow{2}{*}{$\begin{array}{l}\text { Demographic } \\
\text { Characteristics }\end{array}$} & $\begin{array}{l}\text { Typical } \\
\text { stakeholder }\end{array}$ & $\begin{array}{l}\text { Telephone survey - } \\
\text { demographic analysis }\end{array}$ & $\begin{array}{l}\text { Owns own home, lived in residence for } 14 \text { years, lived in community for } 30 \text { years, has non-technical } \\
\text { occupation, has undergrad degree, has not worked nor had a family member work at the site }\end{array}$ \\
\hline & Typical site worker & $\begin{array}{l}\text { Telephone survey - } \\
\text { demographic analysis }\end{array}$ & Is male, works in a technical occupation, is more educated, and lives further from the site \\
\hline \multirow{10}{*}{ Risk Perception } & \multirow{5}{*}{ Familiarity } & Narrative analysis & $\begin{array}{l}\text { Former workers and families with workers are less concerned about the contamination and the risks it } \\
\text { poses }\end{array}$ \\
\hline & & Q methodology & Disagreement over whether the public is at risk \\
\hline & & \multirow{3}{*}{$\begin{array}{l}\text { Telephone survey - } \\
\text { risk judgment analysis }\end{array}$} & $\begin{array}{l}\text { Most of the public believes it could or is suffering adverse health effects from site contamination, has } \\
\text { known about contamination a very long time, and believes they know about exposure and health effects }\end{array}$ \\
\hline & & & Beliefs about risk are equally split among those believing they have high, moderate, and low knowledge. \\
\hline & & & $\begin{array}{l}\text { Risk familiarity (knowledge of contamination, exposure routes, and health effects) judgments are closely } \\
\text { related but are not related to judgments about risk severity estimates or risk management }\end{array}$ \\
\hline & \multirow[b]{2}{*}{ Severity } & $\begin{array}{l}\text { Telephone survey - } \\
\text { risk judgment analysis }\end{array}$ & $\begin{array}{l}\text { Large majority of those believing that they are at risk, associate risk with contamination presence and } \\
\text { believe the risk to be moderate to very high }\end{array}$ \\
\hline & & $\begin{array}{l}\text { Telephone survey - } \\
\text { risk judgment analysis }\end{array}$ & $\begin{array}{l}\text { Judgments about risk magnitude, dread, and being at risk are loosely correlated but also tied to how } \\
\text { these risk are managed, particular with regard to a belief of whether contamination presence necessarily } \\
\text { means risk exposure and the appropriate balance between costs and benefits of remediation }\end{array}$ \\
\hline & Control & Narrative analysis & Most believe they have little or no control over risk exposure \\
\hline & \multirow[b]{2}{*}{ Calibration } & Q methodology & Education can reduce perceived risk (some perspectives) \\
\hline & & $\begin{array}{l}\text { Telephone survey - } \\
\text { risk judgment analysis }\end{array}$ & Large majority favor education to help calibrate risk perceptions with scientific risk analyses \\
\hline \multirow{4}{*}{$\begin{array}{l}\text { Risk } \\
\text { Communication }\end{array}$} & $\begin{array}{l}\text { Poor } \\
\text { communication }\end{array}$ & Narrative analysis & $\begin{array}{l}\text { DOE communication about risks to the public is perceived as fraught with problems, such as too much } \\
\text { technical detail, incompleteness, untruthfulness, bias, secrecy, coercion, and co-optation }\end{array}$ \\
\hline & Secrecy & Narrative analysis & Secrecy destroys trust; open and honest communication builds trust \\
\hline & Openness & Q methodology & Communication and openness is important to all perspectives \\
\hline & Co-optation & $\begin{array}{l}\text { Telephone survey - } \\
\text { risk judgment analysis }\end{array}$ & $\begin{array}{l}\text { Large majority reject the proposition that it is OK for agencies to talk the public into accepting risk; } \\
\text { voluntary and informed consent is required }\end{array}$ \\
\hline \multirow{5}{*}{ Education } & Site & Q methodology & Education is important to all perspectives, but without appearing arrogant \\
\hline & Risk & $\begin{array}{l}\text { Telephone survey - } \\
\text { risk judgment analysis }\end{array}$ & Most of the public believes that more information about risk should be provided \\
\hline & \multirow{2}{*}{ Risk avoidance } & Narrative analysis & The more people know about risks, the more they believe they can avoid them \\
\hline & & Q methodology & Disagreement over whether education is sufficient to avoid risk exposure \\
\hline & Bioremediation & Narrative analysis & $\begin{array}{l}\text { Uncertainty and ignorance about bioremediation undermines its acceptance; public is capable of } \\
\text { understanding bioremediation }\end{array}$ \\
\hline \multirow[t]{2}{*}{ Stewardship } & \multirow{2}{*}{$\begin{array}{l}\text { Long-term } \\
\text { commitment }\end{array}$} & Narrative analysis & $\begin{array}{l}\text { DOE will not commit to permanent risk reduction and long-term maintenance that is needed to protect the } \\
\text { public against risks; accelerated cleanup schedule proves this }\end{array}$ \\
\hline & & Q methodology & Turnover is a problem \\
\hline Community Welfare & Importance & Q methodology & Disagreement over the economic dependence of host communities on the DOE facilities \\
\hline
\end{tabular}




\begin{tabular}{|c|c|c|c|}
\hline $\begin{array}{l}\text { Remediation } \\
\text { timeliness }\end{array}$ & Urgency & Narrative analysis & $\begin{array}{l}\text { Perceived inaction and never-ending study has generated frustration and exacerbated a feeling that } \\
\text { urgent action is needed; but others perceive that an accelerated cleanup schedule proves that DOE is not } \\
\text { really serious about permanent risk reduction (long-term stewardship finding below) }\end{array}$ \\
\hline \multirow{4}{*}{$\begin{array}{l}\text { Remediation } \\
\text { Efficiency }\end{array}$} & \multirow{4}{*}{$\begin{array}{l}\text { Cost-benefit } \\
\text { balance }\end{array}$} & Narrative analysis & $\begin{array}{l}\text { Some believe that health is secondary to cost; others believe that money should not be wasted on } \\
\text { political fixes and unreasonable cleanup levels; funds will run out before site is sufficiently cleaned up }\end{array}$ \\
\hline & & \multirow{2}{*}{ Q methodology } & Efficiency is important; do not waste money and resources \\
\hline & & & Disagreement over whether cost-benefit should govern remediation decisions \\
\hline & & $\begin{array}{l}\text { Telephone survey - } \\
\text { risk judgment analysis }\end{array}$ & Need to balance remediation costs against health benefits equally divides the population. \\
\hline \multirow{5}{*}{ More study } & Speculation & Narrative analysis & Money should not be wasted on unproven technologies \\
\hline & \multirow{4}{*}{$\begin{array}{l}\text { Bioremediation } \\
\text { Alternatives }\end{array}$} & \multirow{2}{*}{ Q methodology } & Other remediation technologies should also be investigated (some perspectives) \\
\hline & & & Disagreement over whether technologies are studied to death \\
\hline & & \multirow[b]{2}{*}{$\begin{array}{l}\text { Telephone survey - } \\
\text { support analysis }\end{array}$} & Most of the public believes that more study is needed to find the best risk reduction technologies \\
\hline & & & $\begin{array}{l}\text { Desire for more study does not correlate with any trust or risk measure, probably because bioremediation } \\
\text { salience is low }\end{array}$ \\
\hline \multirow{3}{*}{$\begin{array}{l}\text { Remediation } \\
\text { Effectiveness }\end{array}$} & \multirow{3}{*}{ Residual risk } & Narrative analysis & $\begin{array}{l}\text { Skepticism about its effectiveness and the health risks posed during bioremediation and that will remain } \\
\text { after bioremediation is finished }\end{array}$ \\
\hline & & \multirow{2}{*}{ Q methodology } & Bioremediation can work (some perspectives) \\
\hline & & & Bioremediation is a long-term solution (some perspectives) \\
\hline \multirow{7}{*}{$\begin{array}{l}\text { Bioremediation } \\
\quad \text { Support }\end{array}$} & No opinion & $\begin{array}{l}\text { Telephone survey - } \\
\text { support analysis }\end{array}$ & $\begin{array}{l}40 \% \text { of public has no opinion about bioremediation, but those that do generally support it; therefore, more } \\
\text { information (if it confirms its desirability) will likely increase support }\end{array}$ \\
\hline & Soft & $\begin{array}{l}\text { Telephone survey - } \\
\text { support analysis }\end{array}$ & Support for bioremediation, however, is soft and subject to easy change in the face of new knowledge \\
\hline & Trust & $\begin{array}{l}\text { Telephone survey - } \\
\text { support analysis }\end{array}$ & $\begin{array}{l}\text { Support is correlated with DOE trust and overall social trust demonstrating that trust stimulates } \\
\text { acceptance }\end{array}$ \\
\hline & Risk & $\begin{array}{l}\text { Telephone survey - } \\
\text { support analysis }\end{array}$ & $\begin{array}{l}\text { Support is correlated negatively with perceived risk severity and dreadfulness, which suggests that the } \\
\text { supporting public believes that the risk of bioremediation failure is not high (again, suggesting the } \\
\text { softness of this support) }\end{array}$ \\
\hline & \multirow[b]{2}{*}{ Short-term fix } & \multirow{2}{*}{$\begin{array}{l}\text { Telephone survey - } \\
\text { support analysis }\end{array}$} & Most believe that bioremediation is at best a short-term fix and that other technologies will be required \\
\hline & & & $\begin{array}{l}\text { Support for bioremediation is undermined by those who see it as only a short-term fix; these stakeholders } \\
\text { are especially opposed to co-optation and a belief that they are at risk }\end{array}$ \\
\hline & Trust and efficacy & Stakeholder dialogue & Trust and efficacy are both important to gaining public support of bioremediation \\
\hline DOE/Social Trust & Relationship & $\begin{array}{l}\text { Telephone survey - } \\
\text { trust judgment } \\
\text { analysis }\end{array}$ & $\begin{array}{l}\text { Correlation between DOE and social trust is low; correlations that exist are weak and related to similarity } \\
\text { of trust measures (e.g., competence to competence, value similarity to value similarity) }\end{array}$ \\
\hline
\end{tabular}




\begin{tabular}{|c|c|c|c|}
\hline \multirow{15}{*}{ DOE Trust } & \multirow{7}{*}{ Overall } & Narrative analysis & Many people express a distrust of DOE; trust is major factor in desire to participate \\
\hline & & \multirow{4}{*}{ Q methodology } & The need to build trust is important to all perspectives \\
\hline & & & Disagreement on whether DOE is trusted (competence, bias, secrecy, certainty, liability, responsible) \\
\hline & & & DOE sometimes appears arrogant and overconfident (some perspectives) \\
\hline & & & Stakeholders can overcome the political power of DOE (some perspectives) \\
\hline & & \multirow{2}{*}{$\begin{array}{l}\text { Telephone survey- } \\
\text { trust judgment } \\
\text { analysis }\end{array}$} & Public trust of DOE decision-making and site management is split; trusters believe that risk is higher \\
\hline & & & Overall trust is highly dependent on the public's judgments of technical competence and shared values \\
\hline & \multirow[b]{2}{*}{$\begin{array}{l}\text { Technical } \\
\text { competence }\end{array}$} & Narrative analysis & $\begin{array}{l}\text { Mixed reaction; judgments of incompetence are primarily based on political interference, inadequate funding, } \\
\text { inadequate regulations, and administrative turnover }\end{array}$ \\
\hline & & $\begin{array}{l}\text { Telephone survey - } \\
\text { trust judgment } \\
\text { analysis }\end{array}$ & $\begin{array}{l}\text { On average, the public judges the technical competence of DOE as moderate; DOE distrusters and risk } \\
\text { aversives are more critical }\end{array}$ \\
\hline & \multirow{3}{*}{ Value similarity } & Narrative analysis & Doubts about shared values due to rapid turnover and unnecessary secrecy \\
\hline & & $\begin{array}{l}\text { Telephone survey - } \\
\text { trust judgment } \\
\text { analysis }\end{array}$ & On average, the public judges the value similarity of DOE lower than its technical competence \\
\hline & & Q methodology & $\begin{array}{l}\text { Demonstrating that DOE places high value on public health and community welfare is important to all } \\
\text { perspectives }\end{array}$ \\
\hline & Deference & $\begin{array}{l}\text { Telephone survey - } \\
\text { trust judgment } \\
\text { analysis }\end{array}$ & $\begin{array}{l}\text { On average, the public is moderately willing to defer to DOE in remediation decision-making; high trusters and } \\
\text { low risk perceivers are more willing; low trusters and high risk perceivers are less willing }\end{array}$ \\
\hline & \multirow{2}{*}{$\begin{array}{l}\text { Political } \\
\text { efficacy }\end{array}$} & \multirow{2}{*}{$\begin{array}{l}\text { Telephone survey - } \\
\text { trust judgment } \\
\text { analysis }\end{array}$} & $\begin{array}{l}\text { A large majority of the public believes they have low or very low influence over DOE decision-making; most } \\
\text { believe it is very low }\end{array}$ \\
\hline & & & $\begin{array}{l}\text { The public's belief that they can influence DOE decision-making is related to their willingness to trust DOE but } \\
\text { not their support of bioremediation, which suggests that this support is soft and subject to quick change }\end{array}$ \\
\hline \multirow{7}{*}{ Social Trust } & \multirow{4}{*}{ Overall } & Narrative analysis & Mixed trust of community citizens \\
\hline & & Q methodology & $\begin{array}{l}\text { Disagreement over whether stakeholders can be trusted with remediation decisions; some argue that decisions } \\
\text { should be based on facts only and that too much emotion and not enough rationality is involved; others disagree }\end{array}$ \\
\hline & & \multirow{2}{*}{$\begin{array}{l}\text { Telephone survey- } \\
\text { trust judgment } \\
\text { analysis }\end{array}$} & $\begin{array}{l}\text { Public is about equally divided on its judgment of the trustworthiness of the public to manage risks; risk } \\
\text { aversives are more distrusting }\end{array}$ \\
\hline & & & Correlations between overall trust and competence/value similarity are quite high \\
\hline & $\begin{array}{l}\text { Technical } \\
\text { competence }\end{array}$ & $\begin{array}{l}\text { Telephone survey - } \\
\text { trust judgment } \\
\text { analysis }\end{array}$ & Most rate technical competence of fellow members of the public as low or very low \\
\hline & Value similarity & $\begin{array}{l}\text { Telephone survey - } \\
\text { trust judgment } \\
\text { analysis }\end{array}$ & Large majority believe they share values with others at least moderately \\
\hline & Deference & $\begin{array}{l}\text { Telephone survey - } \\
\text { trust judgment } \\
\text { analysis }\end{array}$ & Few are willing to defer to other members of the public to manage risks \\
\hline Expert Trust & Overall & ve analysis & ent, DOE, and fellow st \\
\hline
\end{tabular}




\begin{tabular}{|c|c|c|c|}
\hline & & & $\begin{array}{l}\text { experts, some trust them, some only trust independent experts, some trust no experts due to personal agendas } \\
\text { and greed. }\end{array}$ \\
\hline & & Q methodology & Experts are trusted (some perspectives) \\
\hline $\begin{array}{l}\text { State } \\
\text { Government } \\
\text { Trust }\end{array}$ & Overall & Narrative analysis & Trust of state government is higher than DOE and fellow stakeholders, but less than experts \\
\hline \multirow{9}{*}{$\begin{array}{l}\text { Stakeholder } \\
\text { Participation }\end{array}$} & \multirow[b]{2}{*}{ Interest } & Narrative analysis & Most want to be involved in decision-making but only if the involvement is not a waste of time \\
\hline & & Q methodology & $\begin{array}{l}\text { Public participation should continue throughout the process, access to information should be guaranteed, and all } \\
\text { points of view should be considered (some perspectives) }\end{array}$ \\
\hline & \multirow{6}{*}{ Intensity } & Narrative analysis & $\begin{array}{l}\text { Most prefer deliberation and consultation for improved, credible, and public supported decisions; a few prefer } \\
\text { only information dissemination; a very few are willing to defer to DOE to make these decisions because they are } \\
\text { ultimately responsible for the site and they have the authority and money to get cleanup done }\end{array}$ \\
\hline & & Q methodology & $\begin{array}{l}\text { Consultation is more important than drawn-out deliberation; public has limited time for participation (some } \\
\text { perspectives) }\end{array}$ \\
\hline & & Q methodology & Disagreement on whether decisions by committee can work \\
\hline & & \multirow{2}{*}{$\begin{array}{l}\text { Telephone survey - } \\
\text { participation analysis }\end{array}$} & Highest preference is independent facilitator deliberation; lowest is feedback \\
\hline & & & $\begin{array}{l}\text { Trust and participation preference are related; those who trust DOE prefer feedback (a low power strategy) and } \\
\text { those who don't prefer independent facilitation (a high power strategy) }\end{array}$ \\
\hline & & $\begin{array}{l}\text { Telephone survey - } \\
\text { test of model }\end{array}$ & $\begin{array}{l}\text { Deference requires high trust; DOE should not expect that everyone will be happy with any choice it makes } \\
\text { regarding public participation - its best hope is to minimize opposition }\end{array}$ \\
\hline & Fairness & Q methodology & Disagreement on whether some groups are over-represented and others are under-represented \\
\hline
\end{tabular}




\section{Relationships among Risk, Trust, Deference, Participation, and Support}

Figure 55 presents our proposal for the relationships among the most important elements of bioremediation acceptance that we deduced from this study.

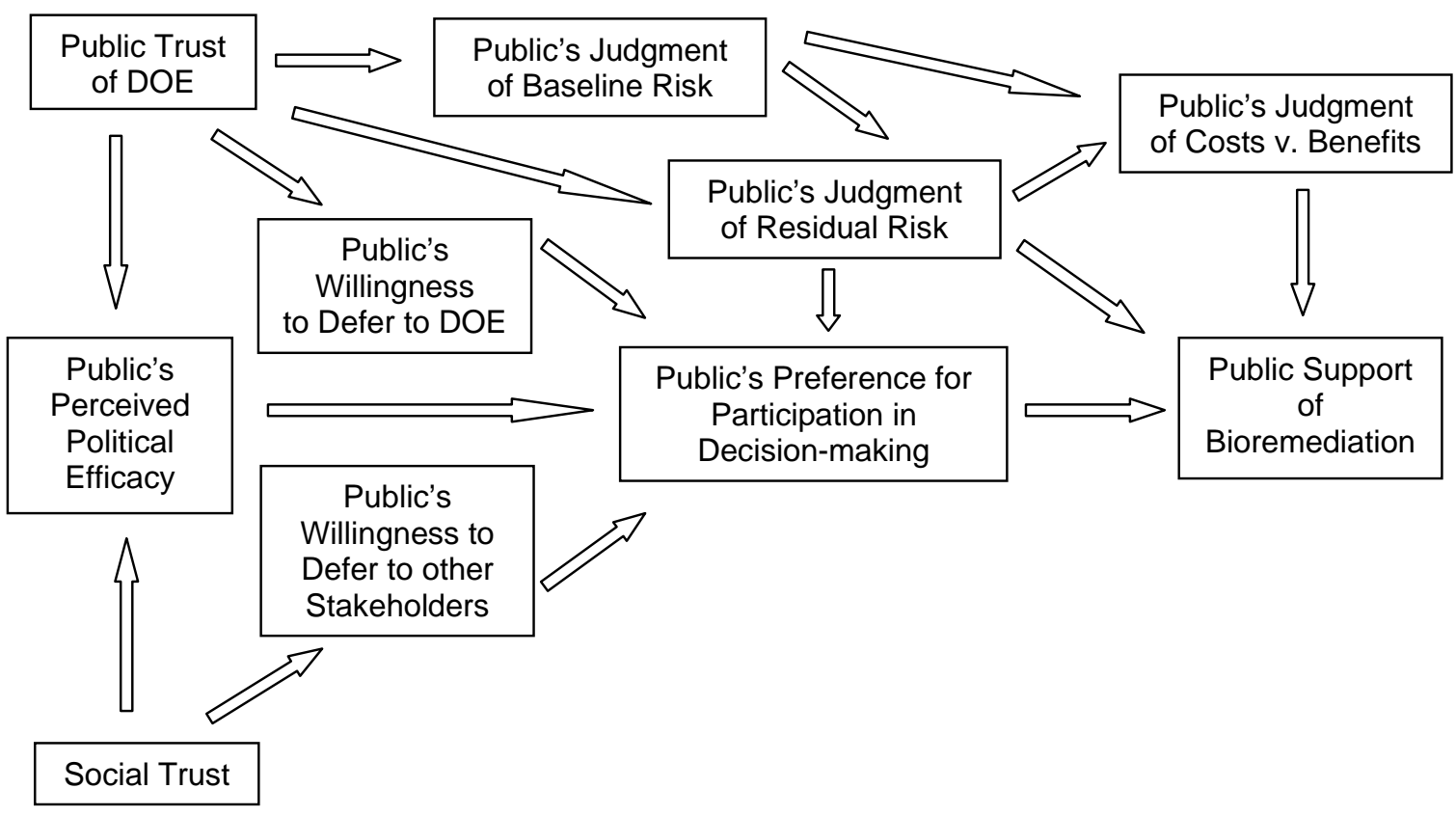

Figure 55. Schematic of Variables Influencing Bioremediation Success

In this diagram, trust is fundamental: it influences both deference and efficacy. With high trust, deference is accorded and perceived efficacy is increased. Alternatively, low trust erodes perceived efficacy. The erosion of efficacy generally stimulates the demand for more power in order to increase public influence over decisions made that affect the public interest.

Trust in DOE also influences the perceived risk that the public faces from contamination. This provides comfort and a willingness to be less vigilant. On the other hand, if trust is low, then a desire to be vigilant to protect against threats to public health is increased.

The combination of high perceived risk (high stakes), inefficacy and unwillingness to defer to DOE's discretion in decision-making leads to a greater demand for empowered public participation.

In this circumstance, demands for participation will increase along with an insistence that more power be accorded to the public in the decision-making process.

The public's judgment of the effectiveness of bioremediation will also influence their participation preference. If unacceptable residual risk remains, the stakes of not participation will be higher and so will their demands for empowered participation.

The public judgments of both baseline and residual risk (decision stakes) also influence their judgment of the relative costs and benefits of risk reduction. Obviously, the higher these risks, the greater the perceived benefit of risk reduction and the more favorable the benefit-cost balance becomes.

Finally, bioremediation acceptance is influence by the perceived benefit-cost balance, the effectiveness of remediation, and the participation process that is used to make a decision. In a low-trust environment, support will become more difficult unless the public becomes convinced through an empowered participation process that risks will be reduced to safe levels regardless of cost. On the other hand, if trust is high, then perceived risk, vigilance, and demands for participation are reduced, which means that bioremediation acceptance will be easier to obtain and maintain. 


\section{Public Participation Recommendation}

What strategy should be used by DOE to involve stakeholders in the decision-making and implementation processes? Because trust of DOE is relatively low, we recommend a two-stage participation process. Initially, we recommend that an efficient, yet productive and empowered process such as independently facilitated deliberation be instituted. This means that the public should be provided a role in defining the agenda, framing the questions that should be answered, and evaluating remediation alternatives. While extant support for bioremediation exists, we believe that this support is not strong. Nevertheless, DOE will not have to overcome much opposition but rather preserve the support that bioremediation enjoys.

After trust is built and public concern ameliorates, we recommend that independently-facilitated deliberation be replaced with consultation. By this, we mean that DOE consults with the public as decisions need to be made about its proposed decisions and the rationales for them. Perhaps a multiorganizational advisory committee that is broadly representative and includes selected officials could work. To improve effectiveness of this strategy, DOE should provide participants with complete, timely, succinct, and easy-to-comprehend information. DOE must consider the suggestions of this committee seriously or else losing the trust that it so earnestly earned in the first stage.

The public generally trusts experts and recognizes that DOE has the legal authority and financial means to complete site remediation. This recognition, along with public participation fatigue forged from previous participation efforts, can form a legitimate basis for reduced participation intensity once trust is gained and deference is increased.

\section{Bioremediation Enhancement Recommendations}

Of course, the proper choice and implementation of an appropriate public participation strategy, as just suggested, is essential. However, other recommendations can be offered to improve bioremediation acceptance.

First, DOE should act quickly to prove that bioremediation is not a quick fix that will leave unacceptable risk in place. Experts should reach consensus on the effectiveness of bioremediation (and that it is not just a cost-cutting measure) and, once selected, should be implemented quickly. DOE should provide assurance that it is committed to long-term care. We suspect that bioremediation will need to be accompanied with other technologies that reduce the concentration of toxic metals and radionuclides onsite and reduce offsite exposure.

Second, DOE should expend significant resources to build public trust by being more open, communicative, responsible, humble, and inclusive. Trust must be earned through transparency, shared values, demonstrated technical competence, inclusiveness, fairness, forthrightness, and willingness to share power. Trust cannot be earned through pro forma public meetings. Meetings with unclear agendas, lack of concrete results, and little demonstrated progress only builds frustration and anger and destroys trust. DOE should also build trust in the community at large through demonstrated consideration of its welfare - both health and economic. Trust is indeed an important component of social capital that is worth the investment.

Third, stakeholders want more information and an honest and forthright communication process. This is encouraging because the public acknowledges that its risk perceptions may need to be calibrated against scientific risk assessments. The public also acknowledges that it needs to know more about bioremediation. Educational programs are encouraged, but they must not be seen as co-optive, coercive, or biased. Uncertainties should be admitted. Again, a properly designed public participation process can help immensely in shaping education and communication programs.

Our bottom line is to reinforce our belief that public support for bioremediation is tenuous and can be easily undermined with new knowledge that questions its effectiveness, cost, or timeliness. It can also be undermined if trust and its concomitant risk perceptions are not properly addressed. We recommend that DOE not rely too heavily on extant public expressions of support. Rather, we suggest that DOE engage in an aggressive informational program that pays special attention to building public confidence in bioremediation effectiveness at reducing risk, its permanence in reducing concentrations at the source and immobilizing movement, its cost, its timeliness, and its performance against alternative technologies. The best forum for achieving this is one that also build trust and efficacy. The sequencing of independent facilitated deliberation followed by consultation is, in our opinion, the best path to success. 


\section{REFERENCES}

Bradbury, J., and K. Branch. 1999. An Evaluation of the Effectiveness of Local Site-Specific Advisory Boards for U.S. Department of Energy Environmental Restoration Programs. Report PNNL-12139. Washington, DC: Pacific Northwest National Laboratory.

DOE Indian Nations Program Web Site. http://www.orp.doe.gov/?

Focht, Will, and Zev Trachtenberg. 2004. "A Trust-Based Guide to Stakeholder Participation." In Swimming Upstream: Collaborative Approaches to Watershed Management, ed. P. Sabatier, W. Focht, M. Lubell, Z. Trachtenberg, A. Vedlitz, and M. Matlock. Cambridge, MA: MIT Press.

Hanford Reservation: http://www.hanford.gov/.

Los Alamos National Laboratory: http://www.lanl.gov/.

Oak Ridge National Laboratory: http://www.ornl.gov/.

Oak Ridge Convention and Visitors Bureau: http://oakridgevisitor.com/.

Oregon Hanford Waste Board. 2002. River without Waste: Recommendations for Protecting the Columbia River from Hanford Site Nuclear Waste; DOE Grant \#DE-FG06-94RL2803; December.

Pacific Northwest National Laboratory: http://www.pnl.gov/.

U.S. Army Corps of Engineers, Northwestern Division: http://www.nwd.usace.army.mil/ps/colrvbsn.htm.

U.S. Department of Energy. 2003. "A NABIR Primer: Bioremediation of Metals and Radionuclides: What It Is and How It Works; $2^{\text {nd }}$ Edition. LBNL 42595(2003). 


\title{
APPENDIX A RESEARCH FORMS
}

\author{
Bioremediation Description \\ Telephone Log \\ Consent Form \\ Personal Interview Forms
}

Telephone Survey Questionnaire 


\section{BIOREMEDIATION DESCRIPTION}

Metal and radionuclide contamination of deep groundwater is a problem occurring on many DOE lands. The picture below depicts a typical situation. A complex mixture of metals and radionuclides including chromium ( $\mathrm{Cr}$ ), uranium $(\mathrm{U})$, and technetium $(\mathrm{Tc})$ has entered an aquifer that is connected to the surface. Such aquifers are often oxidizing environments in which elements such as $\mathrm{Cr}, \mathrm{U}$, and $\mathrm{Tc}$ are mobile in their oxidized forms and move with the groundwater. If the groundwater is more than about 45 feet below the surface, it is very difficult to pump out the contaminated water to clean it. The "subsurface bioremediation" treatment option leaves the water under the ground and encourages microorganisms that live in such environments to alter the form of the contaminants so that they are retained on minerals within the sediments and are thus removed from the groundwater before they reach sensitive water supplies such as drinking water wells or rivers.

By providing nutrients to microorganisms that live underground, we can encourage them to grow and create environments that will stop the movement of metals and radionuclides in the groundwater. For example, some microorganisms are able to conserve energy for growth and reproduction by converting oxidized iron in mineral structures to reduced iron. [Chemically this change is depicted as $\mathrm{Fe}(\mathrm{III}) \rightarrow$ $\mathrm{Fe}(\mathrm{II})$.] The reduced iron can, in turn, chemically reduce the metals and radionuclides to forms that become associated with the soil and are less likely to move with the groundwater. This process produces a relatively stable reactive barrier that may exist for many years in groundwater environments, forming a long-lasting barrier to further transport of the contaminants that is permeable to the flow of groundwater.

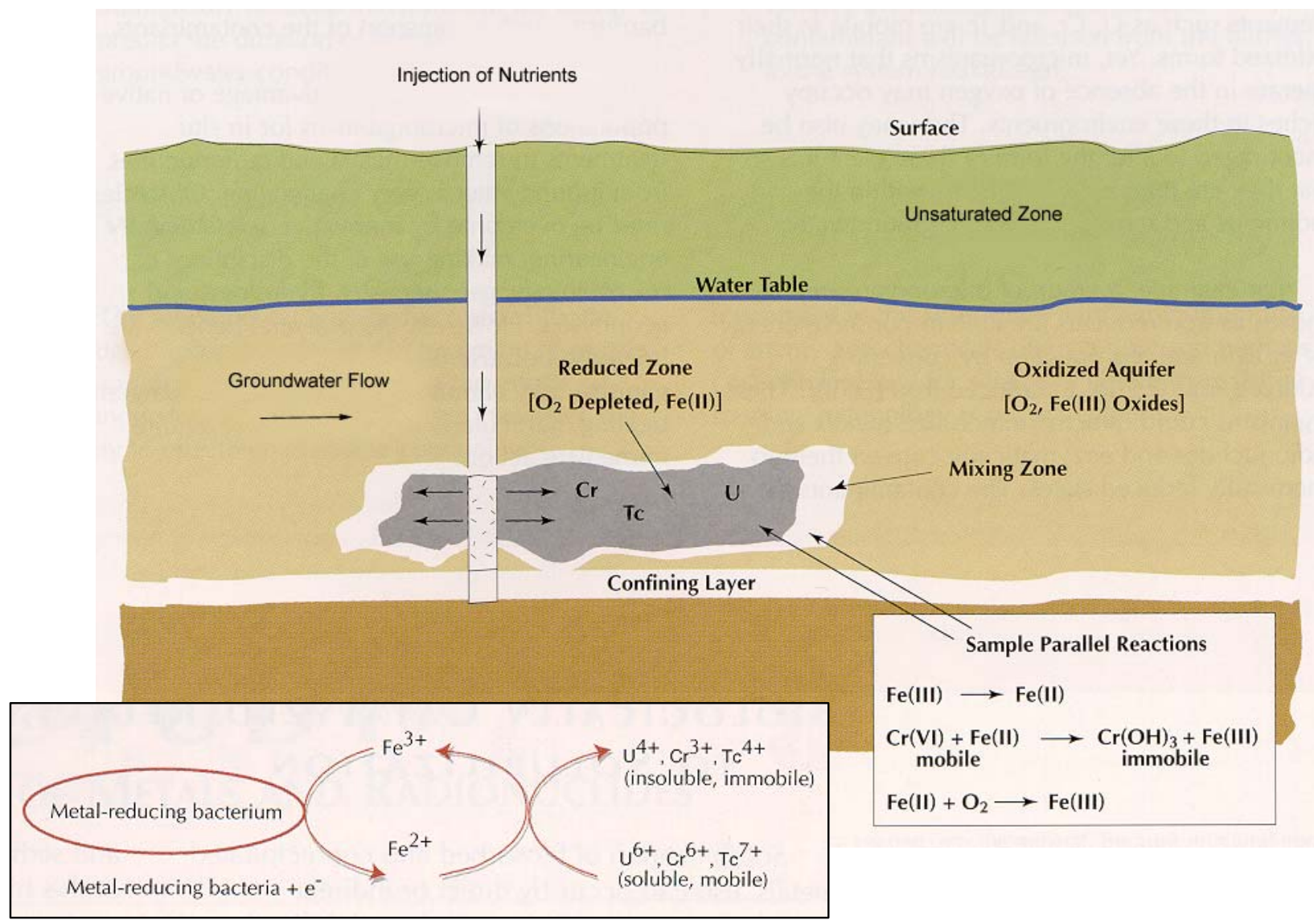

\section{GLOSSARY}

groundwater: water within the earth that supplies wells and springs radionuclide: a radioactive species of atom characterized by its atomic structure aquifer: a water-bearing stratum of permeable rock, sand, or gravel oxidize: to combine with oxygen or to change by removing one or more electrons microorganism: an organism of microscopic or ultramicroscopic size, for example, a bacterium permeable: having pores or openings that permit liquids or gases to pass through 


\section{TELEPHONE LOG}

DATE:

PERSON CALLED:

TELEPHONE :

(day)

(evening)

REFERENCE:

CONTACT MADE?

CALL BACK?

(day/time)

ACCEPTED?

SCHEDULED APPOINTMENT DATE:

SCHEDULED APPOINTMENT TIME:

SCHEDULED APPOINTMENT LOCATION:

COMMENTS 


\section{INFORMED CONSENT}

\section{For Research Being Conducted under the Auspices of Oklahoma State University}

You are being asked to participate in this research project because your views and opinions about cleaning-up ground water by using bacteria are important. This research is being funded by the United States Department of Energy. Your views and the views of others in the community will be anonymously reported to the DOE. The success of this project depends on your honest and forthright input. Your opinions are essential to better understanding the views of people in the community. We assure you that your responses will be treated confidentially and not be attributable to you. There is no penalty of any sort for refusing to participate.

This research will be conducted in two parts. In today's session, which may take us two hours or so to complete, I will ask you to participate in the following activities:

- Complete a short questionnaire about yourself.

- Freely describe your concerns and preferences regarding ground water clean-up.

- Answer questions related to consensus building efforts.

- Describe your awareness of risk due to metals and radioactive materials in ground water.

- Rank statements related to ground water clean-up methods

- Rank four stakeholder participation options in order of your preference for them.

- Judge how much you trust government officials, experts, and fellow stakeholders.

The second part will be done by mail.

- Sort two groups of 40 to 60 statements taken from the first round of interviews.

- Write a brief explanation of the sorted statements.

I need to understand your views and opinions as accurately as possible. With your permission, I would like to tape record our discussions. After the interviews, I will have the tapes transcribed by a professional transcriptionist. No one outside of the research team will have access to the tapes nor will anyone be able to attribute any statement, response, opinion, or view to any particular person. Once the interviews and transcriptions are completed, the tapes will be destroyed to further protect your confidentiality. If you agree to having this interview audiotaped, please check the box next to the statement that follows.

\section{I agree to be audiotaped during this interview}

This research is part of a research effort that includes Dr. Will Focht of Oklahoma State University. The actual interviews will be carried out by Matt Albright, a doctoral graduate student working under the supervision of Dr. Focht. If you have any questions, you may contact Dr. Focht at the Department of Political Science, Oklahoma State University, 519 Math Sciences, Stillwater, OK 74078-1060; telephone number (405) 744-5642; email: wfocht@okstate.edu. You may also contact Gay Clarkson, IRB Executive Secretary, Oklahoma State University, 305 Whitehurst, Stillwater, OK; telephone number (405) 544-5700. 
It is important that you understand the following guidelines:

1. Your participation in this research is entirely voluntary. There is no penalty for refusing to participate. You may stop at any time. The information we collect in this study will be held in strict confidence and all participants will remain anonymous to anyone outside the research team.

2. Our research focuses on how people, in general, express concerns and preferences about technologies for cleaning up metals and radioactive materials in ground water.

3. We are interested in only grouped information, not in individual responses.

Please indicate your willingness to participate in this research by signing your name.

I have read and fully understand this consent form. I sign it freely \& voluntarily. A copy has been given to me.

Date:

Time:

Name (Printed) Signature

Address

e-mail

Phone

I certify that I have personally explained all elements of this form to before requesting the participant to sign it.

Signed: 


\section{PERSONAL INTERVIEW FORMS}

Participant \#

\section{DEMOGRAPHIC QUESTIONNAIRE}

The following 7 questions concern facts about yourself.

1. Gender

[ ] Male [ ] Female

2. Race

[ ] White [ ] Native American [ ] African-American

[ ] Hispanic [ ] Asian-American [ ] Other (specify)

3. Age

[ ] 20-24 [ ] 25-29 [ ] 30-34 [ ] 35-39

[ ] 40-44 [ ] 45-49 [ ] 50-54 [ ] 55-59

[ ] 60-64 [ ] 65-69 [ ] 70-74 [ ] $75+$

4. Highest level of formal education
[ ] Grade School
[ ] High School
[ ] Trade School
[ ] Some college
[ ] Bachelor's
[ ] Some grad
[ ] Master's
[ ] Doctoral/Professional

5. Occupation (specify)

6. Household annual income
[ ] $<\$ 10 \mathrm{~K}$
[ ] $\$ 10 \mathrm{~K}-\$ 29,999$
[ ] $\$ 30 \mathrm{~K}-\$ 49,999$
[ ] $\$ 50 \mathrm{~K}-\$ 69,999$
[ ] $\$ 70 \mathrm{~K}-\$ 89,999$
[ ] \$90K - \$109,999
[ ] $\$ 110 K-\$ 129,999$
[ ] $\$ 130 K-\$ 149,999$
[ ] \$150K - 699,999
[ ] > $\$ 170 \mathrm{~K}$ 


\section{SURFACE CONTAMINATION RISK PERCEPTIONS}

(Circle the hash-mark that best represents your judgment. Explain each judgment.)

\section{Contamination Risks}

If you are not aware of subsurface metal and/or radionuclide contamination at this site please answer the following questions based on what you know about subsurface metal and radionuclide contamination in general.

1. For you personally, how significant are the health risks posed by subsurface contamination from the sight?

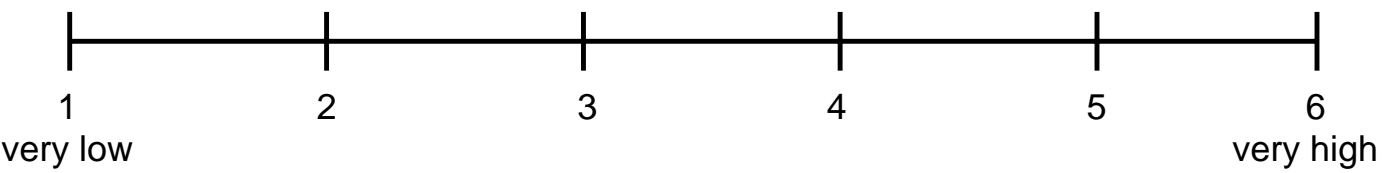

2. To what extent are you aware of health risks from exposure to contaminants at the site?

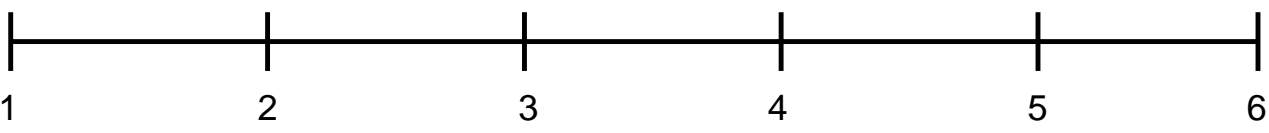

risk level

known precisely

risk level

not known

3. To what extent are the health risks from exposure to contaminants known to science?

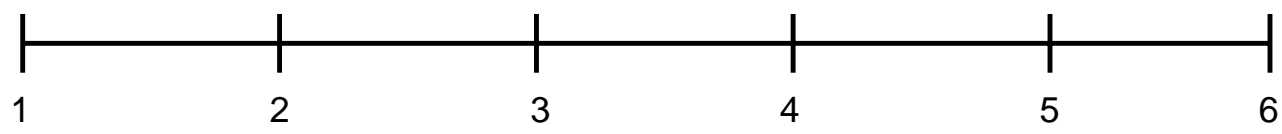

risk level

known precisely

risk level

not known

4. How long after initial exposure to contamination do you believe ill effects will be?

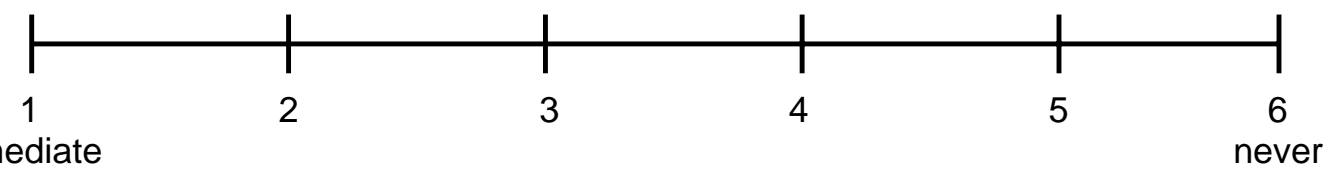

5. To what extent is the health risk voluntary?

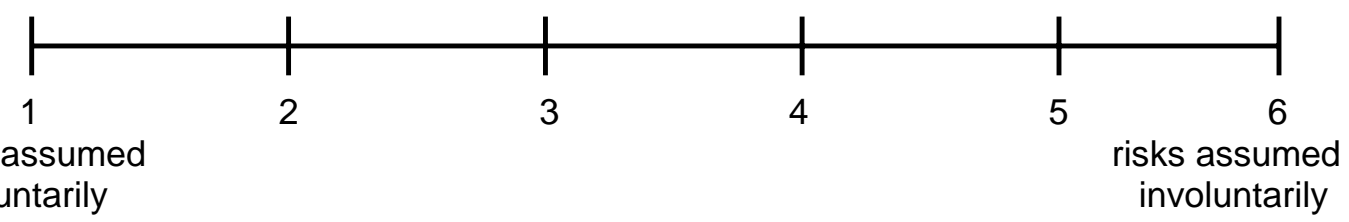


6. To what extent are you in control of how much risk you are exposed to?

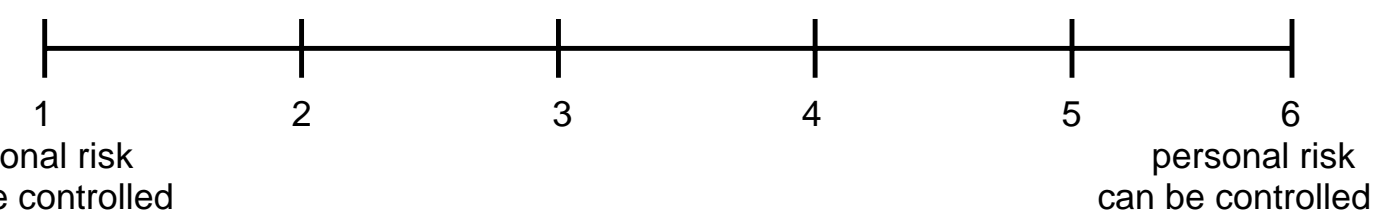

7. To what extent can programs provide long-term control of contamination?

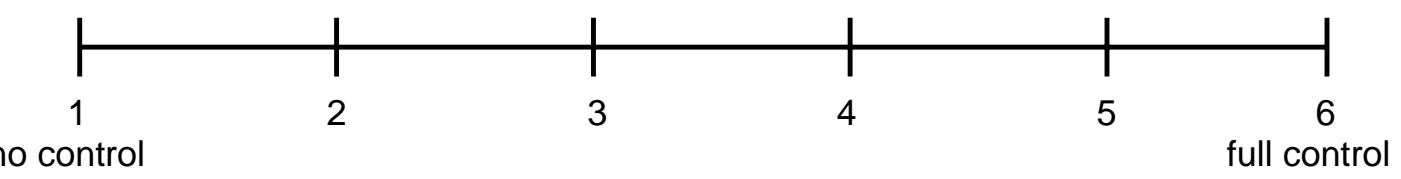

8. Is this a risk that you have learned to live with and can think about reasonably calmly, or is it one that you have great dread for - on the level of a gut reaction?

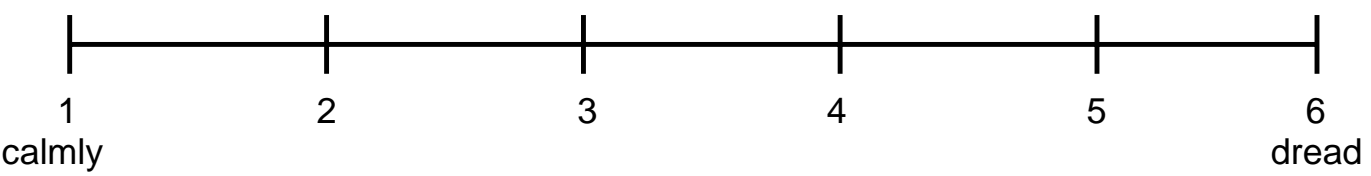

9. Do you feel the consequences of exposure to contamination from the site will be fatal?

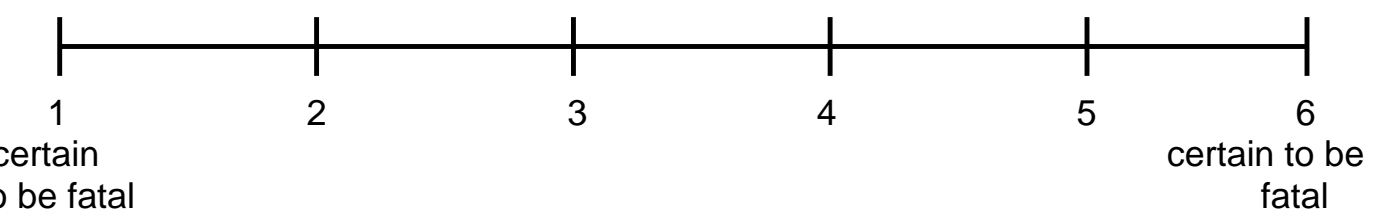




\section{Bioremediation Risks}

Bioremediation of subsurface metals and radionuclides also creates certain risks. These risks are likely to vary with the bioremediation technique employed. Please read the brief description of subsurface bioremediation that we have provided and keep this description of bioremediation in-mind as you answer the following questions.

1. For you personally, how significant are the health risks posed by subsurface bioremediation at the sight?

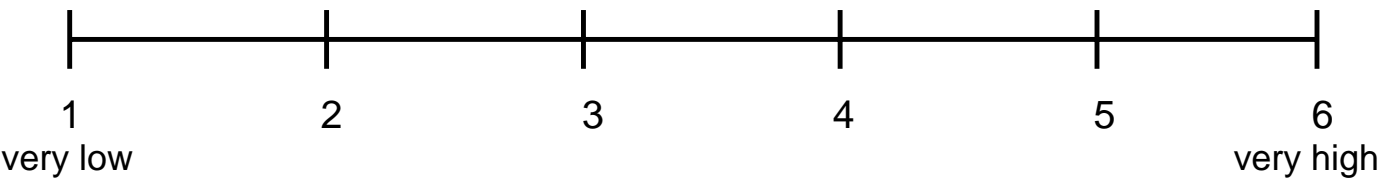

2. To what extent are you aware of health risks from bioremediation of contaminants at the site?

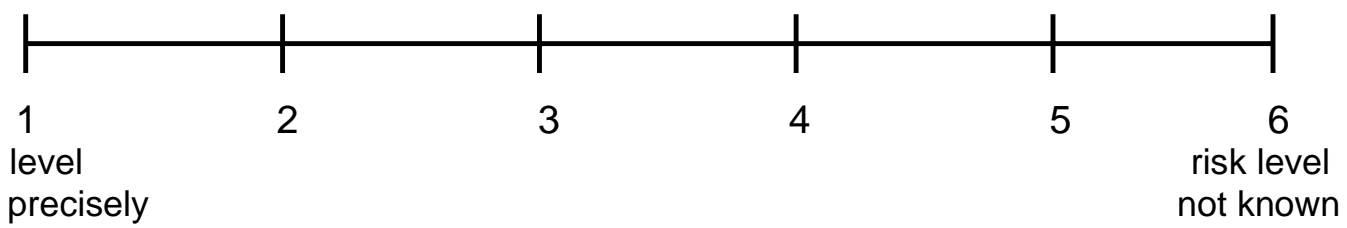

3. To what extent are the health risks from exposure to bioremediation contaminants known to science?

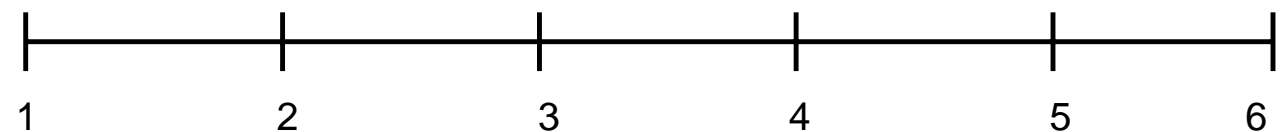

risk level

known precisely

risk level

not known

4. How long after initial exposure to contamination from bioremediation do you believe ill effects will be?

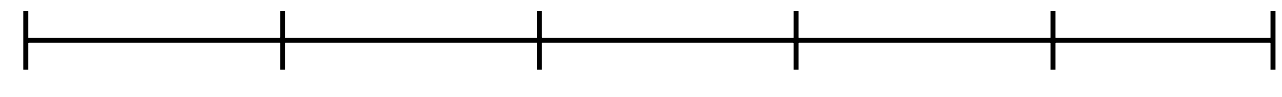

1

2

3

4

5

6

immediate

never

5. To what extent is the health risk voluntary?

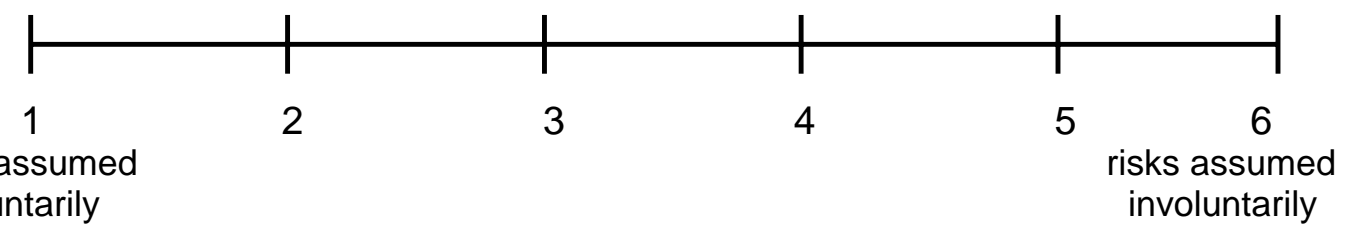


6. To what extent are you in control of how much risk you are exposed to by bioremediation?

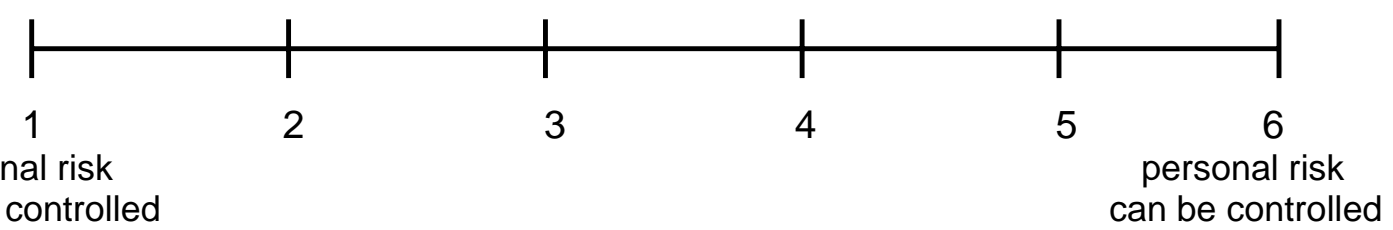

7. To what extent can programs provide long-term control of contamination using bioremediation?

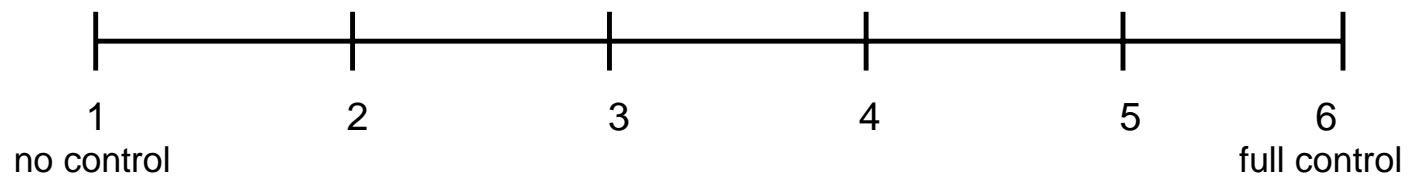

8. Is this a risk that you have learned to live with and can think about reasonably calmly, or is it one that you have great dread for - on the level of a gut reaction?

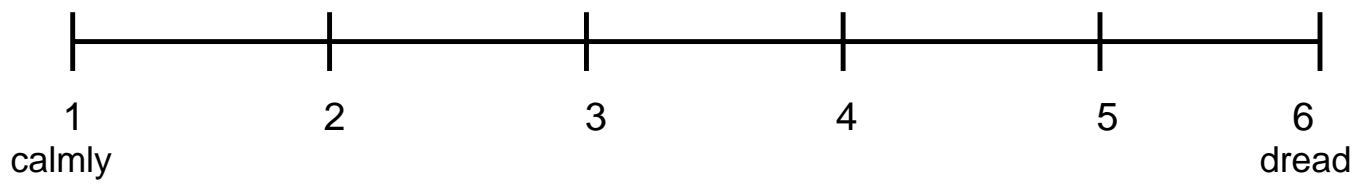

9. Do you feel the consequences of exposure to contamination from bioremediation at the site will be fatal?

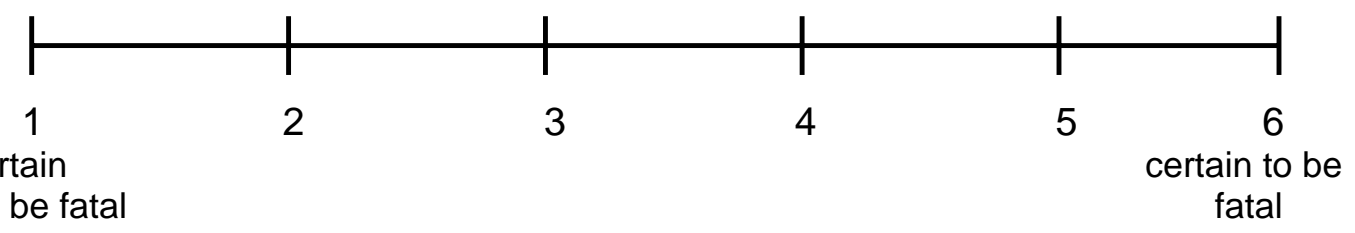




\section{Comparison of Risks}

1. To what extent would the bioremediation of metals and radionuclides in the subsurface reduce total risk to you personally?

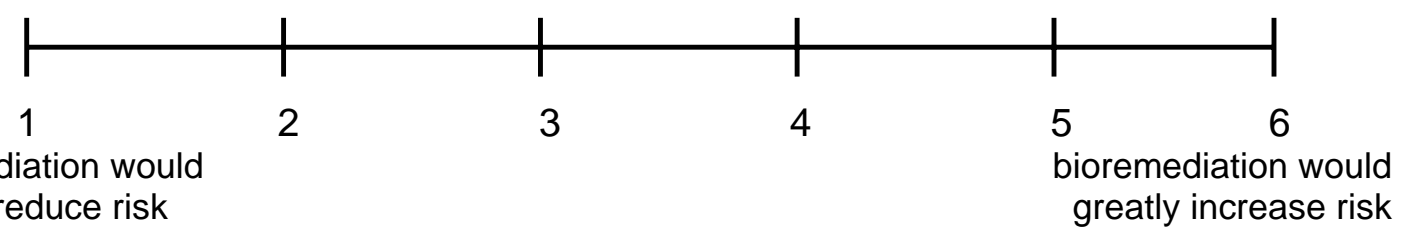

2. To what extent would the bioremediation of metals and radionuclides in the subsurface reduce total risk to the local/regional community?

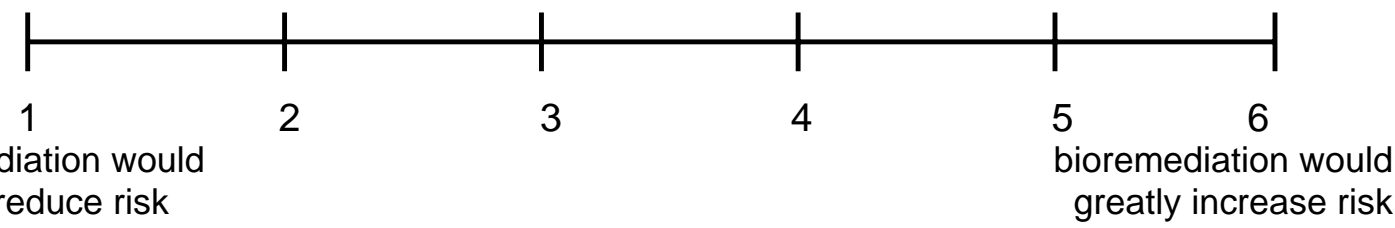

3. Do you support or oppose the use of bioremediation to reduce the risks created by metals and radionuclides in the subsurface? Please explain why.

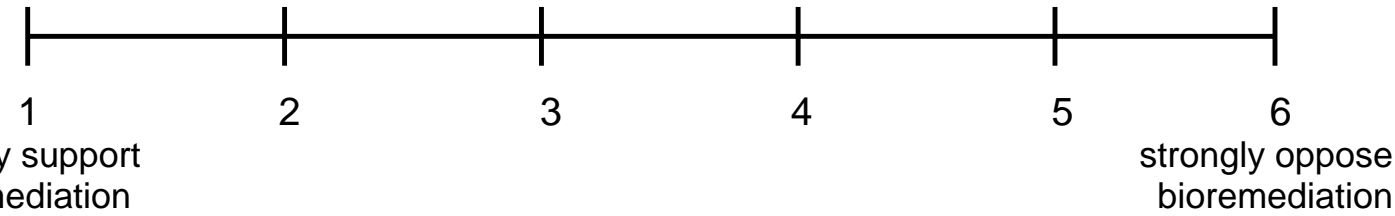

4. Do you think that the local community would support or oppose the use of bioremediation to reduce the risks created by metals and radionuclides in the subsurface? Please explain why.

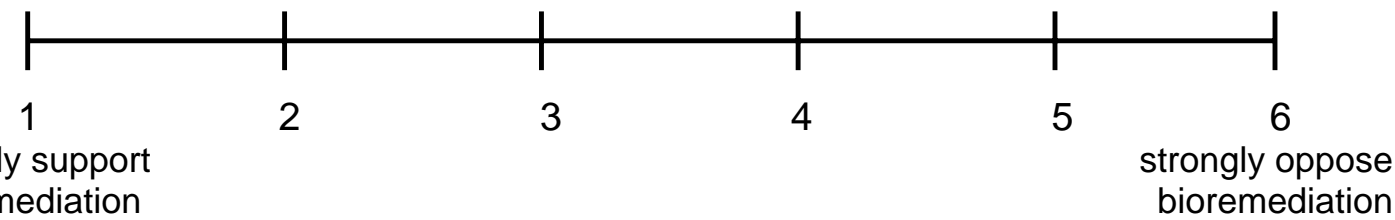

5. For you personally, to what extent are the risks created by bioremediation balanced by the benefits?

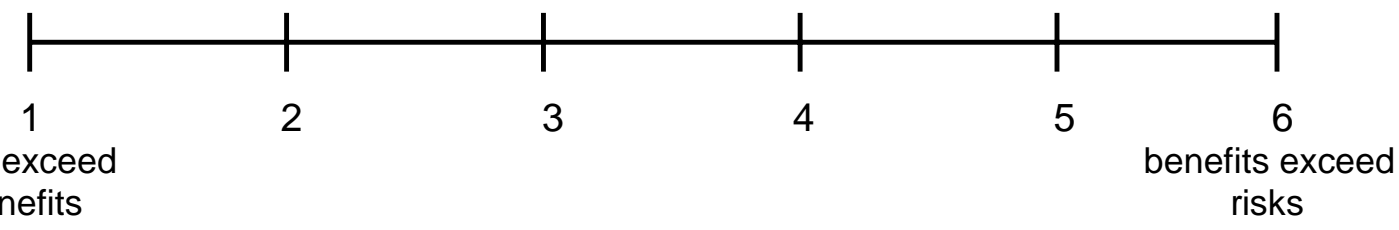


6. For the general community, to what extent are the risks created by bioremediation balanced by the benefits?

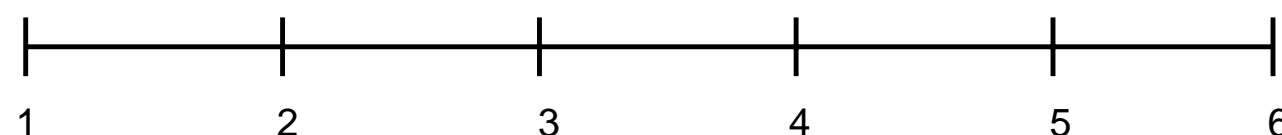

risks exceed

benefits

benefits exceed risks 


\section{TRUST JUDGMENTS}

(Circle the hash-mark that best represents your judgment. Explain each judgment.)

1. How much do you trust or distrust the federal government to develop and oversee bioremediation of groundwater contamination in the soil at this site in a way that you would personally be happy with?

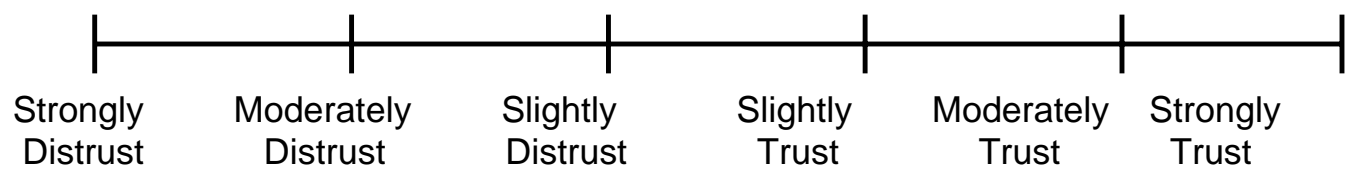

2. How much do you trust or distrust the state government to develop and/or oversee bioremediation of groundwater contamination in the soil at this site in a way that you would personally be happy with?

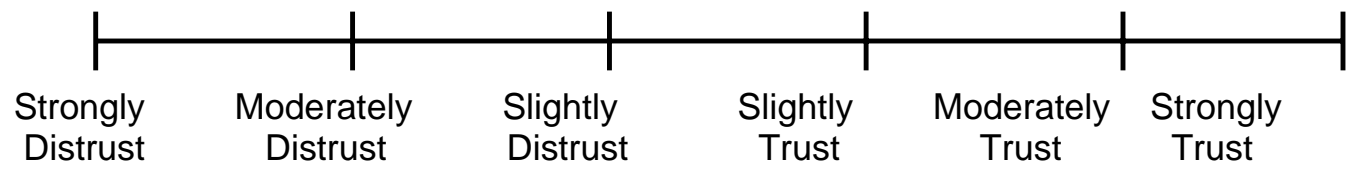

3. How much do you trust or distrust outside experts to develop and/or oversee bioremediation of groundwater contamination in the soil at this site in a way that you would personally be happy with?

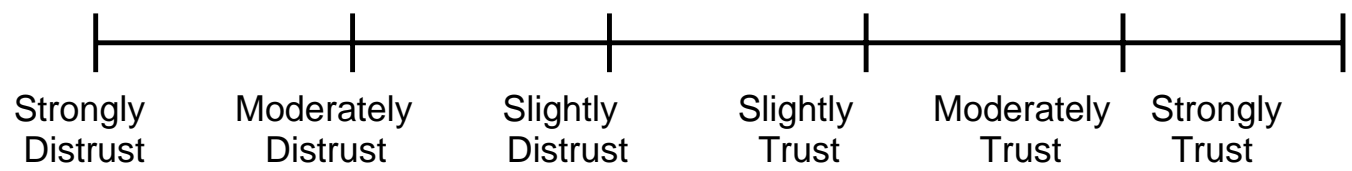

4. How much do you trust or distrust other citizens living in and near the communities surrounding this site to oversee bioremediation of groundwater contamination in the soil in a way that you would personally be happy with?

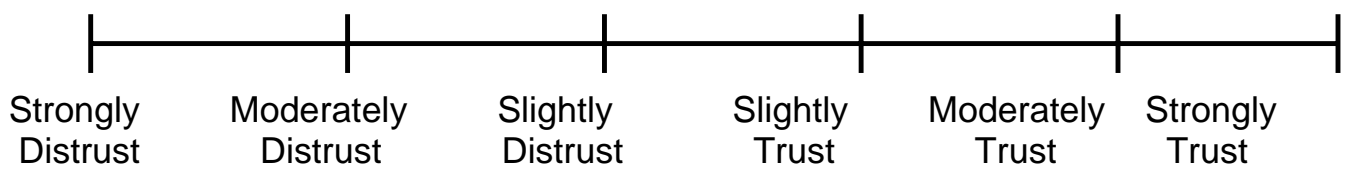




\section{STAKEHOLDER PARTICIPATION OPTIONS}

Below are the descriptions of four ways that stakeholders could participate in decision-making about bioremediation of metal and radionuclide contamination of the groundwater. Please use the form on the next page to rank these options from low to high preference, using highmedium-low preference ratings. "Officials" refers to both government experts and political decision-makers.

Deference Option ("Leave it to the officials to make decisions about bioremediation.")

- Analytic Strategy: Government officials conduct decision analyses as they see fit.

- Decision Strategy: Government officials make and implement their decision as they see fit.

- Communication Strategy: Analytic findings and final decision are reported to the public at a time and in a manner deemed appropriate by government officials.

Information Exchange Option ("Officials listen to all sides, then make decisions about bioremediation.")

- Analytic Strategy: Stakeholders are encouraged to present information about their concerns and decision preferences to government officials to add to their own decision analyses.

- Decision Strategy: Government officials consider all evidence and preferences, including those provided by stakeholders, before making and implementing their decision.

- Communication Strategy: Analytic findings (including those that address information provided by stakeholders) and the final decision are reported to stakeholders at the time of the decision to inform them of the results of their adjudication of conflicting evidence and justify the decision.

Consultation Option (Officials listen to stakeholders, decide on a bioremediation plan, then present the plan to stakeholders for concurrence.")

- Analytic Strategy: Government officials consult with stakeholders about their concerns and preferences before conducting analyses that are responsive to stakeholders' views.

- Decision Strategy: Government officials present their proposed decision, with justification, to the stakeholders and seek their approval (revising it if necessary) before finalizing the decision and implementing it.

- Communication Strategy: Officials seek assurance from stakeholders that the analysis and decision are responsive before the final decision is made. These communications are typically held asynchronously (i.e., official outreach, stakeholder feedback, official response, stakeholder approval).

Deliberation Option ("Stakeholders participate in all phases of the process.")

- Analysis: Analysis is framed jointly by government officials and stakeholders in deliberation before being conducted. Analytic results are then communicated back to the deliberants. This process may be repeated as often as necessary.

- Decision Strategy: Government officials and stakeholders make and oversee their decision together.

- Communication Strategy: Communications about analyses and decisions are made synchronously, preferably after obtaining consensus. 
STAKEHOLDER PARTICIPATION PREFERENCE SCORE SHEET

\begin{tabular}{|c||c|c||}
\hline Card & $\begin{array}{c}\text { Preference Weight } \\
(\mathbf{H}, \mathbf{M}, \mathrm{L})\end{array}$ & $\begin{array}{c}\text { Preference ORDER } \\
\text { (1=LoW, 4=HIGH) }\end{array}$ \\
\hline Deference & & \\
\hline Info Exchange & & \\
\hline Consultation & & \\
\hline Deliberation & & \\
\hline
\end{tabular}

1) Give sheet 1 to individual (and explain as necessary) and have them give you an example of each (do not give them sheet 2).

2) Have individuals write preferences $(H, M, L)$ on sheet 1 (record on sheet 2).

H-really like

M-tolerate

L-not acceptable

3) Have individuals give preference order on sheet 1 (record on sheet 2). 


\section{OPEN-ENDED INTERVIEW QUESTIONS}

1. How much subsurface contamination from metals, radionuclides and toxic chemicals exists at the site? What specific contaminants are involved? Which of these contaminants are you exposed to?

2. How are you personally exposed to radionuclide and toxic contamination in soils at this site? Explain in terms of routes of exposure, durations of exposure, and intensity of exposure.

3. What adverse effects do you believe you have suffered from these exposures?

4. What risks are posed to you currently by contaminated soil at the site before remediation is conducted? Explain qualitatively, and quantitatively, if possible, their probability and severity.

5. Tell me about your view of in situ bioremediation of metals and radionuclides. What are its advantages? What are its disadvantages?

6. Do you support or oppose the use of bioremediation to reduce risk from metal and radionuclide contamination in the subsurface at this site? Why or why not?

7. Do you support the use of bioremediation that would immobilize metals and radionuclides, but leave them in the subsurface environment? Why or why not?

8. What is your definition of acceptable risk vis-à-vis bioremediation of contaminated soil/ground water at this site? In other words, how clean should the soil/ground water be after remediation is complete to satisfy you? Or, how immobile must metals and radionuclide be to satisfy you?

9. Do you think bioremediation of metals \& radionuclides can reduce risks to acceptable levels? Why or why not?

10. Do you think bioremediation of non-radioactive chemical pollutants can reduce risks to acceptable levels? Why or why not?

11. What do you think of microbial bioremediation? Explain.

12. How long does bioremediation of metals \& radionuclides take to do its job effectively? Explain.

13. Is bioremediation enough? Why or why not?

14. Has bioremediation of metals \& radionuclides been proven effective, to your satisfaction? Explain.

15. Is bioremediation cost-effective? Explain.

16. What alternatives exist to bioremediate metals \& radionuclides? Which of these alternatives do you prefer? Why?

17. What concerns you most about bioremediation of metals \& radionuclides? Why?

18. Why do you think others are opposed to bioremediation? Why do you think others support bioremediation?

19. Do you think DOE is competent to perform and oversee bioremediation? Why or why not?

20. Who do you think should be permitted to perform and oversee bioremediation, if not DOE? Why?

21. Do you believe that the risks from exposure to radioactive and toxic pollutants in soil can be reduced to zero?

22. What risks to you would be created by bioremediation of metals \& radionuclides? Explain as above.

23. What risks to you would be created by alternatives to bioremediation? Explain as above.

24. How willing are you to tradeoff bioremediation risks for other risks? Explain.

25. What effect do you believe that increased knowledge of risks of contaminant exposure will have on people's willingness to accept risks? Explain.

26. What effect do you believe that increased knowledge of risks of contaminant exposure will have on people's preferences for being involved in the decision-making process regarding remediation? Explain.

27. How do you want to be involved in the decision-making process regarding the remediation of subsurface contaminated? Explain.

28. How likely is it that the site managers would be willing to sponsor such a decision-making process? Explain.

29. In your opinion, how do other stakeholders wish to be involved in the decision-making process? Explain. 


\section{Oklahoma State University Survey of Residents Living Near US Department of Energy Sites in Hanford, WA; Los Alamos, NM; and Oak Ridge, TN}

\section{INTRODUCTION}

Hello, this is and I'm calling from NSON in Salt Lake City on behalf of Oklahoma State University in Stillwater, Oklahoma, to ask your opinions about the [Hanford, Los Alamos, Oak Ridge] DOE Reservation. We are calling residents near the site to get their opinions on radioactive contamination of soil and groundwater at the site and about how the public should be involved in decisions to clean up this contamination. Your opinions are important to us. This survey will take no more than 20 minutes to complete and all of your answers are confidential. Would this be a good time to do the interview?

The callers should all use the following definition of bioremediation. Consistency is important so only this definition is allowed. Callers should read this to all respondents following the quota (\#2) question.

"Bioremediation means the use of microscopic organisms to make radioactive and toxic metal contaminants in soil and groundwater less hazardous to humans."

If respondents request additional clarification, callers can offer these two examples:

"Microscopic organisms" = for example bacteria

"Toxic metallic contaminants" = for example compounds containing lead or mercury

\section{SURVEY QUESTIONS}

\section{Screening Question}

Before we begin, I need to ask you two questions to determine whether we can continue with the survey:

1. Before I called, were you aware that there is radioactive contamination of soil or groundwater at the site [Hanford, Los Alamos, Oak Ridge] DOE Reservation?

NO [end interview.]
YES

\section{Quota Question}

2. How much do you trust DOE to make decisions about the cleanup of contamination at the site?

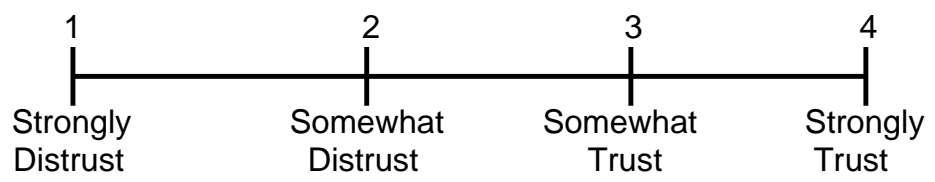

[Group 'trust' and 'somewhat trust' as "High Government Trust" for the quotas]

\{If respondent is beyond the quota for their category, then state, "This survey allows only 134 members in each category. We have already reached that number for the category with the answers you have provided. This concludes the survey. Thank you for your time.\} 


\section{A. Views toward Actual Risk}

The first questions I want to ask you concern your views about the health risks posed to you by subsurface radioactive contamination at the site.

A0. Do you believe that you have suffered adverse health effects from exposure to subsurface contamination?

NO (skip to section B) YES (ask A1-A6 and then skip to C)

A1. How significant do you believe these health risks are? Do you believe that the threat is very low, somewhat low, moderate, somewhat high, or very high?

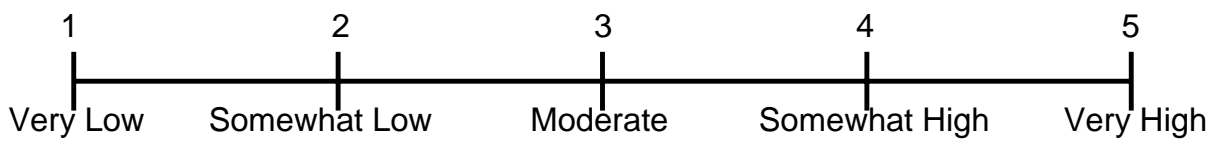

A2. How would you rate your knowledge of the health effects of exposure to subsurface radioactive contamination? Is your knowledge of health effects very low, somewhat low, moderate, somewhat high, or very high?

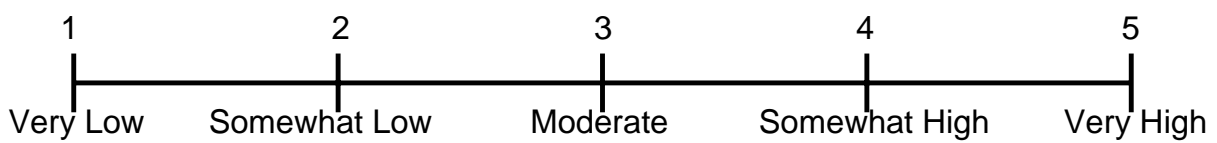

A3. How would you rate your knowledge of how you are exposed to subsurface radioactive contamination? Is your knowledge of exposure very low, somewhat low, moderate, somewhat high, or very high?

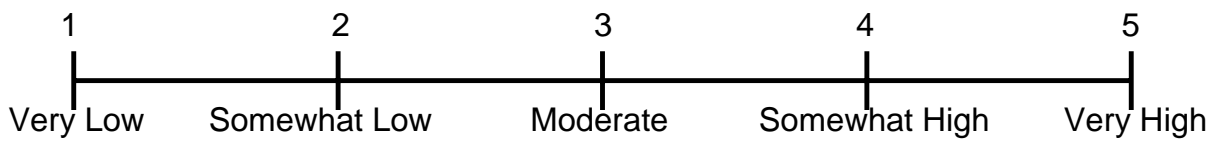

A4. How long have you known about the subsurface radioactive contamination at the site and health risks that this contamination may pose? Have you known about it a very long time, somewhat long time, not recently but not a long time either, somewhat recently, or very recently?

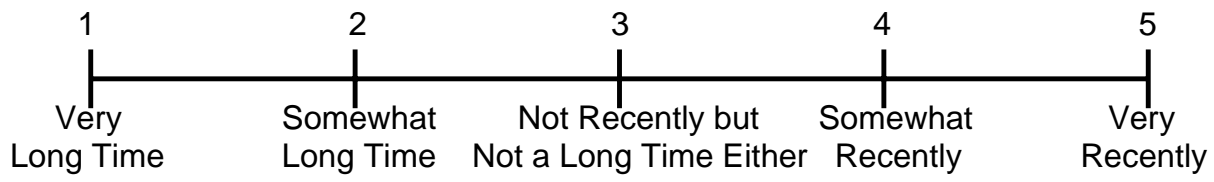

A5. In your opinion, how much choice do you have over whether you are exposed to subsurface radioactive contamination? Is your choice to be exposed very low, somewhat low, moderate, somewhat high, or very high?

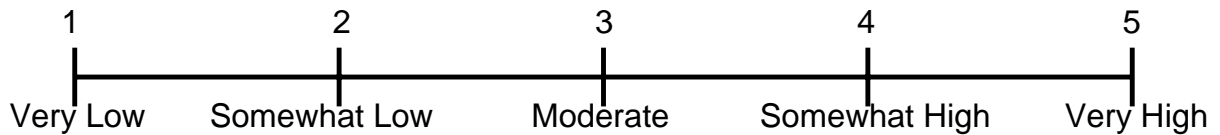

A6. In your opinion, how ghastly or awful are the health risks from subsurface radioactive contamination? Are these risks terrifying, of major concern, of moderate concern, of some concern, or no big deal?

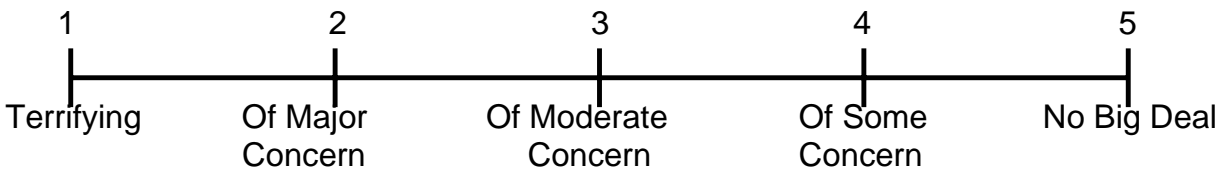




\section{B. Views toward Potential Risk}

B0. Do you believe that you could suffer adverse health effects from exposure to subsurface contamination at the site?

NO (skip to C)

YES

B1. How significant do you believe these health risks are? Do you believe that the threat is very low, somewhat low, moderate, somewhat high, or very high?

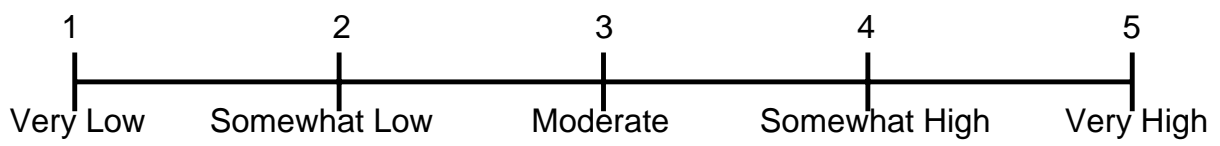

B2. How would you rate your knowledge of the potential health effects of exposure to radioactivity from subsurface contamination at the site? Is your knowledge of potential health effects very low, somewhat low, moderate, somewhat high, or very high?

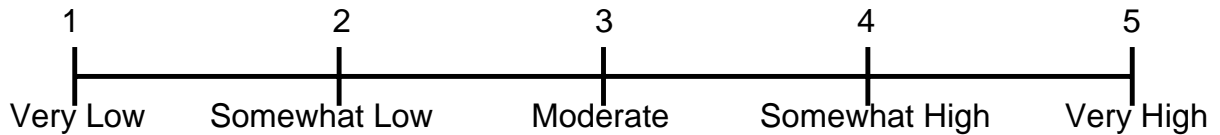

B3. How would you rate your knowledge of how you could be exposed to radioactivity from subsurface contamination at the site? Is your knowledge of exposure very low, somewhat low, moderate, somewhat high, or very high?

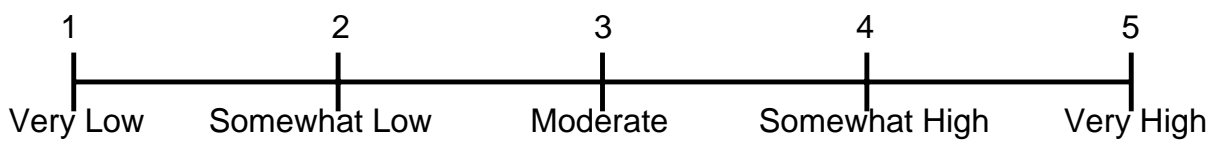

B4. How long have you known about the subsurface radioactive contamination at the site and health risks that this contamination may pose? Have you known about it a very long time, somewhat long time, not recently but not a long time either, somewhat recently, or very recently?

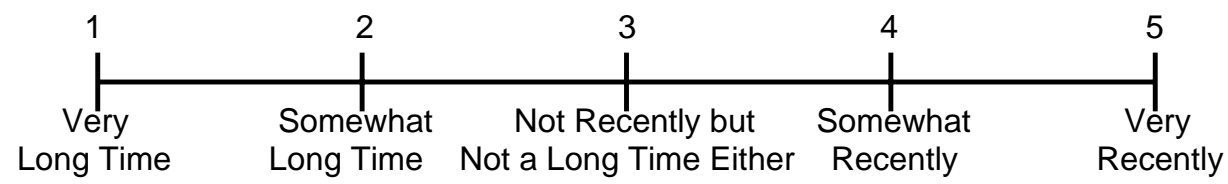

B5. In your opinion, how much choice do you have over whether you will be exposed to subsurface radioactive contamination? Is your choice of exposure very low, somewhat low, moderate, somewhat high, or very high?

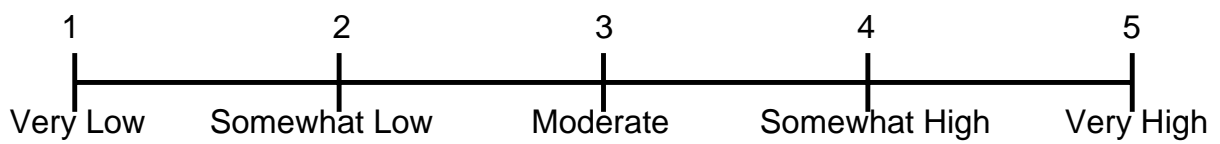

B6. In your opinion, how ghastly or awful are the health risks from subsurface radioactive contamination? Would these risks be terrifying, of major concern, of moderate concern, of some concern, or no big deal?

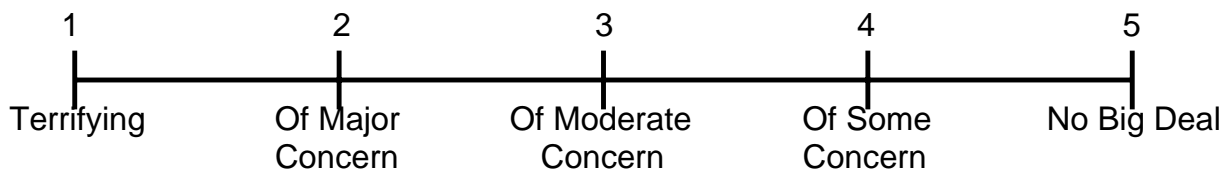




\section{Judgments of DOE as Risk Managers}

These next questions ask for your opinion of the appropriateness of DOE to make decisions on your behalf about how to manage risks from subsurface radioactive contamination at the site.

C1. How much do you trust DOE officials to make decisions on your behalf to properly manage these risks? Do you strongly distrust, somewhat distrust, neither trust nor distrust, somewhat trust, or strongly trust DOE?

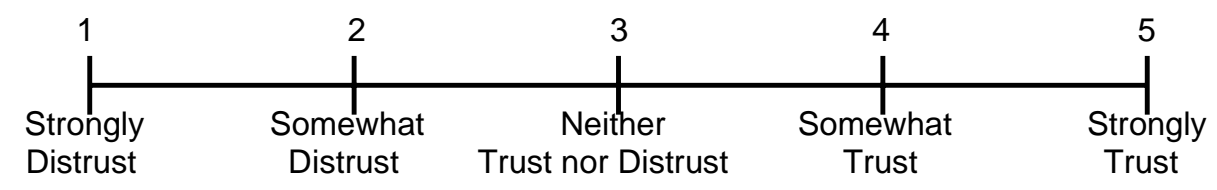

C2. How would you rate your willingness to defer to DOE officials to make decisions on your behalf to properly manage these risks? Is your willingness very low, low, moderate, high, or very high?

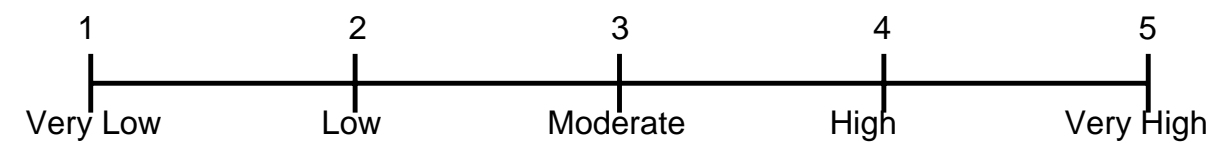

C3. How would you judge the technical competence of DOE managers to properly manage these risks? In your opinion, is their technical competence very low, low, moderate, high, or very high?

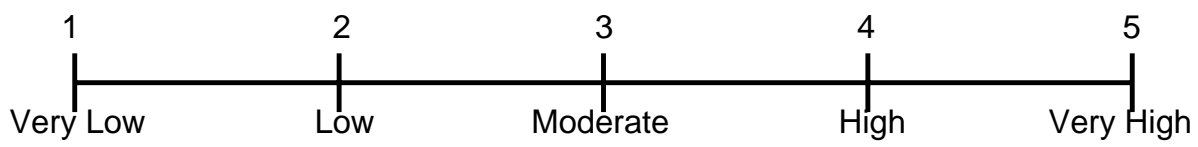

C4. How would you rate the degree to which DOE managers share your values when it comes to properly managing these risks? Are their values very different, somewhat different, mixed, somewhat similar, or very similar to yours?

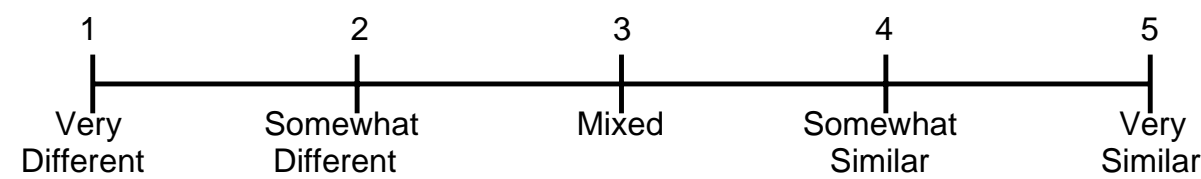

C5. How would you rate the degree of influence that you have over how DOE manages these risks? Do you believe that the amount of influence is very low, low, moderate, high, or very high?

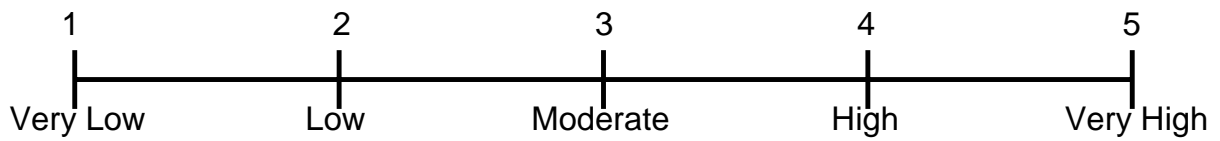

C6. How much do you support or oppose the use of bioremediation to reduce these risks? Do you strongly oppose, oppose, neither oppose nor support, support, or strongly support bioremediation?

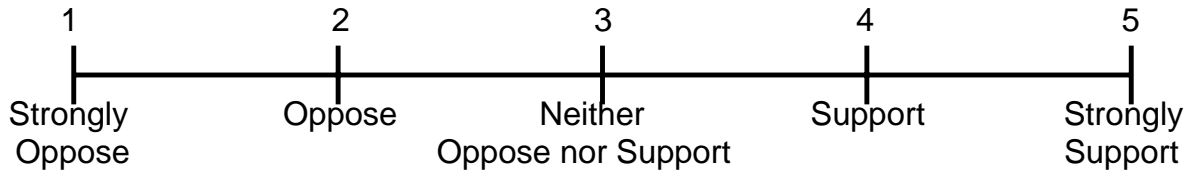




\section{Reactions to Interview Statements}

I will now read six statements that were taken from interviews of stakeholders conducted previously. Please indicate whether you strongly disagree, somewhat disagree, neither disagree nor agree, somewhat agree, or strongly agree with each statement after I read it to you.

D1. Just because there is contamination doesn't mean that we are at risk.

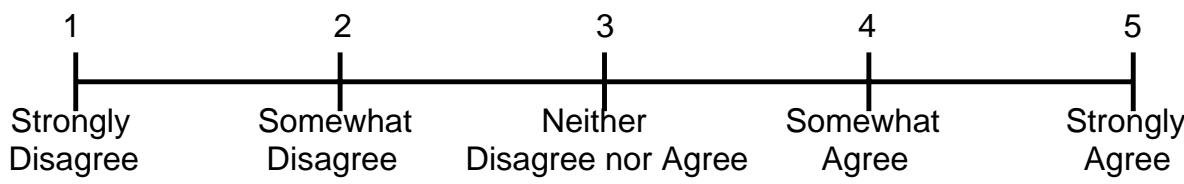

D2. Since many people perceive that there is a higher risk than is actually present, they should become better educated so that their risk perceptions would be better calibrated.

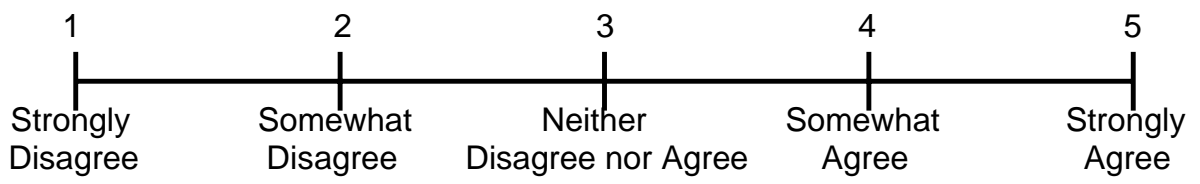

D3. No agency has the right to talk anyone into accepting risk.

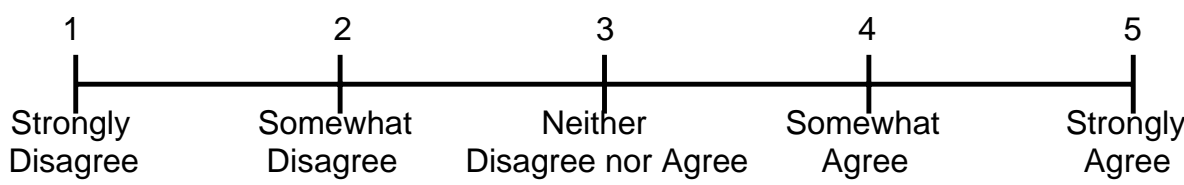

D4. The costs of site cleanup must be balanced against the benefits.

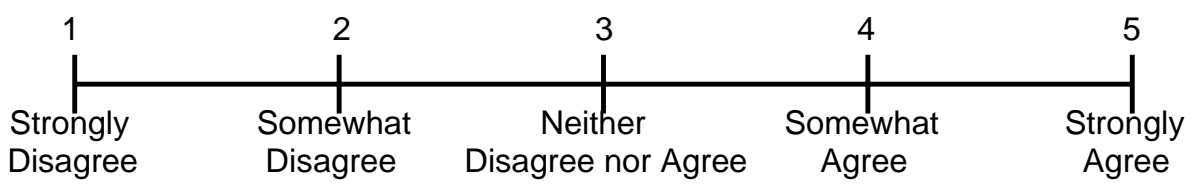

D5. I believe that bioremediation is a short-term fix at best; therefore, other technologies will be required to complete the cleanup.

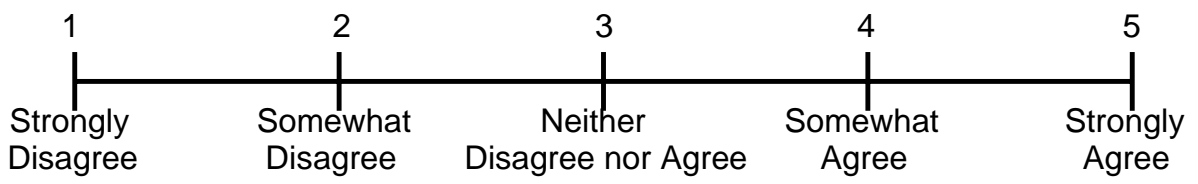

D6. We have time to investigate technologies and pick the ones that will best protect us and the environment. We need not rush into bioremediation.

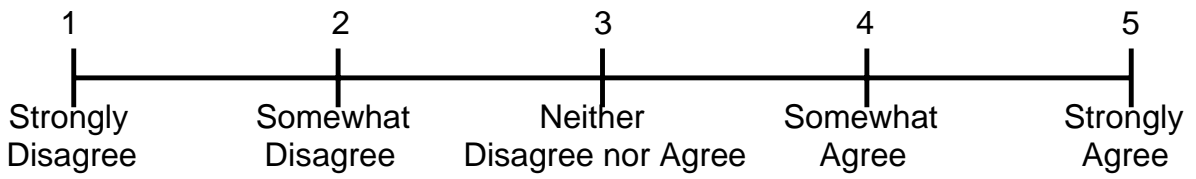




\section{E. Judgments of Stakeholders' as Risk Managers}

These questions ask for your opinion of the appropriateness of your fellow stakeholders making decisions on your behalf about how to manage risks from subsurface radioactive contamination at the site.

E1. How much do you trust other stakeholders to make decisions on your behalf to properly manage the risks of subsurface radioactive contamination? Do you strongly distrust, somewhat distrust, neither trust nor distrust, somewhat trust, or strongly trust DOE?

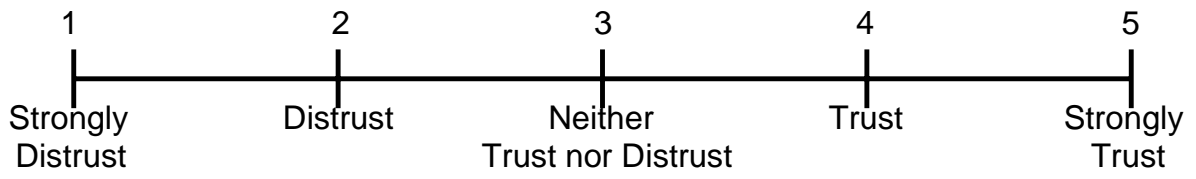

E2. How would you rate your willingness to defer to other stakeholders to make decisions on your behalf to properly manage the risks of subsurface radioactive contamination? Is your willingness very low, low, moderate, high, or very high?

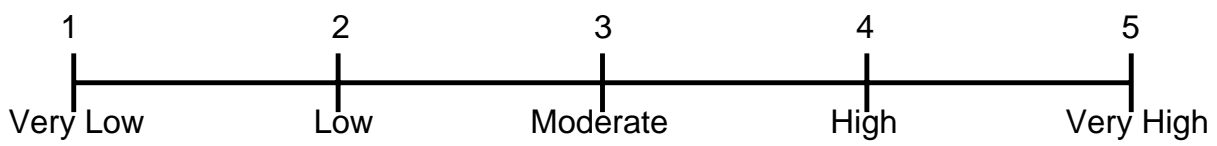

E3. How would you judge the technical competence of other stakeholders to make decisions on your behalf to properly manage the risks of subsurface radioactive contamination? In your opinion, is their technical competence very low, low, moderate, high, or very high?

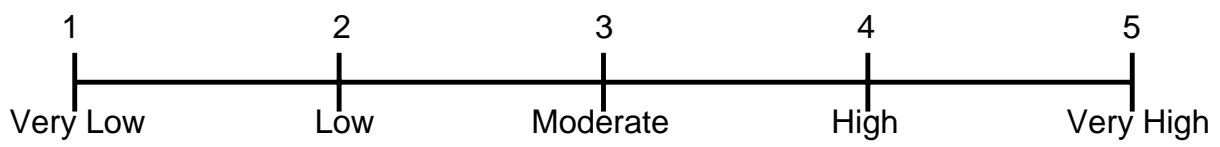

E4. How would you rate the degree to which other stakeholders share your values when it comes to properly managing the risks of subsurface radioactive contamination? Are their values very different, somewhat different, mixed, somewhat similar, or very similar to yours?

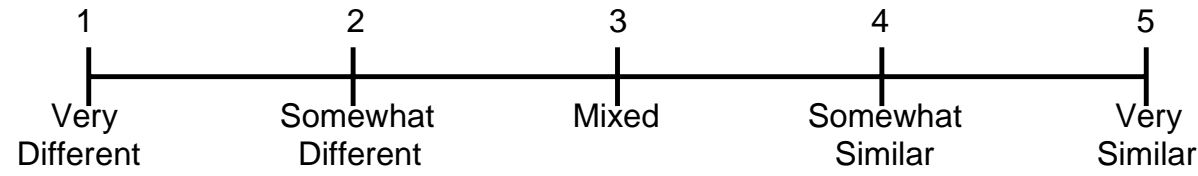




\section{F. Stakeholder Participation Preferences}

Now, I want to ask you about different ways that people having an interest in how risk management decisions get made, can participate in making these decisions. I will read to you four ways that decisions could be made and how such people, referred to as "stakeholders," could participate in the decision-making process. Note that each participation strategy allows more stakeholder participation than the one before it.

- DOE officials make a tentative decision and then submit it to stakeholders for their feedback before making a final decision.

- DOE officials consult with stakeholders first before making a decision that considers stakeholders' preferences.

- DOE officials sponsor and moderate a discussion with stakeholders to make a decision.

- In a negotiation moderated by an independent mediator and assisted by independent analysts, DOE officials participate as equal partners with stakeholders to make a decision.

I am interested in how much you like each of these strategies. I would like to ask you now to judge the level of support you would have for each of these four strategies. As I read each strategy again, please indicate whether you would strongly oppose, somewhat oppose, tolerate, somewhat support, or strongly support it.

F1. DOE officials make a tentative decision and then submit it to stakeholders for their feedback before making a final decision. [Feedback Strategy]

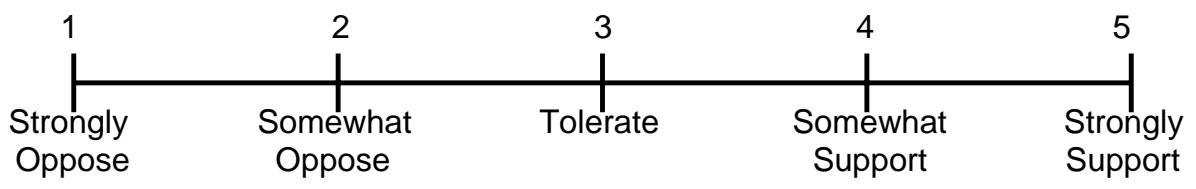

F2. DOE officials consult with stakeholders first before making a decision that considers stakeholders' preferences. [Consultation Strategy]

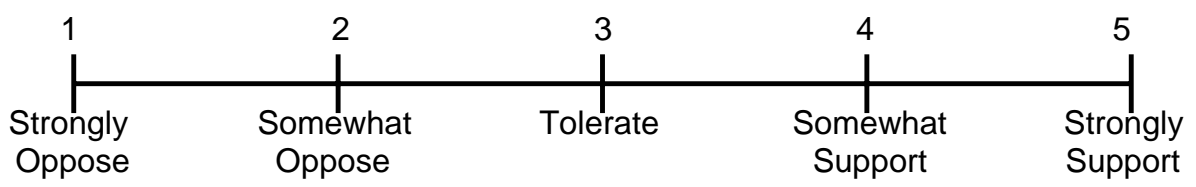

F3. DOE officials sponsor and moderate a discussion with stakeholders to make a decision. [DOE Facilitation Strategy]

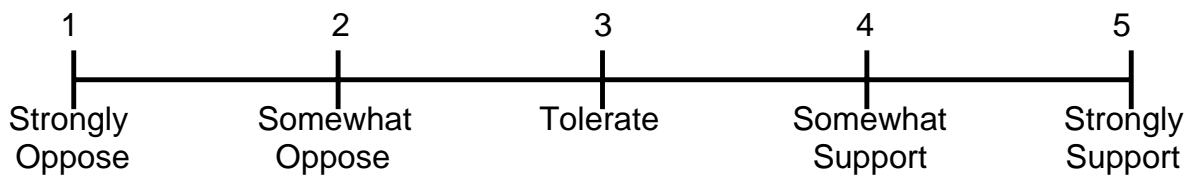

F4. In a negotiation moderated by an independent mediator and assisted by independent analysts, DOE officials participate as equal partners with stakeholders to make a decision. [Independent Facilitation Strategy]

\begin{tabular}{|c|c|c|c|c|}
\hline 1 & 2 & 3 & 4 & 5 \\
\hline $\begin{array}{l}\text { Strongly } \\
\text { Oppose }\end{array}$ & $\begin{array}{c}\text { Somewhat } \\
\text { Oppose }\end{array}$ & Tolerate & $\begin{array}{c}\text { Somewhat } \\
\text { Support }\end{array}$ & \\
\hline
\end{tabular}




\section{G. Demographic Characteristics}

Finally, I have a few more questions about you and your relationship to the site.

G1. As the crow flies, in miles, about how far away from the site do you live? miles

G2. In what direction from the site is your residence located?

${ }_{N}^{N}-\mathrm{S} \_\mathrm{NE} \_\mathrm{SW} \_\mathrm{SE}$

G3. Do you own or rent your current residence?

Own Rent

G4. How long have you lived at your present residence? years

G5. How long have you lived in the area? years

G6. Have you ever worked or are you now working at the site? Yes No

G7. Other than you, has any one in your immediate family worked at the site? Yes No

G8. What is (or was if you are not now working) your primary occupation?

G9. What is the highest level of education that you have achieved?

1. Did not graduate from High School

2. High School Diploma

3. Some College (but no degree)

4. Associates Degree

5. ___ Undergraduate College Degree

6. ___ Some Graduate or Professional School

7. ___ Masters Degree

8. ___ Doctoral or Professional Degree

That's it. Thank you very much for your cooperation in participating in this survey. We sincerely appreciate your help in better understanding how citizens in the area feel about subsurface radioactive contamination at the site and how it should be cleaned up. 
APPENDIX B

NARRATIVE ANALYSIS THEMES AND NODES 
Attitudes toward Risk and Risk Management

\begin{tabular}{|c|c|c|c|c|c|c|c|c|c|}
\hline \multirow{2}{*}{ Theme } & \multirow{2}{*}{$\begin{array}{l}\text { Parent } \\
\text { Node }\end{array}$} & \multirow{2}{*}{ Child Node } & \multirow{2}{*}{$\begin{array}{l}\text { Grandchild } \\
\text { Node }\end{array}$} & \multirow{2}{*}{ Statements } & \multicolumn{5}{|c|}{ Attributes } \\
\hline & & & & & Individual demographics & Site & Gender & $\begin{array}{l}\text { Occu- } \\
\text { pation }\end{array}$ & Total \\
\hline \multirow[t]{7}{*}{$\begin{array}{l}\text { Risk } \\
\text { perception } \\
\text { heuristics } \\
\text { toward health } \\
\text { risks } \\
\end{array}$} & Uncertainty & Unsure of risk & & $\begin{array}{l}\text { Personally I don't have any real } \\
\text { knowledge of what is there and } \\
\text { what the risks are. Radiation has a } \\
\text { bit of a "golly-gee" factor for me }\end{array}$ & $\begin{array}{l}\text { LFD, LFD, OFD, OMD, OFD, OMX, } \\
\text { OMB, OFB, HFX, HFD, HMA, HFB, } \\
\text { HMB, HFA }\end{array}$ & $\begin{array}{l}L=2 \\
O=6 \\
H=6\end{array}$ & $\begin{array}{l}M=5 \\
F=9\end{array}$ & $\begin{array}{l}D=6 \\
B=4 \\
A=2 \\
X=2\end{array}$ & 14 \\
\hline & $\begin{array}{l}\text { Familiarityl } \\
\text { Knowledge }\end{array}$ & $\begin{array}{l}\text { Knowledge of } \\
\text { risk }\end{array}$ & $\begin{array}{l}\text { Lack of } \\
\text { knowledge in } \\
\text { the } \\
\text { community }\end{array}$ & $\begin{array}{l}\text { I don't think the risk levels of } \\
\text { contamination or the complexity of } \\
\text { the clean-up processes are } \\
\text { understood by the general public. }\end{array}$ & $\begin{array}{l}\text { LFD, LFD, LMD, LMD, LFD, LMD, } \\
\text { LFD, LFR, LMR, OMR, OMA, } \\
\text { OMD, OFD, OMD, OMX, OMB, } \\
\text { HFB, HMD }\end{array}$ & $\begin{array}{l}\mathrm{L}=9 \\
\mathrm{O}=7 \\
\mathrm{H}=2\end{array}$ & $\begin{array}{l}M=11 \\
F=7\end{array}$ & $\begin{array}{l}D=11 \\
R=3 \\
B=2 \\
A=1 \\
X=1\end{array}$ & 18 \\
\hline & & & & $\begin{array}{l}\text { I don't think the public wants to } \\
\text { know about the risk or the cleanup. }\end{array}$ & LFD, LMD, LMD, LFD, OFD, OFD & $\begin{array}{l}\mathrm{L}=4 \\
\mathrm{O}=2 \\
\mathrm{H}=0\end{array}$ & $\begin{array}{l}M=2 \\
F=4\end{array}$ & $\mathrm{D}=6$ & 6 \\
\hline & & & $\begin{array}{l}\text { Risk levels } \\
\text { known }\end{array}$ & $\begin{array}{l}\text { Risk levels are known and pretty } \\
\text { well understood. }\end{array}$ & $\begin{array}{l}\text { LMD, LMD, LFD, LMD, LMD, LMD, } \\
\text { LMD, LFD, LFD, LMA, OMD, OMD, } \\
\text { OMD, OMD, OFR, OMD, OMD, } \\
\text { OMD, OMD, OFX, OFD, OFD, } \\
\text { OMD, OMB, OMD, OMD, OFB, } \\
\text { OMR, HMX, HFX, HMD, HFD, } \\
\text { HMD, HXX, HMD, HMA, HMX, } \\
\text { HMR, HMX, HFB, HXX, HFD, } \\
\text { HMD, HFD, HMA, HMX, HFA }\end{array}$ & $\begin{array}{l}\mathrm{L}=10 \\
\mathrm{O}=18 \\
\mathrm{H}=19\end{array}$ & $\begin{array}{l}M=31 \\
F=14 \\
X=2\end{array}$ & $\begin{array}{l}D=29 \\
B=3 \\
A=4 \\
R=3 \\
X=8\end{array}$ & 47 \\
\hline & & & $\begin{array}{l}\text { Risk levels } \\
\text { not known }\end{array}$ & $\begin{array}{l}\text { There is a lot that we don't know } \\
\text { and risk levels cannot be known. }\end{array}$ & $\begin{array}{l}\text { LFX, LFD, LFA, LFD, LMD, LFD, } \\
\text { LFA, LFA, OFD, OMA, OFD, OFD, } \\
\text { OFD, OFD, OFD, OFD, OMD, } \\
\text { OMR, OMD, OMR, HFD, HFB, } \\
\text { HMD, HMB, HMD, HMD, HMX, } \\
\text { HFR, HFA }\end{array}$ & $\begin{array}{l}\mathrm{L}=8 \\
\mathrm{O}=12 \\
\mathrm{H}=9\end{array}$ & $\begin{array}{l}M=11 \\
F=18\end{array}$ & $\begin{array}{l}D=17 \\
B=2 \\
A=5 \\
R=3 \\
X=2\end{array}$ & 29 \\
\hline & & & $\begin{array}{l}\text { Awareness of } \\
\text { risk }\end{array}$ & $\begin{array}{l}\text { I am sufficiently aware of the risks. } \\
\text { I know what I need to worry about, } \\
\text { which ones I don't, and how to } \\
\text { control the ones that are of } \\
\text { concern. }\end{array}$ & $\begin{array}{l}\text { LMD, LFD, LFD, LMD, OFD, OMD, } \\
\text { OFD, OMD, OMR, HMA, HMD }\end{array}$ & $\begin{array}{l}\mathrm{L}=4 \\
\mathrm{O}=5 \\
\mathrm{H}=2\end{array}$ & $\begin{array}{l}M=7 \\
F=4\end{array}$ & $\begin{array}{l}D=9 \\
R=1 \\
A=1\end{array}$ & 11 \\
\hline & & & & $\begin{array}{l}\text { I am very aware of the } \\
\text { contamination at the site and it is of } \\
\text { concern. }\end{array}$ & $\begin{array}{l}\text { LMD, LMD, LMA, OFD, OMD, HFX, } \\
\text { HMR, HMD, HXX, HMX, HMX, } \\
\text { HMD, HFD }\end{array}$ & $\begin{array}{l}\mathrm{L}=3 \\
\mathrm{O}=2 \\
\mathrm{H}=8\end{array}$ & $\begin{array}{l}M=9 \\
F=3 \\
X=1\end{array}$ & $\begin{array}{l}D=7 \\
R=1 \\
A=1 \\
X=4\end{array}$ & 13 \\
\hline
\end{tabular}

\begin{tabular}{|lll|}
\hline L= Los Alamos & $\mathbf{M}=$ Male & $\mathbf{D}=$ Lab employee, retiree, scientist \\
$\mathbf{O}=$ Oak Ridge & $\mathbf{F}=$ Female & $\mathbf{B}=$ Business, self-employed \\
$\mathbf{H}=$ Hanford & $\mathbf{X}=$ No answer & $\mathbf{R}=$ Regulator, EPA, government employee \\
& $\mathbf{A}=$ Public affairs, activist & \\
& $\mathbf{X}=$ No answer & \\
\hline
\end{tabular}




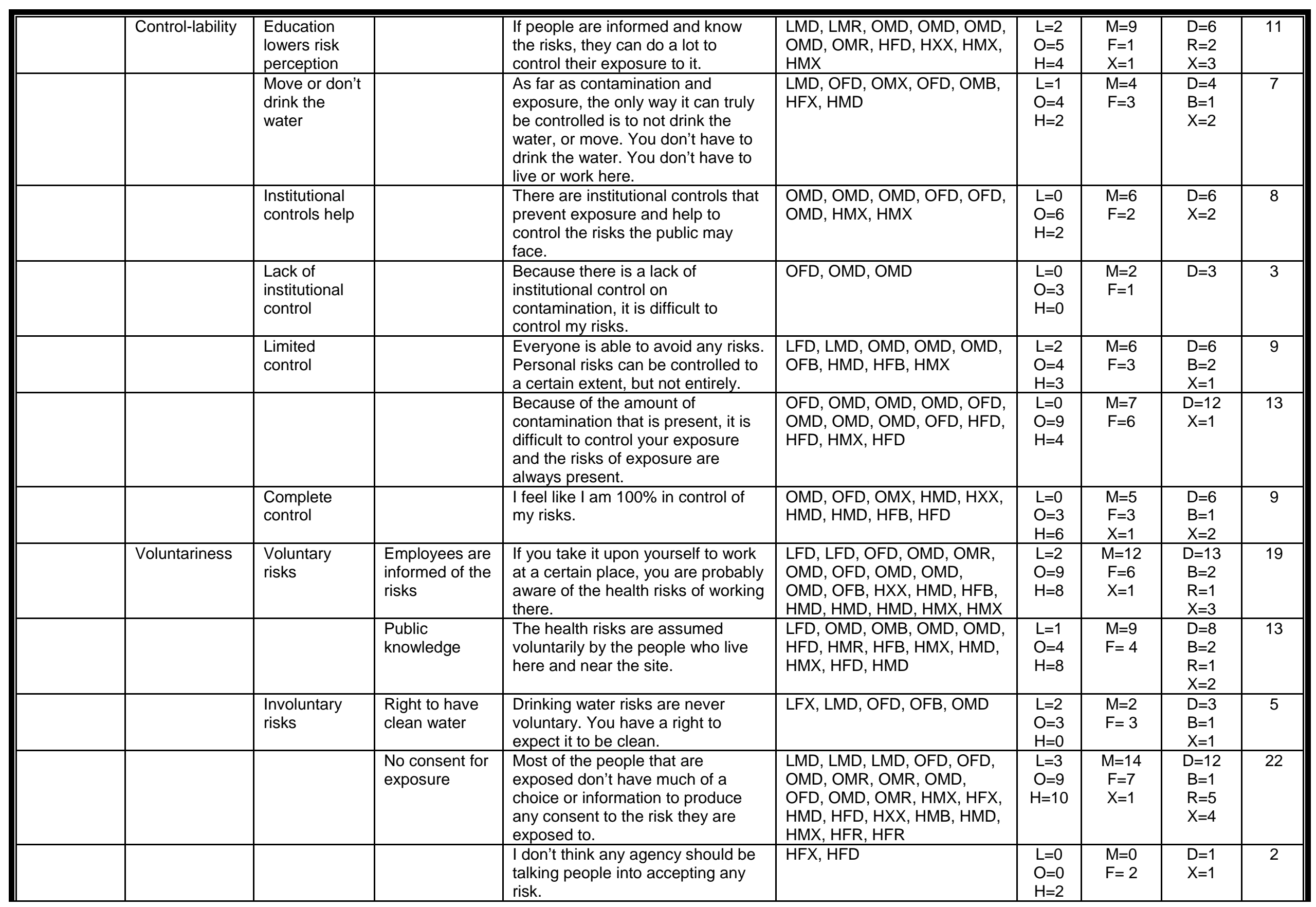




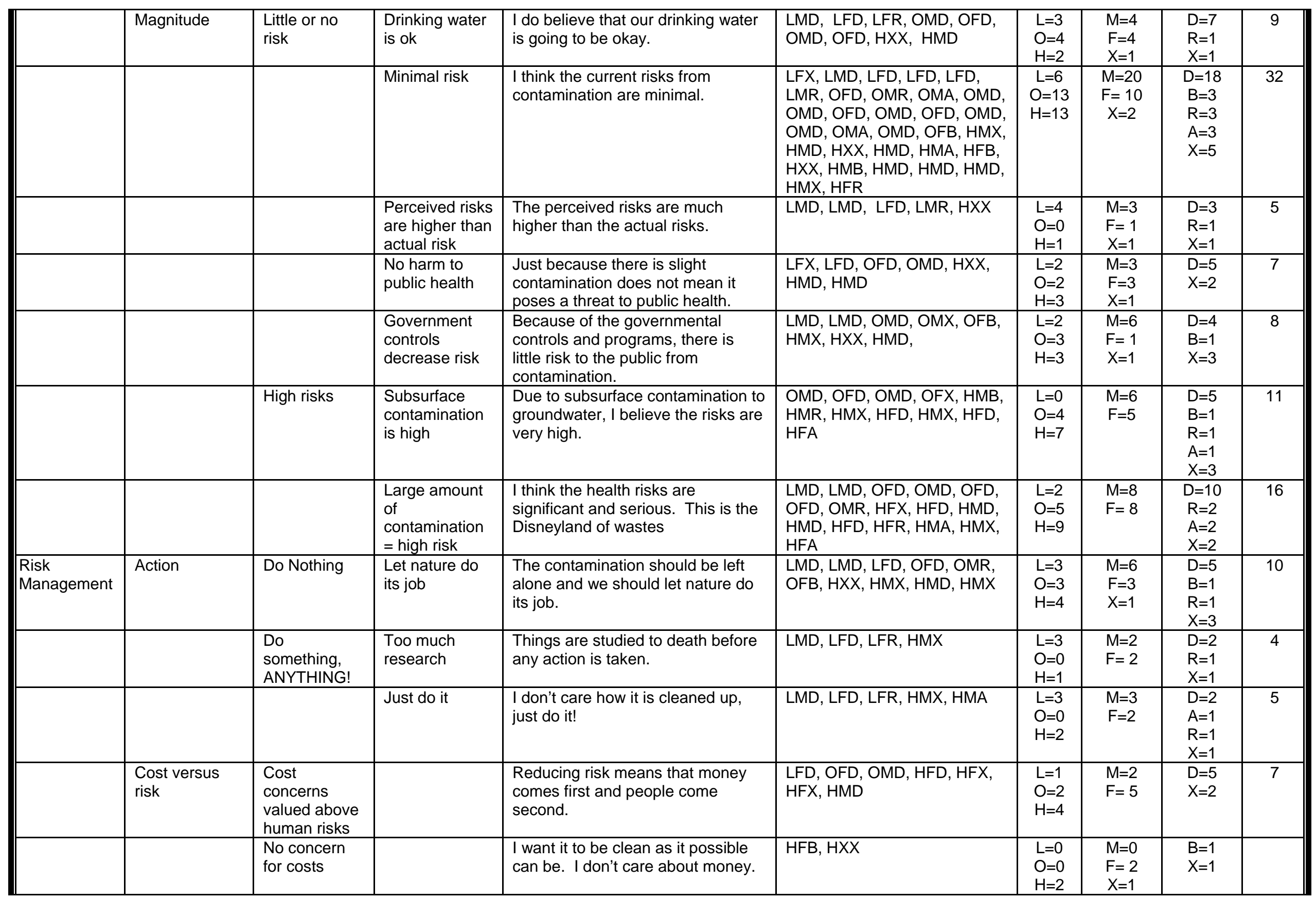









\begin{tabular}{|c|c|c|c|c|c|c|c|c|}
\hline & & & $\begin{array}{l}\text { If DOE was better at handling their } \\
\text { site managers, most of the } \\
\text { environmental problems could have } \\
\text { been avoided. }\end{array}$ & LFD, LFD, LFD, OMD & $\begin{array}{l}\mathrm{L}=3 \\
\mathrm{O}=1 \\
\mathrm{H}=0\end{array}$ & $\begin{array}{l}M=1 \\
F=3\end{array}$ & $\mathrm{D}=4$ & 4 \\
\hline Trust & $\begin{array}{l}\text { Federal } \\
\text { government }\end{array}$ & $\begin{array}{l}\text { Distrust } \\
\text { Federal } \\
\text { Government } \\
29 \\
\end{array}$ & $\begin{array}{l}\text { I moderately distrust the } \\
\text { government. }\end{array}$ & $\begin{array}{l}\text { LFD, LFD, LMD, LMD, LMD, } \\
\text { LMR, OFD, OMD, OMR, HFD, } \\
\text { HFD, HXX, HFB, HMD, HFA }\end{array}$ & $\begin{array}{l}\mathrm{L}=6 \\
\mathrm{O}=3 \\
\mathrm{H}=6\end{array}$ & $\begin{array}{l}M=7 \\
F=7 \\
X=1\end{array}$ & $\begin{array}{l}D=10 \\
B=1 \\
R=2 \\
A=1 \\
X=1\end{array}$ & 15 \\
\hline & & & $\begin{array}{l}\text { I strongly distrust the federal } \\
\text { government. }\end{array}$ & $\begin{array}{l}\text { LFD, OFD, OMD, OFX, OMR, } \\
\text { HMX, HFD, HFB, HFD, HMD, } \\
\text { HFR, HFD, HMA, HFA }\end{array}$ & $\begin{array}{l}\mathrm{L}=1 \\
\mathrm{O}=4 \\
\mathrm{H}=9\end{array}$ & $\begin{array}{l}M=5 \\
F=9\end{array}$ & $\begin{array}{l}D=7 \\
B=1 \\
R=2 \\
A=2 \\
X=2\end{array}$ & 14 \\
\hline & & $\begin{array}{l}\text { Trust federal } \\
\text { government } \\
44\end{array}$ & $\begin{array}{l}\text { I don't think the government is out } \\
\text { to get me, and I strongly trust that } \\
\text { my interests are being looked after. }\end{array}$ & $\begin{array}{l}\text { LMD, LMD, OMD, OMD, OMX, } \\
\text { OMD, OMD, HMR, HMX, } \\
\text { HMD, HMB, HMD }\end{array}$ & $\begin{array}{l}\mathrm{L}=2 \\
\mathrm{O}=5 \\
\mathrm{H}=4\end{array}$ & $\begin{array}{c}M=12 \\
F=0\end{array}$ & $\begin{array}{l}D=8 \\
B=1 \\
R=1 \\
X=2\end{array}$ & 12 \\
\hline & & & I only slightly trust DOE. & $\begin{array}{l}\text { LFX, LFR, LMD, LFD, LFD, } \\
\text { LFD, LFB, LFA, LMA, OMD, } \\
\text { OMD, OMD, OFR, OFD, OFD, } \\
\text { OMR, OMB, OMR, OFR, } \\
\text { OMD, OMR, OMD, OFD, OFB, } \\
\text { OMD, HMD, HMD, HMX, HXX, } \\
\text { HMD, HFD, HMX, HMX }\end{array}$ & $\begin{array}{l}\mathrm{L}=9 \\
\mathrm{O}=16 \\
\mathrm{H}=8\end{array}$ & $\begin{array}{l}M=18 \\
F=14 \\
X=1\end{array}$ & $\begin{array}{l}D=17 \\
B=3 \\
R=6 \\
A=2 \\
X=5\end{array}$ & 32 \\
\hline & $\begin{array}{l}\text { State } \\
\text { government }\end{array}$ & $\begin{array}{l}\text { Distrust state } \\
\text { government } \\
18\end{array}$ & $\begin{array}{l}\text { I probably distrust the state } \\
\text { government because they have } \\
\text { less money and are much more } \\
\text { political. }\end{array}$ & $\begin{array}{l}\text { LFD, LMD, LFD, LFD, LMD, } \\
\text { OFD, OMA, OMD, HFD, HMA }\end{array}$ & $\begin{array}{l}\mathrm{L}=5 \\
\mathrm{O}=3 \\
\mathrm{H}=2\end{array}$ & $\begin{array}{l}M=5 \\
F=5\end{array}$ & $\begin{array}{l}D=8 \\
A=2\end{array}$ & 10 \\
\hline & & & I only slightly distrust the state. & OFD, OFX, OMR, HXX, HMD & $\begin{array}{l}\mathrm{L}=0 \\
\mathrm{O}=3 \\
\mathrm{H}=2\end{array}$ & $\begin{array}{l}M=2 \\
F=2 \\
X=1\end{array}$ & $\begin{array}{l}D=2 \\
R=1 \\
X=2\end{array}$ & 5 \\
\hline & & & $\begin{array}{l}\text { The state government lacks the } \\
\text { level of expertise necessary to deal } \\
\text { with these issues of contamination } \\
\text { and clean up. }\end{array}$ & OFD, OMD, HFD & $\begin{array}{l}\mathrm{L}=0 \\
\mathrm{O}=2 \\
\mathrm{H}=1\end{array}$ & $\begin{array}{l}\mathrm{M}=1 \\
\mathrm{~F}=2\end{array}$ & $\mathrm{D}[3$ & 3 \\
\hline & & $\begin{array}{l}\text { Trust state } \\
\text { government } \\
50\end{array}$ & $\begin{array}{l}\text { Because they have a more vested } \\
\text { interest, I strongly trust the state } \\
\text { government. }\end{array}$ & $\begin{array}{l}\text { LFD, LMD, LMD, LMA, OMD, } \\
\text { OMD, OMD, OMB, OMD, } \\
\text { HFD, HMD, HFD, HMR, HFB, } \\
\text { HMX, HMR }\end{array}$ & $\begin{array}{l}\mathrm{L}=4 \\
\mathrm{O}=5 \\
\mathrm{H}=7\end{array}$ & $\begin{array}{c}\mathrm{M}=12 \\
\mathrm{~F}=4\end{array}$ & $\begin{array}{l}D=10 \\
B=2 \\
A=1 \\
R=2 \\
X=1\end{array}$ & 16 \\
\hline & & & $\begin{array}{l}\text { I moderately trust the state } \\
\text { government. }\end{array}$ & $\begin{array}{l}\text { LFD, LFA, LFD, LFA, OMD, } \\
\text { OFD, OMD, OMD, OFD, OMX, } \\
\text { OMR, HFX, HMD, HMD, HMX, } \\
\text { HFB, HXX, HMD, HFD, HMB, } \\
\text { HMD, HMD, HMX }\end{array}$ & $\begin{array}{c}\mathrm{L}=4 \\
\mathrm{O}=7 \\
\mathrm{H}=12\end{array}$ & $\begin{array}{l}M=13 \\
F=9 \\
X=1\end{array}$ & $\begin{array}{l}D=13 \\
B=2 \\
A=2 \\
R=1 \\
X-5\end{array}$ & 23 \\
\hline
\end{tabular}




\begin{tabular}{|c|c|c|c|c|c|c|c|c|c|}
\hline & & & & I only slightly trust the state. & $\begin{array}{l}\text { LMD, LMD, OFD, OFR, OMD, } \\
\text { OMD, OFB, OMR, HMX, HFR, } \\
\text { HFR }\end{array}$ & $\begin{array}{l}\mathrm{L}=2 \\
\mathrm{O}=6 \\
\mathrm{H}=3\end{array}$ & $\begin{array}{l}M=6 \\
F=5\end{array}$ & $\begin{array}{l}D=5 \\
B=1 \\
R=4 \\
X=1\end{array}$ & 11 \\
\hline & & Community & $\begin{array}{l}\text { Distrust } \\
\text { community } \\
22 \\
\end{array}$ & $\begin{array}{l}\text { Because most citizens would } \\
\text { pursue their own agenda, I would } \\
\text { not trust them. }\end{array}$ & $\begin{array}{l}\text { LFD, LMD, LMD, OMD, OMD, } \\
\text { OMR }\end{array}$ & $\begin{array}{l}\mathrm{L}=3 \\
\mathrm{O}=3 \\
\mathrm{H}=0\end{array}$ & $\begin{array}{l}M=5 \\
F=1\end{array}$ & $\begin{array}{l}\mathrm{D}=5 \\
\mathrm{R}=1\end{array}$ & 5 \\
\hline & & & & $\begin{array}{l}\text { I moderately distrust the citizens } \\
\text { because they lack the knowledge } \\
\text { to understand the problems. }\end{array}$ & $\begin{array}{l}\text { LFX, LFD, LMD, OFD, OMB, } \\
\text { OMR, HMX, HMD, HMD, } \\
\text { HFD, HFA }\end{array}$ & $\begin{array}{l}\mathrm{L}=3 \\
\mathrm{O}=3 \\
\mathrm{H}=5\end{array}$ & $\begin{array}{l}M=6 \\
F=5\end{array}$ & $\begin{array}{l}D=6 \\
B=1 \\
R=1 \\
A=1 \\
X=2\end{array}$ & 11 \\
\hline & & & & I strongly distrust the local citizens. & $\begin{array}{l}\text { LMD, OMX, OFB, HFB, HMD, } \\
\text { HFR }\end{array}$ & $\begin{array}{l}\mathrm{L}=1 \\
\mathrm{O}=2 \\
\mathrm{H}=3\end{array}$ & $\begin{array}{l}\mathrm{M}=3 \\
\mathrm{~F}=3\end{array}$ & $\begin{array}{l}\mathrm{D}=2 \\
\mathrm{~B}=2 \\
\mathrm{R}=1 \\
\mathrm{X}=1\end{array}$ & 6 \\
\hline & & & $\begin{array}{l}\text { Trust } \\
\text { community } \\
39\end{array}$ & $\begin{array}{l}\text { Because of the Lab, I feel that this } \\
\text { community has a firm scientific } \\
\text { base and we all want this place } \\
\text { cleaned up. Therefore I strongly } \\
\text { trust those citizens. }\end{array}$ & $\begin{array}{l}\text { LMD, LFA, LFD, LFD, LMA, } \\
\text { OMD, OMD, OFD, OMD, } \\
\text { OMD, OMD, OFB, OMR, HFX, } \\
\text { HMA, HMX, HFB, HFD, HMD }\end{array}$ & $\begin{array}{l}\mathrm{L}=5 \\
\mathrm{O}=8 \\
\mathrm{H}=6\end{array}$ & $\begin{array}{c}M=11 \\
F=8\end{array}$ & $\begin{array}{l}D=11 \\
B=2 \\
A=3 \\
R=1 \\
X=2\end{array}$ & 19 \\
\hline & & & & I moderately trust the community. & $\begin{array}{l}\text { OMD, OMD, OMD, OMD, } \\
\text { OFD, HMD, HMD, HMR, HMB, } \\
\text { HMA, HFA }\end{array}$ & $\begin{array}{l}\mathrm{L}=0 \\
\mathrm{O}=5 \\
\mathrm{H}=6\end{array}$ & $\begin{array}{l}M=9 \\
F=2\end{array}$ & $\begin{array}{l}D=7 \\
B=1 \\
R=1 \\
A=2\end{array}$ & 11 \\
\hline & & & & $\begin{array}{l}\text { Many citizens pursue their own } \\
\text { agendas, so I would only slightly } \\
\text { trust the community's involvement. }\end{array}$ & $\begin{array}{l}\text { LFD, LFD, OFD, OFD, OFX, } \\
\text { OMD, HMX, HXX, HMX }\end{array}$ & $\begin{array}{l}\mathrm{L}=2 \\
\mathrm{O}=4 \\
\mathrm{H}=3\end{array}$ & $\begin{array}{l}M=3 \\
F=5 \\
X=1\end{array}$ & $\begin{array}{l}D=5 \\
X=4\end{array}$ & 9 \\
\hline & & Experts & $\begin{array}{l}\text { Trust experts } \\
48\end{array}$ & $\begin{array}{l}\text { I rely heavily on the experts in } \\
\text { order to make my own judgments, } \\
\text { and therefore, strongly trust them. }\end{array}$ & $\begin{array}{l}\text { LMD, LFD, LFD, LMD, LMD, } \\
\text { OFD, OFD, OMD, OMD, OMD, } \\
\text { OMD, OMR, HFX, HMD, HMD, } \\
\text { HMX, HMD, HMD, HMD, HMA }\end{array}$ & $\begin{array}{l}\mathrm{L}=5 \\
\mathrm{O}=7 \\
\mathrm{H}=8\end{array}$ & $\begin{array}{c}M=15 \\
F=5\end{array}$ & $\begin{array}{l}D=16 \\
R=1 \\
A=1 \\
X=2\end{array}$ & 20 \\
\hline & & & & $\begin{array}{l}\text { I only moderately trust outside } \\
\text { experts because even though they } \\
\text { are more knowledgeable, they are } \\
\text { usually guided by money. }\end{array}$ & $\begin{array}{l}\text { LMD, LMD, LFD, OMA, OMD, } \\
\text { OMD, OFD, OMD, OFD, } \\
\text { OMB, HXX, HMX, OMA, } \\
\text { HMR, HFB, HXX, HFD, HMX, } \\
\text { HMA }\end{array}$ & $\begin{array}{l}\mathrm{L}=3 \\
\mathrm{O}=7 \\
\mathrm{H}=9\end{array}$ & $\begin{array}{l}M=12 \\
F=5 \\
X=2\end{array}$ & $\begin{array}{l}D=9 \\
B=2 \\
A=3 \\
R=1 \\
X=4\end{array}$ & 19 \\
\hline & & & & I slightly trust outside experts. & $\begin{array}{l}\text { LMD, OFR, OFD, OMX, OMD, } \\
\text { HMD, HFB, HMR, HMX }\end{array}$ & $\begin{array}{l}\mathrm{L}=1 \\
\mathrm{O}=4 \\
\mathrm{H}=4\end{array}$ & $\begin{array}{l}M=6 \\
F=3\end{array}$ & $\begin{array}{l}D=4 \\
B=1 \\
R=2 \\
X=2\end{array}$ & 9 \\
\hline & & & $\begin{array}{l}\text { Distrust } \\
\text { experts } \\
14\end{array}$ & $\begin{array}{l}\text { Outside contractors are usually } \\
\text { motivated by their own agendas } \\
\text { and money rather than what is the } \\
\text { best option. I do not trust them. }\end{array}$ & $\begin{array}{l}\text { LFD, LMA, OMD, OFX, OFB, } \\
\text { OFD, HFX, HFD, HFB, HMX, } \\
\text { HXX, HMD, HFD, HFA }\end{array}$ & $\begin{array}{l}\mathrm{L}=2 \\
\mathrm{O}=4 \\
\mathrm{H}=8\end{array}$ & $\begin{array}{l}M=4 \\
F=9 \\
X=1\end{array}$ & $\begin{array}{l}D=6 \\
B=2 \\
A=2 \\
X=4\end{array}$ & 14 \\
\hline
\end{tabular}




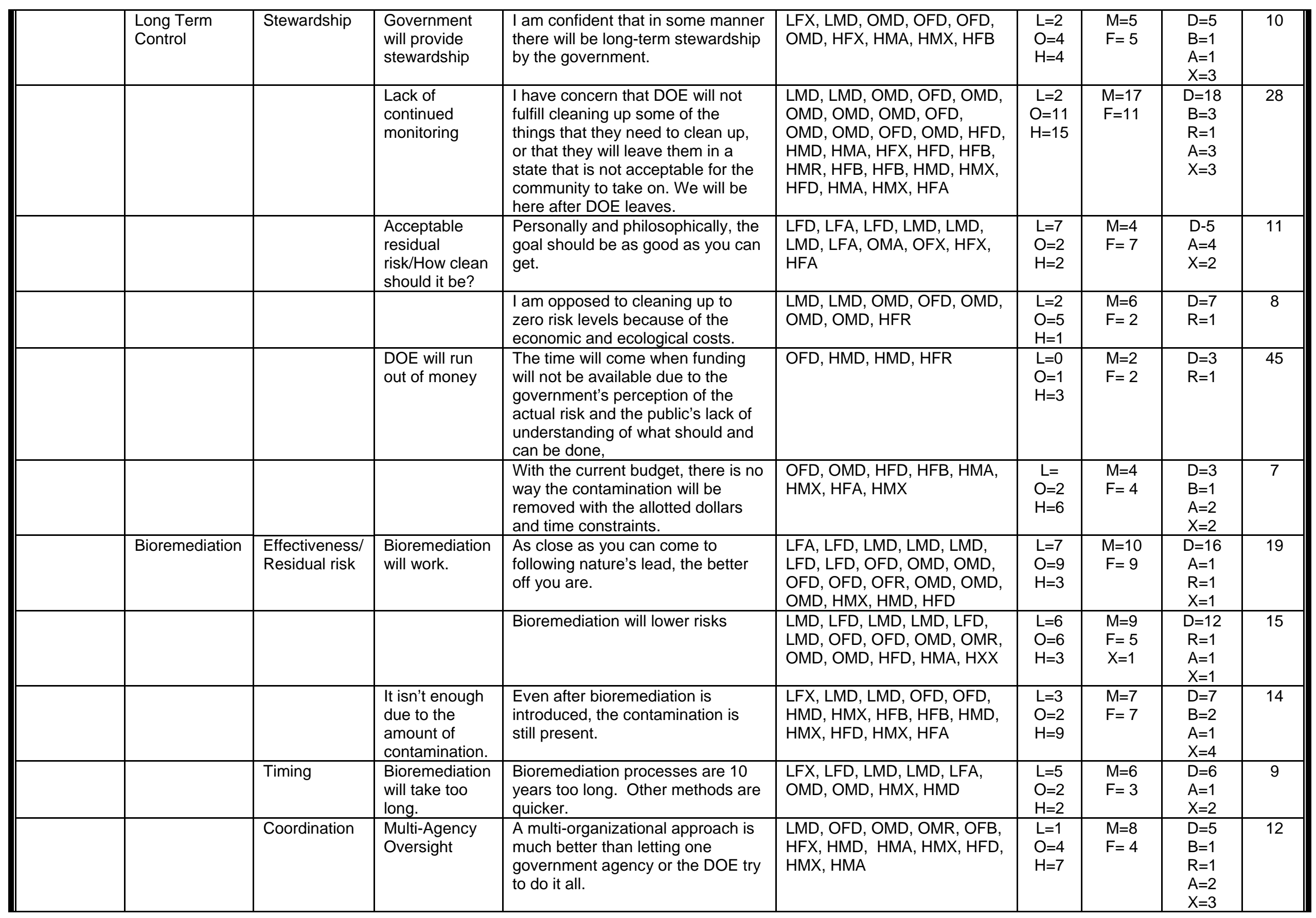




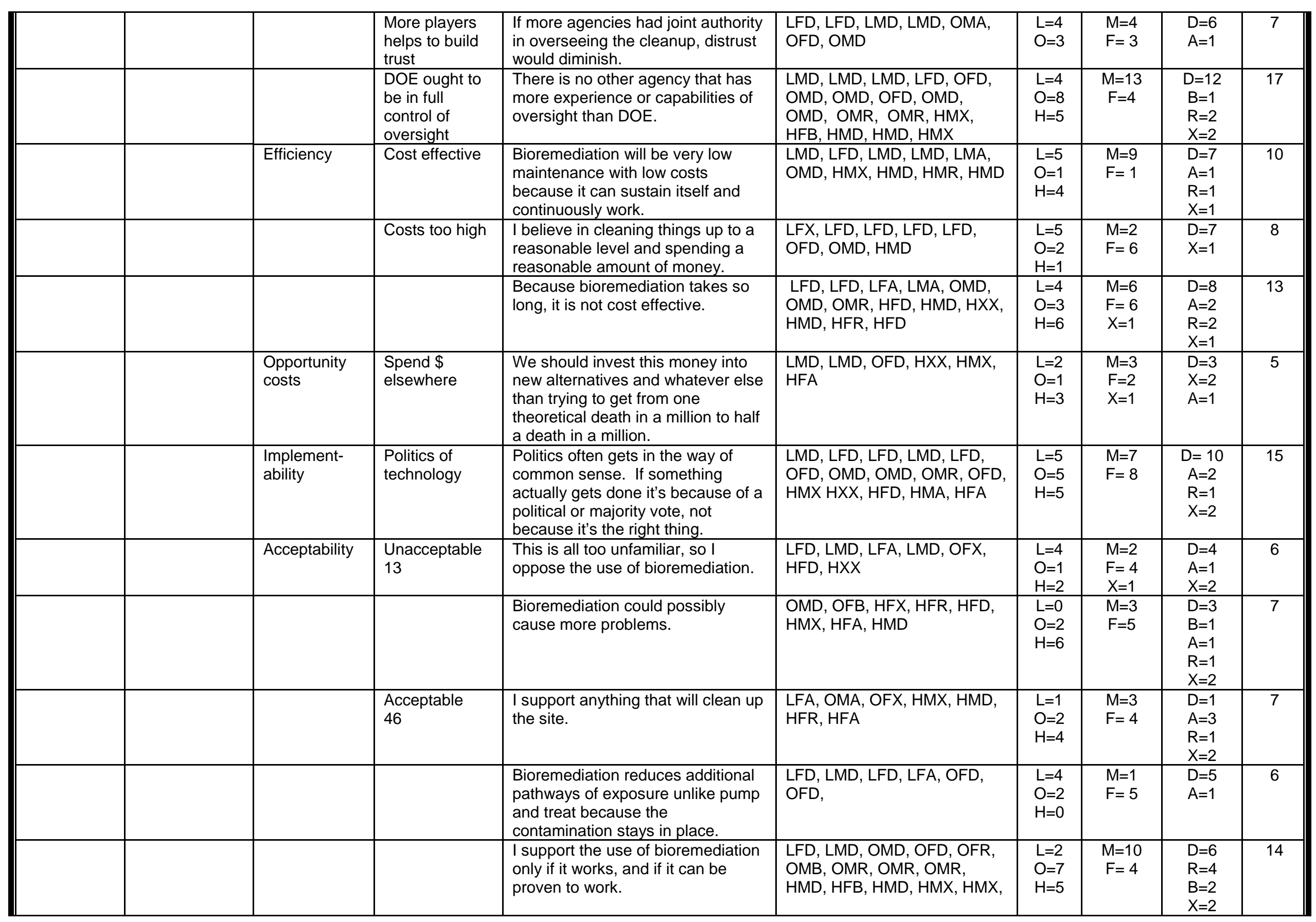




\begin{tabular}{|c|c|c|c|c|c|c|c|c|c|}
\hline & & & & $\begin{array}{l}\text { If the public is educated on } \\
\text { bioremediation, there would be little } \\
\text { resistance to its use. }\end{array}$ & $\begin{array}{l}\text { LFD, LFA, OMA, OFD, OFR, } \\
\text { OMD, OFD, OFD, OFB, HMX, } \\
\text { HMR, HFD, HMB, HMD, }\end{array}$ & $\begin{array}{l}\mathrm{L}=2 \\
\mathrm{O}=7 \\
\mathrm{H}=5\end{array}$ & $\begin{array}{l}M=6 \\
F=8\end{array}$ & $\begin{array}{l}D=7 \\
B=2 \\
R=2 \\
A=2 \\
X=1\end{array}$ & 14 \\
\hline & & & & $\begin{array}{l}\text { If bioremediation reduces the risks } \\
\text { to the public and the workers, I } \\
\text { would support it. }\end{array}$ & LMD, LMA, OMD, OMD, HMA, & $\begin{array}{l}\mathrm{L}=2 \\
\mathrm{O}=2 \\
\mathrm{H}=1\end{array}$ & $\begin{array}{l}\mathrm{M}=5 \\
\mathrm{~F}=0\end{array}$ & $\begin{array}{l}D=3 \\
A=2\end{array}$ & 5 \\
\hline & & & & $\begin{array}{l}\text { I support bioremediation because I } \\
\text { know it works. }\end{array}$ & $\begin{array}{l}\text { LMD, LFD, LFD, OMD, OFD, } \\
\text { OMD, OMD, OMD, OMX, } \\
\text { OMD, OMD, OMD, OMD, } \\
\text { HMD, HFD, HXX, HMR, HMX, } \\
\text { HMD, HMD, }\end{array}$ & $\begin{array}{l}\mathrm{L}=3 \\
\mathrm{O}=10 \\
\mathrm{H}=7\end{array}$ & $\begin{array}{l}M=15 \\
F=4 \\
X=1\end{array}$ & $\begin{array}{l}\mathrm{D}=17 \\
\mathrm{R}=1 \\
\mathrm{X}=2\end{array}$ & 20 \\
\hline & & & $\begin{array}{l}\text { Not enough } \\
\text { knowledge of } \\
\text { bioremediation }\end{array}$ & $\begin{array}{l}\text { I don't think people have enough } \\
\text { information to understand what this } \\
\text { will do to the contamination and } \\
\text { therefore, are wary of it. }\end{array}$ & $\begin{array}{l}\text { LMD, LFA, LMA, OMD, OFR, } \\
\text { HMX, HMD, HFD, HMD, HMX, } \\
\text { HMD, }\end{array}$ & $\begin{array}{l}\mathrm{L}=3 \\
\mathrm{O}=2 \\
\mathrm{H}=6\end{array}$ & $\begin{array}{l}M=8 \\
F=3\end{array}$ & $\begin{array}{l}D=6 \\
A=2 \\
R=1 \\
X=2\end{array}$ & 11 \\
\hline & & & & $\begin{array}{l}\text { Bioremediation is totally foreign to } \\
\text { me other than what I have heard. }\end{array}$ & $\begin{array}{l}\text { LFD, LFD, OFX, OFD, OMD, } \\
\text { HFX, HMD, HMB, HMX, HFA }\end{array}$ & $\begin{array}{l}\mathrm{L}=2 \\
\mathrm{O}=3 \\
\mathrm{H}=5\end{array}$ & $\begin{array}{l}M=4 \\
F=6\end{array}$ & $\begin{array}{l}D=5 \\
A=1 \\
B=1 \\
X=3\end{array}$ & 10 \\
\hline & & & $\begin{array}{l}\text { Education will } \\
\text { lower risk } \\
\text { perception }\end{array}$ & $\begin{array}{l}\text { If the public is armed with good } \\
\text { information, they will be able to } \\
\text { make better decisions and more } \\
\text { accepting of any technology. }\end{array}$ & $\begin{array}{l}\text { LMD, OMD, OMA, OFD, OFR, } \\
\text { OMD, OFD, OMD, OFB, OMR, } \\
\text { HMX, HFD, HMA, HFA }\end{array}$ & $\begin{array}{l}\mathrm{L}=1 \\
\mathrm{O}=9 \\
\mathrm{H}=4\end{array}$ & $\begin{array}{l}\mathrm{M}=8 \\
\mathrm{~F}=6\end{array}$ & $\begin{array}{l}D=7 \\
B=1 \\
R=2 \\
A=3 \\
X=1\end{array}$ & 14 \\
\hline & & & & $\begin{array}{l}\text { Dread is a result of having too little } \\
\text { information. }\end{array}$ & $\begin{array}{l}\text { LMD, LFD, LFD, OFD, OMD, } \\
\text { OMR, }\end{array}$ & $\begin{array}{l}\mathrm{L}=3 \\
\mathrm{O}=3 \\
\mathrm{H}=0\end{array}$ & $\begin{array}{l}M=3 \\
F=3\end{array}$ & $\begin{array}{l}\mathrm{D}=5 \\
\mathrm{R}=1\end{array}$ & 6 \\
\hline & & & $\begin{array}{l}\text { Science is too } \\
\text { new }\end{array}$ & $\begin{array}{l}\text { There hasn't been enough } \\
\text { research conducted in this area. } \\
\text { The science just isn't there to trust } \\
\text { that it will or will not work. }\end{array}$ & $\begin{array}{l}\text { LFD, OFD, OFR, OMD, OMD, } \\
\text { OMD, OMD, OMR, HFX, HFD, } \\
\text { HFB, HFA }\end{array}$ & $\begin{array}{l}\mathrm{L}=1 \\
\mathrm{O}=7 \\
\mathrm{H}=4\end{array}$ & $\begin{array}{l}\mathrm{M}=5 \\
\mathrm{~F}=7\end{array}$ & $\begin{array}{l}D=7 \\
R=2 \\
B=1 \\
A=1 \\
X=1\end{array}$ & 12 \\
\hline & & & $\begin{array}{l}\text { Do not know if } \\
\text { bioremediation } \\
\text { will be effective }\end{array}$ & $\begin{array}{l}\text { Because of the amount of } \\
\text { contamination, I am unsure that } \\
\text { bioremediation would have any } \\
\text { impact. }\end{array}$ & $\begin{array}{l}\text { LFD, OMD, OMD, HMD, HMA, } \\
\text { HFA }\end{array}$ & $\begin{array}{l}\mathrm{L}=1 \\
\mathrm{O}=2 \\
\mathrm{H}=3\end{array}$ & $\begin{array}{l}M=5 \\
F=2\end{array}$ & $\begin{array}{l}D=4 \\
A=2\end{array}$ & 6 \\
\hline & & $\begin{array}{l}\text { New risks } \\
\text { from } \\
\text { technology }\end{array}$ & $\begin{array}{l}\text { Little or no } \\
\text { risks from } \\
\text { bioremediation }\end{array}$ & $\begin{array}{l}\text { Because bioremediation takes } \\
\text { place at the site and specifically on } \\
\text { the contamination, there is little or } \\
\text { no risk to the workers or the public. }\end{array}$ & $\begin{array}{l}\text { LMD, OMD, OMD, OMD, } \\
\text { OMD, OMD, HMX, HMD, HXX, }\end{array}$ & $\begin{array}{l}\mathrm{L}=1 \\
\mathrm{O}=5 \\
\mathrm{H}=3\end{array}$ & $\begin{array}{l}M=8 \\
F=0 \\
X=1\end{array}$ & $\begin{array}{l}\mathrm{D}=7 \\
\mathrm{X}=2\end{array}$ & 9 \\
\hline
\end{tabular}




\begin{tabular}{|c|c|c|c|c|c|c|c|c|c|}
\hline & & & & $\begin{array}{l}\text { The benefits far exceed the risks of } \\
\text { bioremediation because there are } \\
\text { so few risks from the use of it. }\end{array}$ & $\begin{array}{l}\text { LMA, OMD, OFD, OFD, OMD, } \\
\text { OMD, OMX, OMR, HMA, } \\
\text { HMX, HMX }\end{array}$ & $\begin{array}{l}\mathrm{L}=1 \\
\mathrm{O}=7 \\
\mathrm{H}=3\end{array}$ & $\begin{array}{l}M=9 \\
F=2\end{array}$ & $\begin{array}{l}D=5 \\
A=2 \\
R=1 \\
X=3\end{array}$ & 11 \\
\hline & & & $\begin{array}{l}\text { High risks from } \\
\text { bioremediation }\end{array}$ & $\begin{array}{l}\text { If bioremediation is deemed } \\
\text { successful without monitoring over } \\
\text { a sufficient amount of time, a new } \\
\text { personal risk can be developed by } \\
\text { letting it proceed. }\end{array}$ & $\begin{array}{l}\text { LMA, OMD, OMD, OFX, OMR, } \\
\text { HXX }\end{array}$ & $\begin{array}{l}\mathrm{L}=1 \\
\mathrm{O}=4 \\
\mathrm{H}=1\end{array}$ & $\begin{array}{l}M=4 \\
F=1 \\
X=1\end{array}$ & $\begin{array}{l}D=2 \\
A=1 \\
R=1 \\
X=2\end{array}$ & 6 \\
\hline & & & & $\begin{array}{l}\text { Bioremediation only stirs things up. } \\
\text { The contamination will still be } \\
\text { there. }\end{array}$ & OMD, OFD, OFD, HMA, HFA & $\begin{array}{l}\mathrm{L}=0 \\
\mathrm{O}=3 \\
\mathrm{H}=2\end{array}$ & $\begin{array}{l}M=2 \\
F=3\end{array}$ & $\begin{array}{l}D=3 \\
A=2\end{array}$ & 5 \\
\hline & & & $\begin{array}{l}\text { Scared of by- } \\
\text { products }\end{array}$ & $\begin{array}{l}\text { I am concerned about what these } \\
\text { mega-bugs will produce and what } \\
\text { they will leave behind. }\end{array}$ & $\begin{array}{l}\text { LFX, LFD, LFD, LMD, LFD, } \\
\text { LFD, OFD, OFD, OFR, OFX, } \\
\text { OMD, HFD, HFR, HMA }\end{array}$ & $\begin{array}{l}\mathrm{L}=6 \\
\mathrm{O}=6 \\
\mathrm{H}=2\end{array}$ & $\begin{array}{l}\mathrm{M}=3 \\
\mathrm{~F}=11\end{array}$ & $\begin{array}{l}D=9 \\
R=2 \\
A=1 \\
X=2\end{array}$ & 14 \\
\hline
\end{tabular}


Attitudes toward Involvement and Participation Options

\begin{tabular}{|c|c|c|c|c|c|c|c|c|c|}
\hline \multirow{2}{*}{ Theme } & \multirow{2}{*}{ Parent Node } & \multirow{2}{*}{ Child Node } & \multirow{2}{*}{ Grandchild Node } & \multirow{2}{*}{ Statements } & \multicolumn{5}{|c|}{ Attributes } \\
\hline & & & & & Individual demographics & Site & Gender & Occupation & Total \\
\hline \multirow[t]{7}{*}{$\begin{array}{l}\text { Community } \\
\text { Involvement }\end{array}$} & Inclusion & \begin{tabular}{|l} 
Fair \\
participation
\end{tabular} & $\begin{array}{l}\text { No methods } \\
\text { available }\end{array}$ & $\begin{array}{l}\text { There is no real mechanism in } \\
\text { the system to actually get } \\
\text { public input because it s often } \\
\text { at the convenience of the } \\
\text { government }\end{array}$ & LFD, OMD, OMD, OMD & $\begin{array}{l}\mathrm{L}=1 \\
\mathrm{O}=3 \\
\mathrm{H}=0\end{array}$ & $\begin{array}{l}M=3 \\
F=1\end{array}$ & $\mathrm{D}=4$ & 4 \\
\hline & & & $\begin{array}{l}\text { Credibility from } \\
\text { participation }\end{array}$ & $\begin{array}{l}\text { Listening to all sides will help } \\
\text { to make decisions more } \\
\text { effective and comprehensive. } \\
\text { Public input gives the } \\
\text { government more credibility. }\end{array}$ & $\begin{array}{l}\text { LMD, LMD, OMX, OMA, } \\
\text { OFD, OFD, OMD, OMD, } \\
\text { HMD, HMX }\end{array}$ & $\begin{array}{l}\mathrm{L}=2 \\
\mathrm{O}=6 \\
\mathrm{H}=2\end{array}$ & $\begin{array}{l}\mathrm{M}=8 \\
\mathrm{~F}=2\end{array}$ & $\begin{array}{l}D=7 \\
A=1 \\
X=2\end{array}$ & 10 \\
\hline & & Role of CABs & $\begin{array}{l}\text { Public voice } \\
\text { mechanism }\end{array}$ & $\begin{array}{l}\text { The advisory board id not a } \\
\text { mouthpiece for DOE and } \\
\text { enable the public to have } \\
\text { more knowledge about what } \\
\text { they are doing. }\end{array}$ & $\begin{array}{l}\text { LFD, LMD, LMD, LFD, } \\
\text { LMD, OMA, OMD, OFD, } \\
\text { OMD, OMD, HFX, HMX, }\end{array}$ & $\begin{array}{l}\mathrm{L}=5 \\
\mathrm{O}=5 \\
\mathrm{H}=2\end{array}$ & $\begin{array}{l}M=8 \\
F=4\end{array}$ & $\begin{array}{l}D=9 \\
A=1 \\
X=2\end{array}$ & 12 \\
\hline & & & & $\begin{array}{l}\text { I feel that you can't leave it to } \\
\text { stakeholders to make the } \\
\text { decisions. The buck stops } \\
\text { with the people who are } \\
\text { paying the money and doing } \\
\text { the work. } \\
\end{array}$ & LMD, OFD & $\begin{array}{l}\mathrm{L}=1 \\
\mathrm{O}=1 \\
\mathrm{H}=0\end{array}$ & $\begin{array}{l}\mathrm{M}=1 \\
\mathrm{~F}=1\end{array}$ & $\mathrm{D}=2$ & \\
\hline & & $\begin{array}{l}\text { Stakeholders } \\
\text { are too } \\
\text { emotional }\end{array}$ & & $\begin{array}{l}\text { The perception of risk and } \\
\text { significance of risk is very } \\
\text { badly understood by the } \\
\text { public and emotion takes over } \\
\text { rather than logic. }\end{array}$ & $\begin{array}{l}\text { LFD, LMD, LMD, LMD, } \\
\text { OMD, OFD, OFD, OMX, } \\
\text { HMX, HMD, HFB, HMD, } \\
\text { HMX, }\end{array}$ & $\begin{array}{l}\mathrm{L}=4 \\
\mathrm{O}=4 \\
\mathrm{H}=5\end{array}$ & $\begin{array}{l}M=9 \\
F=4\end{array}$ & $\begin{array}{l}\mathrm{D}=9 \\
\mathrm{~B}=1 \\
\mathrm{X}=3\end{array}$ & 13 \\
\hline & & & & $\begin{array}{l}\text { The public ought to be } \\
\text { involved, but their input } \\
\text { should only be taken into } \\
\text { account after the preliminary } \\
\text { data gathering. } \\
\end{array}$ & OFD, OFD, HMX & $\begin{array}{l}\mathrm{L}=0 \\
\mathrm{O}=2 \\
\mathrm{H}=1\end{array}$ & $\begin{array}{l}\mathrm{M}=1 \\
\mathrm{~F}=2\end{array}$ & $\begin{array}{l}D=2 \\
X=1\end{array}$ & 3 \\
\hline & Representation & $\begin{array}{l}\text { Government } \\
\text { representation }\end{array}$ & $\begin{array}{l}\text { Elected } \\
\text { representatives } \\
\text { have power to } \\
\text { make decision }\end{array}$ & $\begin{array}{l}\text { The decision is in the } \\
\text { authority of the regulators } \\
\text { under the law provided by } \\
\text { elected officials. }\end{array}$ & $\begin{array}{l}\text { OMD, OMR, OFD, HMD, } \\
\text { HMD }\end{array}$ & $\begin{array}{l}\mathrm{L}=0 \\
\mathrm{O}=3 \\
\mathrm{H}=2\end{array}$ & $\begin{array}{l}\mathrm{M}=4 \\
\mathrm{~F}=1\end{array}$ & $\begin{array}{l}\mathrm{D}=4 \\
\mathrm{R}=1\end{array}$ & 5 \\
\hline
\end{tabular}




\begin{tabular}{|c|c|c|c|c|c|c|c|c|c|}
\hline \multirow{2}{*}{ Theme } & \multirow{2}{*}{ Parent Node } & \multirow{2}{*}{ Child Node } & \multirow{2}{*}{ Grandchild Node } & \multirow{2}{*}{ Statements } & \multicolumn{5}{|c|}{ Attributes } \\
\hline & & & & & Individual demographics & Site & Gender & Occupation & Total \\
\hline & & $\begin{array}{l}\text { CABs do not } \\
\text { represent the } \\
\text { public's } \\
\text { viewpoint }\end{array}$ & & $\begin{array}{l}\text { In my experience with the } \\
\text { CAB is that they have a } \\
\text { tendency to have their own } \\
\text { agendas that don't really } \\
\text { focus on the real issues at } \\
\text { times. Therefore, I feel that } \\
\text { perhaps as a citizen, my } \\
\text { interests and my concerns are } \\
\text { never really addressed. }\end{array}$ & $\begin{array}{l}\text { LFX, LFD, LFD, OFD, HFB, } \\
\text { HXX }\end{array}$ & $\begin{array}{l}\mathrm{L}=3 \\
\mathrm{O}=1 \\
\mathrm{H}=2\end{array}$ & $\begin{array}{l}M=0 \\
F=5 \\
X=1\end{array}$ & $\begin{array}{l}D=3 \\
B=1 \\
X=2\end{array}$ & 6 \\
\hline & & & & $\begin{array}{l}\text { The government is handed a } \\
\text { recommendation that is based } \\
\text { upon only about } 50 \text { people } \\
\text { who attended the meeting. } \\
\text { To me, that doesn't reflect the } \\
\text { community's opinions or } \\
\text { values. }\end{array}$ & LFD, LFD, LFD, OFB, HFD & $\begin{array}{l}\mathrm{L}=3 \\
\mathrm{O}=1 \\
\mathrm{H}=1\end{array}$ & $\begin{array}{l}M=0 \\
F=5\end{array}$ & $\begin{array}{l}D=4 \\
B=1\end{array}$ & 5 \\
\hline & Equal influence & $\begin{array}{l}\text { Local interests } \\
\text { ought to have } \\
\text { more weight }\end{array}$ & & $\begin{array}{l}\text { This is my backyard and we } \\
\text { are the ones having to deal } \\
\text { with it. The local interest } \\
\text { should have more weight in } \\
\text { decision making than national } \\
\text { interests. }\end{array}$ & $\begin{array}{l}\text { LFX, LFD, LFD, OFD, } \\
\text { OFD, OMB }\end{array}$ & $\begin{array}{l}\mathrm{L}=3 \\
\mathrm{O}=3 \\
\mathrm{H}=0\end{array}$ & $\begin{array}{l}M=1 \\
F=5\end{array}$ & $\begin{array}{l}\mathrm{D}=4 \\
\mathrm{~B}=1 \\
\mathrm{X}=1\end{array}$ & 6 \\
\hline & & $\begin{array}{l}\text { Too many } \\
\text { viewpoints in } \\
\text { the public for } \\
\text { decision-making }\end{array}$ & & $\begin{array}{l}\text { You're trying to come up with } \\
\text { a scenario and you're in a } \\
\text { vacuum in a way, and you } \\
\text { can't please everyone. }\end{array}$ & LFD, LMD, OMD, HMD & $\begin{array}{l}\mathrm{L}=2 \\
\mathrm{O}=1 \\
\mathrm{H}=1\end{array}$ & $\begin{array}{l}M=3 \\
F=1\end{array}$ & $\mathrm{D}=4$ & 4 \\
\hline & & $\begin{array}{l}\text { Lack of public } \\
\text { participation }\end{array}$ & $\begin{array}{l}\text { Individual } \\
\text { participation level }\end{array}$ & $\begin{array}{l}\text { Sitting through a meeting is } \\
\text { pretty tough. Life is too short } \\
\text { to be engaged in a year long } \\
\text { process. }\end{array}$ & $\begin{array}{l}\text { LFX, OMA, OMD, OMD, } \\
\text { OMD }\end{array}$ & $\begin{array}{l}\mathrm{L}=1 \\
\mathrm{O}=4 \\
\mathrm{H}=0\end{array}$ & $\begin{array}{l}M=4 \\
F=1\end{array}$ & $\begin{array}{l}D=4 \\
X=1\end{array}$ & 5 \\
\hline & & & & $\begin{array}{l}\text { We have elected officials and } \\
\text { advisory boards that satisfy } \\
\text { my need as a member of the } \\
\text { public to be involved with } \\
\text { DOE decisions }\end{array}$ & $\begin{array}{l}\text { OFD, OMD, OFD, HMX, } \\
\text { HMD }\end{array}$ & $\begin{array}{l}\mathrm{L}=0 \\
\mathrm{O}=3 \\
\mathrm{H}=2\end{array}$ & $\begin{array}{l}M=3 \\
F=2\end{array}$ & $\begin{array}{l}D=4 \\
X=1\end{array}$ & 5 \\
\hline & & & $\begin{array}{l}\text { Community } \\
\text { participation level }\end{array}$ & $\begin{array}{l}\text { Very few people want to be } \\
\text { involved because it's too time } \\
\text { consuming and there are } \\
\text { personal costs as well. }\end{array}$ & $\begin{array}{l}\text { LMD, LFD, OFD, OFD, } \\
\text { OMX, HFD, }\end{array}$ & $\begin{array}{l}\mathrm{L}= \\
\mathrm{O}= \\
\mathrm{H}=\end{array}$ & $\begin{array}{l}\mathrm{M}= \\
\mathrm{F}=\end{array}$ & & \\
\hline
\end{tabular}




\begin{tabular}{|c|c|c|c|c|c|c|c|c|c|}
\hline \multirow{2}{*}{ Theme } & \multirow{2}{*}{ Parent Node } & \multirow{2}{*}{ Child Node } & \multirow{2}{*}{ Grandchild Node } & \multirow{2}{*}{ Statements } & \multicolumn{5}{|c|}{ Attributes } \\
\hline & & & & & Individual demographics & Site & Gender & Occupation & Total \\
\hline & & & & $\begin{array}{l}\text { The general public out there } \\
\text { has little interest or concern } \\
\text { about what is going on at the } \\
\text { site or with clean-up activities. }\end{array}$ & $\begin{array}{l}\text { LFD, LFD, LMD, LMD, } \\
\text { LFD, LFA, OMD, OMD, } \\
\text { OFD, OFD, OFD, HFD, } \\
\text { HFR }\end{array}$ & $\begin{array}{l}\mathrm{L}=6 \\
\mathrm{O}=5 \\
\mathrm{H}=2\end{array}$ & $\begin{array}{l}M=4 \\
F=9\end{array}$ & $\begin{array}{l}D=11 \\
R=1 \\
A=1\end{array}$ & 13 \\
\hline & & $\begin{array}{l}\text { Active public } \\
\text { participation }\end{array}$ & $\begin{array}{l}\text { Individual } \\
\text { participation level }\end{array}$ & $\begin{array}{l}\text { I actively participate because I } \\
\text { think I can help make a } \\
\text { difference. }\end{array}$ & $\begin{array}{l}\text { LFD, LMD, OMD, OMR, } \\
\text { HMX, HFX, HMD, HMD, } \\
\text { HMD, HFR }\end{array}$ & $\begin{array}{l}\mathrm{L}=2 \\
\mathrm{O}=2 \\
\mathrm{H}=6\end{array}$ & $\begin{array}{l}M=7 \\
F=3\end{array}$ & $\begin{array}{l}D=6 \\
R=2 \\
X=2\end{array}$ & 10 \\
\hline & & & $\begin{array}{l}\text { Community } \\
\text { participation level }\end{array}$ & $\begin{array}{l}\text { This community that wants to } \\
\text { get involved in decision- } \\
\text { making. The people want and } \\
\text { expect to be a part of ay kind } \\
\text { of process that involves the } \\
\text { environment. }\end{array}$ & $\begin{array}{l}\text { LFD, LFD, LMD, LMD, } \\
\text { OMA, OMD, OFD, OFR, } \\
\text { OMD, OMD, OMD, OMD, } \\
\text { HFX, HMD, HFD, HMX, } \\
\text { HXX, HFD, HMX, HFA }\end{array}$ & $\begin{array}{l}\mathrm{L}=4 \\
\mathrm{O}=8 \\
\mathrm{H}=8\end{array}$ & $\begin{array}{c}M=11 \\
F=8 \\
X=1\end{array}$ & $\begin{array}{l}D=13 \\
A=2 \\
R=1 \\
X=4\end{array}$ & 20 \\
\hline & $\begin{array}{l}\text { Information } \\
\text { Access }\end{array}$ & Listening & $\begin{array}{l}\text { Government does } \\
\text { not listen to public } \\
\text { interests }\end{array}$ & $\begin{array}{l}\text { My experience with DOE is } \\
\text { that they decide what they will } \\
\text { do before they get public } \\
\text { input. It would be better if } \\
\text { they would inform the people } \\
\text { and tell them about it than it } \\
\text { just happening and the public } \\
\text { being told after the fact. }\end{array}$ & $\begin{array}{l}\text { LMD, LMD, LFD, LMD, } \\
\text { LFA, OFD, OMA, OMD, } \\
\text { OFD, OMD, OMD, OMD, } \\
\text { OMR, HFX, HXX }\end{array}$ & $\begin{array}{l}\mathrm{L}=5 \\
\mathrm{O}=8 \\
\mathrm{H}=2\end{array}$ & $\begin{array}{l}M=9 \\
F=5 \\
X=1\end{array}$ & $\begin{array}{l}D=10 \\
A=2 \\
R=1 \\
X=2\end{array}$ & 15 \\
\hline & & & & $\begin{array}{l}\text { The people cannot talk to } \\
\text { their government at all. It's so } \\
\text { huge. It's scary and very } \\
\text { imposing. }\end{array}$ & LFD, OFR, & $\begin{array}{l}\mathrm{L}=1 \\
\mathrm{O}=1 \\
\mathrm{H}=0\end{array}$ & $\begin{array}{l}M=0 \\
F=2\end{array}$ & $\begin{array}{l}D=1 \\
R=1\end{array}$ & 2 \\
\hline & & & $\begin{array}{l}\text { Government does } \\
\text { listen to the public } \\
\text { interests }\end{array}$ & $\begin{array}{l}\text { I can credit the public for } \\
\text { having a strong involvement } \\
\text { and the DOE has been very } \\
\text { good at taking their } \\
\text { recommendations and dealing } \\
\text { with the concerns that the } \\
\text { public has spoken about. }\end{array}$ & $\begin{array}{l}\text { LFX, LFD, LMD, LMD, } \\
\text { LFR, LMA, OMD, OMA, } \\
\text { OMD, OFD, OMD, OMD, } \\
\text { OMD, OMD, OMD, HMD, } \\
\text { HMD, HMA, HMX, HMX }\end{array}$ & $\begin{array}{l}\mathrm{L}=6 \\
\mathrm{O}=9 \\
\mathrm{H}=5\end{array}$ & $\begin{array}{c}M=16 \\
F=4\end{array}$ & $\begin{array}{l}D=13 \\
A=3 \\
R=1 \\
X=3\end{array}$ & 20 \\
\hline & & $\begin{array}{l}\text { Return of } \\
\text { Information }\end{array}$ & $\begin{array}{l}\text { Lack of } \\
\text { communication } \\
\text { from DOE to the } \\
\text { public }\end{array}$ & $\begin{array}{l}\text { Don't talk to me like I am a } \\
\text { scientist. Talk to me like I am } \\
\text { an idiot who doesn't know } \\
\text { anything. }\end{array}$ & $\begin{array}{l}\text { LFD, OMA, OFD, OFD, } \\
\text { OFR, OMD, OFD, OMX, } \\
\text { OMR, HMX, HFD, }\end{array}$ & $\begin{array}{l}\mathrm{L}=1 \\
\mathrm{O}=8 \\
\mathrm{H}=2\end{array}$ & $\begin{array}{l}M=5 \\
F=6\end{array}$ & $\begin{array}{l}D=6 \\
A=1 \\
R=2 \\
X=2\end{array}$ & 11 \\
\hline
\end{tabular}




\begin{tabular}{|c|c|c|c|c|c|c|c|c|c|}
\hline \multirow{2}{*}{ Theme } & \multirow{2}{*}{ Parent Node } & \multirow{2}{*}{ Child Node } & \multirow{2}{*}{ Grandchild Node } & \multirow{2}{*}{ Statements } & \multicolumn{5}{|c|}{ Attributes } \\
\hline & & & & & Individual demographics & Site & Gender & Occupation & Total \\
\hline & & & & $\begin{array}{l}\text { There has been an on-going } \\
\text { legacy of DOE's culture of } \\
\text { secrecy. }\end{array}$ & $\begin{array}{l}\text { LFX, LFD, LMD, OFD, } \\
\text { OMD, OMA, OMD, OFD, } \\
\text { OFX, OFD, OMD, OMD, } \\
\text { OMD, HFX, HFB, HFD }\end{array}$ & $\begin{array}{l}L=3 \\
O=10 \\
H=3\end{array}$ & $\begin{array}{l}M=7 \\
F=9\end{array}$ & $\begin{array}{l}D=11 \\
B=1 \\
A=1 \\
X=3\end{array}$ & 16 \\
\hline & & & & $\begin{array}{l}\text { DOE sugar-coats it. They } \\
\text { won't lie, but they won't tell } \\
\text { you the whole truth. }\end{array}$ & LFD, LFX, LMD, HFD & $\begin{array}{l}L=3 \\
O=0 \\
H=1\end{array}$ & $\begin{array}{l}M=1 \\
F=3\end{array}$ & $\begin{array}{l}D=3 \\
X=1\end{array}$ & 4 \\
\hline & & & $\begin{array}{l}\text { Education and } \\
\text { information sharing } \\
\text { will help to lower } \\
\text { risk perceptions } \\
\text { and build trust }\end{array}$ & $\begin{array}{l}\text { I would trust more if I was told } \\
\text { more. People would be more } \\
\text { willing to accept the risks if } \\
\text { they know about them. }\end{array}$ & $\begin{array}{l}\text { LFX, LFD, LFX, LMD, LFD, } \\
\text { LMD, OMX, OMB, OFD, } \\
\text { OMD, OFD, OFD, OFB, } \\
\text { OFD, OMR, OMR, OFD, } \\
\text { OMB, OMD, OMX, HFX }\end{array}$ & $\begin{array}{l}\mathrm{L}=6 \\
\mathrm{O}=14 \\
\mathrm{H}=1\end{array}$ & $\begin{array}{l}M=10 \\
F=11\end{array}$ & $\begin{array}{l}D=11 \\
B=3 \\
R=2 \\
X=5\end{array}$ & 21 \\
\hline & & & & $\begin{array}{l}\text { There is a need for improved } \\
\text { general understanding of } \\
\text { some of these issues so that } \\
\text { people who aren't involved in } \\
\text { the process have more trust } \\
\text { and less fear }\end{array}$ & OMD, OFD, OFD, OFD & $\begin{array}{l}\mathrm{L}=0 \\
\mathrm{O}=4 \\
\mathrm{H}=0\end{array}$ & $\begin{array}{l}\mathrm{M}=1 \\
\mathrm{~F}=3\end{array}$ & $\mathrm{D}=4$ & 4 \\
\hline & & & & $\begin{array}{l}\text { The more information you can } \\
\text { give the public, the better off } \\
\text { we are. I would rather be } \\
\text { overwhelmed with information } \\
\text { than be scared because I } \\
\text { don't know. }\end{array}$ & $\begin{array}{l}\text { OFX, OMR, OMD, OMB, } \\
\text { HMA }\end{array}$ & $\begin{array}{l}\mathrm{L}=0 \\
\mathrm{O}=4 \\
\mathrm{H}=1\end{array}$ & $\begin{array}{l}M=4 \\
F=1\end{array}$ & $\begin{array}{l}D=1 \\
B=1 \\
R=1 \\
A=1 \\
X=1\end{array}$ & 5 \\
\hline & & & $\begin{array}{l}\text { DOE is open with } \\
\text { information }\end{array}$ & $\begin{array}{l}\text { The flow information has been } \\
\text { pretty steady. Anything that } \\
\text { happens at the site, DOE } \\
\text { usually holds a symposium to } \\
\text { inform the community. }\end{array}$ & LFX, LFD, LMD, OMD, & $\begin{array}{l}\mathrm{L}=3 \\
\mathrm{O}=1 \\
\mathrm{H}=0\end{array}$ & $\begin{array}{l}\mathrm{M}=2 \\
\mathrm{~F}=2\end{array}$ & $\begin{array}{l}D=3 \\
X=1\end{array}$ & 4 \\
\hline \multirow[t]{2}{*}{$\begin{array}{l}\text { Stakeholder } \\
\text { Participation } \\
\text { Options } \\
\text { Survey results }\end{array}$} & Deference & High & & & OMB & $\begin{array}{l}\mathrm{L}=0 \\
\mathrm{O}=1 \\
\mathrm{H}=0\end{array}$ & $\begin{array}{l}M=1 \\
F=0\end{array}$ & $\mathrm{~B}=1$ & 1 \\
\hline & & Medium & & & $\begin{array}{l}\text { LFD, OMD, OMD, OMD, } \\
\text { HMD, HMD }\end{array}$ & $\begin{array}{l}\mathrm{L}=1 \\
\mathrm{O}=3 \\
\mathrm{H}=2\end{array}$ & $\begin{array}{l}M=5 \\
F=1\end{array}$ & $\mathrm{D}=6$ & 6 \\
\hline
\end{tabular}




\begin{tabular}{|c|c|c|c|c|c|c|c|c|c|}
\hline \multirow{2}{*}{ Theme } & \multirow{2}{*}{ Parent Node } & \multirow{2}{*}{ Child Node } & \multirow{2}{*}{ Grandchild Node } & \multirow{2}{*}{ Statements } & \multicolumn{5}{|c|}{ Attributes } \\
\hline & & & & & Individual demographics & Site & Gender & Occupation & Total \\
\hline & & Low & & & $\begin{array}{l}\text { LFA, OFD, OMA, OFD, } \\
\text { OFD, OFD, OFR, OFD, } \\
\text { OMD, OMD, OFD, OFX, } \\
\text { OMD, OMR, OFB, OMR, } \\
\text { OMR, HMX, HFX, HMD, } \\
\text { HFD, HMD, HFD, HXX, } \\
\text { HMD, HMA, HFB, HMX, } \\
\text { HMR, HMR, HFB, HXX, } \\
\text { HFD, HMB, HMD, HMD, } \\
\text { HMX, HFR, HFD, HMA, } \\
\text { HMX, HFA, HFA }\end{array}$ & $\begin{array}{l}\mathrm{L}=1 \\
\mathrm{O}=16 \\
\mathrm{H}=26\end{array}$ & $\begin{array}{l}M=21 \\
F=20 \\
X=2\end{array}$ & $\begin{array}{l}D=18 \\
B=4 \\
R=7 \\
A=6 \\
X=8\end{array}$ & 43 \\
\hline & & Rank 4 & & & LFA, OFD, OMB, & $\begin{array}{l}\mathrm{L}=1 \\
\mathrm{O}=2 \\
\mathrm{H}=0\end{array}$ & $\begin{array}{l}M=1 \\
F=2\end{array}$ & $\begin{array}{l}D=1 \\
A=1 \\
B=1\end{array}$ & 3 \\
\hline & & Rank 3 & & & OMD, HMD, HFR, & $\begin{array}{l}\mathrm{L}=0 \\
\mathrm{O}=1 \\
\mathrm{H}=2 \\
\end{array}$ & $\begin{array}{l}M=2 \\
F=1\end{array}$ & $\begin{array}{l}D=2 \\
R=1\end{array}$ & 3 \\
\hline & & Rank 2 & & & $\begin{array}{l}\text { OFD, OMD, OFB, OMD, } \\
\text { HMX, HMD, HFD, HMD, } \\
\text { HMD, }\end{array}$ & $\begin{array}{l}\mathrm{L}=0 \\
\mathrm{O}=4 \\
\mathrm{H}=5\end{array}$ & $\begin{array}{l}\mathrm{M}=6 \\
\mathrm{~F}=3\end{array}$ & $\begin{array}{l}D=7 \\
B=1 \\
X=1\end{array}$ & 9 \\
\hline & & Rank 1 & & & $\begin{array}{l}\text { LFD, OMR, OMR, OMR, } \\
\text { HMX, HFX, HMD, HFD, } \\
\text { HMD, HFD, HXX, HMA, } \\
\text { HFB, HMR, HMX, HFB, } \\
\text { HXX, HMB, HMD, HMD, } \\
\text { HFD, HMA, HMX, HFA, } \\
\text { HFA }\end{array}$ & $\begin{array}{l}\mathrm{L}=1 \\
\mathrm{O}=3 \\
\mathrm{H}=21\end{array}$ & $\begin{array}{c}M=14 \\
F=9 \\
X=2\end{array}$ & $\begin{array}{l}D=8 \\
B=3 \\
R=4 \\
A=4 \\
X=5\end{array}$ & 24 \\
\hline & Deliberation & High & & & $\begin{array}{l}\text { OMA, OFD, OFD, OFX, } \\
\text { OMR, OMR, HMX, HFX, } \\
\text { HMD, HXX, HFB, HMR, } \\
\text { HMX, HFR, HFD, HMA, } \\
\text { HFA, HFA }\end{array}$ & $\begin{array}{l}\mathrm{L}=0 \\
\mathrm{O}=6 \\
\mathrm{H}=12\end{array}$ & $\begin{array}{l}M=8 \\
F=9 \\
X=1\end{array}$ & $\begin{array}{l}D=4 \\
B=1 \\
R=4 \\
A=4 \\
X=5\end{array}$ & 18 \\
\hline & & Medium & & & $\begin{array}{l}\text { LFD, LMD, OFD, OFD, } \\
\text { OMD, OMD, HFD, HMD, } \\
\text { HFD, HFB, HXX, HMB }\end{array}$ & $\begin{array}{l}\mathrm{L}=2 \\
\mathrm{O}=4 \\
\mathrm{H}=6\end{array}$ & $\begin{array}{l}M=5 \\
F=6 \\
X=1\end{array}$ & $\begin{array}{l}\mathrm{D}=9 \\
\mathrm{~B}=2 \\
\mathrm{X}=1\end{array}$ & 12 \\
\hline
\end{tabular}




\begin{tabular}{|c|c|c|c|c|c|c|c|c|c|}
\hline \multirow{2}{*}{ Theme } & \multirow{2}{*}{ Parent Node } & \multirow{2}{*}{ Child Node } & \multirow{2}{*}{ Grandchild Node } & \multirow{2}{*}{ Statements } & \multicolumn{5}{|c|}{ Attributes } \\
\hline & & & & & Individual demographics & Site & Gender & Occupation & Total \\
\hline & & Low & & & $\begin{array}{l}\text { LMD, LMD, LMA, OFR, } \\
\text { OMD, OMD, OMR, OMD, } \\
\text { OFB, OMD, HMD, HMA, } \\
\text { HMX, HMD, HFD, HMD, } \\
\text { HMD, HMD, HMX, HMX }\end{array}$ & \begin{tabular}{|l|}
$L=3$ \\
$O=7$ \\
$H=10$
\end{tabular} & $\begin{array}{l}M=17 \\
F=3\end{array}$ & $\begin{array}{l}D=12 \\
B=1 \\
R=2 \\
A=2 \\
X=3\end{array}$ & 20 \\
\hline & & Rank 4 & & & $\begin{array}{l}\text { OMD, OMR, OMR, HFX, } \\
\text { HMX, HFB, HMR, HFR, } \\
\text { HFD, HFA, HFA, HMA }\end{array}$ & \begin{tabular}{|l|}
$\mathrm{L}=0$ \\
$\mathrm{O}=3$ \\
$\mathrm{H}=9$
\end{tabular} & $\begin{array}{l}M=6 \\
F=6\end{array}$ & $\begin{array}{l}D=2 \\
B=1 \\
R=4 \\
A=3 \\
X=2\end{array}$ & 12 \\
\hline & & Rank 3 & & & $\mathrm{HMD}, \mathrm{HMX}, \mathrm{HMX}$ & \begin{tabular}{|l|}
$\mathrm{L}=0$ \\
$\mathrm{O}=0$ \\
$\mathrm{H}=3$
\end{tabular} & $\begin{array}{l}M=3 \\
F=0\end{array}$ & $\begin{array}{l}\mathrm{D}=1 \\
\mathrm{X}=2\end{array}$ & 3 \\
\hline & & Rank 2 & & & $\begin{array}{l}\text { LFA, OFD, OMR, HMX, } \\
\text { HFD, HFD, HXX, HMA, } \\
\text { HFB, HXX, HMB, HMD, } \\
\text { HMD }\end{array}$ & \begin{tabular}{|l|}
$L=1$ \\
$O=2$ \\
$H=10$
\end{tabular} & $\begin{array}{l}M=6 \\
F=5 \\
X=2\end{array}$ & $\begin{array}{l}D=5 \\
B=2 \\
R=1 \\
A=2 \\
X=3\end{array}$ & 13 \\
\hline & & Rank 1 & & & $\begin{array}{l}\text { LMD, OFX, OMX, OMD, } \\
\text { OFB, OMD, HMD, HMX, } \\
\text { HMD, HFD, HMD, HMX }\end{array}$ & \begin{tabular}{|l|}
$L=1$ \\
$O=5$ \\
$H=6$
\end{tabular} & $\begin{array}{l}M=9 \\
F=3\end{array}$ & $\begin{array}{l}D=7 \\
B=1 \\
X=4\end{array}$ & 12 \\
\hline & Consultation & High & & & $\begin{array}{l}\text { LFA, OMD, OFD, OFR, } \\
\text { OMD, OFD, OMD, OMR, } \\
\text { OMD, OFB, OMD, HMX, } \\
\text { HFX, HFD, HFD, HMA, } \\
\text { HFB, HXX, HFD, HMB, } \\
\text { HMX, HMX }\end{array}$ & \begin{tabular}{|l|}
$L=1$ \\
$O=10$ \\
$H=11$
\end{tabular} & $\begin{array}{l}M=11 \\
F=10 \\
X=1\end{array}$ & $\begin{array}{l}D=10 \\
B=3 \\
R=2 \\
A=2 \\
X=5\end{array}$ & 22 \\
\hline & & Medium & & & $\begin{array}{l}\text { OMA, OFD, OMD, OMR, } \\
\text { HMD, HMD, HXX, HFB, } \\
\text { HMX, HMD, HMX, HMD, } \\
\text { HMD, HMD, HMA, HFA, } \\
\text { HFA }\end{array}$ & \begin{tabular}{|l|}
$L=0$ \\
$O=4$ \\
$H=13$
\end{tabular} & $\begin{array}{l}M=12 \\
F=4 \\
X=1\end{array}$ & $\begin{array}{l}D=8 \\
B=1 \\
R=1 \\
A=4 \\
X=3\end{array}$ & 17 \\
\hline & & Low & & & $\begin{array}{l}\text { OMD, OFX, OMR, HMX, } \\
\text { HMD, HFR, HFD }\end{array}$ & \begin{tabular}{|l|}
$\mathrm{L}=0$ \\
$\mathrm{O}=3$ \\
$\mathrm{H}=4$
\end{tabular} & $\begin{array}{l}M=4 \\
F=3\end{array}$ & $\begin{array}{l}\mathrm{D}=3 \\
\mathrm{R}=2 \\
\mathrm{X}=2\end{array}$ & 7 \\
\hline & & Rank 4 & & & $\begin{array}{l}\text { LFA, LMA, OFB, OMD, } \\
\text { HMX, HFD, HMA, HMA, } \\
\text { HMX, HFB, HXX, HFD, } \\
\text { HMB, HMD, HMX, HMX }\end{array}$ & \begin{tabular}{|l|}
$L=2$ \\
$O=2$ \\
$H=12$
\end{tabular} & $\begin{array}{l}M=10 \\
F=5 \\
X=1\end{array}$ & $\begin{array}{l}D=4 \\
B=3 \\
A=4 \\
X=5\end{array}$ & 16 \\
\hline
\end{tabular}




\begin{tabular}{|c|c|c|c|c|c|c|c|c|c|}
\hline \multirow{2}{*}{ Theme } & \multirow{2}{*}{ Parent Node } & \multirow{2}{*}{ Child Node } & \multirow{2}{*}{ Grandchild Node } & \multirow{2}{*}{ Statements } & \multicolumn{5}{|c|}{ Attributes } \\
\hline & & & & & Individual demographics & Site & Gender & Occupation & Total \\
\hline & & Rank 3 & & & $\begin{array}{l}\text { OMX, OMR, HFX, HFD, } \\
\text { HXX, HMR, HMD, HMD, } \\
\text { HMD, HFD, HMA, HFA, } \\
\text { HFA }\end{array}$ & \begin{tabular}{|l|}
$L=0$ \\
$O=2$ \\
$H=11$
\end{tabular} & $\begin{array}{l}M=7 \\
F=5 \\
X=1\end{array}$ & $\begin{array}{l}D=5 \\
R=2 \\
A=3 \\
X=3\end{array}$ & 13 \\
\hline & & Rank 2 & & & $\begin{array}{l}\text { OMD, OMR, HMD, HMD, } \\
\text { HFB }\end{array}$ & \begin{tabular}{|l|}
$\mathrm{L}=0$ \\
$\mathrm{O}=2$ \\
$\mathrm{H}=3$
\end{tabular} & $\begin{array}{l}M=4 \\
F=1\end{array}$ & $\begin{array}{l}D=3 \\
B=1 \\
R=1\end{array}$ & 5 \\
\hline & & Rank 1 & & & OFD, HFR & \begin{tabular}{|l|}
$\mathrm{L}=0$ \\
$\mathrm{O}=1$ \\
$\mathrm{H}=1$
\end{tabular} & $\begin{array}{l}M=0 \\
F=2\end{array}$ & $\begin{array}{l}D=1 \\
R=1\end{array}$ & 2 \\
\hline & $\begin{array}{l}\text { Information } \\
\text { Exchange }\end{array}$ & High & & & $\begin{array}{l}\text { LFD, LMD, LFD, OMD, } \\
\text { OMR, OMD, OFB, OMD, } \\
\text { HMD, HMA, HMA, HXX, } \\
\text { HMD, HMD, HMD }\end{array}$ & \begin{tabular}{|l|}
$\mathrm{L}=3$ \\
$\mathrm{O}=5$ \\
$\mathrm{H}=7$
\end{tabular} & $\begin{array}{l}M=11 \\
F=3 \\
X=1\end{array}$ & $\begin{array}{l}D=10 \\
B=1 \\
R=1 \\
A=2 \\
X=1\end{array}$ & 15 \\
\hline & & Medium & & & $\begin{array}{l}\text { LFA, OMA, OFD, OMD, } \\
\text { OMD, OMR, HMX, HFD, } \\
\text { HFD, HXX, HMD, HFB, } \\
\text { HMX, HMR, HFB, HFD, } \\
\text { HMB, HMD, HMX }\end{array}$ & \begin{tabular}{|l|}
$L=1$ \\
$O=5$ \\
$H=13$
\end{tabular} & $\begin{array}{l}M=11 \\
F=7 \\
X=1\end{array}$ & $\begin{array}{l}D=8 \\
B=3 \\
R=2 \\
A=2 \\
X=4\end{array}$ & 19 \\
\hline & & Low & & & $\begin{array}{l}\text { OFD, OFD, OFR, OFD, } \\
\text { OFD, OFX, OMD, OMR, } \\
\text { HFX, HMD, HFR, HFD, } \\
\text { HMA, HMX, HFA, HFA }\end{array}$ & \begin{tabular}{|l|}
$L=0$ \\
$O=8$ \\
$H=8$
\end{tabular} & $\begin{array}{l}M=5 \\
F=11\end{array}$ & $\begin{array}{l}D=7 \\
R=3 \\
A=3 \\
X=3\end{array}$ & 16 \\
\hline & & Rank 4 & & & $\begin{array}{l}\text { LMD, LFD, OMX, OMR, } \\
\text { OMD, HMD, HXX, HMD, } \\
\text { HMD, HMD, HMD } \\
\end{array}$ & \begin{tabular}{|l|}
$\mathrm{L}=2$ \\
$\mathrm{O}=3$ \\
$\mathrm{H}=6$ \\
\end{tabular} & $\begin{array}{l}M=9 \\
F=1 \\
X=1\end{array}$ & $\begin{array}{l}\mathrm{D}=8 \\
\mathrm{R}=1 \\
\mathrm{X}=2 \\
\end{array}$ & 11 \\
\hline & & Rank 3 & & & $\begin{array}{l}\text { LFA, OFD, OFB, OMD, } \\
\text { HFD, HMA, HFB, HMX, } \\
\text { HFB, HFD, HMB, HMD, } \\
\text { HMX }\end{array}$ & $\begin{array}{l}\mathrm{L}=1 \\
\mathrm{O}=3 \\
\mathrm{H}=9\end{array}$ & $\begin{array}{l}M=6 \\
F=7\end{array}$ & $\begin{array}{l}D=5 \\
B=4 \\
A=2 \\
X=2\end{array}$ & 13 \\
\hline & & Rank 2 & & & $\begin{array}{l}\text { OMR, OMR, HMX, HFX, } \\
\text { HMD, HMR, HMX, HFR, } \\
\text { HFD, HMA, HMX, HFA, } \\
\text { HFA }\end{array}$ & \begin{tabular}{|l|}
$L=0$ \\
$O=2$ \\
$H=11$ \\
\end{tabular} & $\begin{array}{l}M=8 \\
F=5\end{array}$ & $\begin{array}{l}D=2 \\
R=4 \\
A=3 \\
X=4\end{array}$ & 13 \\
\hline & & Rank 1 & & & & $\begin{array}{l}\mathrm{L}=0 \\
\mathrm{O}=0 \\
\mathrm{H}=0\end{array}$ & $\begin{array}{l}M=0 \\
F=0\end{array}$ & & 0 \\
\hline
\end{tabular}


APPENDIX C

PRESENTATION AT STAKEHOLDER DIALOGUE ON BIOREMEDIATION 
- Study Description

- Results of Personal Interviews

- Bioremediation and Participation Themes

- Results of Q Sorting

- Bioremediation and Participation Perspectives

- Results of Random Telephone Survey

- Demographic Analysis

- Risk and Trust Judgments

- Bioremediation Acceptance

- Participation Preferences

- Conditions for Bioremediation Acceptance 


\section{Bioremediation}

Perceptions, Perspectives, Preferences

Dr. Will Focht and Matt Albright Oklahoma State University

September 22, 2005

\section{Outline of Presentation}




\section{Study Description}

- Purposes

- Stakeholder Reactions to Bioremediation

- Judgments of risk, trust, and acceptability

- Stakeholder Participation Preferences

- Roles of DOE, stakeholders, and third parties

- Sponsor

- US Department of Energy

- Bioremediation and Its Societal Implications and Concerns (BASIC) program

- Investigators

- Oklahoma State University

- University of Oklahoma

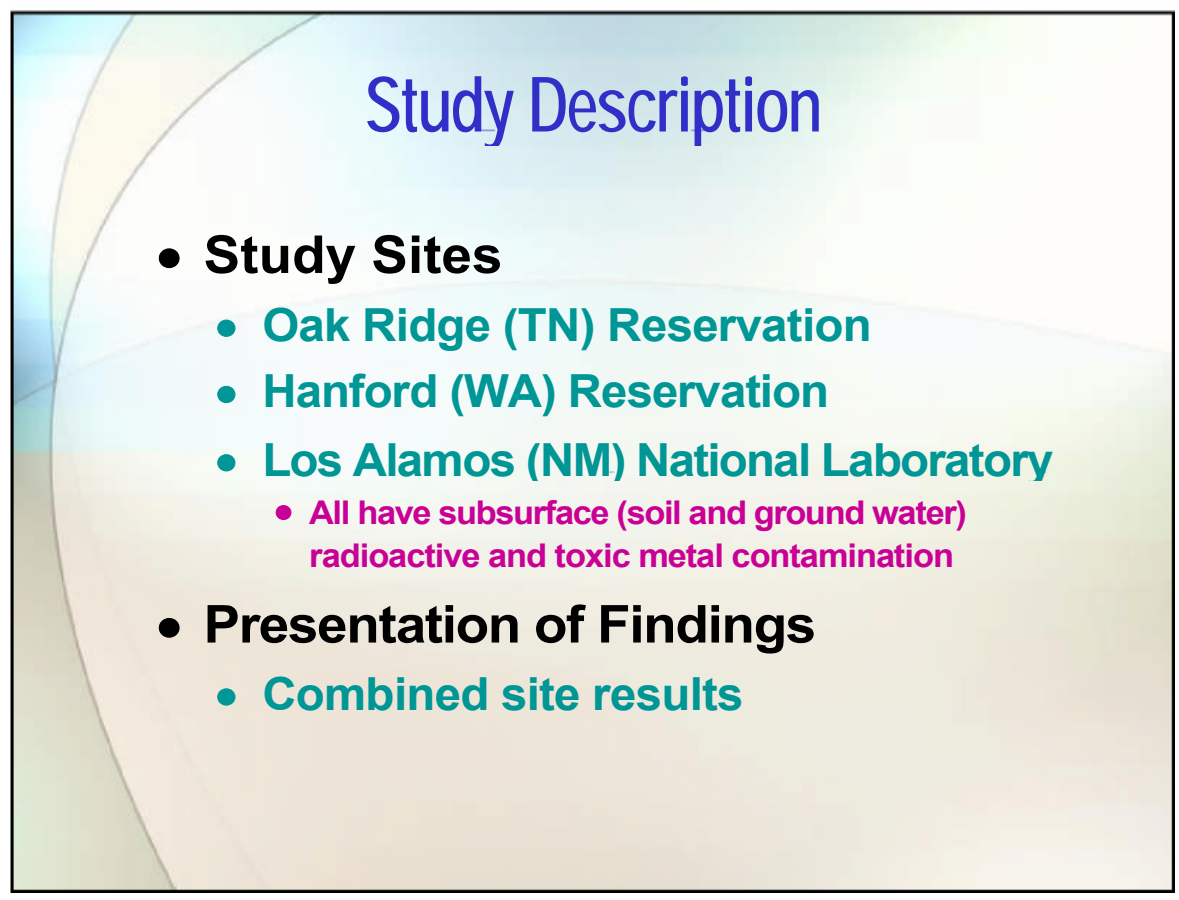




\section{Personal Interviews}

- Respondent Sample

- 72 interviews completed (30 in Oak Ridge)

- Question Categories

- Demographic characteristics

- Contaminant and bioremediation risk perceptions

- Trust judgments

- Bioremediation acceptance

- Participation preferences

- Computerized narrative analysis of transcripts to reveal "themes"

\section{Bioremediation Themes}

- Three thematic categories emerged from the narrative analysis

- Risk Construction Themes

- Risk Management Themes

- Risk Manager Themes 


\section{Risk Construction Themes}

\section{-Risk Perception Dichotomy}

- Split between those who believe that they were at little risk (employees and scientists) and serious risk

\section{-Risk Familiarity}

- Widespread unfamiliarity with:

- Extent and degree of groundwater contamination

- Measurement and definition of cleanup levels

- Feasible remediation technologies

- Info needed by more than Advisory Board members

\section{-Risk Control}

- Information needed to control risks

- Alternative drinking water, move away, or other measure

- Lack of control associated with high risk perception

- Lack of info constitutes exposure without consent

- Action Urgency
Majority view: Frustration with inaction
I don't care how it's cleaned up, just do it; Things are studied to death before
any action is taken; Legions of interviewers, university students, and
contractors take unknown reams of data, talk to endless groups of people,
and then nothing is done
- Minority view: Nothing needs to be done right away
Costs of Remediation
Majority view: Unease with conflict between need for urgency and
reductions in cleanup funds/accelerated timelines
- Reducing risk means that money comes first and people come second.
Minority view: Money should not be wasted on political fixes, unproven
technologies, or unreasonable cleanup levels
Long-Term Stewardship
Concern over ability of DoE to take responsibility for long-term care
- DOE will not fulfill cleanup requirements or they will leave the site in a state
for which the community cannot assume responsibility
DOE wants quick (but inadequate) solutions to get the problem behind it
Effectiveness
- Uncertainty about effectiveness leads to speculation and dissensus
(opinions based on limited knowledge of hydrocarbon bioremediation)
- The closer you can come to following nature's lead, the better off you are
Bioremediation will not take care of the contamination




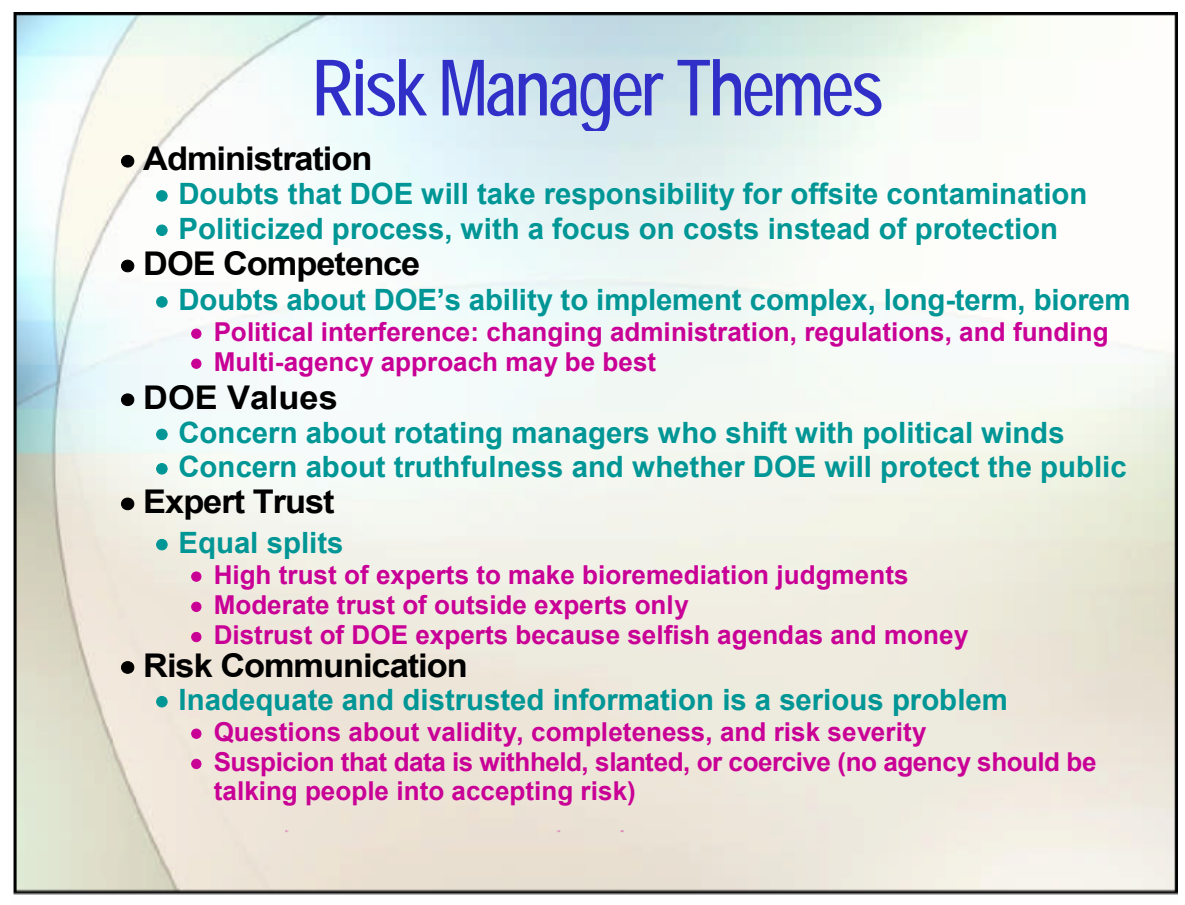

- Interest in Participation
Split between direct participation and indirect representation
- Direct: Community wants to be involved and make a difference
Indirect: Process takes too long; elected officials and citizen
advisory boards should represent public interests; most people
have little concern or interest in bioremediation
Knowledge Required for Effective Participation
- Split over whether public has been told the whole truth
Some believe that DOE deliberately "talks over their heads" to
discourage participation and that DoE continues to manifest a
"culture of secrecy"
Many equate information sharing with lowered risk perceptions and
building trust
Values
Some believe that political appointees, upper level site
managers, and advisory boards do not have the same values
as local citizens
Board members may have their own agendas...my best interests
and concerns are not really addressed
Others believe that risks are poorly understood by the public
and that emotion dominates logic 


\section{Participation Themes}

\section{-Participation Process}

- Most believe that public should be involved, but degree varies

- Majority: Consultation and deliberation preferred (listening to all sides will make the decision more effective and comprehensive; public input gives gov't more credibility)

- Minority: Prefer information exchange only

- Small Minority: Decisions are responsibility of regulators working under the laws passed by elected officials; you can't leave decisions to stakeholders because the buck stops with people doing the work and paying the money

\section{-Time and Effort}

- Preference of consultation over deliberation driven by participation demands and threats to welfare

- Sitting through a meeting is pretty tough; life is too short to engage in a year-long process

- Very few people want to be involved because it's too time consuming and there are personal cost as well - no one wants to be seen as biting the hand that feeds them

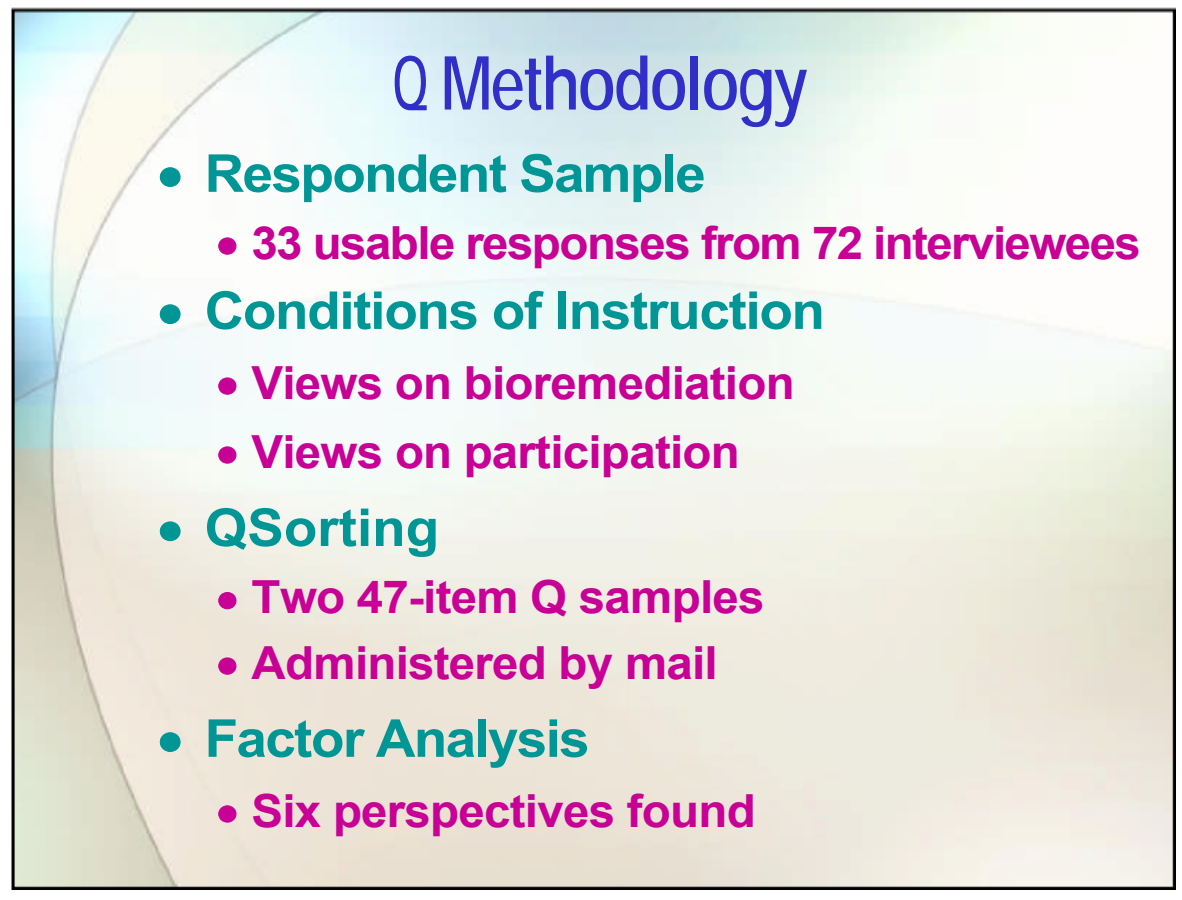




\section{Bioremediation Perspectives}

- Six correlated perspectives
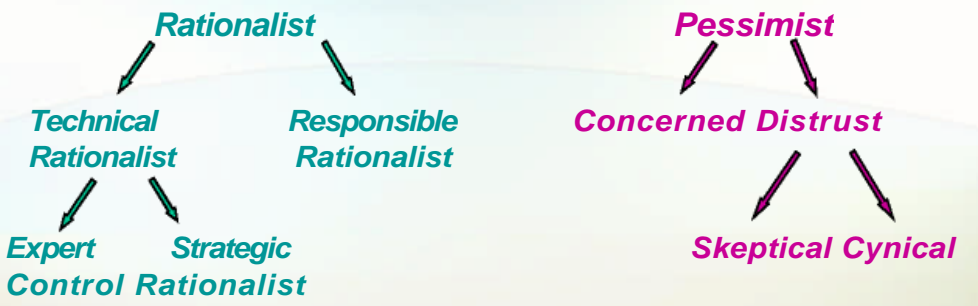

- Rationalist (male, tech professionals \& managers)

- Optimistic, benefit-cost balance, public needs education, site managers should be less arrogant

- Pessimist (female, enviro professionals \& activists)

- Pessimistic, more accountability, doubts about competence \& commitment, more stakeholder involvement

\section{Flavors of Rationalism}

\section{- Technical Rationalist}

- Objective risk assessments dominate

- Expert Control

- Let experts decide

- Strategic Rationalist

- Benefit-cost balance, communication problems, urgency to do something

- Responsible Rationalist

- Community interest best served by balanced remediation and education 


\section{Flavors of Pessimism}

\section{- Distrust}

- Distrust DOE; no trading safety to save money

- Cynical

- Site managers are arrogant, incompetent, secretive; independent oversight necessary; community welfare should be paramount

- Skeptical

- Urgent action is needed and DOE must be held accountable; education is no substitute for action; bioremediation may be appropriate

- Concerned

- Pragmatic; site managers are arrogant and secretive but truthful; cost tradeoffs are necessary; bioremediation needs more study

\section{Recommendations}

- Experts reach consensus on effectiveness

- Increase familiarity among stakeholders

- Not seen as a cost-cutting measure

- DOE commits to long-term management

- Implement as soon as feasible

- DOE expends significant resources in building trust among stakeholders

- Be more open, communicative, responsible, humble, and inclusive of stakeholders

- More regulation is not the answer; fiduciary responsibility is 


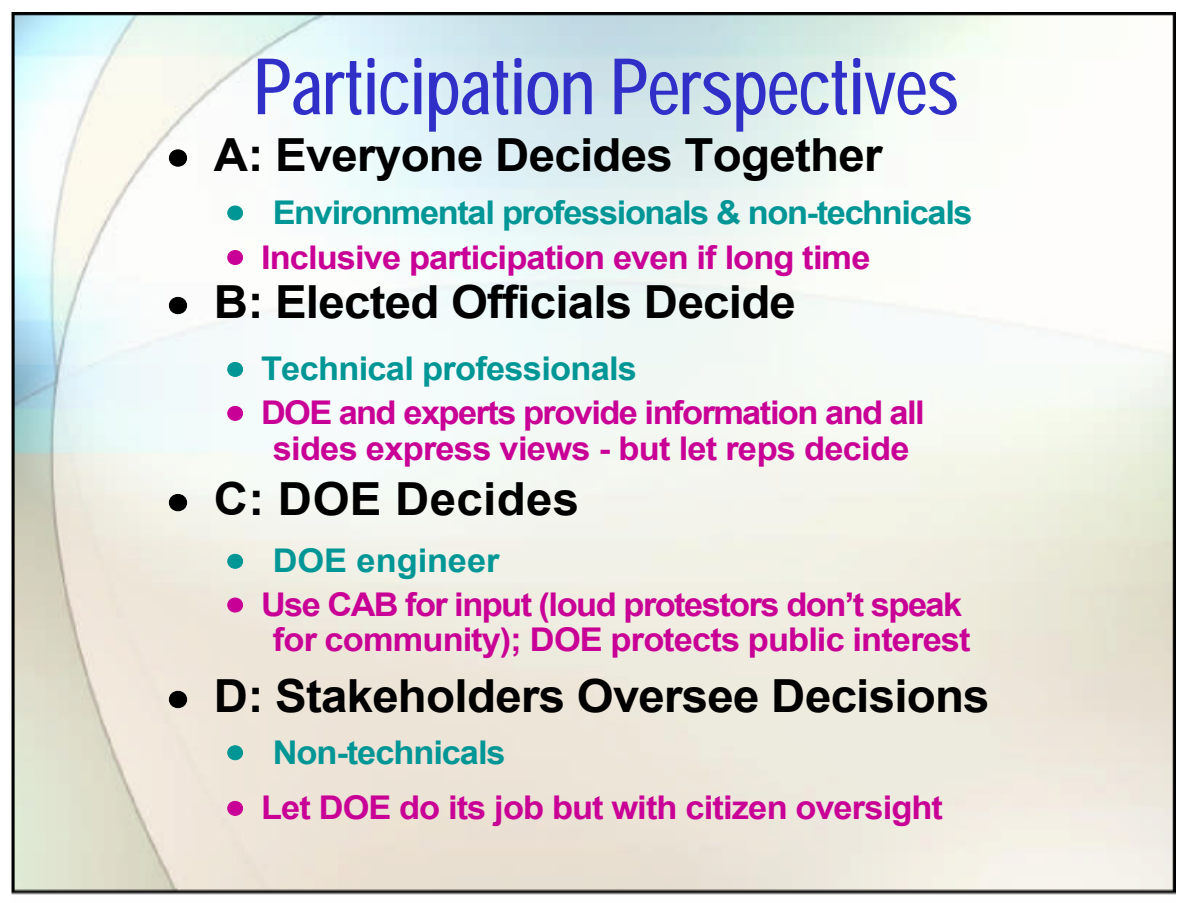

\section{Recommendations}

- Involve stakeholders throughout decisionmaking process but in a consultancy role

- People have limited time for direct participation

- So, broadly representative, multi-organizational, advisory committee that includes elected officials

- DOE seriously considers committee suggestions

- Participants provided with complete, timely, succinct \& easy-to-comprehend information

- DOE works to build community trust through involvement of stakeholders and explicit consideration of community welfare in its deliberations 


\section{Telephone Survey}

- Random sample of 1950 adults living near the sites (adjoining zip codes)

- 650 at each of the three sites

- Screened to ensure awareness of contamination

- Stratified by trust of DOE (equally split)

- Conducted by NSON Corp. (SLC, Utah) over 12 days in November 2003

- Results and analysis delayed 16 months (PI moved from OU to ISU)

- Questions

- Similar to those asked in the interviews

- Analyzed using descriptive and correlational statistics

\section{Demographic Analysis}

- Gender

- Slightly more males $(50.6 \%)$

- More males work onsite

- Proximity of residence to site

- Median distance $=\mathbf{2 0}$ miles

- Closer is less technical, less likely to work at the sites, and more likely to reside downwind

- Frequency of downwind exposure

- Average time that wind comes from site $=12.7 \%$

- Rent or own residence

- Own $=83 \%$

- Owners stay in residence and community longer

- Duration of residence at current location

- Average duration = 14 years; median $=10$ years

- Longer more likely to work onsite and less education

- Duration of residence in the community

- Average duration $=30$ years; median $=27$ years 


\section{Demographic Analysis}

- Personal site employment

- $72 \%$ respondents have never worked at the site

- More likely male, technically trained, live further away

- Family site employment

- $60 \%$ have no family members who ever worked at the site

- More likely to live further away and longer in community

- Education

- $97.3 \%$ high school graduates; $41 \%$ college graduates - National: $80 \%$ high school; $28 \%$ college

- More likely technically trained \& live shorter in house

- Occupation

- $72 \%$ are non-technical; $19 \%$ technical (scientists, engineers, medicine, educators, fire service, site workers)

- Technical careerists more likely to live further away and longer in community

\section{Demographic Conclusions}

- Connections to sites (a minority) suggest more technical backgrounds, more distance from sites, and longer community residence

- Residents near these sites manifest greater community ties (home ownership, duration in communities) than national averages

- Suggests that these communities are more dependent on and perhaps stabilized by the sites 


\section{Risk Judgments}

- Beliefs about suffering health effects

- Actually at risk $=13 \%$; potentially at risk $=54 \%$

- Not at risk $=33 \%(1 / 3)-$ excluded from below

- Duration of knowledge about contamination and health risks from exposure

- Long time $=78 \%$; recently $=11 \%$

- More likely to live in community longer

- Beliefs about risk severity

- Moderate to very high $=72 \%$

- More likely to see risk as dreadful

- Presence of contamination implies risk

- $55 \%$ agree; $41 \%$ disagree

- More likely to believe that the person is suffering from adverse health effects and that risks are severe \& dreadful

\section{Risk Judgments}

\section{- Dread}

- Terrifying $=13 \%$; major concern $=40 \%$; some concern $=16 \%$; minor concern $=4 \%$

- More likely to judge risk as severe and believe that the presence of contamination implies risk

- Risk perception should be calibrated to scientific risk assessments through education

- $82 \%$ agree; $14 \%$ disagree

- More likely to trust DOE and not equate contamination with risk 


\section{Risk Judgments}

- Knowledge of exposure routes

- $37 \%$ rate their knowledge as high

- $27 \%$ rate their knowledge as low

- More likely to be knowledgeable about contamination and work at the site

\section{- Knowledge of health effects}

- $35 \%$ rate their knowledge as high

- $26 \%$ rate their knowledge as low

- More likely to be knowledgeable about contamination and exposure routes; more likely to work at the site

\section{Risk Judgments}

- Agencies should not talk anyone into accepting risk (co-optation)

- $60 \%$ agree; $16 \%$ disagree

- More likely to equate contamination with risk

- Personal control over exposure

- $22 \%$ rate their control as high or very high

- $59 \%$ rate their control as low or very low

- Risk reduction should be balanced against cost

- $55 \%$ agree; $40 \%$ disagree

- More likely to trust DOE and support risk perception calibration

- Less likely to believe they suffer adverse health effects, see risk as dreadful, or equate contamination with risk 


\section{Risk Judgment Conclusions}

- Site employment increases knowledge of exposure routes and health effects

- Low sense of personal exposure control

- Correlations among distrust, high risk severity, dread, equating contamination with risk, resistance to cooptation, and opposing benefit/cost balance suggest two distinct perspectives on risk

- Risk perception calibration support may be explained by strong desire for education by both DOE trusters and distrusters

\section{Trust Judgments DOE}

\section{- Trust of DOE}

- 39\% trust; $49 \%$ distrust

\section{- Technical competence}

- $39 \%$ high; $22 \%$ low

\section{- Value similarity}

- $34 \%$ high; $42 \%$ low

- High correlation among these three variables 


\section{Trust Judgments DOE}

- Deference to DOE to make remediation decisions on their behalf

- $25 \%$ willing to defer; $40 \%$ unwilling

- Degree to which the respondent believes that he or she can exert personal influence over DOE decisions

- $8 \%$ high; $76 \%$ low

- More likely to trust DOE

- Less likely to believe that they are suffering adverse health effects and that the presence of contamination implies risk

\section{DOE Trust and Demographics}

- Those that live closer to the site express less trust of DOE and judge its values as less similar to theirs

- Site workers are more trusting of DOE and judge its values as more similar 


\section{DOE Trust Conclusions}

- Trusters more likely to have site employment connections, defer to DOE, see DOE as technically competent, and judge DOE's values as similar to their own

- Distrusters more likely to live closer to the sites, believe that contamination implies risk, they are suffering adverse health effects, risks are severe and dreadful, and personal control over exposure is low

\section{DOE Trust and Risk}

- Beliefs about suffering adverse health effects decreases trust and increases sense of powerlessness

- Similarly, risk severity decreases trust (but not belief that one can influence DOE)

- Dread decreases trust

- Sense of control over exposure increases trust (except for technical competence)

- Risk severity and dread weaken bioremediation support 


\section{Trust Judgments Social}

- Trust of Other Stakeholders

- $36 \%$ trust; $40 \%$ distrust

- Value similarity

- $35 \%$ high; $22 \%$ low

- Technical competence

- $17 \%$ high; $30 \%$ low

- Deference

- $15 \%$ willing to defer; $38 \%$ unwilling

- These four trust variables are highly correlated

\section{Trust Judgments Social}

- Social trusters are more likely to defer to other stakeholders' decisions, believe that stakeholders are technically competent, and believe that they share similar values

- They are less likely to judge risks as severe

- Social trusters also tend to trust DOE 


\section{Trust Conclusions}

- Social trust levels are similar to DOE trust levels except for technical competence and deference, and are correlated

- Since greater DOE trust and lower risk knowledge is associated with higher risk perceptions, both education and trust building efforts are necessary to reduce stakeholders' risk perceptions

\section{Bioremediation Acceptance}

\section{- Bioremediation support}

- $47 \%$ support; $12 \%$ oppose; $41 \%$ neither

- More support among DOE trusters

\section{- Bioremediation is short-term fix at best}

- $60 \%$ agree; $11 \%$ disagree

- More popular among those who believe that they suffer adverse health effects and that cooptation is wrong

- Less popular among those who do not equate contamination with risk

- No reason to rush; need more study

- $45 \%$ agree; $32 \%$ disagree (no correlations) 


\section{Bioremediation Predictors}

\section{- Demographics and "No Rush" view}

- No correlations

\section{- Risk}

- Weak link between short-term fix \& beliefs about suffering health effects, impropriety of cooptation, and the presence of contamination implies risk

\section{- DOE Trust}

- Weakly influences support

- Deference and efficacy do not influence support perhaps because stakeholders do not believe that they can affect decisions

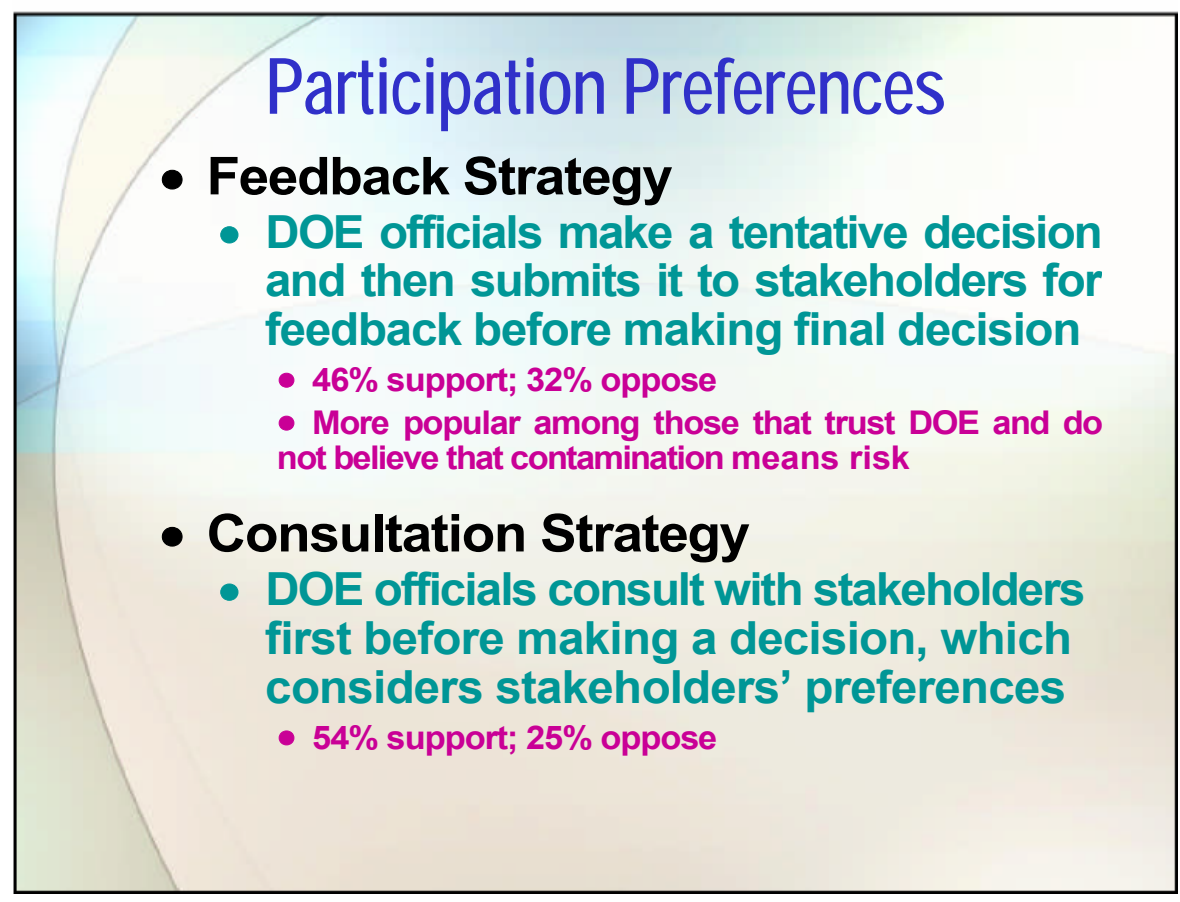




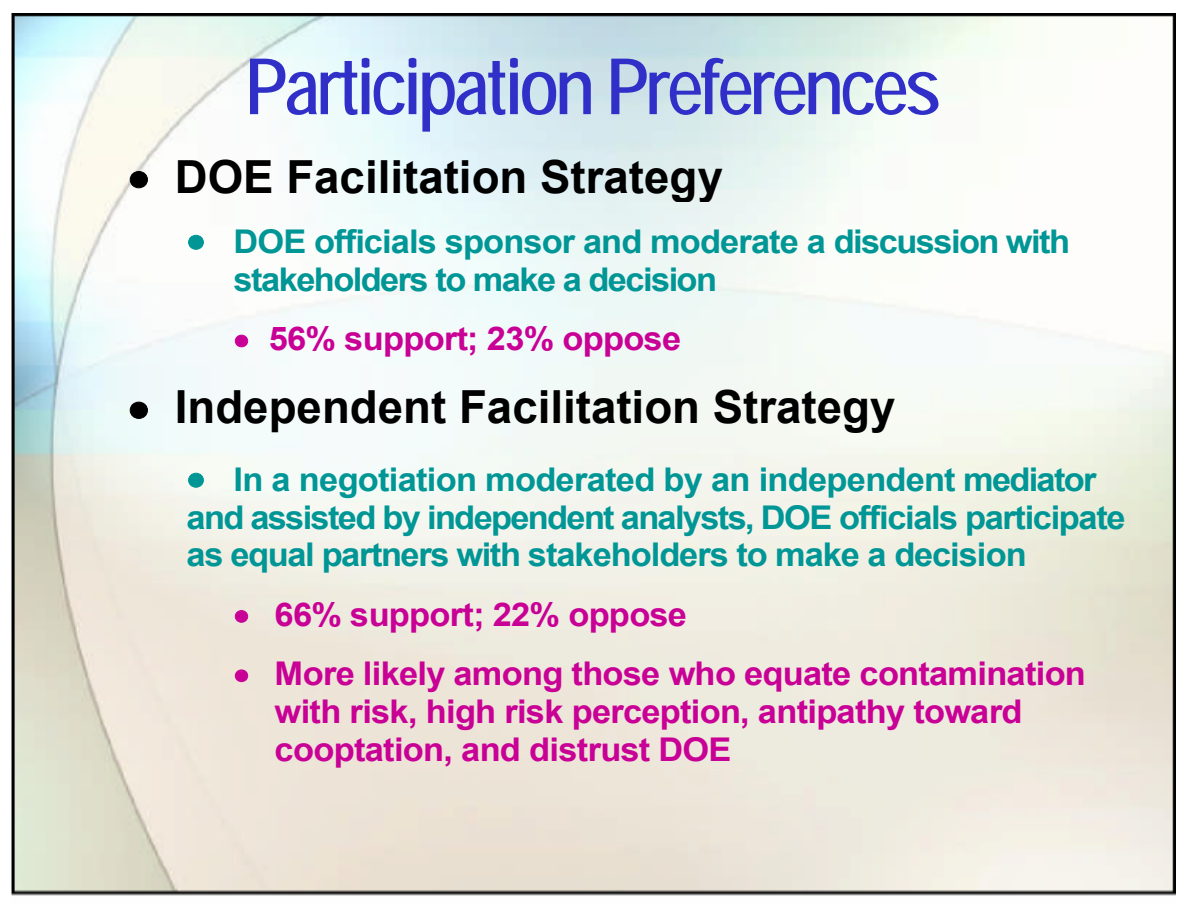

\section{Participation Predictors}

- High DOE trust and low risk perceptions correlate with low intensity strategy (feedback)

- Low DOE trust, high opposition to cooptation, and high risk perceptions correlate with high intensity strategy (independent facilitation) 


\section{Now, it's your turn...}

\section{Bioremediation Acceptance Questions}

\section{-Timeliness}

-When should bioremediation start? How long should it take?

\section{- Effectiveness}

- How much risk can be reduced?

- Should other remedial measures be undertaken?

-What personal exposure control measures should be provided, if any?

- Cost versus Risk Reduced

- How much risk should be allowed to remain? What role should stakeholders play in deciding this?

- At what financial cost?

\section{- Trust}

- How important should building trust be? How much trust is necessary? How can trust be earned by DOE? By other stakeholders?

\section{- Responsibility}

- Who should conduct bioremediation? Who should oversee it?

- How about long-term responsibility? 


\section{Bioremediation Acceptance Questions}

\section{- Information}

- What role should education play in decision-making?

- What information should be communicated?

- How should information be distributed, by whom, and when?

- Will more information bring risk perceptions and scientific risk assessments closer together?

\section{- Environmental Justice}

- Should those who live nearby deserve special consideration? How should such people be identified? How?

- Deference and Efficacy

- Who should make bioremediation decisions? How?

- Stakeholder Participation

- What strategy should be used by DOE to involve stakeholders in the decision-making and implementation processes? 
APPENDIX D

PRESENTATION DELIVERED TO DOE PERSONNEL 


\section{Bioremediation}

\section{Gaining Stakeholder Acceptance}

Dr. Will Focht and Matt Albright

Oklahoma State University

October 6, 2005

\section{Outline of Presentation}

\section{- Presentation made at Oak Ridge}

- Study Description

- Results of Personal Interviews

- Contamination, bioremediation \& participation themes

- Results of Q Sorting

- Bioremediation and participation perspectives

- Results of Random Telephone Survey

- Combined results and site-specific results

- Demographic analysis

- Risk and trust judgments

- Bioremediation acceptance

- Participation preferences

- Results of Oak Ridge Focus Group Meeting

- Enhanced analysis-deliberation prescription

- DOE Discussion: Reactions \& Suggestions 


\section{Study Description}

- Purposes

- Stakeholder Reactions to Contamination and Bioremediation

- Judgments of risk, trust, and acceptability

- Stakeholder Participation Preferences

- Roles of DOE, stakeholders, and third parties

- Sponsor

- US Department of Energy

- Bioremediation and Its Societal Implications and Concerns (BASIC) program

\section{- Investigators}

- Oklahoma State Univ; Univ of Oklahoma

\section{Study Description}

\section{- Study Sites}

- Oak Ridge (TN) Reservation

- Hanford (WA) Reservation

- Los Alamos (NM) National Laboratory

- All have subsurface (soil and ground water) radioactive and toxic metal contamination

- Presentation of Findings

- Composite

- Site comparisons 


\section{Personal Interviews}

- Respondent Sample

- 72 intensive face-to-face interviews

- Question Categories

- Demographic characteristics

- Contaminant and bioremediation risk perceptions

- Trust judgments of DOE and each other

- Bioremediation acceptance

- Participation preferences

- Computerized narrative analysis of transcripts to reveal "themes"

\section{Bioremediation Themes}

- Three thematic categories emerged from the narrative analysis

- Risk Construction

- Risk Management

- Risk Manager 


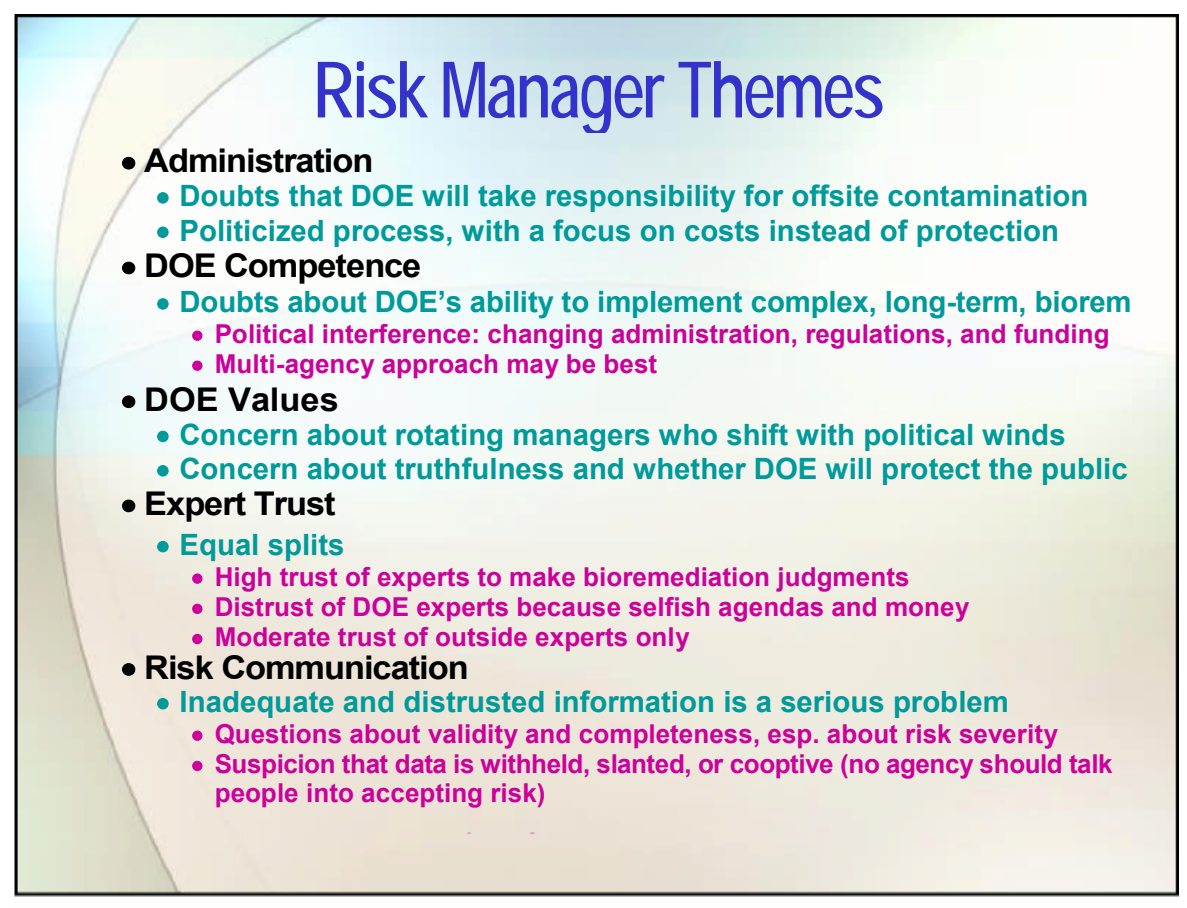

- Interest in Participation
Split between direct participation and indirect representation
- Direct: Community wants to be involved and make a difference
advisory boards should represent public interests; most people
have little concern or interest in bioremediation
Knowledge Required for Effective Participation
- Split over whether public has been told the whole truth
- Some believe that DOE deliberately "talks over their heads" to
discourage participation and that DoE continues to manifest a
"culture of secrecy"
Many equate information sharing with lowered risk perceptions
and building trust
- Values
Some believe that political appointees, upper-level site
managers, and advisory boards do not have the same values
as local citizens
"Board members may have their own agendas...my best interests
and concerns are not really addressed"
and that emotion dominates logic 


\section{Participation Themes}

\section{-Participation Process}

- Most believe that the public should be involved, but degree varies

- Majority: Consultation and deliberation preferred (“'Listening to all sides will make decisions more effective and comprehensive"; "Public input gives gov't more credibility")

- Minority: “Decisions are responsibility of regulators working under the laws passed by elected officials"; "You can't leave decisions to stakeholders because the buck stops with people doing the work and paying the money"

\section{- Time and Effort}

- Preference of consultation over deliberation driven by participation demands and threats to $\mathrm{C}$ welfare

- Sitting through a meeting is pretty tough; life is too short to engage in a year-long process

- Very few people want to be involved because it's too time consuming and there are personal costs as well - no one wants to be seen as biting the hand that feeds them

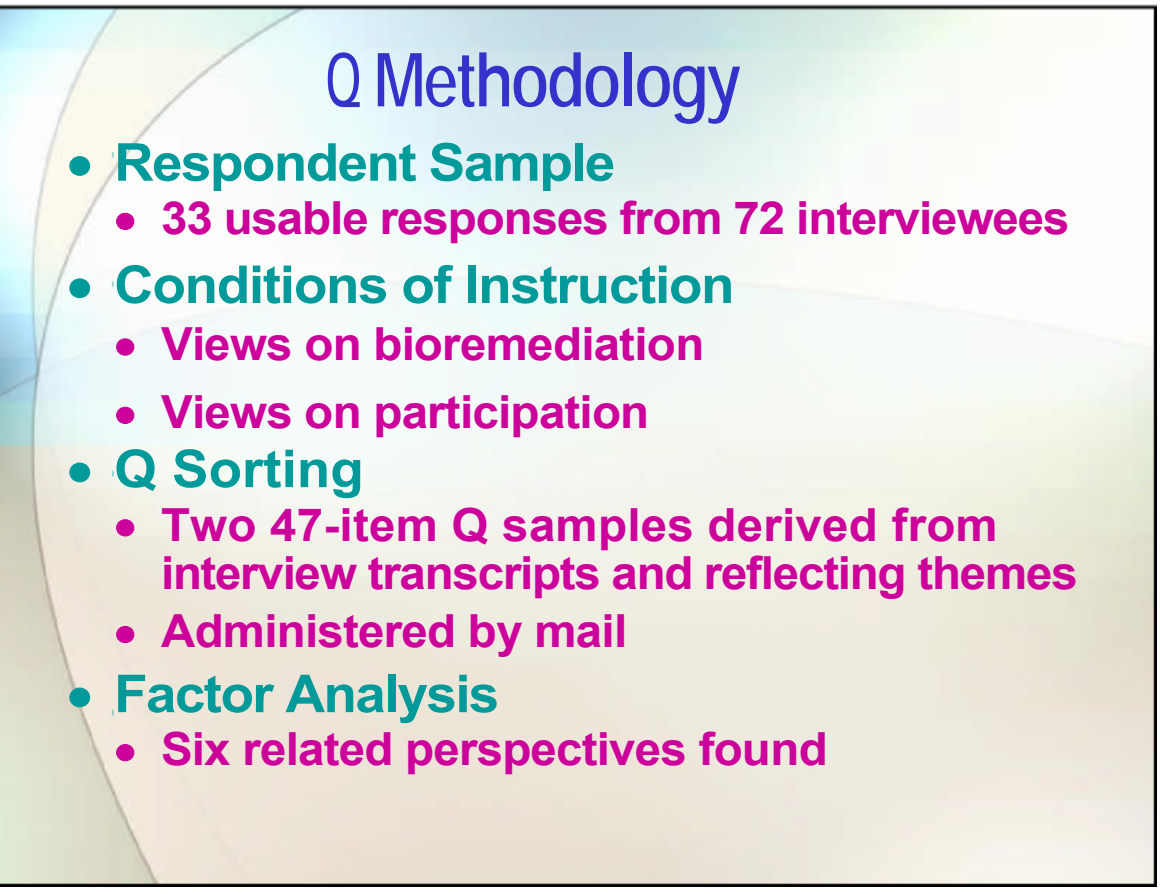



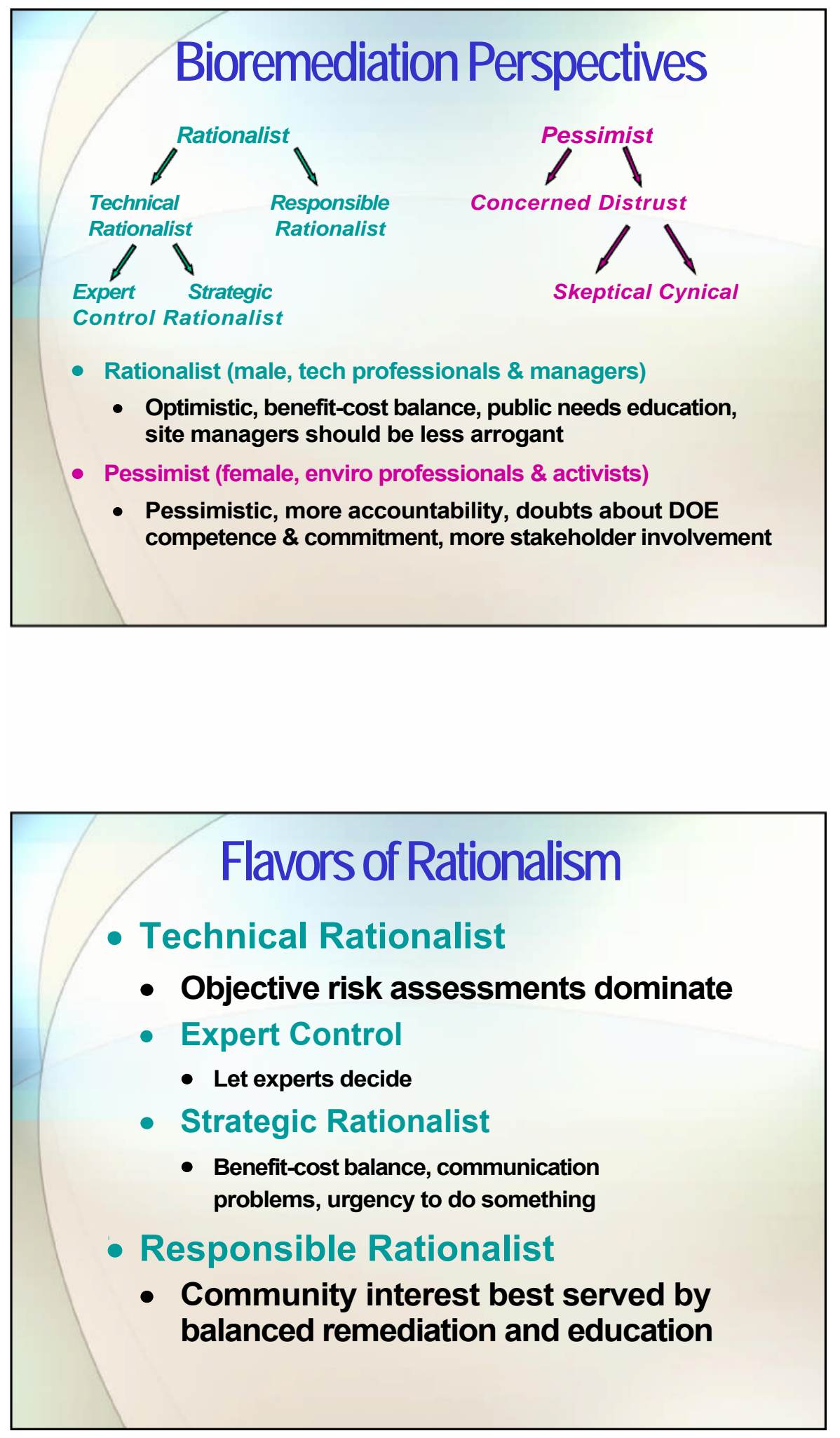


\section{Flavors of Pessimism}

\section{- Distrust}

- Distrust DOE; no trading safety to save money

- Cynical

- Site managers are arrogant, incompetent, secretive; independent oversight necessary; community welfare should be paramount

- Skeptical

- Urgent action is needed and DOE must be held accountable; education is no substitute for action; bioremediation may be appropriate

- Concerned

- Pragmatic; site managers are arrogant and secretive but truthful; cost tradeoffs are necessary; bioremediation needs more study

\section{Recommendations}

- Experts reach consensus on effectiveness

- Increase knowledge among stakeholders

- No implication as a cost-cutting measure - DOE commits to long-term management

- DOE expends significant resources to build trust with and among stakeholders

- Be more open, communicative, responsible, humble, and inclusive of stakeholders

- Implement as soon as feasible

- More regulation is not the answer; fiduciary responsibility is 


\section{Participation Perspectives}

- A: Everyone Decides Together

- Environmental professionals \& non-technicals

- Inclusive participation even if it takes a long time

- B: Elected Officials Decide

- Technical professionals

- DOE and experts provide information and all sides express views - but let reps decide

- C: DOE Decides

- DOE engineer

- Use CAB for input (loud protestors don't speak for community); DOE protects public interest

- D: Stakeholders Oversee Decisions

- Non-technicals

- Let DOE do its job but with citizen oversight

\section{Recommendations from Q}

- Involve stakeholders throughout decisionmaking process but in a consultancy role

- People have limited time for direct participation

- Use broadly representative, multi-organizational, advisory committee that includes elected officials

- DOE seriously considers committee suggestions

- Participants provided with complete, timely, succinct \& easy-to-comprehend information

- DOE works to build community trust through involvement of stakeholders and explicit consideration of community welfare in its deliberations 


\section{Telephone Survey}

- Random sample of 1950 adults living near the sites (adjoining zip codes)

- 650 at each of the three sites

- Screened to ensure awareness of contamination

- Stratified by trust of DOE (equally split)

- Conducted by NSON Corp. (SLC, Utah) over 12 days in November 2003

- Results \& analysis delayed 16 months (PI moved to ISU)

- Questions

- Similar to those asked in the interviews

- Analyzed using descriptive and correlational statistics

\section{Demographic Analysis}

- Gender

- Slightly more males $(50.6 \%)$

- More males work onsite

- Proximity of residence to site

- Median distance $=\mathbf{2 0}$ miles

- Closer is less technical, less likely to work at the sites, and more likely to reside downwind

- Frequency of downwind exposure

- Average time that wind comes from site $=12.7 \%$

- Rent or own residence

- Own $=83 \%$

- Owners stay in residence and community longer

- Duration of residence at current location

- Average duration = 14 years; median $=10$ years

- Longer more likely to work onsite and less education

- Duration of residence in the community

- Average duration $=30$ years; median $=27$ years 


\section{Demographic Analysis}

- Personal site employment

- $72 \%$ respondents have never worked at the site

- More likely male, technically trained, live further away

- Family site employment

- $60 \%$ have no family members who ever worked at the site

- More likely to live further away and longer in community

- Education

- $97.3 \%$ high school graduates; $41 \%$ college graduates - National: $80 \%$ high school; $28 \%$ college

- More likely technically trained \& shorter current residence

- Occupation

- $72 \%$ are non-technical; $19 \%$ technical (scientists, engineers, medicine, educators, fire service, site workers)

- Technical careerists more likely to live further away and longer in community

\section{Demographic Conclusions}

- Connections to sites (a minority) suggest more technical backgrounds, more distance from sites, and longer community residence

- Residents near these sites manifest greater community ties (home ownership, duration in communities) than national averages

- These communities are more dependent on, and perhaps stabilized by, the sites 


\section{Risk Judgments}

- Beliefs about suffering health effects

- Actually at risk $=13 \%$; potentially at risk $=54 \%$

- Not at risk $=33 \%(1 / 3)-$ excluded from below

- Duration of knowledge about contamination and health risks from exposure

- Long time $=78 \%$; recently $=11 \%$

- More likely to live in community longer

- Beliefs about risk severity

- Moderate to very high $=72 \%$

- More likely to see risk as dreadful

- Presence of contamination implies risk

- $55 \%$ agree; $41 \%$ disagree

- More likely to believe that the person is suffering from adverse health effects and that risks are severe \& dreadful

\section{Risk Judgments}

\section{- Dread}

- Terrifying $=13 \%$; major concern $=40 \%$; some concern $=16 \%$; minor concern $=4 \%$

- More likely to judge risk as severe and believe that the presence of contamination implies risk

- Risk perception should be calibrated to scientific risk assessments through education

- $82 \%$ agree; $14 \%$ disagree

- More likely to trust DOE and not equate contamination with risk 


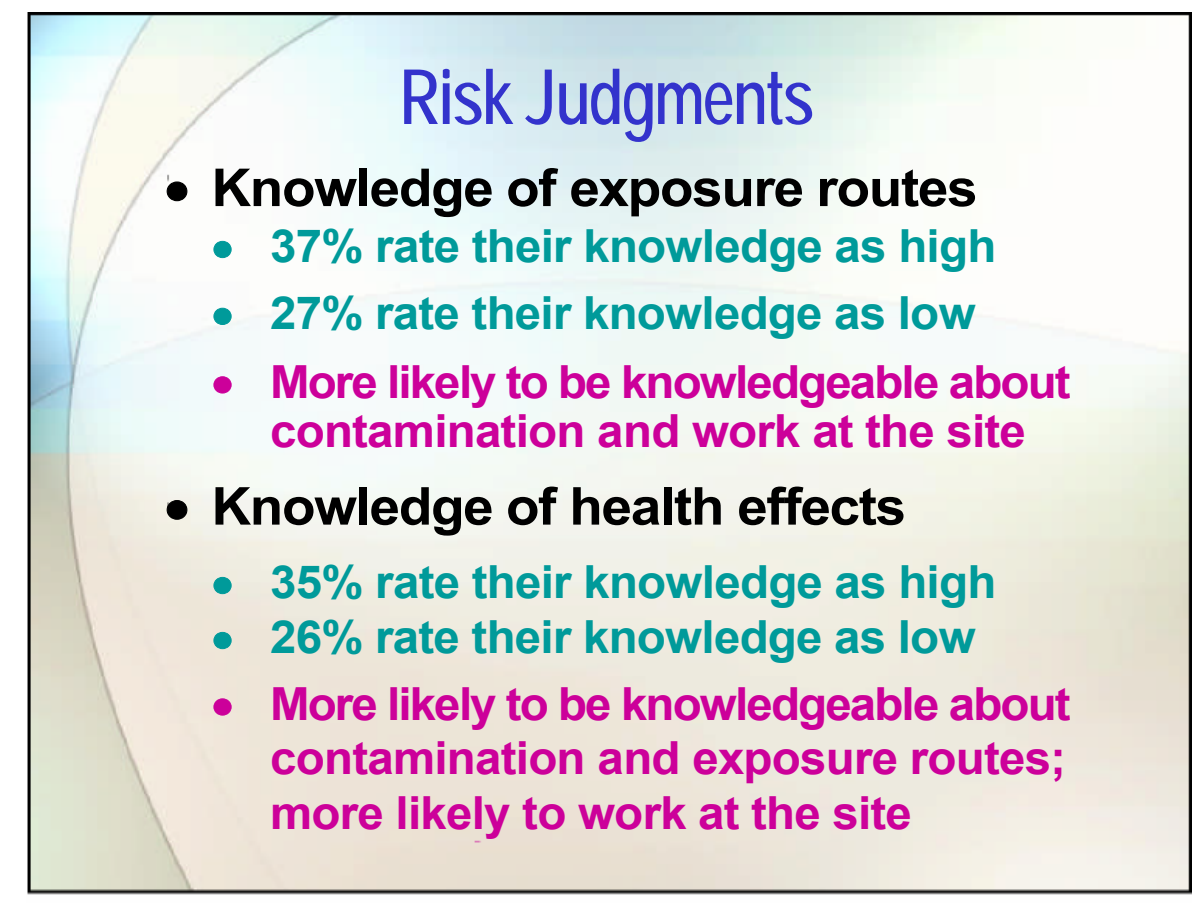

\section{Risk Judgments}

- Agencies should not talk anyone into accepting risk (co-optation)

- $60 \%$ agree; $16 \%$ disagree

- More likely to equate contamination with risk

- Personal control over exposure

- $22 \%$ rate their control as high or very high

- $59 \%$ rate their control as low or very low

- Risk reduction should be balanced against cost

- $55 \%$ agree; $40 \%$ disagree

- More likely to trust DOE and support risk perception calibration

- Less likely to believe they suffer adverse health effects, see risk as dreadful, or equate contamination with risk 


\section{Risk Judgments}
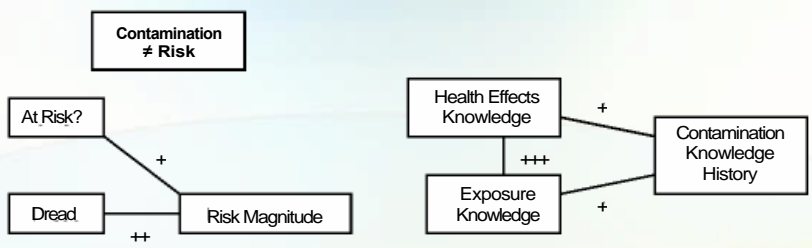

- Risk Perception Heuristics

- No relationship between controllability and any other heuristic

- Dread, not familiarity predicts risk judgments

- Fear, not knowledge, drives risk perception

- Contamination knowledge history does not correlate with any non-familiarity heuristic

- Health effects knowledge is correlated to risk perception only at Oak Ridge

\section{Risk Judgment Conclusions}

- Site employment increases knowledge of exposure routes and health effects

- Low sense of personal exposure control

- Risk perception calibration support may be explained by strong desire for education by both DOE trusters and distrusters

- Correlations among distrust, high risk severity, dread, equating contamination with risk, resistance to cooptation, and opposing benefit/cost balance suggest two distinct perspectives on risk 


\title{
Trust Judgments DOE
}

- Trust of DOE

\author{
- $39 \%$ trust; $49 \%$ distrust
}

- Technical competence

$$
\text { - } 39 \% \text { high; } 22 \% \text { low }
$$

\section{- Value similarity}

\section{- $34 \%$ high; $42 \%$ low}

- High correlation among these three variables

\section{Trust Judgments DOE}

- Deference to DOE to make remediation decisions on their behalf

- $25 \%$ willing to defer; $40 \%$ unwilling

- Degree to which the respondent believes that he or she can exert personal influence over DOE decisions

- $8 \%$ high; $76 \%$ low

- More likely to trust DOE

- Less likely to believe that they are suffering adverse health effects and that the presence of contamination implies risk 


\section{DOE Trust and Demographics}

- Those that live closer to the site express less trust of DOE and judge its values as less similar to theirs

- Site workers are more trusting of DOE and judge its values as more similar

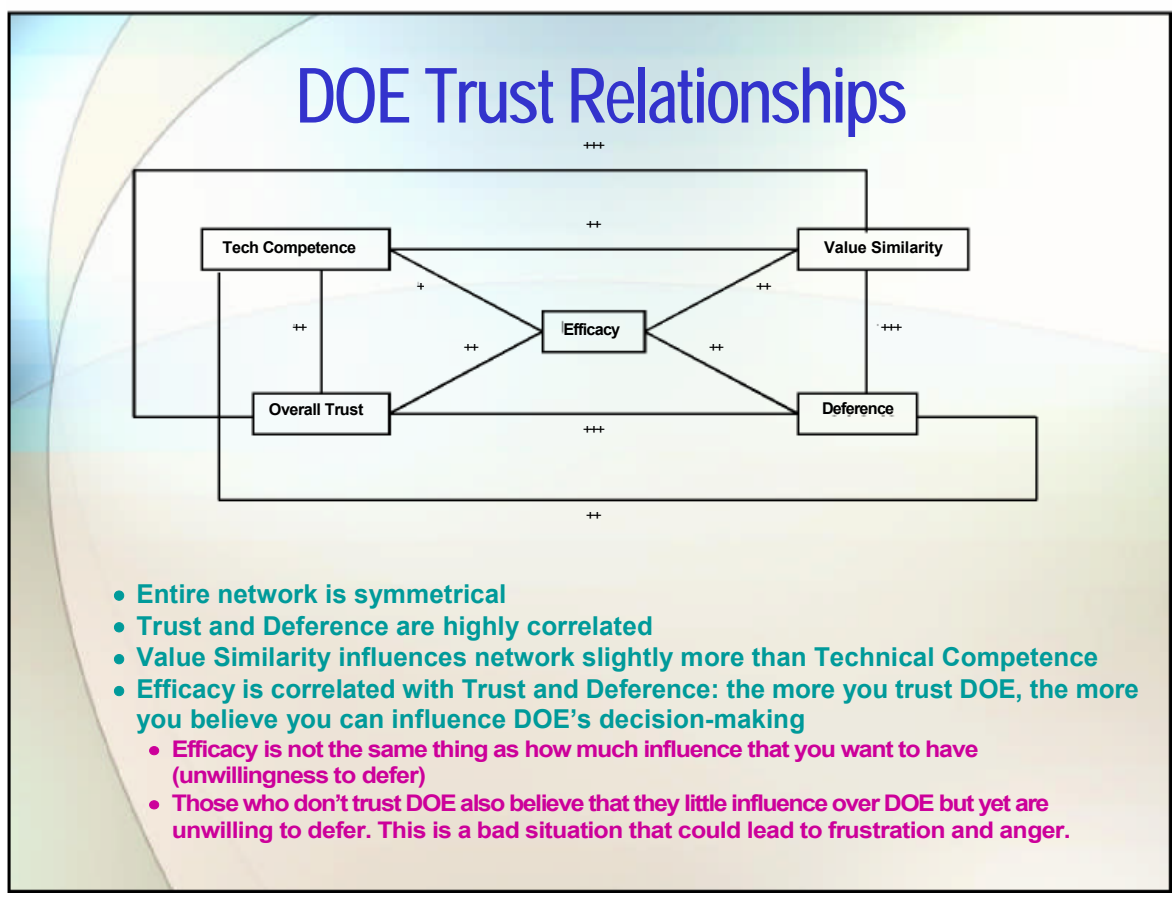




\section{DOE Trust Conclusions}

- Trusters more likely to have site employment connections, defer to DOE, see DOE as technically competent, and judge DOE's values as similar to their own

- Distrusters more likely to live closer to the sites; \& believe that contamination implies risk, they are suffering adverse health effects, risks are severe and dreadful, and their personal control over exposure is low

\section{DOE Trust and Risk}

- Distrust is associated with beliefs about suffering adverse health effects, risk severity, dread, and personal control over exposure

- Efficacy is not directly associated with risk variables 


\section{Trust Judgments Social}

- Trust of other stakeholders

- $36 \%$ trust; $40 \%$ distrust

- Technical competence

- $17 \%$ high; $30 \%$ low

- Value similarity

- $35 \%$ high; $22 \%$ low

- Deference

- $15 \%$ willing to defer; $38 \%$ unwilling

- These four trust variables are highly correlated

\section{Trust Judgments Social}

- Social trusters are more likely to defer to other stakeholders' decisions, and believe that stakeholders are technically competent and share values

- DOE trusters also tend to trust each other, though association is not strong 

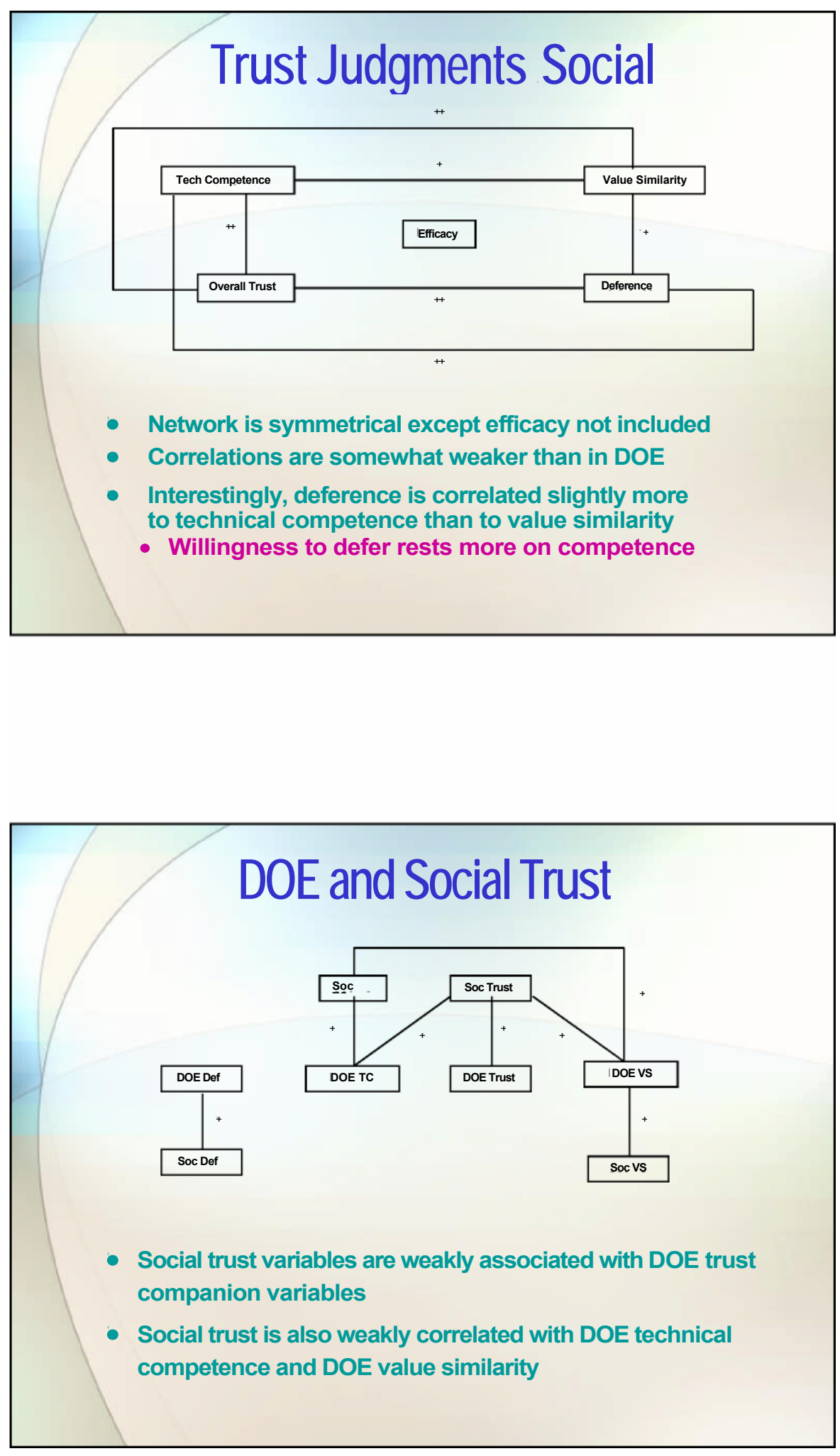


\section{Trust Conclusions}

- Social trust levels are similar to DOE trust levels, but:

- Less high tech competence \& deference

- Less low value similarity \& overall trust

- Recalling that lower risk knowledge is associated with higher risk perception, as is DOE distrust, both education and trust building efforts are necessary to reduce stakeholders' risk iudaments

\section{Bioremediation Acceptance}

\section{- Bioremediation support}

- $47 \%$ support; $12 \%$ oppose; $41 \%$ neither

- More support among DOE trusters

- Bioremediation is short-term fix at best

- $60 \%$ agree; $11 \%$ disagree

- More popular among those who believe that they suffer adverse health effects and that cooptation is wrong

- Less popular among those who do not equate contamination with risk

- No reason to rush; need more study

- $45 \%$ agree; $32 \%$ disagree

- No correlations! 


\section{Bioremediation Support Predictors}

\section{- Risk}

- Risk severity and dread weaken bioremediation support

- Weak link between short-term fix and beliefs about suffering health effects, impropriety of cooptation, and the presence of contamination implies risk

- DOE Trust

- Weakly influences support

- Deference and efficacy do not influence support perhaps because stakeholders do not believe that they can affect decisions

\section{Participation Preferences}

\section{- Feedback Strategy}

- DOE officials make a tentative decision and then submits it to stakeholders for feedback before making final decision

- $46 \%$ support; $32 \%$ oppose

- More popular among those that trust DOE and do not believe that contamination means risk

- Consultation Strategy

- DOE officials consult with stakeholders first before making a decision, which considers stakeholders' preferences

- $54 \%$ support; $25 \%$ oppose 


\section{Participation Preferences}

- DOE Facilitation Strategy

- DOE officials sponsor and moderate a discussion with stakeholders to make a decision

- $56 \%$ support; $23 \%$ oppose

- Independent Facilitation Strategy

- In a negotiation moderated by an independent mediator and assisted by independent analysts, DOE officials participate as equal partners with stakeholders to make a decision

- $66 \%$ support; $22 \%$ oppose

- More likely among those who equate contamination with risk, high risk perception, antipathy toward cooptation, and distrust DOE

\section{Participation Predictors}

- High DOE trust and low risk perceptions correlate with low intensity strategy (feedlback)

- Low DOE trust, high opposition to cooptation, and high risk perceptions correlate with high intensity strategy (independent facilitation) 


\section{Site Differences}

\section{Demographic Differences}

- Gender

- Fewer males in Hanford (48\%); more in Los Alamos (54\%)

- Education

- Less in Oak Ridge (assoc); more in Los Alamos (some grad)

- Technical occupation

- Less at Hanford (12\%); more at Los Alamos (30\%)

- Personal onsite employment

- $16 \%$ at Hanford; $33 \%$ elsewhere

- Family onsite employment

- $55 \%$ at Oak Ridge; $31 \%$ elsewhere

- Proximity to site

- Mean = $\mathbf{1 1}$ miles at Oak Ridge; 50 miles elsewhere

- Downwind exposure

- $20 \%$ at Hanford; $7 \%$ elsewhere 


\section{Unique Demographic Correlations}

\section{- Los Alamos}

- More males have technical occupations

- Those in technical occupations live further away

- Personal and family site employees own their own homes and live in their homes longer

- Oak Ridge

- No unique demographic correlations

- Hanford

- No unique demographic correlations

\section{Risk Differences}

- Beliefs about suffering health effects

- Less actual at Los Alamos (7\%); $15 \%$ elsewhere

- Contamination knowledge history

- More recent at Los Alamos (median = somewhat long time); very long time elsewhere

- Contamination does not imply risk

- More people strongly agree at Los Alamos (24\%); fewer strongly agree at Hanford (12\%)

- Agencies should not co-opt risk acceptance

- Fewer people strongly agree at Los Alamos (52\%); $62 \%$ elsewhere 


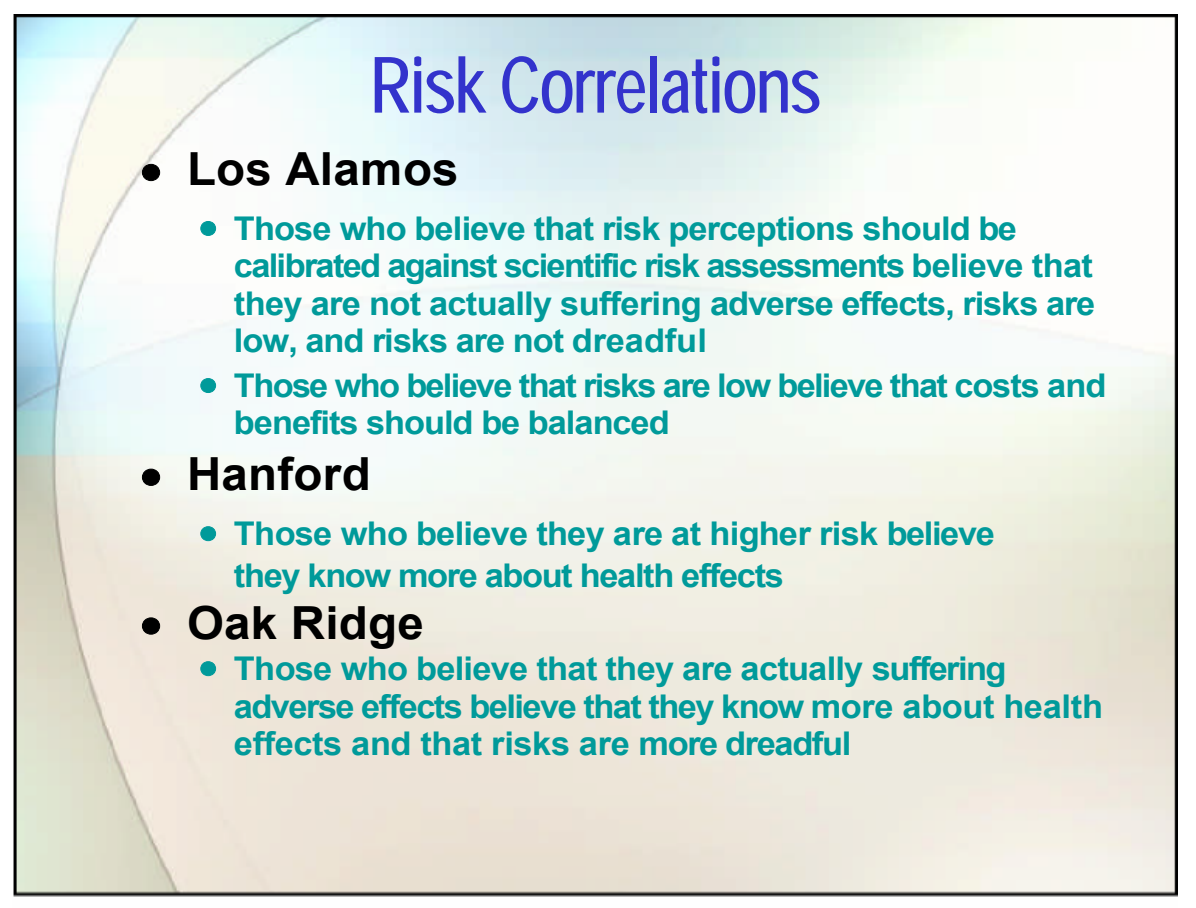

\section{Unique DemographicRisk Correlations}

- Los Alamos

- People living further away believe that they are not actually suffering adverse health effects; that risk perceptions should be calibrated with scientific assessments; and costs should be balanced against benefits

- People who own their homes do not believe that they are actually suffering adverse health effects and that contamination does not imply risk

- Those living longer in the community believe they have known about contamination and its risks longer

- Personal and family site employees believe that they are not actually at risk, that risks are low (personal only) and less dreadful, contamination implies risk (family only) risk perceptions should be calibrated, exposure can be personally controlled (personal only), and costs should be balanced against benefits

- Those in technical occupations believe that they are less at risk and that costs should be balanced against benefits 


\section{Unique DemographicRisk Correlations}

- Oak Ridge

- Males dread risk less, believe they have less contamination knowledge, and believe that contamination does not imply risk

- Site employees knew about contamination longer

- Technical job holders believe they have more exposure knowledge

- More educated stakeholders do not believe they are actually suffering health effects, contamination does not imply risk, and support cooptation

- Hanford

- Site employees believe they know more about health effects and exposure knowledge

- Longer community residents believe that they have known about contamination longer

\section{Trust Differences}

- DOE Trust

- More strong distrust at Los Alamos (30\%); $21 \%$ elsewhere

- LA: Strongly bipolar in trust judgments

- Strongly and somewhat trust $=40 \%$

- Strongly and somewhat distrust $=51 \%$

- Willingness to Defer to DOE

- More very unwilling at Los Alamos (29\%); $19 \%$ elsewhere 


\section{Trust Correlations}

- Los Alamos

- No DOE-social trust correlations

- Difference in mean trust values $\mathbf{= 0 . 2 2}$

- Highest mean social trust (2.99)

- Hanford

- Social trusters tend to trust DOE but not on the grounds of value similarity, and feel more efficacious with respect to DOE

- Difference in mean trust values $\mathbf{= 0 . 3 8}$

- Lowest mean trust of DOE (2.45)

\section{- Oak Ridge}

- Social trusters tend to also trust DOE and feel more efficacious with respect to DOE

- Difference in mean trust values $\mathbf{= 0 . 0 2}$

\section{Demographic Trust Correlations}

- Los Alamos

- Technical job holders, site employees, and those living further away are more trusting, more willing to defer to DOE, and more efficacious

- Hanford

- None

- Oak Ridge

- None 

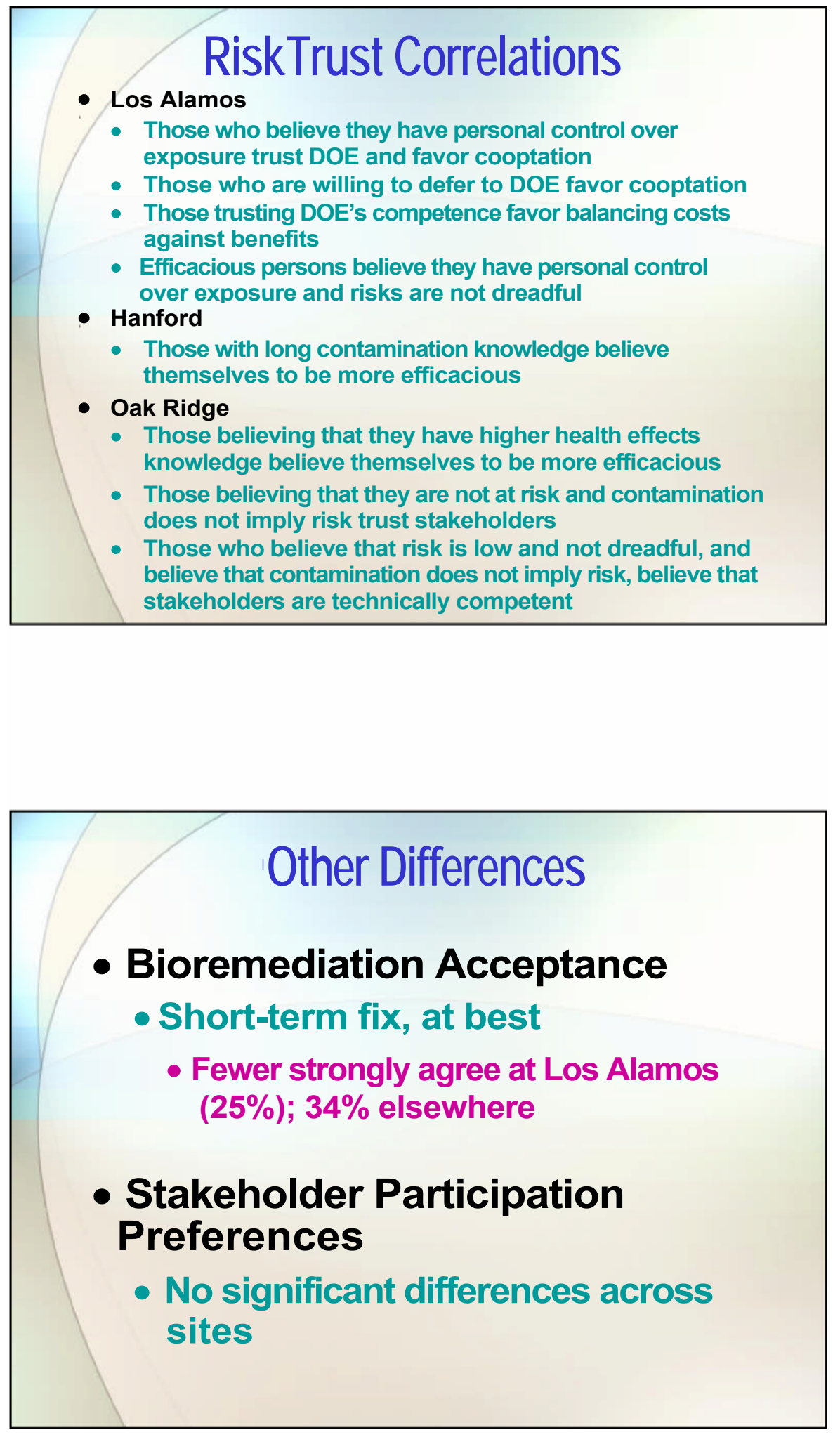


\section{Bioremediation Acceptance Correlations}

\section{- Los Alamos}

- Those who support bioremediation believe that it should be implemented as soon as feasible (it is not a short-term fix), live further away or work at the site, and manifest somewhat greater trust of DOE

- Those who want more study (because we need not rush) believe that risks are low, perceptions should be calibrated, contamination does not imply risk, and cost and benefits should be balanced

\section{- Oak Ridge}

- Those who support bioremediation believe that contamination does not imply risk, that more study is not needed, and exhibit somewhat greater social trust

- Those that think bioremediation is a short-term fix believe risks are high and dreadful, and do not trust DOE

\section{- Hanford}

\section{- Nothing unique}

\section{Stakeholder Participation Correlations}

\section{- Los Alamos}

- Those who prefer the feedback option believe that risks are low, that costs and benefits should be balanced, and trust DOE

- Those who support independent facilitation live further away, distrust DOE, have no employment connections, and do not believe costs and benefits need to be balanced

\section{- Oak Ridge}

- Those who prefer the feedlback option believe that they are efficacious

- Those who support independent facilitation believe that bioremediation is a short-term fix

\section{- Hanford}

- Nothing unique 


\section{SiteSpecific Conclusions}

- Los Alamos

- A dichotomy is apparent between "technical rationalists" (tech occupations, onsite employment, rational decision strategies, believe that they are more informed, and trust DOE) and "skeptics" (risk averse, distrusting, proinvolvement, and non-technical occupations)

- Social and DOE trust building is strongly encouraged

- Oak Ridge

- A substantial reservoir of trust exists

- Those who believe themselves efficacious and knowledgeable are inclined to support bioremediation

- Hanford

- Views of those at this site are most similar to the composite views of all three sites

- Higher levels of distrust perhaps lead to increased confidence that they are at risk, which may make it more difficult to gain support for bioremediation

\section{Bioremediation Acceptance Questions}

\section{- Timeliness}

-When should bioremediation start? How long should it take?

\section{- Effectiveness}

- How much risk can be reduced?

- Should other remedial measures be undertaken?

- What personal exposure control measures should be provided, if any?

\section{- Cost versus Risk Reduced}

- How much risk should be allowed to remain? What role should stakeholders play in deciding this?

- At what financial cost?

\section{- Trust}

- How important should building trust be? How much trust is necessary? How can trust be earned by DOE? By other stakeholders?

- Responsibility

- Who should conduct bioremediation? Who should oversee it?

- How about long-term responsibility? 


\section{Bioremediation Acceptance Questions}

- Information

- What role should education play in decision-making?

- What information should be communicated?

- How should information be distributed, by whom, and when?

- Will more information bring risk perceptions and scientific risk assessments closer together?

- Environmental Justice

- Should those who live nearby deserve special consideration? How should such people be identified? How?

- Deference and Efficacy

- Who should make bioremediation decisions? How?

- Stakeholder Participation

- What strategy should be used by DOE to involve stakeholders in the decision-making and implementation processes?

\section{Stakeholders' Recommendation}

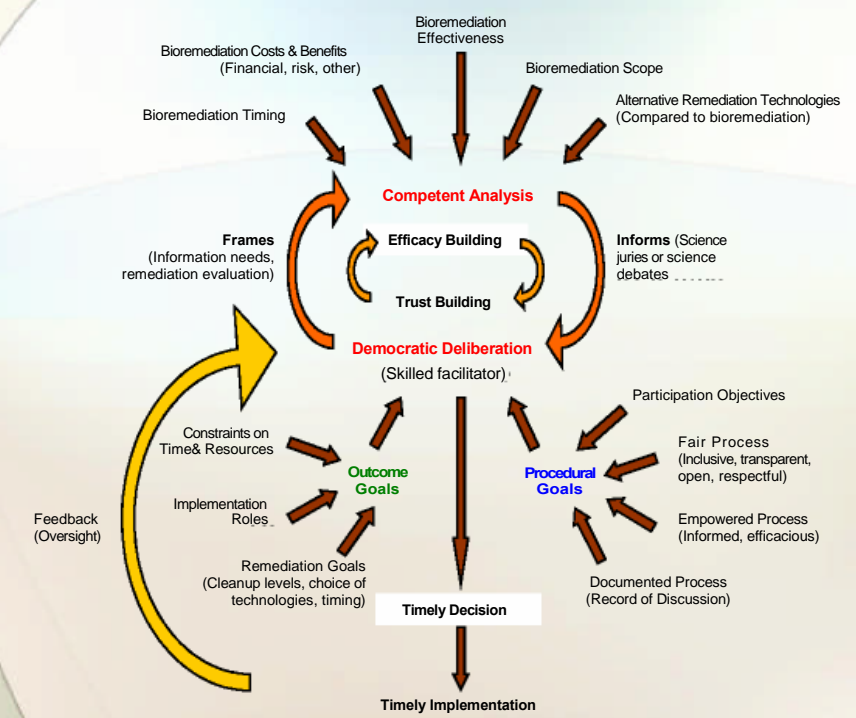




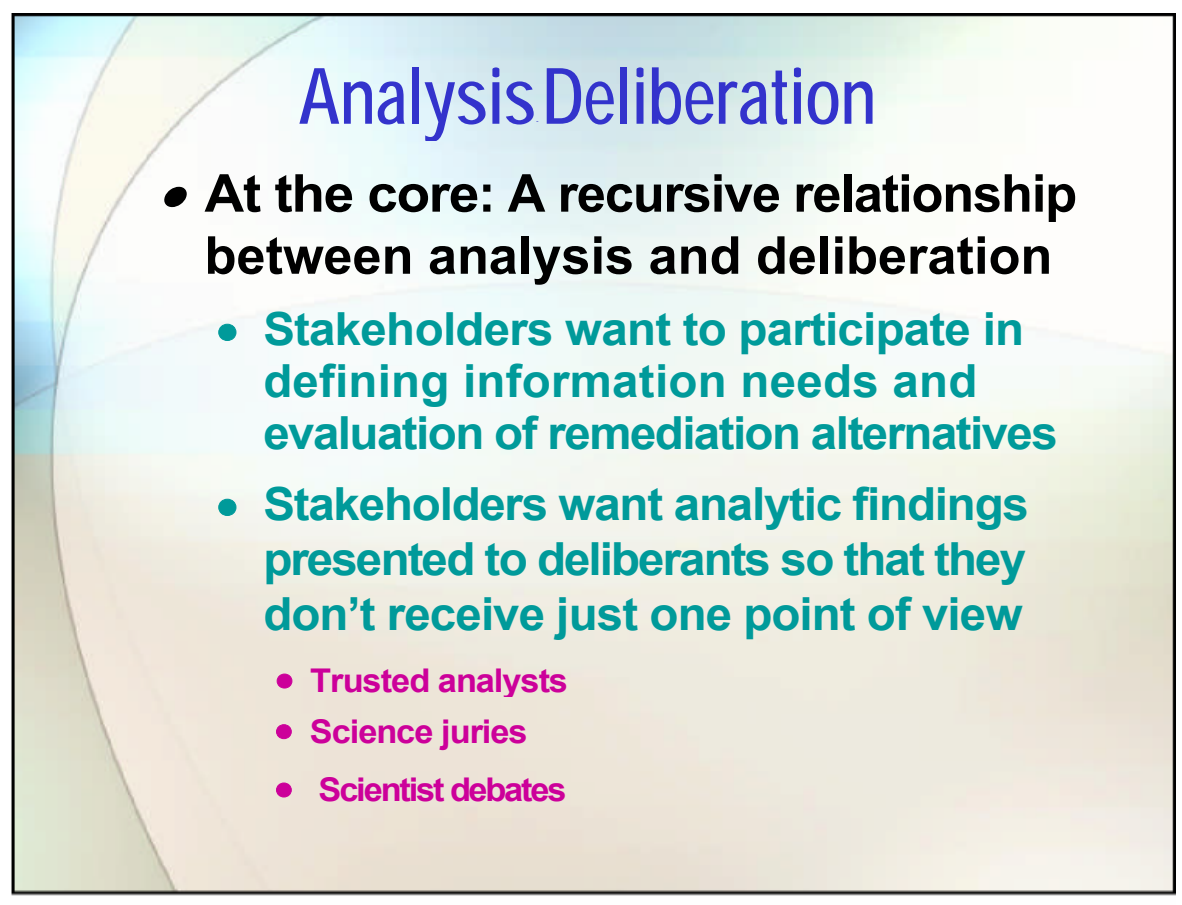

\section{Augmented Analysis Deliberation}

- To be incorporated into the analysis and deliberation relationship:

- Efforts to build political efficacy

- Internal efficacy = belief that one can influence decisions

- External efficacy = resources required to influence decisions

- Efforts to build trust

- Between DOE and stakeholders

- Among stakeholders 


\section{Concerning Analysis}

\section{- Analyses should be performed as soon as}

possible to address:

- Effectiveness of bioremediation

- Performance confidence

- Level of contamination (risk) that will remain

- Side effects

- Bioremediation costs compared to benefits

- Time required for deploy the technology and time required to complete remediation

- Scope of bioremediation

- Problems for which it is best suited

- Areas that bioremediation would be used

- Comparison of bioremediation against other feasible remediation strategies with respect to these performance criteria

\section{Concerning Deliberation}

- Should be more democratic; less techno-autocratic

- Fair

- Inclusive, transparent, open, respectful

- Empowered

- Informed and efficacious

- Should be well-specified

- Participation objectives

- Roles of citizen stakeholders

- Roles of DOE and experts

- Should be documented with "Records of Discussion" that dentify:

- Concerns raised

- Who raised these concerns

- How the concerns were addressed

- This record will:

- Legitimize participation

- Avoid endless reconsiderations of the same issues so that genuine progress can be made 


\section{More on Deliberation}

- To ensure worthwhile participation, stakeholders should participate in decisions that:

- Define the goals of the participation process, including:

- Cleanup levels

- Selection of remediation technologies

- Timing of remediation programs

- Implementation responsibilities and protocols

- Stakeholder oversight processes

- Identify constraints that must be met to get to decisions within a reasonable time and using available resources

- A skilled and independent facilitator should ensure that discussions:

- Stay on point

- Ensure respectful participation

- Provide fair opportunity to all who wish to participate

- Make progress toward decisions in a timely manner

\section{Summary}

- Stakeholders are frustrated with participation for its own sake

- The process is only a means to an end; don't let the process prevent timely and effective remediation

- Stakeholders want:

- Well-defined goals and timelines

- Confidence that their participation will make a difference

- Timely and unbiased information

- DOE and the communities should not give up on stakeholder participation 


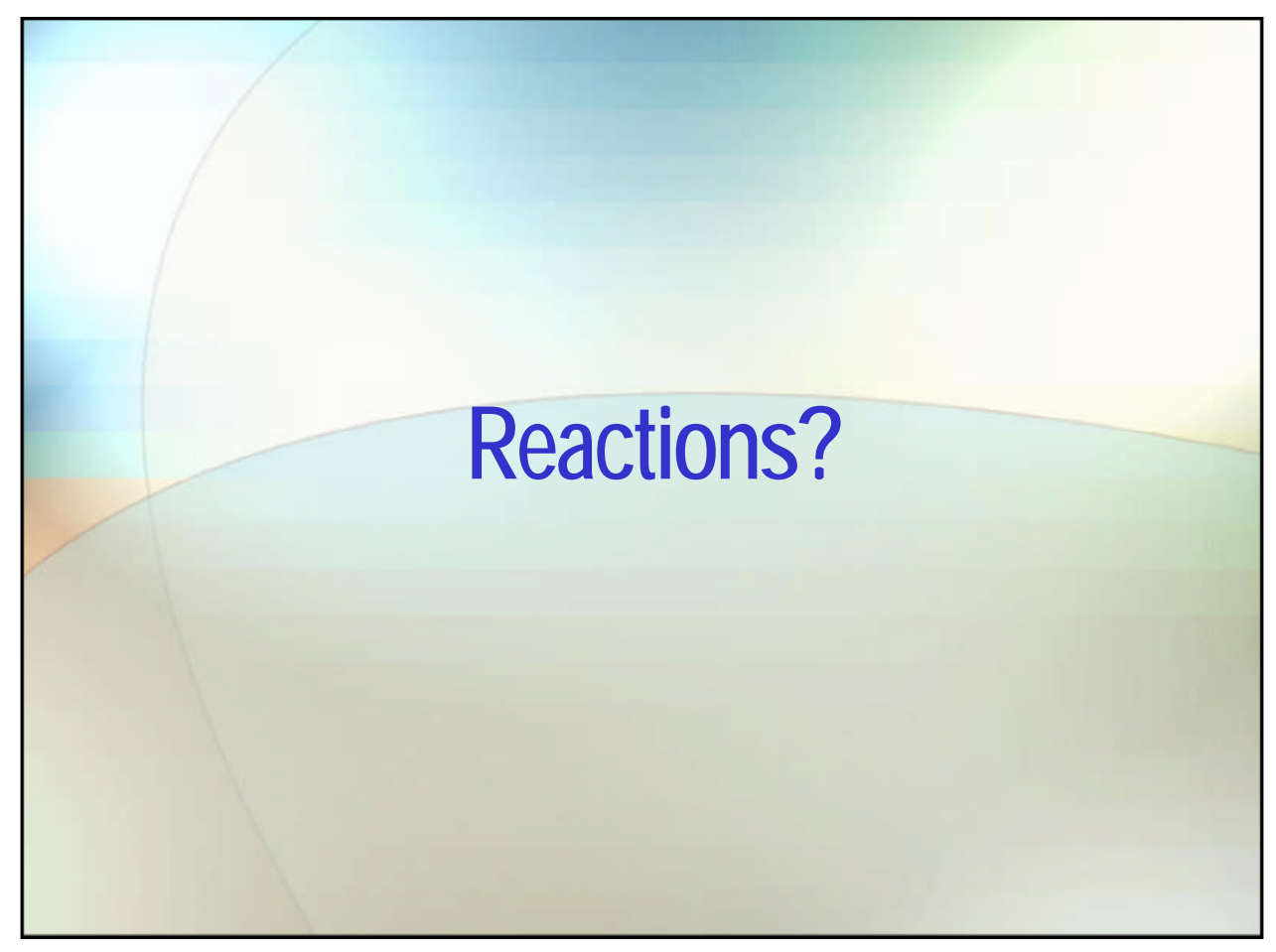

